\title{
24 Triterpene einschließlich Steroide
}

\author{
O. STICHER
}

24.1 Übersicht über die pharmazeutisch interessierenden Stoffgruppen . . . . . . . . . . . . 916

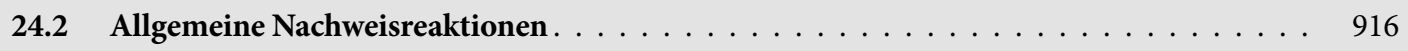

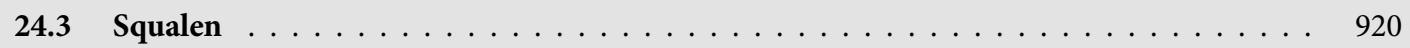

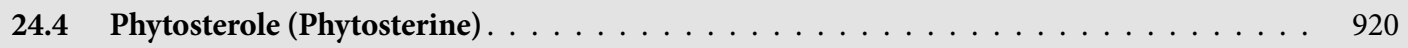

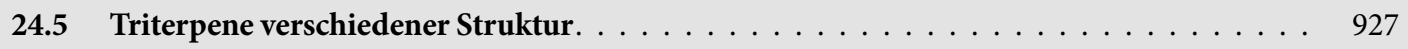

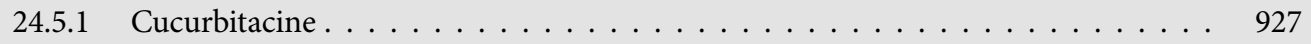

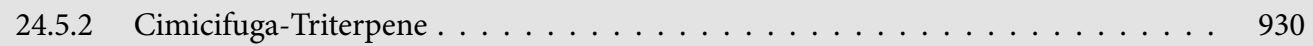

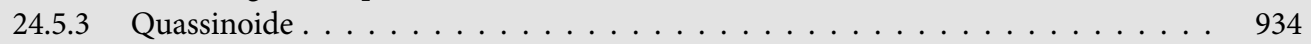

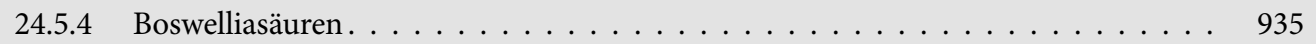

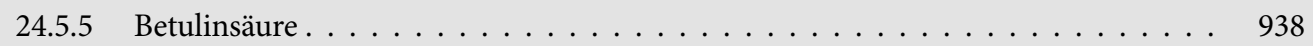

24.5.6 Ringelblumenblüten . . . . . . . . . . . . . . . . . . . . . . . 940

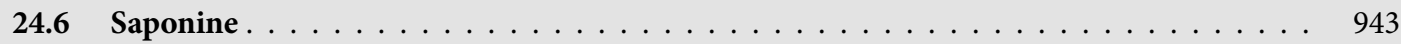

24.6.1 Begriffsbestimmung . . . . . . . . . . . . . . . . . . . . 943

24.6.2 Vorkommen, chemische und physikalische Eigenschaften, Einteilung. . . . . . . . . 943

24.6 .3 Analytik von Saponindrogen . . . . . . . . . . . . . . . . . . . . . . . 944

24.6.4 Saponine als Hämolysegifte, hämolytischer Index, Strukturspezifität . . . . . . . . . 946

24.6.5 Metabolismus, Pharmakokinetik und Toxikologie der Saponine . . . . . . . . . . . . 948

24.6.6 Wirkungen der Saponine . . . . . . . . . . . . . . . . . . . . . . . . . . . . . . . . . . . . . . . . . .

24.6 .7 Arzneidrogen mit Saponinen . . . . . . . . . . . . . . . . . . . . . . 951

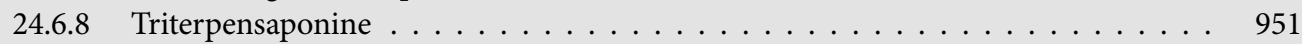

24.6 .9 Steroidsaponine. . . . . . . . . . . . . . . . . . . . 980

24.7 Herzwirksame Steroide . . . . . . . . . . . . . . . . . . . . . . . . . . 989

24.7.1 Begriffsbestimmung, Geschichtliches . . . . . . . . . . . . . . . . . . . . . . 989

24.7.2 Aufbau der herzwirksamen Steroidglykoside . . . . . . . . . . . . . . . . . . . . 990

24.7.3 Einige chemische Eigenschaften, Farbreaktionen . . . . . . . . . . . . . . . . . . . 992

24.7.4 Verbreitung im Pflanzenreich, verwendete Extrakte/Reinstoffe. . . . . . . . . . . . . 996

24.7.5 Pharmakokinetik und Metabolismus. . . . . . . . . . . . . . . . . . . 996

24.7.6 Wirkungen auf biochemischer Ebene und Anwendungsgebiete . . . . . . . . . . . . 998

24.7 .7 Analytische Kennzeichnung. . . . . . . . . . . . . . . . . . . . . . . 1000

24.7 .8 Digitalis lanata und Lanataglykoside . . . . . . . . . . . . . . . . . . . . 1001

24.7.9 Digitalis purpurea und Purpureaglykoside . . . . . . . . . . . . . . . . . . . 1005

24.7.10 Strophanthin und andere Reinglykoside mit großer Abklingquote . . . . . . . . . . 1007

24.7.11 Weitere Drogen mit herzwirksamen Steroiden . . . . . . . . . . . . . . . . 1008

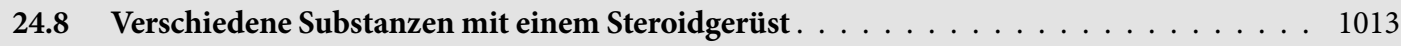

24.8 .1 Uzarawurzel . . . . . . . . . . . . . . . . . . . . . . . . . 1013

24.8.2 Condurango- oder Kondurangorinde . . . . . . . . . . . . . . . . . . . . . . 1014

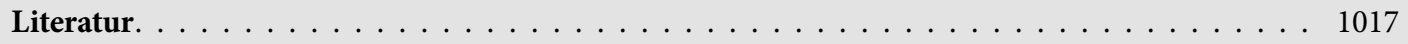




\section{$>$ Einleitung}

Die Triterpene gehören zur Naturstoffgruppe der Isoprenoide (vgl. Kap. 23). Sie stellen eine außerordentlich umfangreiche Klasse von Terpenen dar. Sie werden in diesem Kapitel zusammen mit den sich davon ableitenden Steroiden zusammengefasst. Die Muttersubstanz aller Triterpene ist der azyklische $\mathrm{C}_{30}$-Kohlenwasserstoff Squalen. Seine Zyklisierung wird durch Epoxidierung einer endständigen Doppelbindung eingeleitet. Da die Squalen-2,3-Epoxidstufe vor der Zyklisierung obligat durchlaufen werden muss, enthalten nahezu alle Triterpene und Steroide in Position C-3 eine Sauerstofffunktion. Vom Squalen ausgehend lassen sich zwei Hauptwege erkennen: Der eine führt zu den tetra- und pentazyklischen Triterpenen, der andere über Cycloartenol zu den Cucurbitacinen und via das wichtigste Stoffwechselintermediärprodukt, das Cholesterol, zu den Phytosterolen, Cardenoliden und Bufadienoliden sowie zu den Steroidsapogeninen.

\section{1 Übersicht über die pharma- zeutisch interessierenden Stoffgruppen}

Die Triterpene sind eine außerordentlich umfangreiche Klasse von Terpenen. Von wenigen Ausnahmen abgesehen, kommen fast nur tetra- und pentazyklische Vertreter vor. Soweit man weiß, synthetisieren alle Organismen die Muttersubstanz aller Triterpene, das Squalen (\$ Abb. 24.1 und 24.2), auf dieselbe Weise: durch hydrierende Dimerisierung von Farnesyldiphosphat. Somit handelt es sich bei den Triterpenen, aus biochemischer Sicht, eigentlich um Disesquiterpene. $\mathrm{Zu}$ den Triterpenen werden auch jene Terpene gezählt, die weniger als 30 Kohlenstoffatome haben. Das Hauptkontingent an Triterpenen mit verminderter C-Zahl stellen die Steroide, die dadurch charakterisiert sind, dass von der $\mathrm{C}_{30}$-Zwischenstufe 3 Methylgruppen oxidativ abgespalten werden: Man erreicht die Stufe der $\mathrm{C}_{27}$-Steroide mit dem wichtigen Cholesterol. Vom Cholesterol leiten sich alle übrigen Steroide ab. Es können aus $\mathrm{C}_{30}$-Triterpenen auch größere Struktureinheiten abgespalten werden, wofür die Quassiabitterstoffe ( $>$ Kap. 24.5.3) als Beispiel genannt werden können.

Die physikalisch-chemischen Eigenschaften der Triterpene und, davon abhängig, ihre physiologischen Eigen- schaften (Ort der Speicherung, Reaktionsfähigkeit in biologischen Systemen) hängen von der weiteren Variation der lipophilen Vorstufen ab. Es lassen sich der Polarität und der näheren Ausgestaltung nach 3 Hauptgruppen unterscheiden:

- Lipophile Triterpene. Sie kommen als Ausscheidungen unterschiedlicher Art vor: Phytosterole und Phytosterolester höherer Fettsäuren im Blattwachs höherer Pflanzen; Triterpensäuren und Triterpenalkohole in den Harzen, in Milchsäften sowie in Borken von Holzgewächsen (Beispiele: $>$ Abb. 24.3).

- Hochoxidierte Triterpene. Sie stellen Verbindungen mittlerer Polarität dar, die weder in Wasser noch in Petrolether sonderlich gut löslich sind, besser in Dichlormethan, Ether und Ethanol. Analog wie in der Sesqui- und Diterpenreihe führt die Beladung des Triterpenmoleküls mit Hydroxy-, Epoxy-, Carbonyl-, Carboxyl- und Lactongruppen zu biologisch sehr aktiven, oft auch hochtoxischen Derivaten. Von Interesse sind die Cucurbitacine (จ Kap. 24.5.1).

- Hydrophile, glykosidische Triterpene. In diese Gruppe gehören die Saponine (\$ Kap. 24.6).

\subsection{Allgemeine Nachweis- reaktionen}

Triterpene und Steroide sind farblose Substanzen, die sich aber mit vielen Reagenzien zu farbigen Verbindungen umsetzen lassen. Diese Farbreaktionen spielen in der Drogenanalytik eine Rolle:

- als Reagenzglas- oder als Tüpfelreaktion zur Vorprüfung; in den Pharmakopöen gelegentlich auch zur Identitätsprüfung;

- als Sprühreagenzien zum Nachweis auf Chromatogrammen;

- zur photometrischen Gehaltsbestimmung (Rosskastaniensamen, Digitalis-purpurea-Blätter).

Farbreaktionen mit aromatischen Aldehyden. Bei der Umsetzung von Hydroxytriterpenen mit Anisaldehyd, Vanillin und anderen aromatischen Aldehyden in starken Mineralsäuren (z. B. Schwefelsäure, Schwefelsäure-Phosphorsäure-Ggemisch, Perchlorsäure) bilden sich Farbstoffe, deren Absorptionsmaximum, je nach Reaktionspartner, zwischen 510 und $620 \mathrm{~nm}$ liegt. Wahrscheinlich handelt es sich primär um eine Dehydrationsreaktion; die durch Doppelbindungen aktivierten Methylengruppen könnten 
- Abb. 24.1

$2 \mathrm{x}_{15} \longrightarrow$<smiles>CC(C)=CCCC(C)=CCCC(C)=CCCC=C(C)CCC=C(C)CCC=C(C)C</smiles>

Squalen $\mathrm{C}_{30}$

Konformationsänderungen, Zyklisierung
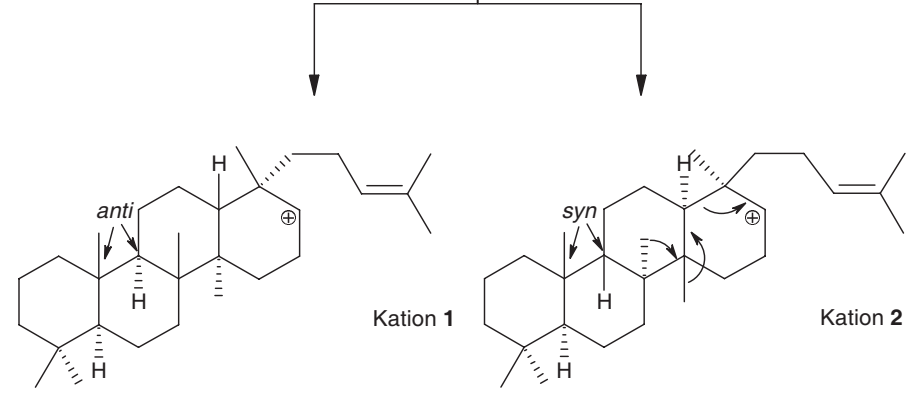

trans-anti-trans-Verknüpfung

trans-syn-trans-Verknüpfung

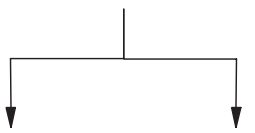

$\mathrm{CH}_{3}$-Verschiebungen, Ringverengung

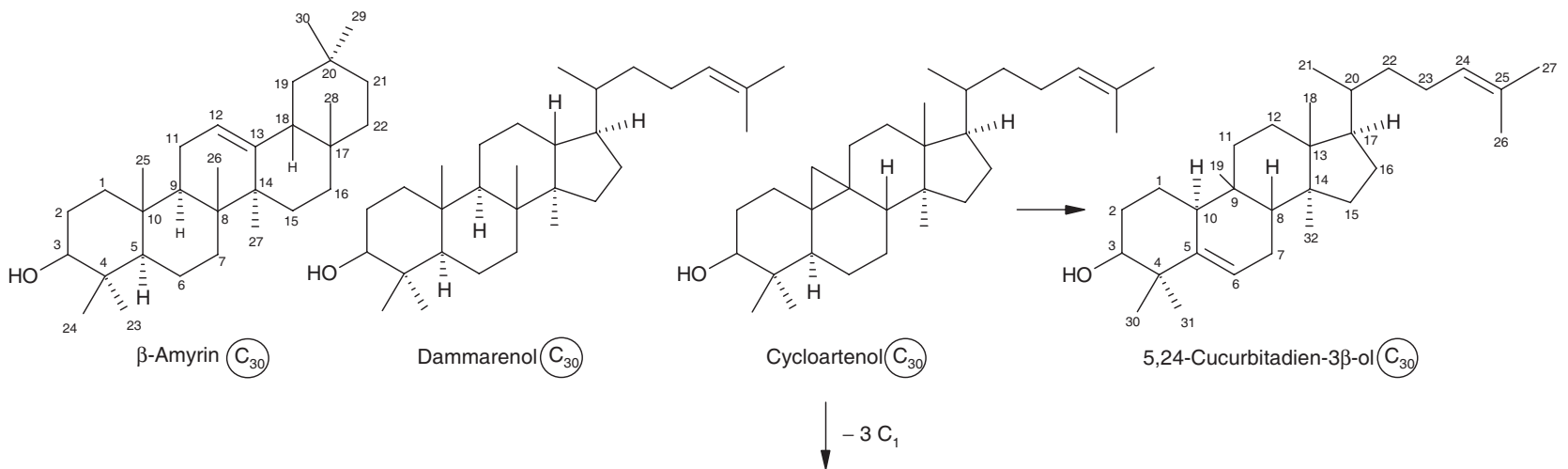
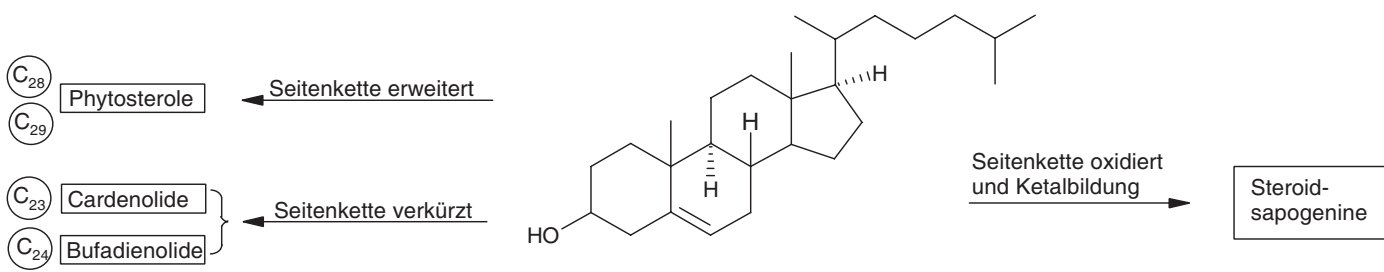

Cholesterol $\mathrm{C}_{27}$

Übersicht über die Hauptklassen der Triterpene. Es lassen sich aufgrund von Strukturvergleichen und Biosynthesestudien 2 Hauptreihen bilden. Die über die Zwischenstufe 1 bzw. deren biosynthetisches Äquivalent führende Reihe führt zu den tetra- und pentazyklischen Triterpenen. Die Seitenkette wird nicht verkürzt. Das zyklische Gerüst kann mit $O$-Funktionen besetzt werden. Die über die Zwischenstufe 2 bzw. deren biosynthetisches Äquivalent führende Reihe führt zum Cycloartenol, der Muttersubstanz aller pflanzlichen Steroide. Hinweis: Man achte auf die Bezifferung des Cucurbitadienolskeletts. Es besteht die Vereinbarung, 2 Ziffern zu überspringen, um bei Derivaten mit weiteren C-Atomen in der Seitenkette die Plätze frei zu halten 


\section{- Abb. 24.2}

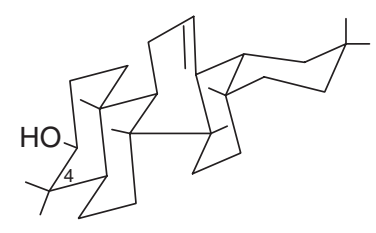

1 a

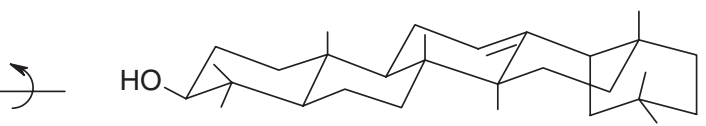

1b

$\beta$-Amyrin<smiles>CC(C)=CCCC(C)C1CCC2CCCC(CC3CCC(O)CC3C)C1C2</smiles>

Dammarenol (5 $\alpha$-Euphan-24-en)

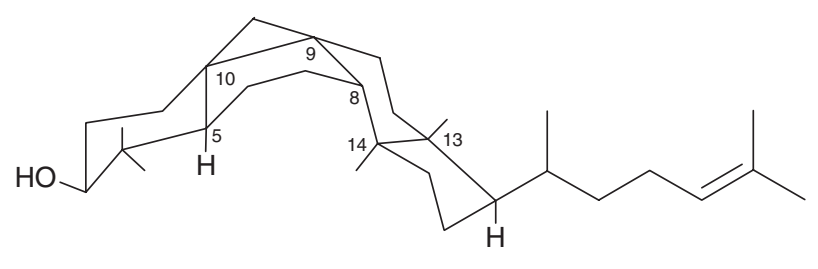

Cycloartenol

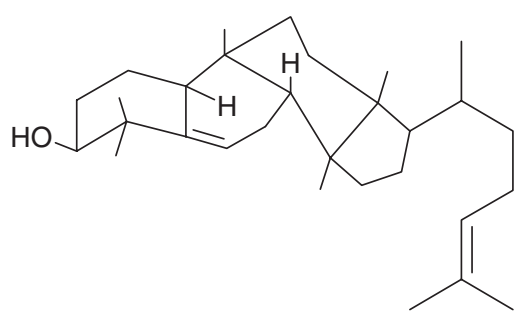

5,24-Cucurbitadien-3ß-ol

Konformationsformeln der 4 in der vorhergehenden $>A b b$. 24.1 angeführten Haupttypen der Triterpene. In den starren tetra- und pentazyklischen Ringsystemen sind Konfiguration und Konformation wechselseitig festgelegt. Konformationsformeln lassen sich unterschiedlich wiedergeben, abhängig davon, von welcher Seite man das Molekülmodell betrachtet. Beispiel: $\beta$-Amyrin (1a bzw. 1b)

dann mit Aldehyden farbige Kondensationsprodukte bilden (Beispiel: zur dünnschichtchromatographischen Untersuchung von Süßholzwurzeln). Die Aldehyd-SäureReaktion ist wenig spezifisch. Es reagieren zahlreiche andere Stoffgruppen: Sesqui- und Diterpene, Olefine, Phenole, Indolderivate u. a. m.

Reaktion mit Schwefelsäure und Acetanhydrid. Ungesättigte und hydroxylierte Triterpene und Steroide ergeben bei der Umsetzung mit Acetanhydrid und Schwefelsäure rote, blaue oder grüne Färbungen (\$ Tabelle 24.1). Die Reaktion ist in der Literatur als Liebermann-Burchard-Reaktion (LBR) bekannt.

Als die farbgebenden Komponenten der LBR sieht man Carbeniumionen an (\$Abb. 24.4). Zunächst finden Dehydrationen statt; es kommt - evtl. nach Umlagerung und/oder Kondensation mehrerer Moleküle - zur Ausbil- dung konjugierter Polyensysteme, die ein Proton addieren. Die Farbstoffe zerfallen leicht in Gegenwart von Wasser, weshalb sich auch Farbzonen auf Chromatogrammen nicht konservieren lassen.

\section{Reaktion mit anorganischen Säuren und Oxidations-} mitteln [Zlatkis-Zak-Reaktion (ZZR)]. Zahlreiche ungesättigte und hydroxylierte Triterpene und Steroide geben nach Umsetzung mit anorganischen Säuren und Oxidationsmitteln Färbungen, die aber nur eine gewisse Zeit, im Mittel etwa 30 min lang, beständig sind. Als Oxidationsmittel nimmt man meist Eisen(III)-Salze, seltener Kupfer(II)- oder Cer(IV)-Sulfat. Der Reaktionsmechanismus ist in Einzelheiten nicht bekannt. Wahrscheinlich finden Oxidations- und Dehydrationsreaktionen statt, die $\mathrm{zu}$ konjugierten Polyensystemen führen. Im Falle des Cholesterols gelang es, das Hauptreaktionsprodukt als 
- Abb. 24.3

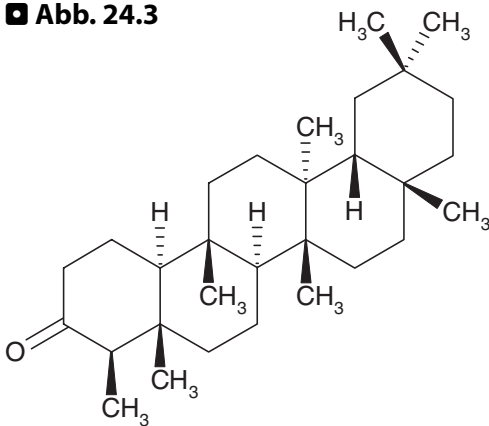

Friedelin, $\mathrm{C}_{30} \mathrm{H}_{50} \mathrm{O}$; im Kork der Korkeiche (Quercus suber)

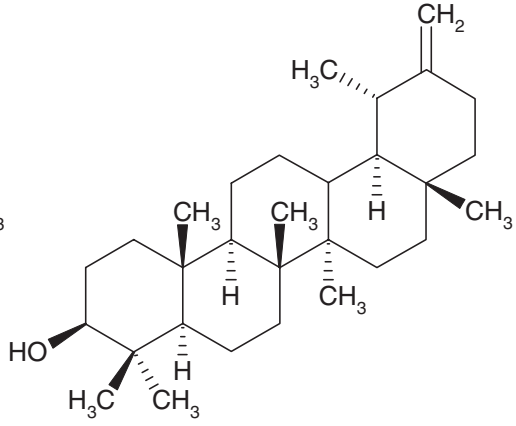

Taraxasterol, $\mathrm{C}_{30} \mathrm{H}_{50} \mathrm{O}$; im Milchsaft des Löwenzahns (Taraxacum officinale)

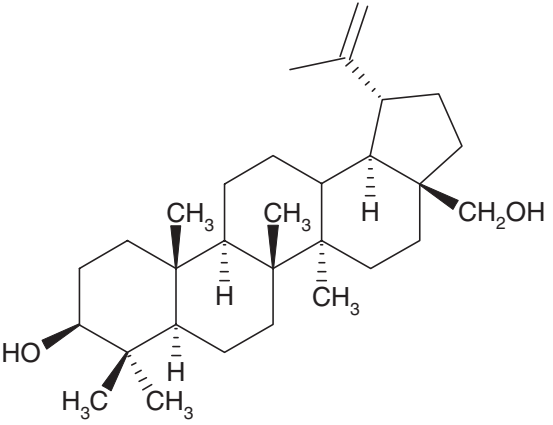

Betulin, $\mathrm{C}_{30} \mathrm{H}_{50} \mathrm{O}_{2}$;

in der Rinde von Birke und Erle

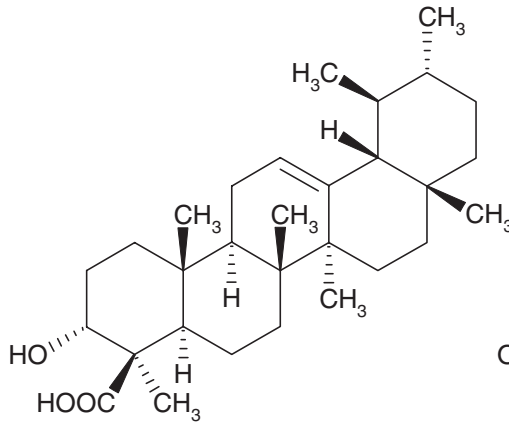

$\beta$-Boswelliasäure, $\mathrm{C}_{30} \mathrm{H}_{48} \mathrm{O}_{3}$; im Weihrauch

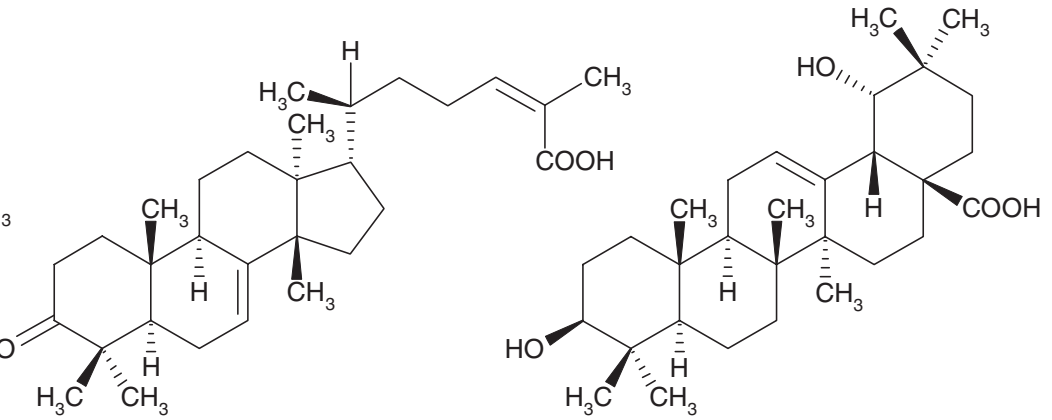

Masticadienonsäure, $\mathrm{C}_{30} \mathrm{H}_{46} \mathrm{O}_{3}$; im Mastix
Siaresinolsäure, $\mathrm{C}_{30} \mathrm{H}_{48} \mathrm{O}_{4}$; in der Siambenzoe

Beispiele für Triterpene, die lipophile Eigenschaften aufweisen. Sie kommen in der Wachsschicht von Blättern, in verkorkten Geweben, Milchsäften und Harzen vor

\section{- Tabelle 24.1}

\section{Farbreaktionen einiger Triterpene und Steroide}

\section{Steroid Farbtöne}

$\beta$-Sitosterin Intensiv violett $\rightarrow$ blaugrün $\rightarrow$ smaragdgrün

Stigmasterin Rot $\rightarrow$ blau $\rightarrow$ intensiv grün

Digitoxin Braun $\rightarrow$ grün

Digoxin $\quad$ Rot $\rightarrow$ violett $\rightarrow$ dunkelviolett $\rightarrow$ blaugrün

Gitoxin $\quad$ Gelb $\rightarrow$ braun $\rightarrow$ grün

Diosgenin Rötlich $\rightarrow$ braungelb $\rightarrow$ braun

Ouabain $\quad$ Gelblich $\rightarrow$ kräftig orangegelb

Scillarenin Rosa $\rightarrow$ grün

Scillarosid Intensiv violett $\rightarrow$ blau $\rightarrow$ blaugrün

Vorgehen: Man suspendiert etwa 0,5 mg Substanz in $1 \mathrm{ml}$ Essigsäureanhydrid und fügt unter Kühlung 2 Tropfen konz. Schwefelsäure dazu. Es treten der Reihe nach die in der Tabelle wiedergegebenen Farben auf.
3,3'-Bis-(cholesta-2,4-dien) zu identifizieren. Die Protonierung dieses Tetraens führt zu einem gefärbten Carbeniumion. Das DAB benutzt die ZZR zur Aescinbestimmung in Rosskastaniensamen. Verwendet wird dabei das Eisen(III)-chlorid-Essigsäure-Reagens (vgl. Kap. 24.6.3).

Reaktion mit Antimon(III)-chlorid. Als Reagens dient eine 20- bis 30\%ige Lösung des Salzes in einem Essigsäure 99\%-Acetanhydrid-Gemisch oder in Chloroform bzw. Dichlormethan. Hydroxytriterpene und Hydroxysteroide geben mit dem Reagens farbige Produkte, deren Absorptionsmaxima zwischen 560 und $680 \mathrm{~nm}$ liegen. Durch Wasser werden die Farbkomplexe zerstört.

Die Reaktion ist wenig spezifisch. Es reagieren außer Terpenen und Steroiden die Carotinoide, die Vitamine A und D sowie viele Flavonoide (sie bilden stabile Chelate). 


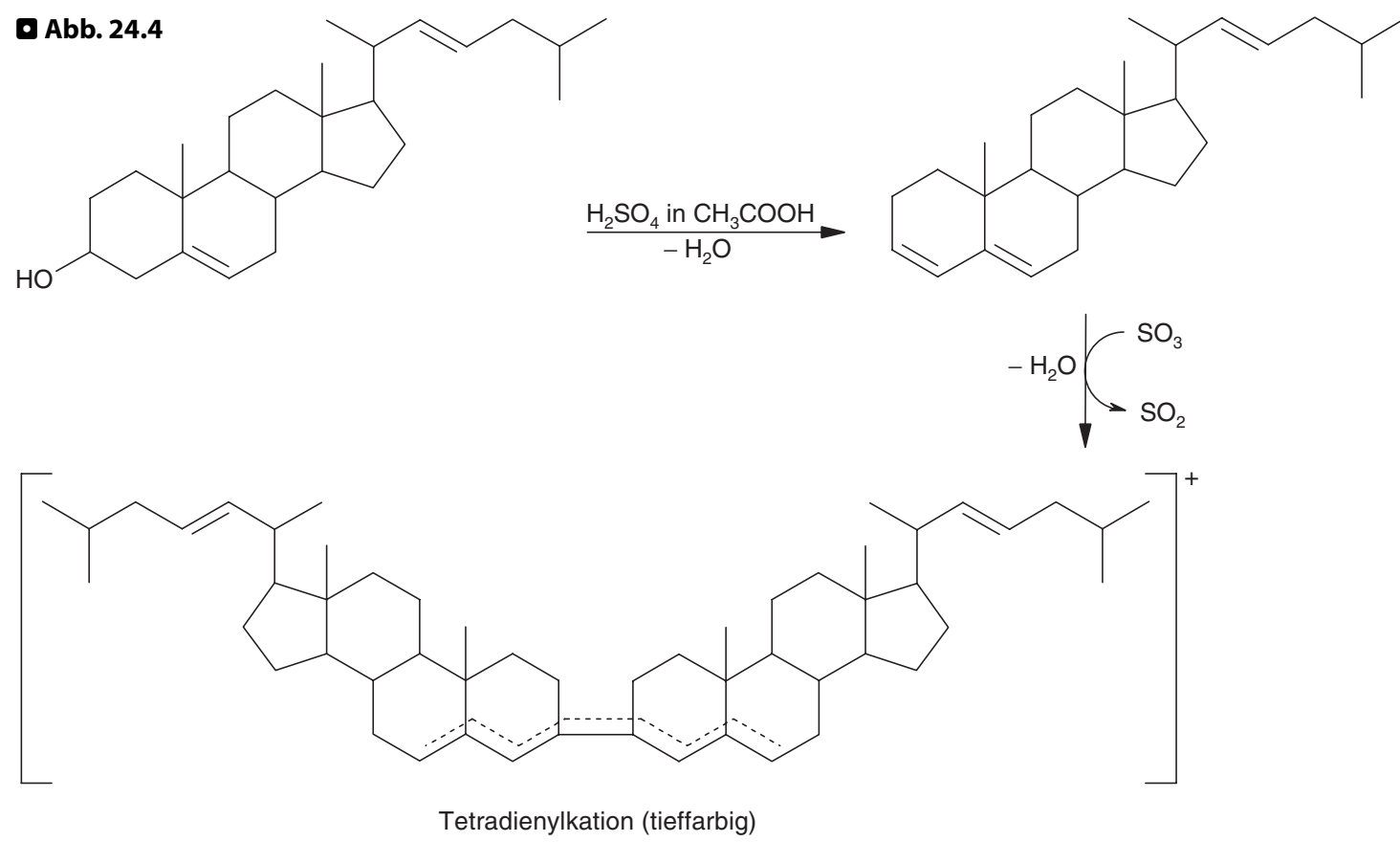

Vorstellungen zum Ablauf der Liebermann-Burchard-Reaktion. Konzentrierte Schwefelsäure in Essigsäure $99 \%$ wirkt dehydratisierend und oxidierend. Ausgehend von im Molekül vorhandenen alkoholischen Gruppen und Doppelbindungen bildet sich ein System von konjugierten Doppelbindungen aus. Das nach Anlagerung eines Protons mesomeriestabilisierte Carbeniumion absorbiert im sichtbaren Bereich

\subsection{Squalen}

Es handelt sich um einen azyklischen $\mathrm{C}_{30}$-Kohlenwasserstoff mit 6 trans-ständigen Doppelbindungen, der zuerst aus Haifischleber (Haie: zoologisch Squaloideae) isoliert worden ist. In kleinen Konzentrationen kommt Squalen als Begleitstoff in pflanzlichen Ölen sowie in einigen weiteren pflanzlichen Produkten vor: in Olivenöl $(0,1-0,7 \%)$, in Getreidekeimölen und in medizinischer Hefe. Der menschliche Hauttalg enthält 5\% Squalen.

Squalen ist bei Raumtemperatur eine farblose, ölige Flüssigkeit, die sich in Wasser praktisch nicht, in Lipidlösungsmitteln gut löst. Ähnlich wie ungesättigte Fettsäuren ist auch Squalen bei Zutritt von Luftsauerstoff autoxidabel. Es hat einen schwachen, angenehmen Geruch und weist bakterizide Eigenschaften auf.

Die quantitative Bestimmung des Squalens erfolgt am besten gaschromatographisch. In der pharmazeutischen Technologie, mehr noch in der kosmetischen Industrie, verwendet man das hydrierte Squalen (Perhydrosqualen, Squalan), für Hautcremes, Hautöle, flüssige Emulsionen,
Lippenstifte und andere Produkte. Es fungiert als Lösungsmittel für fettlösliche Farbstoffe oder Wirkstoffe; es wirkt zudem „hautglättend“ und ist v. a. sehr gut hautverträglich.

Squalen ist aus biochemischer Sicht ein wichtiger Körper, da es ein Intermediärprodukt des Stoffwechsels ist, das zur Biosynthese von Triterpenen und Steroiden führt. Seine Zyklisierung wird durch Epoxidierung einer endständigen Doppelbindung (vermittelt durch eine mischfunktionelle Oxygenase) eingeleitet. Da die Squalen-2,3-Epoxidstufe vor der Zyklisierung obligat durchlaufen werden muss, enthalten - gleichsam als Relikt - nahezu sämtliche Triterpene und Steroide in Position C-3 eine Sauerstofffunktion.

\subsection{Phytosterole (Phytosterine)}

Unter Phytosterolen (PS) oder Phytosterinen versteht man die in höheren Pflanzen vorkommenden Substanzen mit einem Steroidgerüst (\$ Abb. 24.5), die dem Prototyp 
D Abb. 24.5

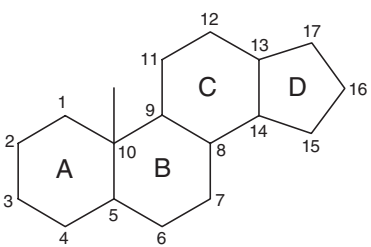

10-Methylsteran

bedeutet $\mathrm{CH}_{3}$

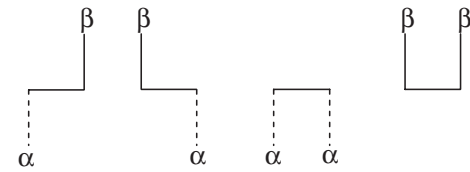

Substituenten an Nachbaratomen

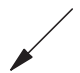

\begin{tabular}{|c|l|}
\hline & betroffene Ringe \\
\hline 5 und 10 & $\mathrm{~A} / \mathrm{B}$ cis oder trans \\
9 und 8 & $\mathrm{~B} / \mathrm{C}$ cis oder trans \\
14 und 13 & $\mathrm{C} / \mathrm{D}$ cis oder trans \\
\hline
\end{tabular}

\begin{tabular}{|c|l|}
\hline & $\begin{array}{l}\text { angulare } \\
\text { Substituenten }\end{array}$ \\
\hline $\begin{array}{c}10 \text { und } 9 \\
8 \text { und } 14\end{array}$ & $\begin{array}{l}\text { syn oder anti } \\
\text { syn oder anti }\end{array}$ \\
\hline
\end{tabular}<smiles>CCC1CC[C@@H]2CCCC[C@]2(C)CCC2CCCC12</smiles><smiles>C[C@H]1CC[C@@H]2CCCC1CC1C3CCCC3CCC12</smiles><smiles>CC12CCCC1CCC(CCC1CCCC1)C2</smiles><smiles>CC12CCCCC1CCC1C3CCCC3CCC12</smiles>

$\dot{H}$

$5 \alpha$-Reihe (Ringe A / B trans)

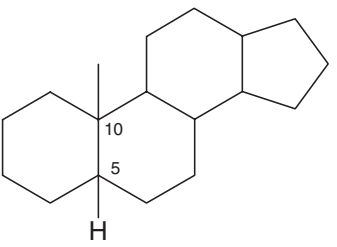

$5 \beta$-Reihe (Ringe A / B cis)<smiles>CC12CCCC=C1CCC1C3CCCC3CCC12</smiles>

ungesättigte Steroide (4-En-derivat)

Den Steroiden liegt das Sterangerüst (Cyclopentanoperhydrophenanthrengerüst) zugrunde. Es hat 6 in einer Reihe miteinander verbundene ", asymmetrische" C-Atome (C-5, C-10, C-9, C-8, C-14 und C-13), sodass theoretisch 32 Enantiomerenpaare denkbar sind; allerdings sind in der Natur nur eine kleine Anzahl davon verwirklicht. Zur Kennzeichnung der relativen Konfiguration zweier benachbarter C-Atome verwendet man die Symbole cis und trans, wenn es sich um C-Atome handelt, die beiden Ringen gemeinsam sind; für die cis-Stellung benachbarter angularer Substituenten ist die Bezeichnung syn, für die trans-Stellung das Präfix anti in Gebrauch.

Die cis- oder trans-Stellung beliebig anderer (nicht benachbarter) Substituenten wird in Bezug auf die Methylgruppe an C-10 festgelegt: $a$ bedeutet trans-Stellung, $\beta$ bedeutet cis-Stellung. Untere Hälfte: Die Reihe mit der Verknüpfung der Ringe A und B in trans-Stellung wird auch als 5a-Reihe bezeichnet; die Reihe mit der Verknüpfung in cis-Stellung als $5 \beta$-Reihe. Einführung einer Doppelbindung in 4,5- (oder 5,6-)Stellung führt zu ungesättigten Steroiden

aller Sterole, dem Cholesterol, nahe stehen. Cholesterol (Formel vgl. $\rightarrow A b b .24 .1$ ) ist ein $\mathrm{C}_{27}$-Steroid; dabei entfallen $17 \mathrm{C}$-Atome auf das tetrazyklische Ringsystem, $2 \mathrm{C}$-Atome auf die beiden $\beta$-Methylgruppen an $\mathrm{C}$ - 10 und an C-13 und 8 C-Atome auf die Alkylseitenkette an C-17. Die Mehrzahl der in höheren Pflanzen vorkommenden Sterole ( $>A b b$. 24.6-24.8) enthalten eine $\mathrm{C}_{10}$-Seitenkette und die Mehrzahl der in Pilzen vorkommenden Sterole einen $\mathrm{C}_{9}$-Rest. Daher teilte man früher die Sterole ein in die $\mathrm{C}_{27}$-Zoosterine, die $\mathrm{C}_{28}$-Mykosterine und in die $\mathrm{C}_{29}$-Phytosterine. Diese Unterteilung hat ihren Sinn verloren, seitdem auch in höheren Pflanzen $\mathrm{C}_{27^{-}}$und $\mathrm{C}_{28}$-Sterole gefunden worden sind. Beispielsweise ist in Solanum- und Nicotiana-Arten nicht wie üblich Sitoste- 
Abb. 24.6

4,4-Dimethylsterine

(Cycloartenoltyp)<smiles>[R]C1CCC2C3=CC[C@H]4[C@@H](O)C(O)CC[C@]4(C)[C@H]3CCC12C</smiles>

4-Methylsterine (Gramisterol)

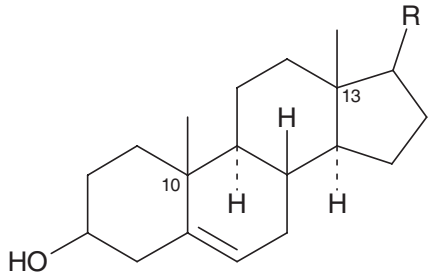

Demethylsterine - Phytosterine im engen Sinn ( $\beta$-Sitosteroltyp)

$\mathrm{R}=$ Alkyl- oder Alkenylkette mit 8, 9 oder 10 C-Atomen (s. Abb. 24.7)

Die pflanzlichen Sterole (Synonyme: Phytosterole, Phytosterine) unterteilt man in 3 Klassen, wobei die Methylgruppensubstituenten am C-4 die Einteilung liefern. Am weitesten verbreitet sind die Demethylsterole: Die verbleibenden beiden Methylgruppen an C-10 und C-13 sind in allen Fällen $\beta$-ständig angeordnet

- Abb. 24.7<smiles>CC(C)CCC[C@H](C)C1CCC(C)C1(C)C</smiles>

Cholesterol $\mathrm{C}_{8}$-Seitenkette<smiles>CC[C@@H](/C=C/[C@@H](C)C1CCC(I)C1(C)I)C(C)C</smiles>

Stigmasterol $\mathrm{C}_{10}$-Seitenkette (24S)

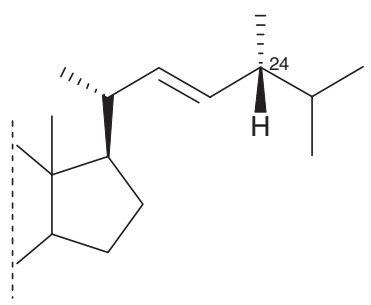

Ergosterol $\mathrm{C}_{9}$-Seitenkette $(24 R)$

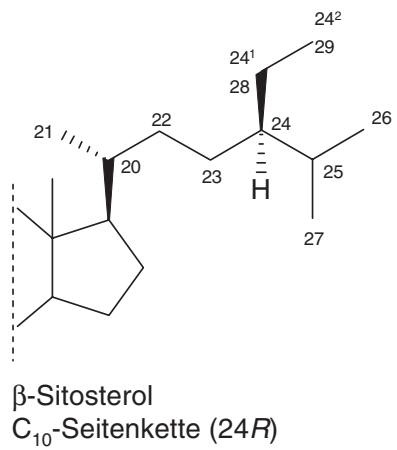

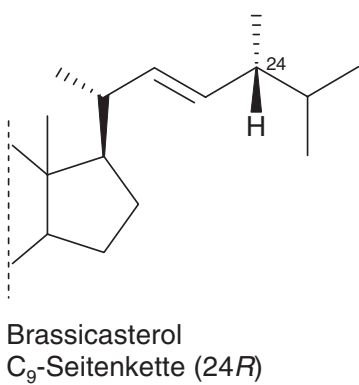

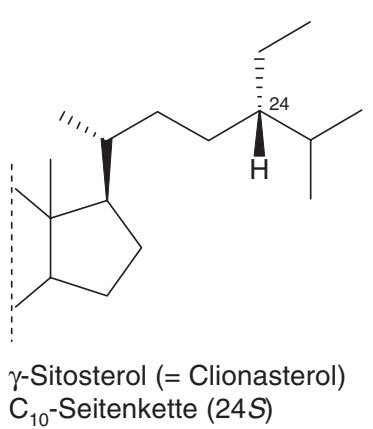

Variation der C-17-Seitenkette. Grundkörper der Reihe sind Steroide mit einer $C_{8}$-Seitenkette, wie sie im Cholesterol vorliegt. Die in Pilzen vorkommenden Sterine („,Mykosterine“) haben eine $\mathrm{C}_{9}$-Seitenkette (z. B. Ergosterol), doch kommen Vertreter auch in höheren Pflanzen vor (z. B. Brassicasterol). Die Mehrzahl der in höheren Pflanzen vorkommenden Phytosterine ist am C-17 mit einer $\mathrm{C}_{10}$-Seitenkette substituiert. Die Ethylsubstitution der $\mathrm{C}_{8}$-Kette erfolgt, wie nähere Biosynthesestudien ergaben, in 2 Schritten, durch sukzessive Übertragung von Methylgruppen. Eine weitere Variation ist gegeben durch die Einführung einer Doppelbindung und durch die Konfiguration am C-24 ( $\beta$ - bzw. $\gamma$-Sitosterol).

Hinweis: Man achte auf die Nummerierung der Seitenkette. Der Ethylseitenrest erhält nach IUPAC-IUB 1976 die Ziffern 28 und 29 bzw. nach den neueren IUPAC-Empfehlungen (IUPAC-IUB 1989) $24^{1}$ und $24^{2}$ (vgl. Übersicht von Goad 1991) 
- Abb. 24.8

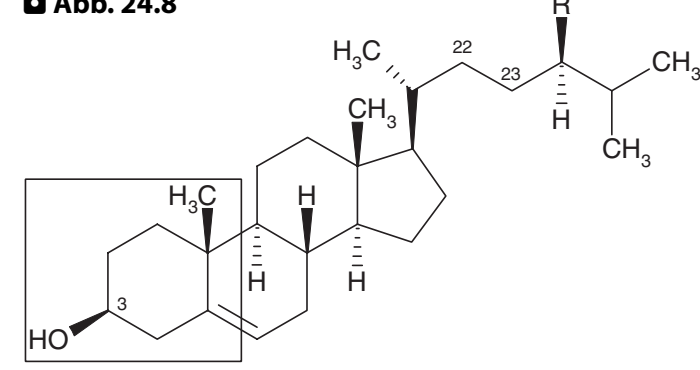

$\mathrm{R}=\mathrm{C}_{2} \mathrm{H}_{5}: \beta$-Sitosterol, $\mathrm{C}_{29} \mathrm{H}_{50} \mathrm{O}$

$\mathrm{R}=\mathrm{CH}_{3}$ : Campesterol, $\mathrm{C}_{28} \mathrm{H}_{48} \mathrm{O}$

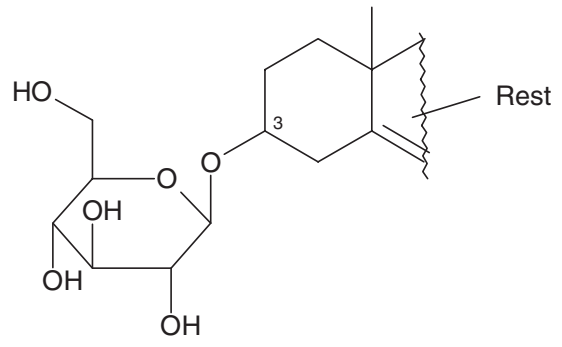

Sitosterylglucosid
Rest

Sitosterylpalmitat

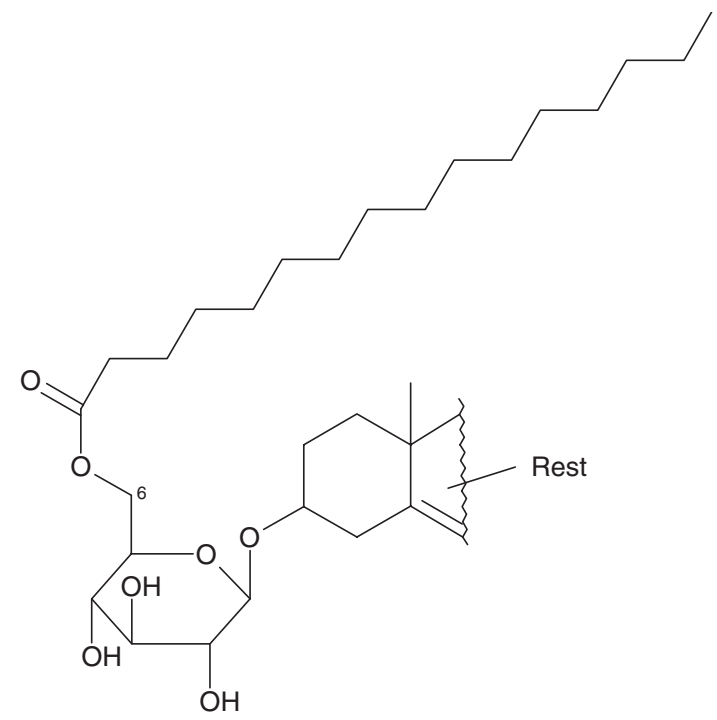

6-O-Palmitoyl- $\beta$-D-glucosyl-sitosterol

$\beta$-Sitosterol ist ein vermutlich in allen grünen Pflanzen vorkommendes Phytosterol. Weitverbreitet ist auch das chemisch nahe verwandte Stigmasterol (= 22,23-Dehydro- $\beta$-sitosterol) sowie das Campesterol (= 29-Nor- $\beta$-sitosterol). Phytosterole kommen in sehr unterschiedlicher Bindung vor: als D-Glucoside, als Fettsäureester und als 6-Acylglucoside

rol, sondern Cholesterol das Hauptsterol. Auch viele Rotalgen synthetisieren und speichern bevorzugt Cholesterol.

Vorkommen und Gewinnung. PS wurden aus allen nur denkbaren Organen und Geweben isoliert: aus Blättern, Stängeln, Wurzeln, Blüten, Früchten und Samen. Die Hauptmenge ist in den intrazellulären Organellen und in den Plasmamembranen lokalisiert.

Präparativ oder im technischen Maßstab gewinnt man PS am bequemsten aus dem sog. unverseifbaren Anteil von Pflanzenfetten bzw. Pflanzenölen. Der Anteil liegt zwischen 0,1 und 1\%. Die Art des Sterols sowie das Mengenverhältnis bestimmter Sterole zueinander (Quotient aus Stigmasterol/Campesterol) ist für ein bestimmtes Pflanzenfett charakteristisch. Als Rohstoff zur Gewinnung von $\beta$-Sitosterol kommen das Baumwollsaatöl und das Wachs des Zuckerrohrs in Frage. Sojabohnenöl enthält $0,2 \%$ Sitosterole, hauptsächlich $\gamma$-Sitosterol, d. i. das 24-Epimere des $\beta$-Sitosterols. In kleiner Menge kommen in der Natur neben den PS auch die hydrierten Verbindungen vor, die als Stanole bezeichnet werden. Stanole werden aus dem sog. Tallöl, einem Nebenprodukt der holzverarbeitenden Industrie, durch Hydrierung der da- 
rin enthaltenen PS erhalten. Sie bestehen aus einem Gemisch von Sitostanol und Campestanol.

Die heute häufig verwendeten fettlöslichen Ester von PS und von Stanolen gewinnt man durch Veresterung von Sitosterol bzw. dem aus Tallöl erhaltenen Sitostanol-Campestanol-Gemisch mit Fettsäuren.

Wirkungsspektrum. Als Bestandteil von Biomembranen kommt den Sterolen eine wichtige Funktion zu. Durch ihre Wechselwirkung mit Phospholipiden sind sie für die Stabilität der Membranen wesentlich. PS und insbesondere von Sterolen oder tetrazyclischen Triterpenen abgeleitete Oxysterole zeigen ein breites Wirkungsspektrum. So werden ihnen u. a. cholesterolsenkende, entzündungshemmende, antibakterielle, antifungale und tumorhemmende Eigenschaften zugeschrieben. Oxysterole sind wahrscheinlich für die Aufrechterhaltung eines stabilen inneren physiologischen Gleichgewichts (Homöostase) des Cholesterolhaushalts verantwortlich.

Cholesterolsenkung: Früher wurden zur Senkung des Cholesterolspiegels wegen der geringen Löslichkeit und Resorption von freien PS Tagesdosen von bis zu $30 \mathrm{~g}$, in der Regel 3-mal 3 g/Tag, verwendet. Heute werden PS und insbesondere Stanole zur Erhöhung der Löslichkeit und Resorption mit Fettsäuren verestert [= Phytosterol-/Stanolester (PSE)]. Dadurch kann die tägliche Einnahme auf 2-3 g reduziert werden. PSE hemmen kompetitiv die Resorption des Cholesterols im Dünndarm, und zwar die des exogenen, mit der Nahrung zugeführten Cholesterols sowie die Rückresorption des aus dem enterohepatischen Kreislauf stammenden Cholesterols. Von den verschiedenen diskutierten Theorien zum Wirkungsmechanismus stehen die Verdrängung des Cholesterols in den „gemischten Mizellen“ (engl.: „dietary mixed micelles“) durch PS/PSE sowie der Rücktransport von Cholesterol in den Dünndarm im Vordergrund (> Abb. 24.9). Wegen der geringen Löslichkeit muss Cholesterol vor der Resorption in Mizellen aus amphiphilen Molekülen (Mono- und Diacylglycerole, freie Fettsäuren, Phospholipide, Gallensäuresalze) inkorporiert werden. Cholesterol wird in diesen Mizellen durch die besser löslichen PS, insbesondere durch deren Ester, ersetzt, wodurch ein niedrigerer Cholesterolgehalt in den Mizellen und damit eine reduzierte Cholesterolresorption resultiert. PS/PSE werden nur zu einem geringen Anteil resorbiert (0,02-3,5\%). Im Vergleich dazu beträgt die Resorption von Cholesterol 35-70\%. Der Grund dafür liegt wahrscheinlich in der geringen Veresterung der Sterole durch AcylCoA-Cholesterolacyltransferase, was eine Voraussetzung für die Inkorporation in Chylomikronen darstellt. Der Transfer von Cholesterol aus den Mizellen durch die Bürstensaummembran der Dünndarmenterozyten ist nicht vollständig aufgeklärt. Während bisher eine passive Diffusion angenommen worden ist, sprechen neuere Untersuchungen für die Existenz eines spezifischen Cholesteroltransporters in der Dünndarmmukosa, der für den Transport des Cholesterols in die Zelle verantwortlich ist. Der Weg von der Zelle in die Leber ist ein komplexer Vorgang (vgl. dazu Lehrbücher der Physiologie bzw. Pharmakologie). Biliäres Cholesterol kann durch sog. ABC-Transporter wie ABCA1 u. a. (vgl. $>A b b .24 .9)$ wieder in den Dünndarm zurücktransportiert werden.

Neue klinische Studien mit PSE ergaben, dass der LDL-Gehalt zwischen 10-15\% gesenkt wird, während der HDL-Gehalt unverändert bleibt. Eine kürzlich durchgeführte Metaanalyse hat ergeben, dass eine tägliche Dosis von $2 \mathrm{~g}$ PSE als optimal betrachtet wird. Diese $2 \mathrm{~g} / \mathrm{Tag}$ werden in den USA von den Richtlinien des „National Cholesterol Education Program“ empfohlen (vgl. Übersichten von Moreau et al. 2002; de Jong et al. 2003; Trautwein et al. 2003). Zur Senkung des Cholesterolspiegels vgl. auch die folgende Infobox „Cholesterolsenkung“.

\section{Infobox}

Cholesterolsenkung. Die LDL-Cholesterolkonzentration im Plasma resultiert aus der Cholesterolbiosynthese in der Leber und aus der Cholesterolmenge, die aus dem Dünndarm resorbiert wird. Zur Cholesterolsenkung kommen daher im Wesentlichen zwei Mechanismen in Frage: die Hemmung der Cholesterolsynthese sowie die Hemmung der Cholesterolresorption. Die Cholesterolsynthesehemmer senken den Cholesterolplasmaspiegel (Gesamt- und LDL-Cholesterol) über die Hemmung der HMG-CoA-Reduktase (vgl. Kap. 23.1 und $>A b b .23 .4$ ) als Schlüsselenzym der hepatischen Cholesterolbiosynthese. Kompensatorisch exprimieren Leberzellen auf ihrer Oberfläche mehr LDL-Rezeptoren, die LDL-Cholesterol aus dem Blut in die Hepatozyten aufnehmen. Die Cholesterolresorptionshemmer hemmen im Dünndarm die Resorption von Nahrungsund biliärem Cholesterol. Als Lipidsenker werden heute vorwiegend Statine, Nicotinsäure und Nicotinsäurederivate, Fibrate (Cholesterolsynthesehemmung und Abbausteigerung) sowie Anionenaustauscher und Ezetimib (Cholesterolresorptionshemmer) eingesetzt. Zu den pflanzlichen Lipidsenkern gehören Phytosterole, Knoblauch und Artischockenextrakte. 
- Abb. 24.9

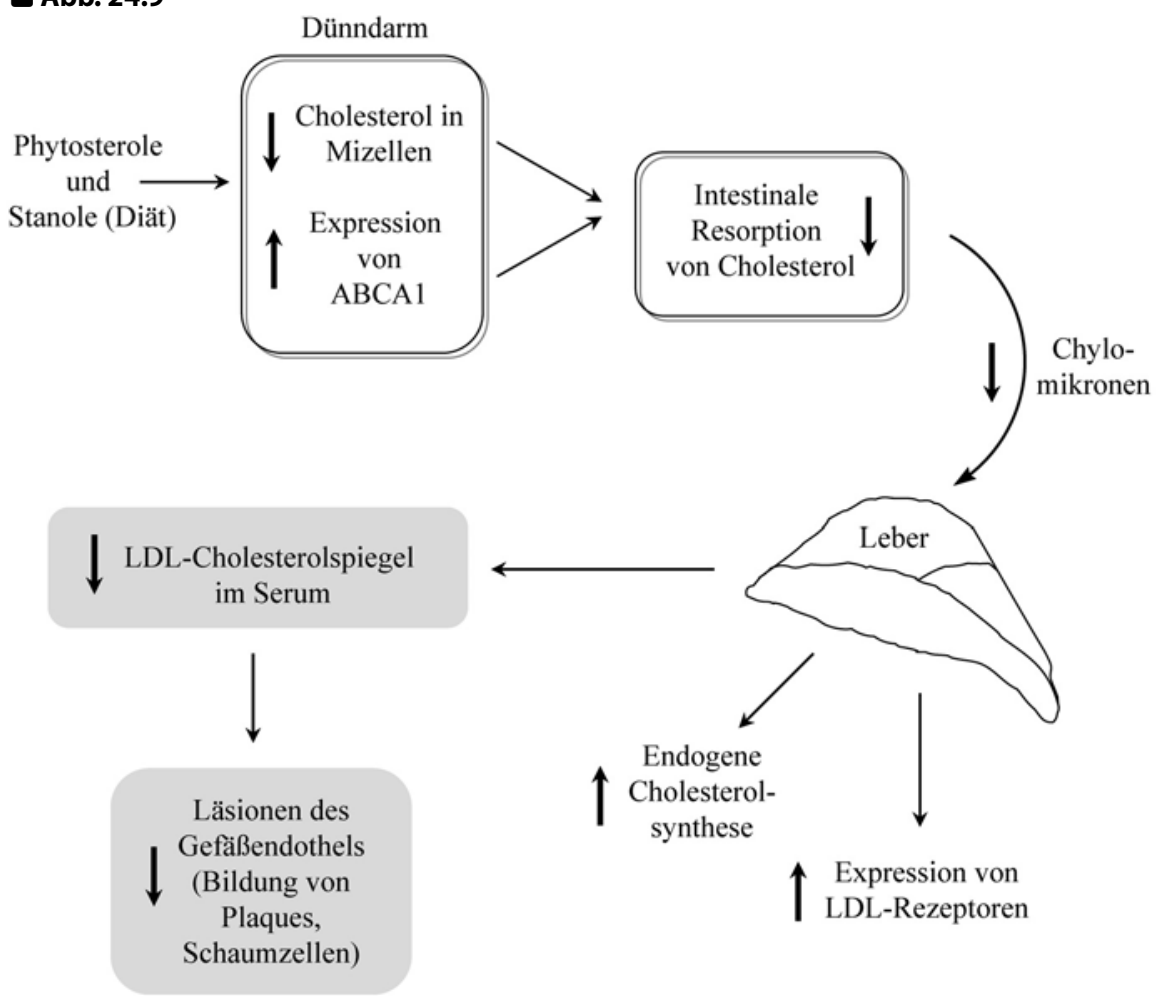

Potentielle Effekte von Phytosterolen und Stanolen auf den Lipid- und Lipoproteinstoffwechsel (abgeändert nach de Jong et al. 2003). Tier- und In-vitro-Studien haben ergeben, dass Phytosterole und Stanole, die in der chemischen Struktur mit dem Cholesterol verwandt sind, die Inkorporation von Cholesterol in gemischte Mizellen im Dünndarmlumen reduzieren und die Expression des Cholesteroltransporters ABCA1 erhöhen. Daraus resultieren eine reduzierte Resorption von Cholesterol und ein eingeschränkter Cholesterolfluss mit Chylomikronen in die Leber, was zu einem Anstieg der endogenen Cholesterolsynthese und der Expression von LDL-Rezeptoren in der Leber führt. Als Gesamteffekt dieser Änderungen im Metabolismus ergibt sich eine Reduktion der Konzentration von LDL-Cholesterol im Serum. Tierstudien haben ferner ergeben, dass eine erhöhte Zufuhr von Phytosterolen und Stanolen arteriosklerotische Läsionen des Gefäßendothels (Bildung von Plaques, Schaumzellen) erniedrigt (vgl. Übersicht von de Jong et al. 2003). Abkürzungen: $L D L$ „low density lipoprotein", $A B C A 1$ ein Cholesteroltransporter (ABC von „ATP-binding cassette")

Sitosterol (Sitosterin). Die Handelsprodukte sind nicht einheitlich. Für arzneiliche Zwecke geeignete Präparate müssen mindestens $95 \%$ Gesamtsterole und mindestens $85 \%$ ungesättigte PS enthalten, berechnet als $\beta$-Sitosterol. Die Substanz stellt ein weißes, geruch- und geschmackloses Pulver dar; unlöslich in Wasser, etwas löslich in Ethanol, gut löslich in Chloroform. Etwa 0,5\% des p.o. verabreichten $\beta$-Sitosterols werden resorbiert (vgl. Übersicht von Trautwein et al. 2003).

Zur cholesterolsenkenden Wirkung von $\beta$-Sitosterol (>) unter Wirkungsspektrum. In Tagesdosen von 20-50 mg wird $\beta$-Sitosterol bei der Behandlung der benignen Prostatahyperplasie (BPH) eingesetzt. Während verschiedene Autoren zum Schluss kommen, dass die Substanz die subjektiven Symptome eines Prostataadenoms verbessert, eine schnellere und vollständigere Entleerung der Blase ermöglicht und die Behandlungserfolge - ohne bekannten Wirkungsmechanismus - mit denjenigen von $5 \alpha$-Reduktasehemmern vergleichbar sind (vgl. z. B. Berges et al. 1995), wird von anderer Seite das Vorliegen von zuverlässigen wissenschaftlichen Belegen einer über den Plazeboeffekt hinausgehenden Wirksamkeit nicht nur für Sitoste- 
rol, sondern für alle Phytopharmaka mit der Indikation BPH bezweifelt (Brom 1996). Inwiefern die therapeutische Anwendung von $20-50 \mathrm{mg} \beta$-Sitosterol enthaltenden Phytopharmaka zur Behandlung der BPH relevant ist, ist schwierig zu beurteilen, da die tägliche Einnahme von Phytosterolen mit der Nahrung im Durchschnitt bei $\sim 250 \mathrm{mg}$ liegt (vgl. Übersicht von Moreau et al. 2002) und ihre Resorption nur gering ist.

Stigmasterol (Stigmasterin). Es unterscheidet sich vom $\beta$-Sitosterol durch eine Doppelbindung in der Seitenkette. Im Vergleich zu Sitosterol erleichtert dies den chemischen Abbau der Kette, weshalb Stigmasterol als Ausgangsmaterial zur Partialsynthese von Hormonen von Interesse ist. Es kommt mit den Sitosterolen, denen es in seinen physikalischen Eigenschaften weitgehend ähnlich ist, zusam- men vor, beispielsweise im unverseifbaren Anteil des Sojabohnenöls.

Beispiele für oxidierte Phytosterole. In jeder Stoffgruppe kommen neben den sauerstoffarmen Derivaten mehr oder weniger stark oxidierte Vertreter vor, die in der Regel biologisch und pharmakologisch aktiv sind. Auch bei den Phytosterolen finden sich entsprechende $O$-Varianten, wofür als Beispiel Withaferin A und Carpesterol angeführt seien. Withaferin A ist ein Vertreter der über 100 bekannten Withanolide ( $(A b b$. 24.10). Withanolide, ursprünglich aus Withania-Arten und inzwischen auch aus verschiedenen anderen Gattungen der Familie Solanaceae [IIB24a] isoliert, weisen das Kohlenstoffskelett des Ergostans $\left(\mathrm{C}_{28}\right)$ auf. Typische funktionelle Merkmale der Withanolide sind eine Oxogruppe an C-1, eine Doppel-
- Abb. 24.10

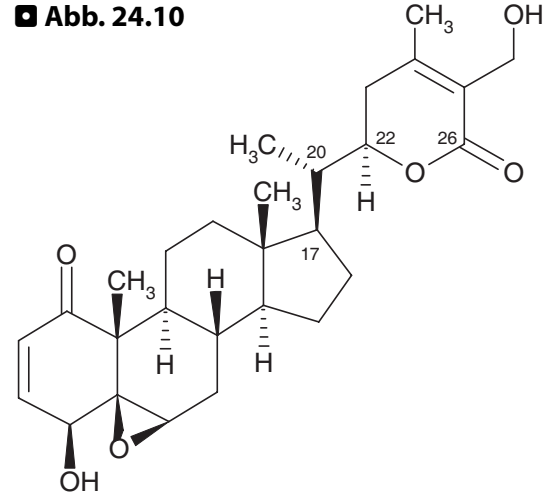

Withaferin $\mathrm{A}, \mathrm{C}_{28} \mathrm{H}_{38} \mathrm{O}_{6}$<smiles>CC[C@H](C)[C@@H](C)[C@@H](C)[C@@H](O)C[C@H](C)[C@H](C)CC</smiles>

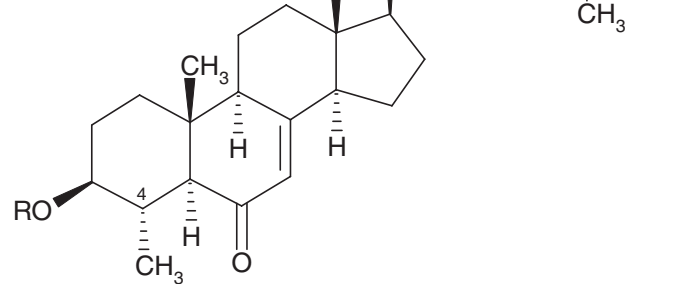<smiles>O=POc1ccccc1</smiles>
$\mathrm{C}_{37} \mathrm{H}_{54} \mathrm{O}_{4}$

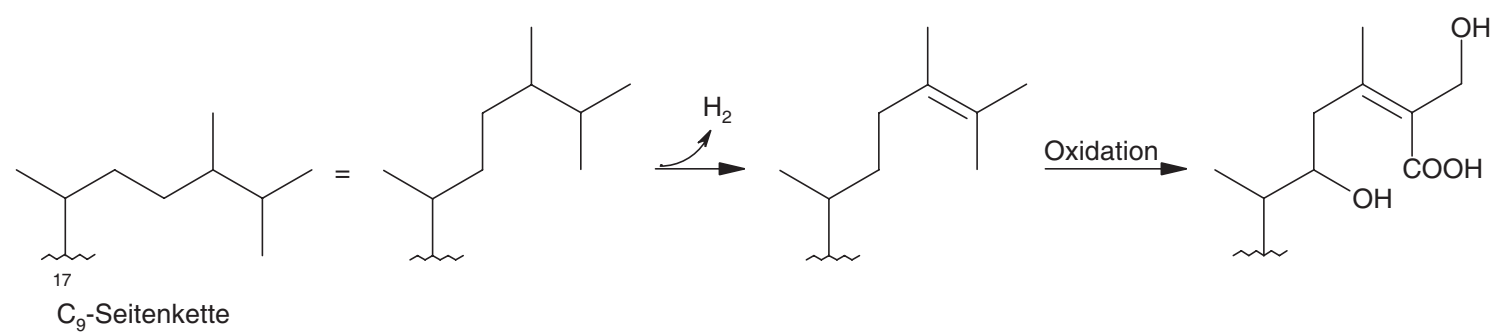

Withaferin A ist ein oxidativ modifiziertes Phytosterol mit einer $C_{9}$-Seitenkette (Typus: Brassicasterol, \ Abb. 24.7). Die 22-OH und das 26-Carboxyl bilden einen 6-gliedrigen Lactonring; das Vorkommen in Withania-Arten zusammen mit dem Lactonmerkmal, das in der Chemie durch das Suffix ",-olid“ gekennzeichnet wird, hat der ganzen Stoffgruppe den Namen Withanolide eingebracht. Im Carpesterol, einem Steroid der 4-Methylklasse mit einer $\mathrm{C}_{10}$-Seitenkette ist die Oxidation weniger weit fortgeschritten 
bindung zwischen C-2 und C-3, ein hoher Oxidationsgrad sowie ein 6- oder 5-gliedriger Lactonring. Withaferin A und chemisch ähnliche Withanolide zeigten in Laborstudien antiarthritische, antiphlogistische, antitumorale, antibakterielle, antifungale und immunsuppressive Wirkungen (vgl. Übersicht von Christen 1989). Carpesterol (> Abb. 24.10) wurde aus den Früchten mehrerer Solanum-Arten isoliert. In reiner Form bildet es farblose Kristalle, die sich in Wasser und in Alkohol sehr schlecht

\section{Kernaussagen}

Unter Phytosterolen (PS) versteht man die in höheren Pflanzen vorkommenden Substanzen mit einer dem Cholesterol nahe verwandten chemischen Struktur. PS tragen durch ihre Wechselwirkung mit Phospholipiden wesentlich zur Stabilität von Membranen bei. Sie haben cholesterolsenkende, entzündungshemmende, antibakterielle, antifungale und tumorhemmende Eigenschaften, wovon die cholesterolsenkende Wirkung am besten untersucht ist. Zur Senkung des Cholesterolspiegels wer- lösen. Seine antiphlogistische Wirkung im Mauspfotenödemtest war wesentlich stärker als diejenige von Hydrocortison und Withaferin A (Bhattacharya et al. 1980). Withanolide enthaltende Pflanzen werden in der Volksmedizin mehrerer Länder bei verschiedenen Indikationen angewendet. $\mathrm{Ob}$ das erwähnte viel versprechende Wirkungsspektrum der Withanolide allerdings therapeutisch genutzt werden kann, ist im Augenblick nicht absehbar.

den PS und ihre hydrierten Verbindungen, die Stanole, zur Erhöhung von Löslichkeit und Resorption mit Fettsäuren verestert [= Phytosterol-/Stanolester (PSE)]. PSE hemmen die Resorption des Cholesterols im Dünndarm. Klinische Studien mit PSE ergaben, dass der LDL-Gehalt zwischen 10-15\% gesenkt wird, während der HDL-Gehalt unverändert bleibt. Eine tägliche Dosis von $2 \mathrm{~g}$ PSE wird heute nach den Richtlinien des "National Cholesterol Education Program" in den USA empfohlen. PSE werden vorwiegend als Nahrungsergänzungsmittel (Functional Food) vertrieben.

\section{Schlüsselbegriffe}

ABC-Transporter

Benigne Prostatahyperplasie

Carpesterol

Cholesterol

Cholesterolsenkung

Nachweisreaktionen
Phytosterole

Phytosterolester

Sitosterol

Squalen

Stanole

Stanolester

\subsection{Triterpene verschiedener Struktur}

Unter den Triterpenen sind in den letzten Jahren nichtglykosidische, pentazyklische Triterpene mit entzündungshemmender Wirkung (vgl. Übersicht von Safayhi u. Sailer 1997), aber auch mit antiviraler, immunmodulierender und antitumoraler Wirkung besonders intensiv untersucht worden. Dazu zählen Substanzen wie die Boswelliasäuren, die Betulinsäure und die Triterpenalkohole der Ringelblumenblüte (von Calendula officinalis L.). Sie werden zusammen mit den Cucurbitacinen, Cimicifuga-Triterpenen und den Quassinoiden in diesem Kapitel besprochen. Dieselben bzw. ähnliche Wirkungen zeigen häufig auch pentazyklische Triterpenaglykone von Saponinen (vgl. dazu Kap. 24.6.8).

\subsubsection{Cucurbitacine}

Cucurbitacine sind $\mathrm{C}_{30}$-Triterpene der 4,4-Dimethylklasse, die gehäuft in Pflanzenarten aus der Familie der Kürbisgewächse (Familie: Cucurbitaceae [IIB8a]) auftreten. Sie stehen biogenetisch dem Cycloartenol nahe (Formel vgl. (7) Abb. 24.1); dessen Cyclopropanring ist geöffnet, aber so, dass die Methylgruppe an C-9 steht. Durch diese formale Verschiebung der 10-ständigen Methylgruppe in die 9 $\beta$-Position unterscheiden sich die Cucurbitacine von allen übrigen Triterpenen. Eine weitere wesentliche Variation liegt im Reichtum der Cucurbitacine an $O$-Funktionen, womit ihre Reaktionsfreudigkeit sowie ihre biologischen und pharmakologischen Aktivitäten zusammenhängen (vgl. Übersicht von Miró 1995). 
- Tabelle 24.2

Übersicht über Drogen und ihre Stammpflanzen, die Cucurbitacine enthalten (vgl. Bauer u. Wagner 1983). Ohne Angabe der Familie der Stammpflanze handelt es sich um Cucurbitaceen

\begin{tabular}{|c|c|c|c|}
\hline Pflanzenart & Arzneidroge & $\begin{array}{l}\text { Frühere Verwendung in der } \\
\text { Allopathie }\end{array}$ & Homöopathie \\
\hline $\begin{array}{l}\text { Bryonia cretica L. } \\
\text { (Rote Zaunrübe) }\end{array}$ & Wurzeln & $\begin{array}{l}\text { Als drastisches Purgans, } \\
\text { Emetikum }\end{array}$ & $\begin{array}{l}\text { Bei akuten fieberhaften, katarrhalischen } \\
\text { und rheumatischen Erkrankungen }\end{array}$ \\
\hline $\begin{array}{l}\text { Cayaponia tayuya (MART.) } \\
\text { LOGN. }\end{array}$ & Wurzeln & $\begin{array}{l}\text { Als Purgans, bei Rheuma, } \\
\text { Arthritis }\end{array}$ & \\
\hline $\begin{array}{l}\text { Citrullus colocynthis (L.) } \\
\text { SCHRAD. (Koloquinte) }\end{array}$ & $\begin{array}{l}\text { Geschälte } \\
\text { Beerenfrüchte } \\
\text { mit Samen }\end{array}$ & $\begin{array}{l}\text { Als drastisches Abführmittel, } \\
\text { Wurmmittel }\end{array}$ & $\begin{array}{l}\text { Gegen Krämpfe der glatten Muskulatur, } \\
\text { bei Neuralgien und Neuritiden }\end{array}$ \\
\hline $\begin{array}{l}\text { Ecballium elaterium (L.) } \\
\text { A. RICH. (Spritzgurke) }\end{array}$ & Früchte & Als Drastikum & Bei Diarrhoen und Koliken \\
\hline $\begin{array}{l}\text { Gratiola officinalis L. } \\
\text { (Gottesgnadenkraut; } \\
\text { Scrophulariaceae) }\end{array}$ & Kraut & $\begin{array}{l}\text { Als Drastikum und Anthel- } \\
\text { mintikum, bei Leberleiden, } \\
\text { chronischen Hautleiden }\end{array}$ & $\begin{array}{l}\text { Bei Gastroenteritis, Nieren- und Blasen- } \\
\text { katarrh }\end{array}$ \\
\hline $\begin{array}{l}\text { Iberis amara L. } \\
\text { (Brassicaceae) }\end{array}$ & Samen & $\begin{array}{l}\text { Zur Anregung der Magen- } \\
\text { saftsekretion, als Amarum }\end{array}$ & $\begin{array}{l}\text { Bei Herzmuskelschwäche, Verdauungs- } \\
\text { störungen }\end{array}$ \\
\hline $\begin{array}{l}\text { Luffa purgans MART. } \\
\text { (Synonym: L. operculata } \\
\text { COGN.) }\end{array}$ & Früchte & Als Purgans, Diuretikum & $\begin{array}{l}\text { Gegen Erkrankungen der oberen Luft- } \\
\text { wege, als Heuschnupfenmittel }\end{array}$ \\
\hline
\end{tabular}

Vorkommen. Außer in Cucurbitaceen (\$ Tabelle 24.2) sporadisch in Arten weiterer Familien, z. B. in Begoniaceae, Brassicaceae, Datiscaceae, Scrophulariaceae. Sie können in jedem Organ - Wurzel, Stängel, Blatt, Früchten, Samen - gespeichert sein.

Chemische Eigenschaften. Die Cucurbitacine ( $(A b b$. 24.11) liegen im lebenden Gewebe als 2-O-Glykoside vor, die schwer kristallisierbar sind. Die nach Enzymeinwirkung (Elaterase, eine $\beta$-Glucosidase) sich bildenden Aglykone sind hingegen kristallisierfreudig. Sie bilden farblose Kristalle, die sich gut in Ethanol lösen. Die Lösungen können die Ebene des polarisierten Lichtes nach rechts drehen (Cucurbitacin B), oder sie sind linksdrehend ( $\mathrm{z}$. B. Cucurbitacin E). In Gegenwart von Schwefelsäure (Tüpfelreaktion, als Sprühreagens, Lösung) werden Cucurbitacine intensiv rot oder rotviolett. Nach ihrem Verhalten $\mathrm{Fe}(\mathrm{III})-$ Salzen gegenüber lässt sich ein Diosphenoltyp [Fe(III)-positiv, z. B. Cucurbitacin E] von einem $\alpha$-Ketoltyp [Fe(III)-negativ, z. B. Cucurbitacin B] unterscheiden.

Analytische Kennzeichnung. DC-Nachweis der Cucurbitacine [Fließmittel: Chloroform-Methanol (95:10) bzw.
Toluol-Ethylacetat (25:75); Schicht: HPTLC-Platten Kieselgel $60 \mathrm{~F}_{254}$; Nachweis: Vanillin-Phosphorsäure; Triphenyltetrazoliumchloridlösung in $\mathrm{NaOH} ; \mathrm{FeCl}_{3}$-Lösung]. Mit Vanillin-Phosphorsäure fluoreszieren $\Delta^{23}$-Cucurbitacine im UV $365 \mathrm{~nm}$ rot und 23,24-Dihydrocucurbitacine gelb. Cucurbitacine mit $\alpha$-Ketolstruktur färben sich mit Triphenyltetrazoliumchloridlösung/ $\mathrm{NaOH}$ rot, solche mit Diosphenolstruktur erscheinen als rotbraune Zonen auf gelbem Grund nach Besprühen mit $\mathrm{FeCl}_{3}$-Lösung. Zur sicheren Identifizierung der Cucurbitacine (insbesondere geringer Mengen) gilt heute die HPLC-MS als Standardmethode. Zur quantitativen Bestimmung eignet sich am besten die RP-HPLC (vgl. Übersicht von Dinan et al. 2001 und darin zitierte Literatur).

Biologische Wirkungen. Alle Cucurbitacine weisen einen bitteren Geschmack auf. Sie wirken lokal reizend, insbesondere auf die Schleimhäute des Magen-Darm-Traktes. Cucurbitacine wirken zytotoxisch und hemmend auf das Wachstum von experimentell erzeugten Tumoren (kanzerostatische Wirkung). Ferner sind entzündungshemmende, antimikrobielle, antifungale, anthelmintische, hepatoprotektive und antifertile Wirkungen nachgewiesen wor- 
- Abb. 24.11<smiles>[R16][R16]([H])([H])C</smiles>

Cucurbitacin $\mathrm{B}, \mathrm{C}_{32} \mathrm{H}_{46} \mathrm{O}_{8}$ $\mathrm{Ac}=-\mathrm{COCH}_{3}$

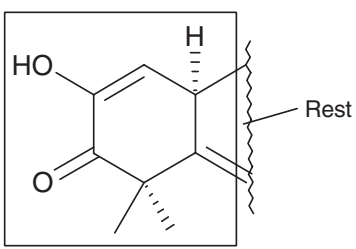

Cucurbitacin E (Rest wie Cucurbitacin B)

\section{Zur biosynthetischen Einordnung:}

Squalen

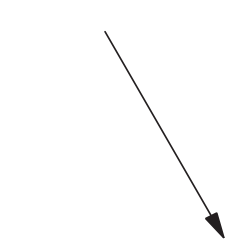<smiles></smiles>

1<smiles>CC1=C2CC[C@@H]3C(C)(C)C(O)CC[C@]3(C)C2(C)CCC1C</smiles>

Lanosterol

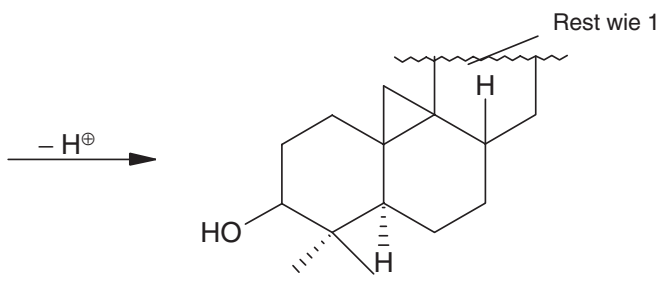

Cycloartenol

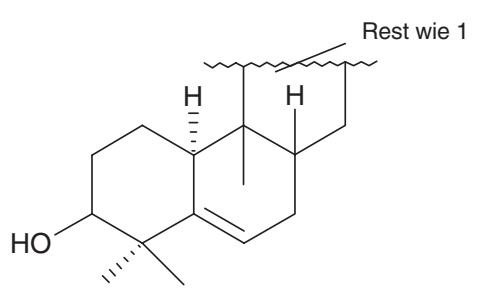

Cucurbita-5,24-dien-3 $\beta$-ol

Die Cucurbitacine sind ",echte" Sterole insofern, als sie in enger biosynthetischer Beziehung zu den beiden Grundkörpern der Sterole, dem Lanosterol und dem Cycloartenol, stehen: Ein hypothetisches Carbeniumion 1 könnte sich in 3 facher Weise durch Abspaltung eines Protons stabilisieren. Das Cucurbita-5,24-dien-3 $\beta$-ol, von dem sich die bisher bekannten Cucurbitacine durch Oxidations- und Dehydrierungsreaktionen herleiten lassen, wurde bisher noch nicht als Pflanzeninhaltsstoff nachgewiesen 
den. Cucurbitacine wirken ferner wachstumsregulierend, fraßschutzhemmend und insektizid (vgl. Übersicht von Miró 1995). Neue Untersuchungen ergaben, dass die Cucurbitacine, insbesondere Cucurbitacin B, im Vergleich mit Adriamycin eine starke Hemmung der Proliferation von humanen Krebszelllinien [Kolon (HCT-116), Brust (MCF-7), Lunge (NCI-H460), ZNS (SF-268)] und die Curcurbitacine B, D, E und I im Vergleich mit Ibuprofen, Naproxen und Vioxx (Anm.: Vioxx wurde 2004 wegen erhöhter Anfälligkeit von Testpersonen auf Herzinfarkt und Schlaganfall vom Markt genommen) eine bemerkenswerte selektive COX-2-Hemmung aufweisen (Jayaprakasam et al. 2003). Die potente Antitumoraktivität der Cucurbitacine beruht nach Sun et al. (2005) auf einer selektiven Hemmung des Jak/STAT-Signalweges (Jak = Janus-Kinase; STAT $=$ „signal transducer and activator of transcription").

Auf einzelnen dieser Wirkungen beruht die frühere Anwendung der Koloquinten und der Zaunrübe als Emetikum, als drastisches Purgans und als Emmenagogum. Die Koloquinten wurden auch als Wurmmittel und zur Ungezieferbekämpfung eingesetzt. Andere Pflanzen wurden bei rheumatischen und allergischen Krankheiten, zur Behandlung von Leberleiden, Asthma, Arthritis sowie Magen-Darm-Beschwerden empfohlen (vgl. auch $>\mathrm{Ta}$ belle 24.2). Trotz der starken kanzerostatischen Wirkung einzelner Cucurbitacine scheiterte der therapeutische Einsatz an ihrer relativ hohen Toxizität. Aus dem gleichen Grund sollten cucurbitacinhaltige Drogen nicht mehr verwendet werden.

\subsubsection{Cimicifuga-Triterpene}

Cimicifuga-Triterpene ( $\left(A b b\right.$. 24.12) sind $\mathrm{C}_{30}$-Triterpene, die biogenetisch ebenfalls wie die Cucurbitacine (Kap. 24.5.1) dem Cycloartenol (Formel vgl. ( Abb. 24.1) nahestehen.

Herkunft. Die Cimicifuga-Triterpene kommen in Cimicifuga-(Actaea)-Arten, insbesondere im Wurzelstock (Black Cohosh USP, in Vorbereitung; Cimicifugae rhizoma PhEur, in Bearbeitung) von Actaea racemosa L. (Cimicifuga racemosa L. NutT.), der Traubensilberkerze (Familie: Ranunculaceae [IIB1a]), vor. Heimat der Traubensilberkerze ist das östliche Nordamerika, wo sie in schattigen Laubwäldern verbreitet ist. Die Pflanze gehörte zum Arzneischatz der nordamerikanischen Indianer. Diese ver- wendeten den in Scheiben geschnittenen Wurzelstock für unterschiedliche Krankheitsbilder. Die Pflanze gehört heute an natürlichen Standorten zu den gefährdeten Spezies und sollte daher wegen des vermehrten Bedarfs in Kultur genommen werden (Popp et al. 2003).

\section{Inhaltsstoffe}

- Triterpenglykoside( ( Abb. 24.12)vom9,19-Cyclolanostan(Cycloartan)-Typ [USP-Entwurf (PF 30(4) 2004) $=$ mindestens $0,4 \%$ Triterpenglykoside berechnet als 23-epi-26-Desoxyactein]. Bis heute sind ca. 40 verschiedene Glykoside isoliert worden (vgl. z. B. Shao et al. 2000; Chen et al. 2002b; Watanabe et al. 2002);

- Phenolcarbonsäuren (Kaffee-, Ferula-, Isoferulasäure);

- Phenylpropanoide: Hydroxyzimtsäureester der Fukiaund Piscidiasäure (>Abb. 24.12), z. B. Fukinolsäure, Cimicifugiasäuren A, B, E, F, Cimiracemate A-D; ferner Cimiciphenol und Petasiphenol (3,4-Dihydroxyphenyl-2-oxopropylester); Cytisin, Methylcytisin.

\section{Analytische Kennzeichnung}

Prüfung auf Identität. Fingerprint-DC insbesondere der Cycloartanderivate (USP-Entwurf) [Fließmittel: obere Phase einer Mischung von Butanol-Wasser-Essigsäure 99\% (50:40:10); Referenzsubstanzen: Black Cohosh Extrakt RS sowie Aescin, Isoferulasäure; Nachweis: UV $365 \mathrm{~nm}$, Sprayreagens = Mischung von Methanol-Essigsäure 99\%-Schwefelsäure-Anisaldehyd (85:10:5:0,5)]. Die Hauptzonen der Untersuchungslösung müssen in Laufstrecke, Farbe und Größe den Hauptzonen des Referenzextrakts entsprechen. Es erfolgt keine Zuordnung der einzelnen Triterpenglykoside. Als aussagekräftigere Fingerprintmethode, aber auch zur quantitativen Bestimmung einzelner Triterpenglykoside, bieten sich heute verschiedene LC/MS- bzw. LC/MS/MS-Methoden an (vgl. Wang et al. 2005b und darin zitierte Literatur).

Gehaltsbestimmung. Quantitative Bestimmung (USPEntwurf) der 6 wichtigsten Triterpenglykoside (berechnet als 23-epi-26-Desoxyactein) mit der HPLC unter Verwendung eines ELSD-Detektors. Sie basiert auf der Methode von Li et al. (2002), die die Trennung und quantitative Bestimmung von insgesamt 18 Substanzen (Triterpene und Phenole) erlaubt.

Verwendung. Zur Herstellung von alkoholischen und isopropanolischen Extrakten, die für die Produktion von 
- Abb. 24.12

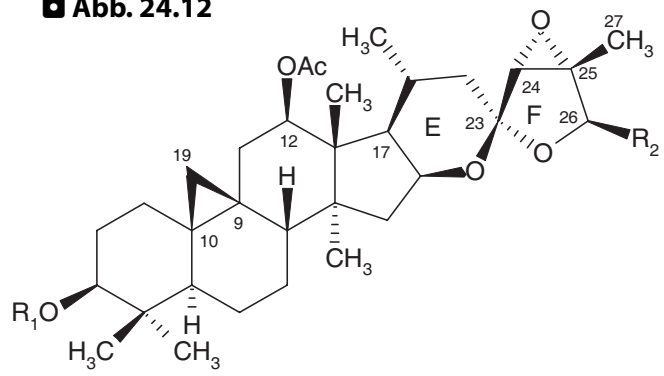

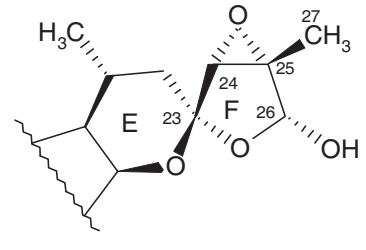

Actein $(26 R)$

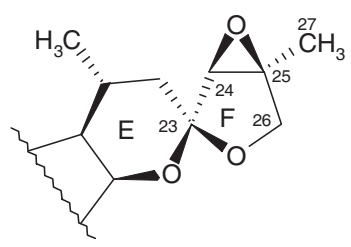

23-epi-26-Desoxyactein

Actein (26S) $\left(\mathrm{R}_{1}=\beta\right.$-D-Xylose; $\left.\mathrm{R}_{\overline{\mathrm{z}}} \mathrm{OH}\right)$

26-Desoxyactein $\left(R_{1}=\beta\right.$-D-Xylose; $\left.R_{2}=H\right)$

Acetylacteol $\left(\mathrm{R}_{1}=\mathrm{H}, \mathrm{R}_{2}=\mathrm{OH}\right)$

26-Desoxyacetylacteol $\left(R_{1}=R_{2}=H\right)$

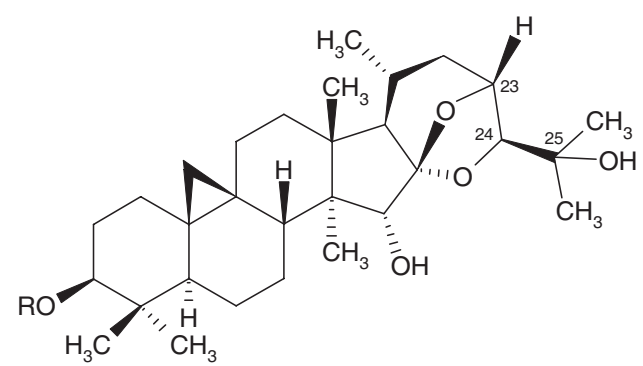

Cimicifugosid $(\mathrm{R}=\beta$-D-Xylose)

Cimicifugosid $M(=$ Cimiaracemosid $C)(R=\alpha$-L-Arabinose $)$

Cimigenol $(\mathrm{R}=\mathrm{H})$<smiles>[R]c1cc(C[C@@H](O)[C@@H](O)C(O)O)ccc1O</smiles>

Fukiasäure $(\mathrm{R}=\mathrm{OH})$

Piscidiasäure $(\mathrm{R}=\mathrm{H})$

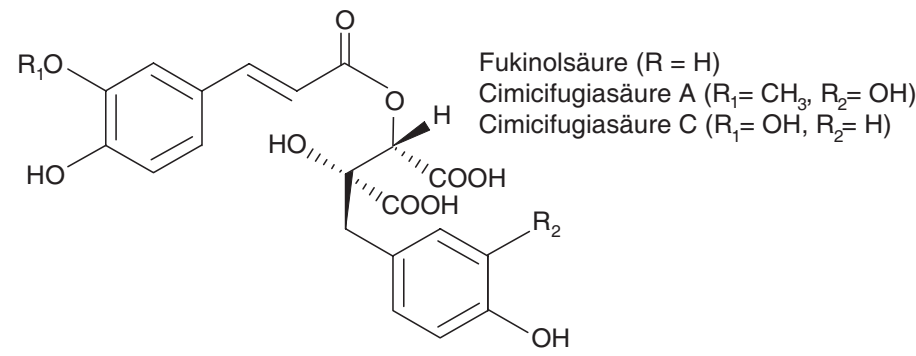

Bei den Hauptinhaltsstoffen der Traubensilberkerze handelt es sich um Triterpenglykoside vom 9,19-Cyclolanostan-Typ und um Phenylpropanoide. Charakteristisch für die Triterpenglykoside ist ein Cyclopropanring, der die strukturelle Verwandtschaft zum Cycloartenol (> Abb. 24.1) dokumentiert. Als Zuckerkomponente sind bisher Xylose und Arabinose gefunden worden. Von den bisher bekannten Aglykonen kommen Acetylacteol, 26-Desoxyacetylacteol und Cimigenol häufig vor. Bei der früher unter der Bezeichnung 27-Desoxyactein bekannten Verbindung handelt es sich nach heutiger Nomenklatur um 23-epi-26-Desoxyactein (Chen et al. 2002a). Actein kommt in der 26(S)- (Hauptsubstanz) und 26(R)Konfiguration vor (vgl. Li et al. 2002). Bei den Phenylpropanoiden handelt es sich neben ubiquitär vorkommenden Phenolcarbonsäuren insbesondere um Ester der Fukia- und Piscidiasäure, die strukturelle Ähnlichkeit mit der Rosmarinsäure (vgl. () Abb. 26.12) aufweisen

Phytopharmaka zur Behandlung klimakterischer Beschwerden (vgl. Infobox „Klimakterische Beschwerden“) Verwendung finden.

Wirkungen und Wirkungsmechanismus. Östrogenartig [Reduktion der LH-Sekretion ( $\mathrm{LH}=$,luteinizing hormone"), osteoprotektiv], antiproliferativ. Während HRT mit Östrogenen bei östrogensensitiven Brustkrebspatientinnen heute kontraindiziert ist, gelten Extrakte aus dem Cimicifuga-racemosa-Wurzelstock (CR-Extrakte) als Al- ternative zur HRT. Die aufgrund von Tier- und In-vitroVersuchen postulierte östrogene Wirkung der CR-Extrakte wird allerdings kontrovers diskutiert. Während in verschiedenen neueren Untersuchungen keine östrogenen bzw. sogar antiöstrogene Effekte nachgewiesen werden konnten, wurde in kürzlich durchgeführten In-vitro-Rezeptorbindungsstudien festgestellt, dass bisher nicht bekannte Substanzen an einen noch unbekannten Östrogenrezeptor (ER) binden (vgl. Übersichten von Borelli et al. 2003; Piersen 2003 und darin zitierte Literatur). Seidlová- 


\section{Infobox}

Klimakterische Beschwerden. Mit Klimakterium (Wechseljahre) wird die Übergangsphase von der reproduktiven zur nichtreproduktiven Phase im Leben der Frau bezeichnet. Es umfasst die Menopause (Zeitpunkt der letzten Menstruation) sowie die Prä- und Postmenopause. Dabei treten wichtige hormonelle Änderungen (Stopp der Östrogenund Progesteronproduktion, vermehrte Produktion von Gonadotropinen) auf, die eine Reihe von Beschwerden erzeugen können. Etwa ein Drittel der Frauen im Klimakterium ist subjektiv symptomfrei. Ein Drittel leidet unter vegetativen Beschwerden und ein weiteres Drittel unter der gesteigerten Form des Menopausensyndroms, d. h. Hitzewallungen, Schwindel und Schweißausbrüche; daneben auch psychonervöse (Schlafstörungen, Nervosität, Reizbarkeit, allgemeine Leistungs- und Gedächtnisminderung) sowie somatische und atrophische Störungen. Bei den klinischen

Wuttke et al. (2003) konnten mit einem ethanolischen CRExtrakt an ovarektomierten Ratten unter Einsatz der Realtime-PCR-Technologie die schon früher festgestellten östrogenen Effekte in der Achse Hypothalamus-Hypophyse (Reduktion der LH-Sekretion) und in den Knochen (osteoprotektive Eigenschaften) belegen, während im Uterus keine festgestellt werden konnten.

In In-vitro-Untersuchungen wurde festgestellt, dass CR-Extrakte u. a. die durch Östrogene induzierte Proliferation von humanen östrogenrezeptorpositiven Brust-

\section{Infobox}

Selektive Östrogenrezeptormodulatoren (SERM). Der SERM-Begriff ("selective estrogen receptor modulators") wird für synthetische, östrogenartig wirkende Substanzen, z. B. Raloxifen, verwendet. Mit SERM-Eigenschaften werden selektive, organspezifische und östrogenähnliche Wirkungen verbunden, die im Gegensatz zum natürlichen Liganden Estradiol nicht generalisiert wirken, d. h. dass sie nur einen Teil der Östrogenwirkungen auslösen, andere dagegen unterdrücken. Die davon abgeleitete "Phyto-SERM-Theorie" besagt, dass Phytoöstrogene und östrogenartig wirkende Pflanzenextrakte wie z. B. die Extrakte von C.racemosa je nach Organgewebe östrogenagonistische bzw. -antagonistische Effekte auslösen. Im Unterschied zu einer Östrogentherapie sollen die Phyto-SERMs ausschließlich die erwünschten Östrogenwirkungen im ZNS, dem kardiovaskulären und Urogenitalsystem sowie an den Knochen ohne die
Studien wird im Allgemeinen die Beeinflussung folgender Indizes und Scores gemessen: Menopauseindex nach Kupperman (Erfassung klimakterischer Symptome), Hamilton Anxiety Scale (HAMA; Bewertung von Angstzuständen), Profile of Mood Scale (POMS; Selbstbeurteilungsskala zur Erfassung wechselnder Stimmungszustände), die Clinical Global Impression Scale (CGI; Nutzen-Risiko-Bewertung der Behandlung) sowie die Menopause Rating Scale (MRS; erfasst zehn Kardinalsymptome, eingeteilt in die Symptomgruppen Hot Flushes, psychische atrophische und somatische Beschwerden). Als therapeutische Maßnahme kommen die Hormonersatztherapie [„hormone replacement therapy" (HRT)] mit Östrogenen, selektiven Östrogenrezeptormodulatoren (z. B. Raloxifen) sowie Phytotherapeutika in Betracht [? dazu auch Infobox "Prämenstruelles Syndrom (PMS)"; Kap. 23.3.2].

krebszellinien (T47D und MCF-7) hemmen. Untersuchungen von ethanolischen und isopropanolischen CR-Extrakten mit MCF-7 und östrogenrezeptornegativen (MDA-MB231) Brustkrebszelllinien ergaben, dass die antiproliferative Wirkung auf einer Induktion der Apoptose (programmierter Zelltod) beruht, die durch Caspasen hervorgerufen wird (vgl. dazu () Abb. 24.15). Die antiproliferative Wirkung des Extrakts war vergleichbar mit derjenigen des Östrogenrezeptorantagonisten Tamoxifen (vgl. Hostanska et al. 2004a und darin zitierte

schwerwiegenden Nebenwirkungen der Hormontherapie in der Brust und am Uterus aufweisen (vgl. Übersichten von Wuttke et al. 2002; Piersen 2003 und darin zitierte Literatur). Bei der Indikation Menopausebeschwerden gilt es z. B. Hitzewallungen und Schlaflosigkeit zu unterdrücken, die Knochenmasse und Knochendichte bzw. die funktionelle Integrität des Gefäßsystems zu erhalten, ohne gleichzeitig das Risiko für Brust- und Endometrium-(Gebärmutterschleimhaut-)karzinome zu erhöhen. Mit der Übertragung des SERM-Begriffs auf Phytoöstrogene werden diese Substanzen als Wunderdrogen - z. B. bei allen Menopausebeschwerden - geradezu mystifiziert und Estradiol mit seinen Krebs erregenden Eigenschaften im Gegensatz dazu verteufelt. Diese Klassifizierung in "gut" und „böse" gipfelt darin, dass Phytoöstrogene für Marketingzwecke völlig unkorrekt als „östrogenfrei“ apostrophiert werden (Vollmer u. Zierau 2004). 
Literatur). Andere Autoren (Burdette et al. 2003) kommen zum Schluss, dass die Wirkung von CR-Extrakten bei Hitzewallungen nicht via ER-, sondern via Serotoninrezeptoren zustande kommt. Die bisher noch unbekannten CR-Liganden zeigten die größte Affinität zu den $5-\mathrm{HT}_{1 \mathrm{~A}^{-}}, 5-\mathrm{HT}_{1 \mathrm{D}^{-}}$und 5- $\mathrm{HT}_{7}$-Rezeptoren, mit der größten Selektivität zum 5- $\mathrm{HT}_{7}$-Rezeptor. Serotonin hemmt die $\mathrm{LH}-$ Sekretion vom Hypothalamus via den $5-\mathrm{HT}_{1 \mathrm{~A}^{-}}$ Rezeptor.

Das „Östrogenproblem“ kann erst vollständig aufgeklärt werden, wenn die dafür verantwortlichen Inhaltsstoffe bekannt sind. Als wertbestimmende Inhaltsstoffe wurden bisher die Triterpenglykoside bzw. Isoflavonoide (Formomonetin) angesehen. Isoflavonoide konnten in neueren Untersuchungen nicht mehr nachgewiesen werden (vgl. dazu Kenelly et al. 2002). Triterpenglykoside, insbesondere Actein, 23-epi-26-Desoxyacetein und Cimiracemosid A sowie die Zimtsäureester sind nach neuen Untersuchungen für die nachgewiesene antiproliferative Wirkung verantwortlich (Einbond et al. 2004; Hostanska et al. 2004b). Ester der Fukia- und Piscidiasäure zeigen vasoaktive und antioxidative Effekte. Das Postulat, dass in CR-Extrakten Substanzen mit einer ähnlichen Wirkung wie Raloxifen vorhanden sind, die je nach Organgewebe eine selektive Östrogenrezeptormodulation (vgl. Infobox „Selektive Östrogenrezeptormodulatoren“) bewirken, ist bis heute nicht bewiesen.

Anwendungsgebiete. Zubereitungen aus dem Cimicifuga-racemosa-Wurzelstock gelten als pflanzliche Gynäkologika. Sie werden bei prämenstruellen und dysmenorrhoischen sowie klimakterisch bedingten neurovegetativen Beschwerden verwendet (Kommission E). Gemäß ESCOP sind die Indikationen: klimakterische Beschwerden wie Wallungen, Schwitzen, Schlafstörungen, Nervosität, Reizbarkeit. Wie neuere Studien zeigen, scheinen die CR-Extrakte positiv hinsichtlich des Erhalts von Knochenmasse und Knochendichte bei Patientinnen mit Osteoporose zu sein (Wuttke et al. 2003).

Nach Borelli u. Ernst (2002) entsprechen von den 2002 vorliegenden 9 kontrollierten Studien zur klinischen Wirksamkeit von Cimicifuga-Extrakten im Vergleich zu Plazebo bzw. zur Östrogentherapie nur 4 Studien dem heute gültigen Standard. Drei davon finden für den Extrakt ähnliche Effekte wie für eine HRT, während die vierte den Extrakt für unwirksam im Menopauseindex fand. Die Autoren kommen zum Schluss, dass die klinische Wirksamkeit zur Behandlung klimakterischer Be- schwerden in allen durchgeführten Studien nicht überzeugend dargestellt werden konnte und dass Langzeitstudien bisher fehlen. Andere Autoren (vgl. Übersicht von Wuttke et al. 2002, 2003; Osmers et al. 2005) kommen zum Schluss, dass die bisher durchgeführten klinischen Studien die therapeutische Wirksamkeit bei guter Verträglichkeit und einem geringen Risiko von Nebenwirkungen bestätigen.

Nebenwirkungen. Gelegentlich sind Magenbeschwerden, Kopfschmerzen, Schwindel und Gewichtszunahme beobachtet worden. Das in der Literatur (Whiting et al. 2002) beschriebene Auftreten einer akuten Hepatitis bei einer 47-jährigen Frau in Australien nach einer zweiwöchigen Einnahme einer Traubensilberkerzenmedikation (ohne nähere Angaben, ohne analytische Überprüfung) muss mit Vorsicht interpretiert werden. Osmers et al. (2005) konnten in einem RCT mit einem isopropanolischen Extrakt keine klinisch relevanten Veränderungen wichtiger Leberenzyme ( $\gamma$-Glutamyltranspeptidase, Aspartataminotransferase, Alaninaminotransferase) im Vergleich zu Plazebo feststellen.

\section{! Kernaussagen}

Alkoholische und isopropanolische Extrakte von Cimicifuga racemosa werden zur Behandlung klimakterischer Beschwerden als Alternative zu einer HRT verwendet. Neben einer östrogenartigen Wirkung der Extrakte wird eine SERM postuliert, die von bisher nicht bekannten Wirkstoffen durch Bindung an einen nicht näher charakterisierten ER erzeugt werden soll. Im Unterschied zu einer Östrogentherapie sollen Phyto-SERMs ausschließlich die erwünschten Östrogenwirkungen (Linderung der während der Menopause auftretenden Unannehmlichkeiten) ohne die schwerwiegenden Nebenwirkungen der HRT (Brustund Endometriumkarzinome) aufweisen. Der Cimicifuga-Extrakt soll auch die postmenopausal gesteigerte Knochenresorption (Osteoporose) positiv beeinflussen ( $>$ Hinweis). Die bisher als wertbestimmende Inhaltsstoffe geltenden Triterpenglykoside vom Cycloartantyp sind als Leitsubstanzen anzusehen. Sie spielen bei der Qualitätskontrolle eine Rolle.

Hinweis. Die klinische Wirksamkeit von Cimicifuga-Präparaten zur Linderung klimakterischer Beschwerden wird kontrovers diskutiert. 


\subsubsection{Quassinoide}

Quassinoide sind $\mathrm{C}_{18^{-}}$bis $\mathrm{C}_{25}$-Terpenoide, die sich von Triterpenen ableiten und zusammen mit Indolalkaloiden weit verbreitet in der Familie der Simaroubaceae vorkommen. Sie haben wie das Carpesterol (Formel vgl. $>A b b$. 24.10) nur eine Methylgruppe am C-4. Die meisten der bisher über 150 bekannten Quassinoide haben ein $\mathrm{C}_{20}$-Grundgerüst (> Abb. 24.13). Der Name Quassinoide leitet sich von Quassin, der ersten bekannten Substanz aus dieser Naturstoffgruppe, ab.

Vorkommen. Pharmazeutisch von Interesse ist einmal das Bitterholz (Quassiae lignum) von Picrasma excelsa (Sw.) Planch (Jamaika-Bitterholz) und von Quassia amara L.
(Surinam-Bitterholz) (Familie: Simaroubaceae [IIB18f]). P. excelsa ist ein stattlicher, $15-20 \mathrm{~m}$ hoch wachsender Baum Westindiens (Jamaika, Martinique, Barbados); Q. amara, ein 2-5 $\mathrm{m}$ hoch wachsender Strauch, der in Guayana, dem nördlichen Brasilien und Venezuela heimisch ist. Die Droge besteht aus dem Holz der Stämme. Daneben gibt es eine Anzahl von Pflanzen der Familie Simaroubaceae, die in der traditionellen Medizin verschiedener Länder für die Behandlung der Malaria und der Amöbenruhr verwendet werden.

Anwendungsgebiete und Wirkungen. Bitterholz wird, wie der Name sagt, aufgrund des bitteren Geschmacks als anregendes Bittermittel bei Appetitlosigkeit und dyspeptischen Beschwerden verwendet.
Abb. 24.13

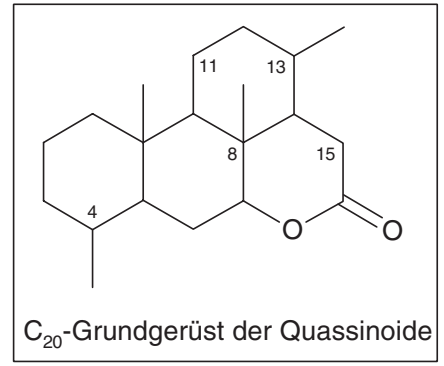

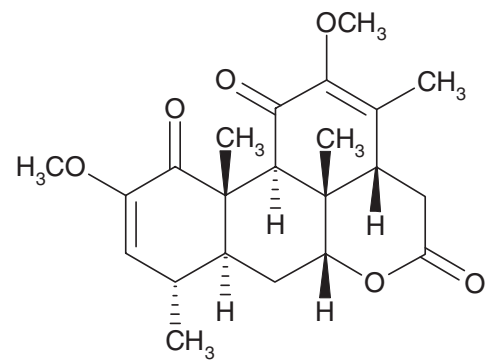

Quassin

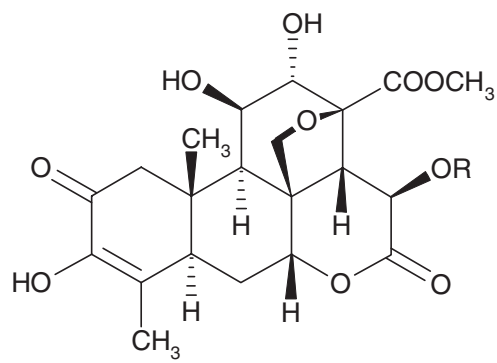

Brucein $\mathrm{A}\left(\mathrm{R}=\mathrm{COCH}_{2} \mathrm{CH}\left(\mathrm{CH}_{3}\right)_{2}\right)$ Bruceantin $\left(\mathrm{R}=\mathrm{COCH}=\mathrm{C}\left(\mathrm{CH}_{3}\right) \mathrm{CH}\left(\mathrm{CH}_{3}\right)_{2}\right)$

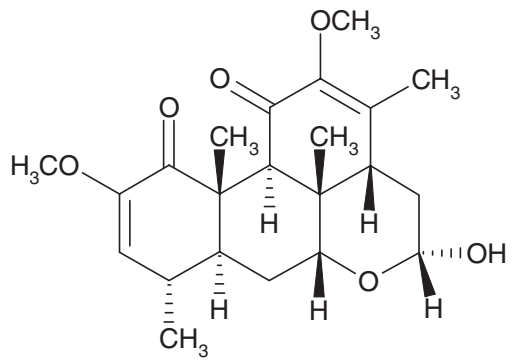

Neoquassin

Bei den Quassinoiden handelt es sich um Triterpenabkömmlinge, die aus tetrazyklischen Triterpenen durch oxidative Veränderungen entstehen. Bei den Hauptbitterstoffen von Quassiae lignum (Quassin, Neoquassin) sowie den antileukämisch und Anti-Malaria-wirksamen Quassinoiden aus Brucea javanica handelt es sich um tetrazyklische $C_{20}-\delta$-Lactone mit zahlreichen $O$-Funktionen im Molekül. Die Wirksamkeit wird verstärkt, wenn zusätzlich ein weiterer Ring vorliegt, in dem die C-8-Methylgruppe mit dem C-11 bzw. C-13 durch eine O-Brücke verknüpft ist (z. B. bei Brucein A, Bruceantin). Der Oxidationsgrad und das Substitutionsmuster des A-Rings ist ebenfalls für die Wirkung wesentlich. Die am besten wirksamen Verbindungen haben eine Hydroxylgruppe entweder am C-1 oder C-3 und eine einer Doppelbindung benachbarte Carbonylgruppe. Viele aktive Quassinoide weisen auch eine Esterfunktion auf. Ein Verlust dieser Funktion ist mit einer starken Verminderung der Wirkung verbunden (vgl. Polonsky 1985; Phillipson et al. 1993) 
Daneben haben die Quassinoide eine Reihe von spezifischen Wirkungen. Nachgewiesen worden sind u. a. amöbizide, herbizide, insektizide, antimikrobielle, antivirale (Anti-HIV), antiphlogistische, Antitumor- (antileukämisch) und Anti-Malaria-Wirkungen (vgl. Übersichten von Polonsky 1985; Phillipson et al. 1993; Okano et al. 2000). Von diesen Wirkungen sind insbesondere die antileukämische und die starke In-vitro-Aktivität gegen Plasmodium falciparum erwähnenswert (vgl. Text $>A b b$. 24.13). Der klinische Einsatz von Bruceantin scheiterte Mitte der 80er Jahre des letzten Jahrhunderts aus Wirksamkeits- und Toxizitätsgründen. Dennoch bilden die
Quassinoide auch heute noch eine interessante Naturstoffgruppe bei der Suche nach neuen Wirkstoffen (vgl. Cuendet u. Pezzuto 2004; Übersicht von Guo et al. 2005).

\subsubsection{Boswelliasäuren}

Herkunft. Boswelliasäuren ( $\left(>A b b\right.$. 24.14) sind $\mathrm{C}_{30}$-Triterpene vom Oleanan- und Ursan-Typ, die in verschiedenen Boswellia-Arten, insbesondere in Boswellia carteri BIRDW. und Boswellia serrata RoxB. (Familie: Burseraceae [IIB18b]) gefunden wurden. Von der ersten Stammpflanze

- Abb. 24.14<smiles>CC(C)[13CH3]</smiles>
Oleanantyp

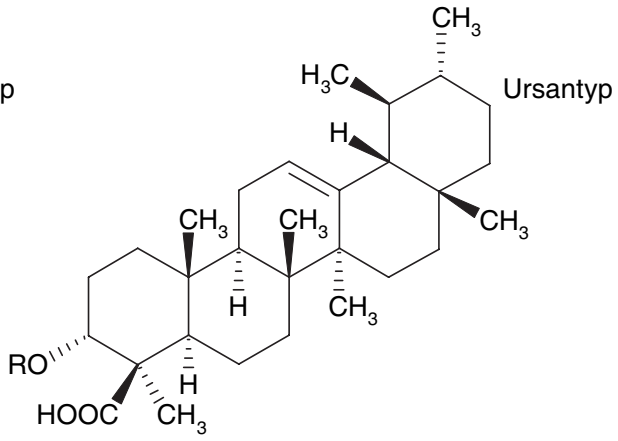

$\alpha$-Boswelliasäure $(\mathrm{R}=\mathrm{H})$

Acetyl- $\alpha$-boswelliasäure $(R=$ Acetyl)

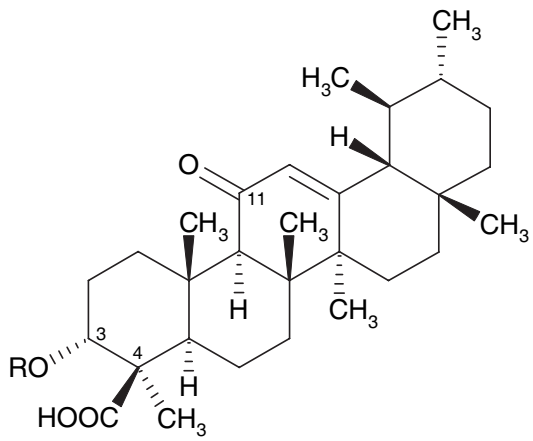

11-Keto- $\beta$-boswelliasäure $(R=H)$

3-Acetyl-11-keto- $\beta$-boswelliasäure $(R=$ Acetyl)
$\beta$-Boswelliasäure $(R=H)$ Acetyl- $\beta$-boswelliasäure $(R=$ Acetyl $)$<smiles>C[C@H]1CC[C@]2(C)CC[C@]3(C)C(=C[C@H](O)[C@@H]4[C@@]5(C)CC[C@@H](O)[C@@](C)(C(=O)O)[C@@H]5CC[C@]43C)[C@]2(C)[C@@H]1C</smiles>

11- $\alpha$-Hydroxy- $\beta$-boswelliasäure

Gummiharze von Boswellia carteri (Weihrauch, Adenharz) und B. serrata (indischer Weihrauch, Salai Guggal) enthalten neben ätherischem Öl und Gummi bis zu 60\% Harz, dessen Hauptbestandteile pentazyklische Triterpensäuren (Boswelliasäuren; BA, von „,boswellic acid“) darstellen. Die beiden Harze weisen ein unterschiedliches Spektrum an BAs auf. Stärkste Hemmwirkung der 5-LOX und von NF-KB zeigte die nur im Harz des indischen Weihrauchs vorhandene 3-Acetyl-11-keto$\beta$-boswelliasäure. Wirksam sind auch Acetyl- $\alpha$ - und Acetyl- $\beta$-boswelliasäure, 11-Keto- $\beta$-boswelliasäure sowie Diole, bei denen anstelle der Carboxylgruppe an C-4 eine Hydroxymethylgruppe vorliegt. Neben pentazyklischen finden sich im Harz von Boswellia-Arten auch tetrazyklische Triterpene, z. B. die Tirucallsäuren, die ebenfalls biologische Effekte aufweisen (vgl. Übersicht von Ammon et al. 2003) 
wird ein Gummiharz, bekannt unter dem Namen Olibanum (Weihrauch), gewonnen. Die zweite Stammpflanze liefert indischen Weihrauch (Indian Olibanum oder Salai Guggal). Olibanum ist in modernen Arzneibüchern lange Zeit nicht mehr aufgeführt worden. Heute ist neben Olibanum indicum (Indischer Weihrauch von B. serrata; DAC 2005) eine Monographie für die PhEur in Bearbeitung. Im Vordergrund des Interesses stehen heute verschiedene Boswelliasäuren (BAs), insbesondere 11-Keto$\beta$-boswelliasäure (K $\beta \mathrm{BA})$ und 3-Acteyl-11-keto- $\beta$-boswelliasäure (AKBBA) sowie Acetyl- $\alpha-(\mathrm{A} \alpha \mathrm{BA})$ und Acetyl- $\beta$-boswelliasäure (A $\beta B A)$.

Gewinnung. Zur Herstellung reiner BAs eignet sich eine einfache, aber effiziente kombinatorische Strategie, bei der in einer 2-Stufen-Semisynthese die BAs im Gummiharzgemisch z. B. in AK $\beta B A$ überführt werden können. Je nach Boswellia-Art kann damit der AKßBA-Gehalt von 0,1-3\% auf $25-35 \%$ gesteigert werden (Jauch u. Bergmann 2003).

\section{Traditionelle Verwendung von indischem Weihrauch,} Wirkungen. Salai Guggal (von B. serrata) ist ein traditionelles Arzneimittel aus der ayurvedischen Medizin, das in Indien für eine Reihe von entzündlichen Erkrankungen, wie z. B. chronische Polyarthritis, Osteoarthritis und zervikale Spondylosis, verwendet wird. In der traditionellen chinesischen Medizin (TCM) wird das Gummiharz von B. carteri auch als Krebsmittel verwendet. Die bisher bekannten pharmakologischen Wirkungen von Olibanum werden als entzündungshemmend, analgetisch, antiarthritisch, antiproliferativ, immunmodulatorisch, hepatoprotektiv und antimikrobiell beschrieben.

\section{Wirkungsmechanismen}

- Entzündungshemmende Wirkung. Die entzündungshemmende Wirkung von Salai Guggal konnte in einer Vielzahl von Tiermodellen und in In-vitro-Untersuchungen nachgewiesen werden. Verantwortlich dafür sind die BAs, die als spezifische Nichtredoxhemmstoffe der 5-Lipoxygenase (5-LOX) gelten, die dieses Enzym über einen nichtkompetitiven Mechanismus blockieren. Die 12-LOX und die Cyclooxygenase werden durch die BAs nicht gehemmt. Aus den durchgeführten Untersuchungen geht hervor, dass das pentazyklische Triterpengerüst der BAs für die Bindung an das Enzym erforderlich ist, während funktionelle Gruppen, insbesondere die Kombination der 11-Ketofunktion mit einer hydrophilen Gruppe an C-4, für die Hemmung der 5-LOX essentiell sind. Durch die Hemmung der 5-LOX kann die Entstehung von Leukotrienen reduziert bzw. unterbunden werden. Vermehrte Leukotrienproduktion wird bei einer Reihe von chronisch-entzündlichen Erkrankungen wie z. B. bei Colitis ulcerosa, Morbus Crohn, allergische Rhinitis (vgl. Infobox S. 864) Asthma bronchiale und rheumatoider Arthritis beobachtet, und es scheint, dass diese Leukotriene für die Aufrechterhaltung der chronischen Entzündung verantwortlich sind. Heute scheint allerdings die Hemmung der 5-LOX nicht mehr im Vordergrund zu stehen. Neue Untersuchungen ergaben, dass die entzündungshemmende Wirkung der BAs ähnlich wie bei den Sesquiterpenen (vgl. S. 872; Arnikablüten) durch Hemmung der Aktivierung des Transkriptionsfaktors NF- $\kappa B$ erfolgt. AK $\beta B A$ und $A \alpha B A$ modifizieren selektiv den NF- $\kappa \mathrm{B} / \mathrm{I} \kappa \mathrm{B}-$ Komplex durch Hemmung des IкB-Kinase-Komplexes (vgl. dazu $>A b b$. 23.44). Durch die Hemmung der Phosphorylierung von IKK $\alpha$ und der p65-Protein-Untereinheit wird die Wanderung von NF- $\kappa B$ in den Zellkern und die anschließende Freisetzung von Entzündungsmediatoren wie TNF $\alpha$ reduziert (vgl. Übersicht von Ammon 2003; Syrovets et al. 2005a und darin zitierte Literatur).

- Antitumorwirkung. Neben der entzündungshemmenden Wirkung konnte in verschiedenen Arbeiten gezeigt werden, dass BAs eine Antitumorwirkung haben (> dazu auch Infobox „Tumorhemmendes Potential von Pflanzenstoffen“; S. 979). In-vitro-Untersuchungen von BAs an Tumorzellinien zeigten eine Hemmung der Proliferation von Leukämie-, Glioblastom- und anderen Krebszellen. AK $\beta B A$ zeigte in einer niedrigen Konzentration ( $\mathrm{IC}_{50}$ von $2-4 \mu \mathrm{M}$ ) eine zytotoxische Wirkung auf humane Meningiomzellkulturen. Die Antitumorwirkung scheint auf die Hemmung der Topoisomerasen I und II $\alpha$, von NF- $\kappa B$ sowie aufdie Induktion des programmierten Zelltodes (Apoptose) zurückzuführen zu sein. An Dickdarmkrebszelllinien (HAT 29) konnte einerseits gezeigt werden, dass die BAs die Apoptose durch die Aktivierung der beiden klassischen Apoptosesignalkaskaden (> Abb. 24.15) auslösen. Dabei sind die Caspasen-3, -8 und -9 involviert. Andererseits konnte am Beispiel von AK $\beta B A$ und $A \beta B A$ nachgewiesen werden, dass die Substanzen

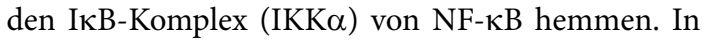
diesem Falle wird die Expression der antiapoptotischen Proteine Bcl-2 und Bcl- $\mathrm{x}_{\mathrm{L}}$ abreguliert und von Cyclin D1 (Regulator des Zellwachstums) reduziert. 
- Abb. 24.15

Todesrezeptorweg

Mitochondrialer Weg

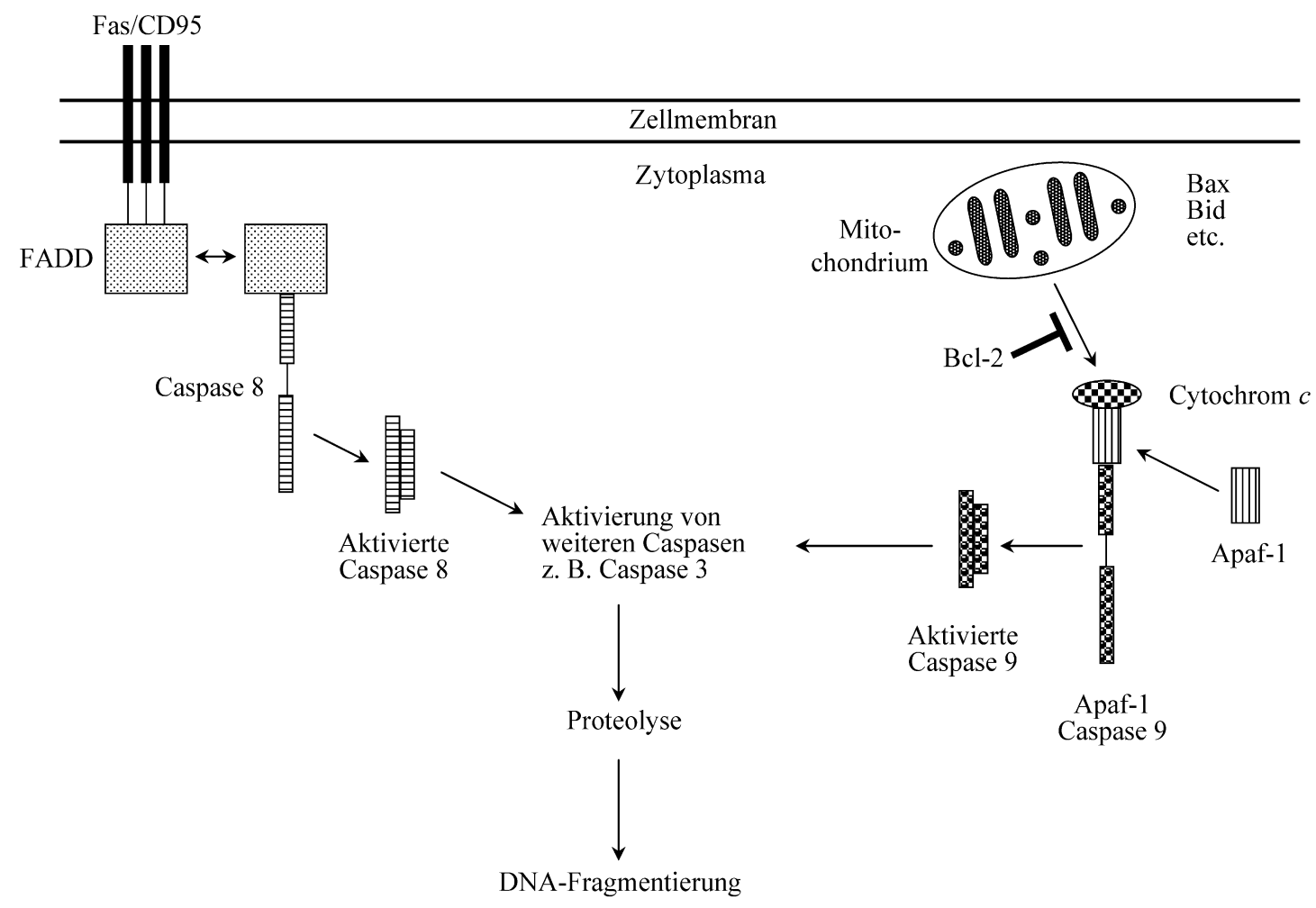

Signalkaskaden zur Auslösung der Apoptose (abgeändert nach Löffler u. Petrides 2003). Unter Apoptose (programmierter Zelltod) versteht man im Gegensatz zur Nekrose den durch genetische Informationen einer Zelle regulierten Zelluntergang bzw., Zellselbstmord“. Sie dient der gezielten Eliminierung von Zellen. Die Apoptose wird über verschiedene Signalkaskaden reguliert, wobei ein gemeinsamer Endpunkt aller Wege die Aktivierung von proteolytisch wirkenden Caspasen ist. Die zwei klassischen Signalkaskaden zur Auslösung der Apoptose sind der Todesrezeptorweg („,death receptor") und der mitochondriale Weg. Beim mitochondrialen Weg kommt es infolge eines externen Signals zu einer Aktivierung der Bcl-2-Proteinfamilie und der Bax-Subfamilie. Sie führt zur Anheftung dieser Proteine an die Mitochondrienmembran, was zu einer Freisetzung von Cytochrom c führt. Cytochrom c bindet an das cytosolische Protein Apaf-1, das Caspasen aktiviert (Caspase $9 \rightarrow$ Caspase 3 u. a.). Der Todesrezeptorweg läuft über einen Liganden-Rezeptor-Komplex (Fas/CD95) in der Plasmamembran. Dabei interagiert das Adaptorprotein FADD mit dem Todesrezeptor CD95. Bindung der inaktiven Caspase 8 an den Komplex führt zur Spaltung und Aktivierung der Caspase 8 und der Aktivierung weiterer Caspasen (Caspase 3 u. a.). Die Initiatorcaspasen 8 und 9 sind damit in der Lage, eine proteolytische Caspasekaskade auszulösen, was zum programmierten Zelltod führt. Antiapoptotische Vertreter der Bcl-2-Proteinfamilie können die mitochondriale Freisetzung von Cytochrom c verhindern. Abkürzungen: Apaf-1 „apoptotic protease activating factor 1", FADD „fast-associated death domain“, Bid, Bax proapoptotische Vertreter der Bcl-2-Proteinfamilie 
Diese Mechanismen sind für die durch BAs erzeugte Apoptose der Zellen in vitro und in vivo verantwortlich [Modelle: humane Prostatakrebszellen (PC-3), Lungenfibroblasten (MRC-5) und Xenotransplantate]. Von 11-Keto-BAs wurde ferner nachgewiesen [Modell: humane polymorphkernige Leukozyten (PMNL)], dass sie Mitogen-aktivierte Proteinkinasen (MAPKs) aktivieren (vgl. dazu Kap. 24.5.5; Betulinsäure). MAPKs sind involviert in Zellwachstum, -differenzierung, -proliferation und -tod (vgl. Altmann et al. 2004; Syrovets et al. 2005b und darin zitierte Literatur).

Klinik, mögliche Anwendungsgebiete. Alkoholische Extrakte (100 mg) aus dem Gummiharz von B. serrata zeigten im Tierversuch bei der Behandlung von chronischen Entzündungen etwa die gleiche Wirkung wie Phenylbutazon (100 mg). Sie erwiesen sich auch in klinischen Versuchen bei Patienten mit chronischer Polyarthritis, Colitis ulcerosa und Hirntumoren (Astrozytome) wirksam. Bei Patienten mit chronischer Polyarthritis ergab sich in $60-70 \%$ der Fälle ein Rückgang der Schmerzen, der Schwellungen und der Gelenksteifigkeit. Bei Patienten mit Colitis ulcerosa ergaben sich ähnliche Ergebnisse wie bei der Behandlung mit dem Standardpräparat Sulfasalazin: in $80 \%$ der Fälle trat eine Remission auf. Bei Patienten mit Astrozytomen konnte das peritumorale Hirnödem stark reduziert werden (Verringerung des Ödemvolumens um durchschnittlich ein Drittel), während der Tumor selbst nicht beeinflusst wurde. Mit Ausnahme zweier neuerer klinischer Studien bei Patienten mit Morbus Crohn und Bronchialasthma waren die bisherigen klinischen Untersuchungen bei chronischer Polyarthritis, chronischer Kolitis, Colitis ulcerosa, peritumoralem Hirnödem sowie Hirntumoren nicht GCPkonform. In einer doppelblindkontrollierten, randomisierten Studie bei Patienten mit Morbus Crohn war ein Weihrauchprodukt im Vergleich mit dem Standardpräparat Mesalazin vergleichbar. In einer doppelblinden, plazebokontrollierten Studie bei Patienten mit chronischem Asthma bronchiale zeigten $70 \%$ der mit Boswelliaharz behandelten Patienten eine gegenüber der Plazebogruppe signifikante Verbesserung der Krankheitssituation (vgl. Ammon 2003 und darin zitierte Literatur). Eine erst kürzlich durchgeführte doppelblinde, plazebokontrollierte klinische Studie eines Extrakts von indischem Weihrauch ergab bei Patienten mit Osteoarthritis eine signifikante Abnahme der Schmerzen im Knie sowie eine Verbesserung der Beweglichkeit (Kimmatkar et al. 2003). In Zukunft sind weitere Untersuchungen zur richtigen Dosierung mit standardi- sierten Produkten bzw. mit reinen BAs und vermehrt GCP-konforme klinische Studien notwendig, um die Wirksamkeit bei den einzelnen Indikationen sowie die Unbedenklichkeit der BAs und der Harzprodukte zu belegen. In China wird gegenwärtig ein Gemisch von Acetyl$\alpha$-BA und Acetyl- $\beta$-BA (1:1) auf die Eignung zur Chemoprävention untersucht (Zhao et al. 2003).

Nebenwirkungen. Bei den BAs handelt es sich um entzündungshemmende Substanzen, die im Gegensatz zu den klassischen Antiphlogistika/Antirheumatika keine schwerwiegenden Nebenwirkungen aufweisen. Beobachtet wurden gastrointestinale Beschwerden und allergische Reaktionen.

\section{Kernaussagen}

Boswelliasäuren sind pentazyklische Triterpensäuren des Gummiharzes von Boswellia-Arten. Sie besitzen insbesondere entzündungshemmende und antiproliferative Eigenschaften. Alkoholische Extrakte aus dem Gummiharz des indischen Weihrauchs (Olibanum indicum von $B$. serrata) zeigten im Tierversuch bei der Behandlung von chronischen Entzündungen etwa die gleiche Wirkung wie Phenylbutazon. Sie erwiesen sich auch in klinischen Versuchen bei Patienten mit chronischer Polyarthritis, Colitis ulcerosa, Morbus Crohn, Bronchialasthma, Osteoarthritis und pertitumoralem Hirnödem wirksam. Die BAs sind viel versprechende Modellsubstanzen zur Entwicklung neuer entzündungshemmender Wirkstoffe. Ob sich einzelne BAs dank ihrer Antitumorwirkung auch zur Chemoprävention eignen, muss in weiteren Untersuchungen abgeklärt werden.

\subsubsection{Betulinsäure}

Betulinsäure (\$ Abb. 24.16) zeigt eine Reihe von biologischen Aktivitäten, darunter entzündungshemmende, Invitro-Anti-Malaria- und antivirale Wirkungen sowie eine spezifische Zytotoxizität gegen verschiedene Tumorzelllinien:

- Zytotoxische Wirkung. Im Jahre 1995 wurde von Betulinsäure (BS) erstmals in In-vitro- und In-vivo-Untersuchungen die Hemmung des Wachstums verschiedener menschlicher Melanomzellen nachgewiesen (>) dazu auch Infobox „Tumorhemmendes Potential 


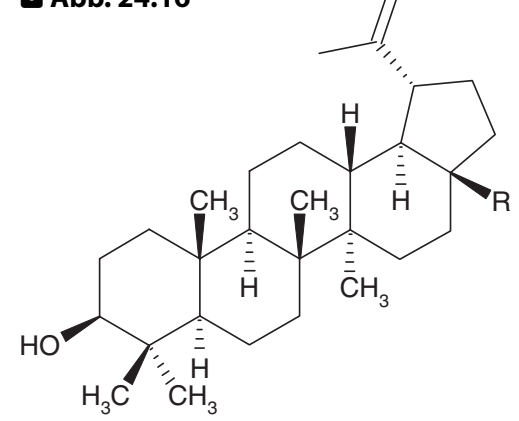

Betulin $\left(\mathrm{R}=\mathrm{CH}_{2} \mathrm{OH}\right)$

Betulinsäure $(\mathrm{R}=\mathrm{COOH})$

Betulinsäure ist ein pentazyklisches Triterpen vom Lupantyp. Die Substanz ist in der Pflanzenwelt weit verbreitet; allerdings wird sie in der Regel nur in kleinen Mengen gebildet. Es ist jedoch relativ einfach, Betulinsäure halbsynthetisch aus Betulin zu gewinnen, das der Hauptinhaltsstoff der Birkenrinde ist (bis zu 22\% in Rinde verschiedener Betula-Arten)

von Pflanzenstoffen“; S. 979). Ursprünglich wurde eine selektive Zytotoxizität gegenüber Melanomzellen bei vollständigem Fehlen einer Toxizität angenommen [Hemmung von MEL-4 (primärer Hauttumor), MEL1 (Lymphknoten), MEL-2 (Pleuraflüssigkeit), MEL-3 (Leber); $\mathrm{ED}_{50}$-Werte im Bereich $1-5 \mu \mathrm{g} / \mathrm{ml}^{-1}$ ]. BS zeigte auch eine potente antiproliferative Aktivität bei anderen Tumorarten, z. B. bei epithelialen Hirntumoren (Glioblastom, Medulloblastom, Neuroblastom), ferner bei einer ganzen Palette weiterer humaner neoplastischer Zelllinien von Eierstock (Ovarium), Gebärmutter (Uterus), Lunge (vgl. Übersicht von Cichewicz u. Kouzi 2004 und darin zitierte Literatur, berücksichtigt bis 2002) sowie von schuppenförmigen menschlichen Zelllinien von Kopf und Nacken (Thurnher et al. 2003). Die Wirkung scheint insofern selektiv, als das Wachstum normaler Zellen durch BS nicht gehemmt wird.

- Wirkungsmechanismen der zytotoxischen Aktivität. Als Wirkungsmechanismen stehen heute der durch BS induzierte programmierte Zelltod (Apoptose) und die Hemmung der Aktivierung von NF-kB im Vordergrund. BS induziert die Apoptose durch Änderungen im Membranpotential der Mitochondrien [= mitochondrialer Weg der Apoptoseauslösung (vgl. () Abb. 24.15)]. Andererseits wird eine Caspase-unabhängige Apoptose für BS postuliert, bei der mitogenaktivierte
Proteinkinasen (MAPKs) beteiligt sind (vgl. dazu auch Boswelliasäuren, Kap. 24.5.4). BS aktiviert in einem frühen Stadium der Apoptose die Proteinuntergruppen p38 MAPK und JNK. Es scheint, dass die MAPKKaskade von BS durch die Produktion von ROS (reaktive Sauerstoffspezies) ausgelöst wird. SAR-Untersuchungen von BS und BS-Derivaten haben ergeben, dass für die apoptotischen Effekte am C-17 eine Carbonylgruppe essentiell ist. Der Transkriptionsfaktor NF- $\mathrm{KB}$ ist für die Regulation der Expression verschiedener Gene verantwortlich, deren Produkte an der Karzinogenese beteiligt sind [z. B. Anti-ApoptoseGene (u. a. Bcl-2), COX-2, Matrixmetalloproteinase-9 (MMP-9), Adhäsionsmoleküle, Chemokine, proinflammatorische Cytokine, iNOS]. Substanzen wie BS, die die NF-кB-Aktivierung hemmen, haben daher das Potential, die Karzinogenese zu unterdrücken (vgl. ( Abb. 23.43). BS hemmt die durch TNF $\alpha /$ Karzinogene induzierte Aktivierung von IKK (vgl. ( Abb. 23.43, 23.44), womit die Phosphorylierung sowie der

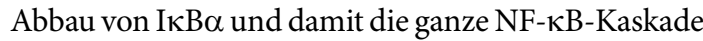
unterdrückt wird. BS zeigte in weiteren Untersuchungen eine Hemmung der Topoisomerasen I und II $\alpha$. Kürzlich wurde an menschlichen Tumorzelllinien [DU145 (Prostata), L132 (Lunge), A549 (Lunge), PA-1 (Eierstock)] für BS und einzelne Derivate auch eine antiangiogene Aktivität nachgewiesen (Tan et al. 2003; Takada u. Aggarwal 2003; Thurnher et al. 2003; Mukherjee et al. 2004; Übersicht von Cichewicz u. Kouzi 2004 und darin zitierte Literatur].

- Antivirale Aktivität. Eine weitere Hauptwirkung von BS ist die antivirale Aktivität. BS und Derivate hemmen selektiv die HIV-1-, nicht aber die HIV-2-Replikation. Die bisher nachgewiesenen Angriffspunkte und Wirkungsmechanismen sind vielfältig, scheinen aber mit dem Viruseintritt in die Zelle und mit dem Reifeprozess verknüpft zu sein. So konnte von einzelnen Derivaten gezeigt werden, dass sie den Eintritt des HIV-1-Virus in die Zelle durch Interaktion mit dem viralen Glykoproteinkomplex gp120-gp41 blockieren (vgl. Aiken u. Chen 2005). Antivirale Wirkung zeigt BS auch bei Herpes-simplex-(HSV-1-) und Influenza-A-Viren.

- Entzündungshemmende Wirkung. BS zeigte im Carrageenan- und Serotonin-induzierten Mauspfotenödemtest sowie im TPA- (TPA $=12-O$-Tetradecanoylphorbol-13-acetat) und EPP-(Ethylphenylpropiolat) Mausohrödemtest eine corticoidähnliche antiphlogistische Wirkung, die in diesen Testsystemen mit der 
Wirkung von Phenylbutazon und Indometacin vergleichbar ist. Es ist davon auszugehen, dass die antiphlogistische Wirkung ebenfalls durch den Eingriff von BS in die Transkription von Zytokinen erfolgt (vgl. dazu $\odot A b b$. 23.44).

- Antiplasmodiale Wirkung. In vitro wurde eine AntiMalaria-Wirkung $\left(\mathrm{IC}_{50}=10,46 \mu \mathrm{g} / \mathrm{ml}\right)$ auf das asexuelle Erythrozytenstadium bei Plasmodium falciparum nachgewiesen, die sich aber in einem murinen Invivo-Modell mit $P$. berghei nicht reproduzieren ließ. Neue Untersuchungen an P. falciparum ergaben, dass BS und einzelne Derivate die Erythrozytenmembran modifizieren. Durch die Interaktion (Wasserstoffbrückenbindung) von BS mit der Lipidbilayerschicht der Erythrozytenmembran wird das Parasitenwachstum gestört, da durch die modifizierten Erythrozytenmembranen das Eindringen der Merozoiten in die Erythrozyten gehemmt wird. Die Autoren der Studie (Ziegler et al. 2004) glauben, dass der festgestellte Link zwischen der Membranmodifzierung und der antiplasmodialen Aktivität ein neuer Ansatzpunkt für die Entwicklung von Anti-Malariamitteln darstellt.

Dank der einzigartigen In-vitro-Zytotoxizität, der signifikanten In-vivo-Aktivität, der geringen Toxizität sowie der interessanten Wirkungsmechanismen handelt es sich

\section{! Kernaussagen}

Betulinsäure ist ein in der Pflanzenwelt weit verbreitetes Triterpen vom Lupan-Typ, das nur in kleinen Mengen vorkommt und deshalb heute aus Betulin (von Betula-Arten) gewonnen wird. BS und eine Reihe halbsynthetischer Derivate haben in vitro und in vivo eine potente antiproliferative Aktivität. Als Wirkungsmechanismen werden der durch BS induzierte programmierte Zelltod (Apoptose) bzw. die Hemmung der Aktivierung von NF-kB angenommen. Neben der entzündungshemmenden Wirkung ist insbesondere die selektive Hemmwirkung von HIV-1 nachgewiesen. BS blockiert den Eintritt des HIV-1-Virus in die Zelle durch Interaktion mit dem viralen Glykoproteinkomplex gp120-gp41. BS und einzelne Derivate sind viel versprechende Modellsubstanzen zur Behandlung von Tumoren sowie von viralen Affektionen. Leider ist trotz der großen Anstrengungen der letzten Jahre das Ziel einer therapeutischen Anwendung von BS kaum näher gerückt. bei BS um eine viel versprechende neue Modellsubstanz. Obwohl in den letzten Jahren Hunderte von halbsynthetischen Derivaten hergestellt wurden und auf ihre Wirkung untersucht worden sind, ist das Ziel einer therapeutischen Anwendung von BS weder als Krebsmittel noch als Virustatikum kaum näher gerückt. Das National Cancer Institute der USA ist im Rahmen des „Rapid Access to Intervention Development Program“ bemüht, BS in klinischen Studien testen zu lassen.

\subsubsection{Ringelblumenblüten}

Herkunft. Ringelblumenblüten (Calendulae flos PhEur 5) bestehen aus den völlig entfalteten, getrockneten und vom Blütenstandboden befreiten Einzelblüten von Calendula officinalis L. (Familie: Asteraceae [IIB28b]). Bei C. officinalis handelt es sich um eine $30-50 \mathrm{~cm}$ hohe, von der Mitte an verzweigte, meist einjährige Kultur- und Zierpflanze Mittel- und Südeuropas mit breitlanzettlichen Blättern und gelb bis orange gefärbten Blüten mit vielen Zungenund wenigen Röhrenblüten. Die PhEur lässt als Droge nur die Blüten kultivierter, gefüllter Formen zu.

Sensorische Eigenschaften. Die Droge ist gelb bis orange gefärbt und hat einen aromatischen Geruch.

\section{Inhaltsstoffe}

- Triterpenalkohole (4-5\%) mit Mono-, Di- und Triolen verschiedener Grundstruktur, frei und mit Fettsäuren verestert (จAbb. 24.17; vgl. Übersichten von Isaac 1994 und 2000);

- Triterpensaponine (2-10\%), als Saponoside bzw. Calenduloside A-F und Calendasaponine A-D (Yoshikawa et al. 2001) bezeichnet (> Abb. 24.17);

- Flavonoide (0,3-0,8\%; PhEur = mindestens $0,4 \%)$, darunter Isorhamnetin- und Quercetinglykoside;

- Carotinoide mit orangefarbenen Carotinen und gelben Xanthophyllen;

- Polysaccharide mit Rhamnoarabinogalactan- und Arabinogalactanstruktur;

- ätherisches Öl (ca. 0,2-0,3\%), vorwiegend aus Sesquiterpenen bestehend; ferner

- Polyacetylene, Cumarine, Phenolcarbonsäuren, Sterole und Sterolglykoside, Ionon- und Sesquiterpenglykoside (Marukami et al. 2001). 

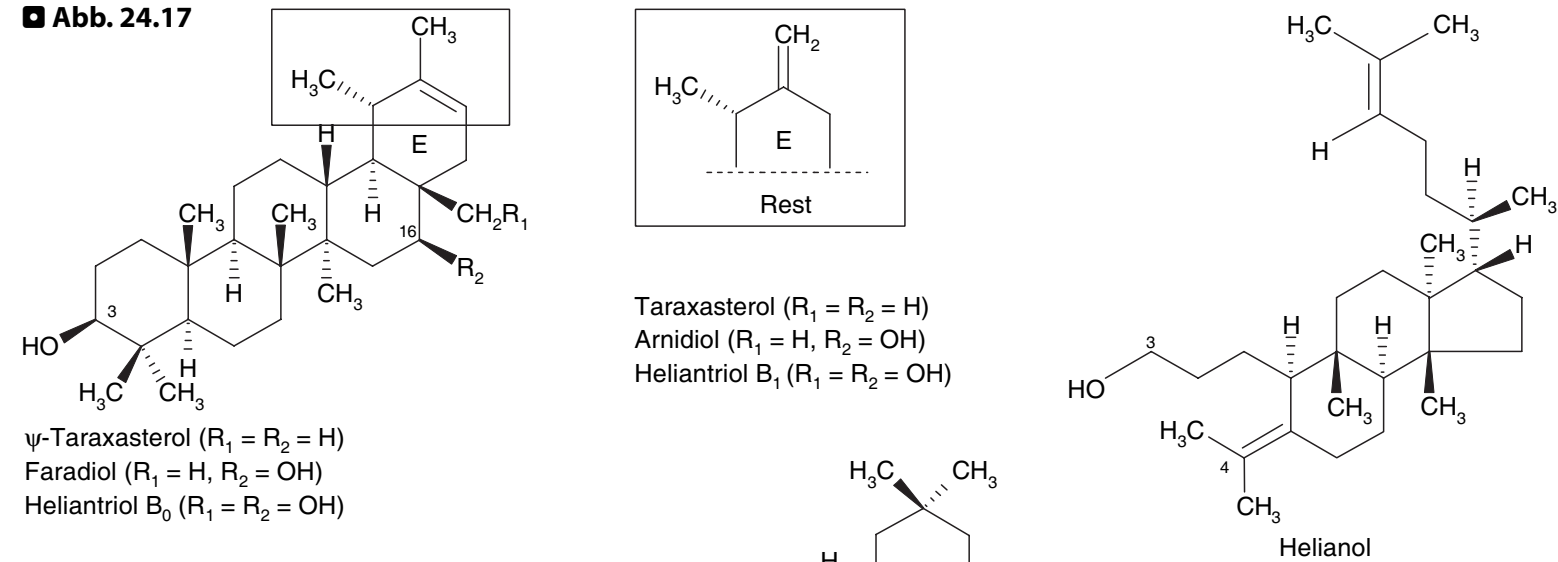

$\psi$-Taraxasterol $\left(\mathrm{R}_{1}=\mathrm{R}_{2}=\mathrm{H}\right)$

Faradiol $\left(\mathrm{R}_{1}=\mathrm{H}, \mathrm{R}_{2}=\mathrm{OH}\right)$

Heliantriol $\mathrm{B}_{0}\left(\mathrm{R}_{1}=\mathrm{R}_{2}=\mathrm{OH}\right)$

Taraxasterol $\left(\mathrm{R}_{1}=\mathrm{R}_{2}=\mathrm{H}\right)$ Arnidiol $\left(\mathrm{R}_{1}=\mathrm{H}, \mathrm{R}_{2}=\mathrm{OH}\right)$ Heliantriol $\mathrm{B}_{1}\left(\mathrm{R}_{1}=\mathrm{R}_{2}=\mathrm{OH}\right)$

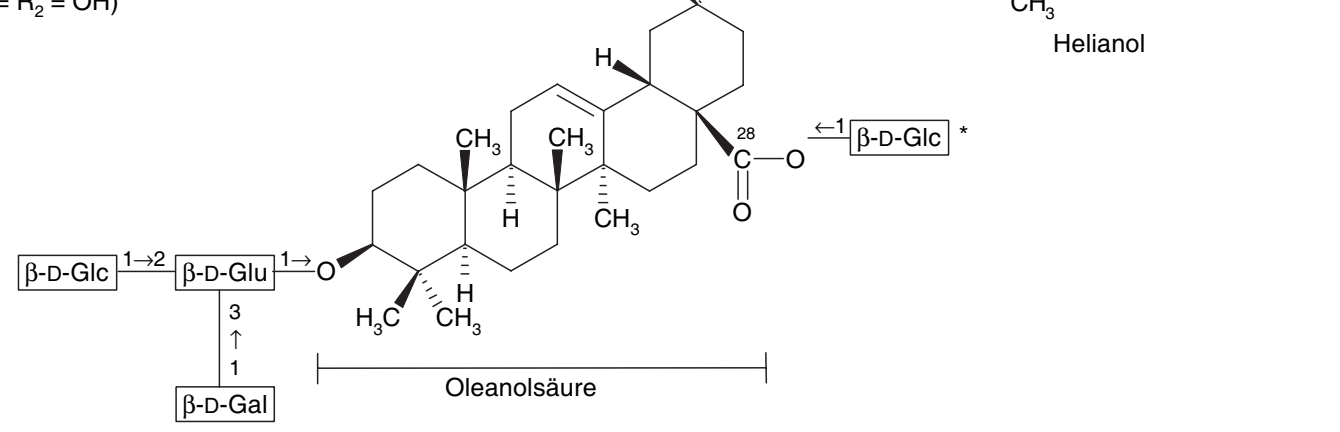

Calendulosid A, * Calendulosid B (Deglucosylcalendulosid A)

Bei den Hauptwirkstoffen der Ringelblumenblüte handelt es sich um Mono-, Di- und Triterpenalkohole, die zu 98\% als 3-Monoester (hauptsächlich Laurin-, Myristin- und Palmitinsäureester) vorkommen. Für die entzündungshemmende Wirkung sind insbesondere freie und veresterte Monole (Typ Taraxasterol) und Diole (Typ Faradiol/Arnidiol) verantwortlich. Die freien Monole sind weniger aktiv als die Diole. Bei den Monolen ist $\psi$-Taraxasterol die aktivste Substanz, bei den Diolen Faradiol. Die antiphlogistische Wirkung wird bei Substanzen verstärkt, die eine 16-OH-Gruppe aufweisen. Zugleich wird die Wirkung durch eine Veresterung über die 3-OH-Gruppe vermindert (Della Loggia et al. 1994; ZitterlEglseer et al. 1997). Ebenfalls für die tumorhemmende Wirkung scheint die 16-OH-Gruppe ein wesentliches Strukturmerkmal zu sein (Yasukawa et al. 1996). In den Röhrenblüten ist Helianol (3,4-seco-Triterpenalkohol) mit einem Euphangrundgerüst der Hauptbestandteil der Triterpenalkoholfraktion.

Die Saponine der Ringelblumenblüte sind relativ einfach gebaute Glykoside der Oleanol-, Moron, Cochalin- und Machaerinsäure. Die 3-OH- der Oleanolsäure ist glykosidisch an Glucuronsäure (Glu) gebunden, die ihrerseits an Glucose und/ oder Galactose gebunden ist. Die 28-Carboxylgruppe kann, wie im Falle des Calendulosid A und der Calendasaponine A-D (nicht abgebildet), mit Glucose verestert sein

\section{Analytische Kennzeichnung}

Prüfung auf Identität. Fingerprint-DC (PhEur) von Flavonoiden und Phenolcarbonsäuren [Fließmittel: wasserfreie Ameisensäure-Wasser-Ethylacetat (10:10:80); Referenzsubstanzen: Kaffeesäure, Chlorogensäure, Rutin; Nachweis: Diphenylboryloxyethylamin/Macrogol 400]. Die Substanzen erscheinen im UV bei $365 \mathrm{~nm}$ als verschiedenfarbig fluoreszierende Banden.
Gehaltsbestimmung. Die Gehaltsbestimmung der Flavonoide erfolgt wie in Kap. 26.5.5 unter Aluminiumchelatkomplex beschrieben. Anstelle der Flavonoide sollten die freien sowie die 3-O-veresterten Triterpenalkohole nachgewiesen und quantitativ bestimmt werden. HPLCMethoden zum Nachweis und zur Bestimmung der Triterpenester sind bei Reznicek u. Zitterl-Eglseer (2003) und bei Neukirch et al. (2004) beschrieben. Im ersten Fall werden drei Faradiol-3-monoester, im zweiten acht Faradiol-, 
Arnidiol- und Calenduladiol-3-monoester simultan quantitativ bestimmt.

Verwendung. Als Teedroge (auch als Schmuckdroge für Teemischungen), zur Herstellung von Tinkturen [Calendulae tincturae (DAC 2005)], hydroalkoholischen [Calendulae extractum fluidum (DAC 2005)] und $\mathrm{CO}_{2}$-Extrakten sowie von Calendulaöl.

Wirkungen. Bei lokaler Anwendung Förderung der Wundheilung, entzündungshemmende und granulationsfördernde Effekte (Kommission E). Für Extrakte, Tinkturen und Fraktionen bzw. für Reinstoffe wurden antiphlogistische, wundheilende, antibakterielle, antifungale, antivirale, immunstimulierende und antitumorale Wirkungen nachgewiesen (vgl. Übersichten von Isaac 1994, 2000). Als Hauptwirkstoffe für die antiphlogistische Wirkung gelten die freien und veresterten Triterpenalkohole, die lipophiler Natur sind. Nach Untersuchungen am Crotonöl-Mausohr-Dermatitis-Testmodell erwies sich Faradiol (im Extrakt nicht enthalten) als aktivste Substanz. Faradiol zeigte dosisabhängig dieselben entzündungshemmenden Effekte wie Indometacin. Allerdings gelten die Faradiolmonoester, die bei den Triterpenen quantitativ vorherrschen (2-4\%), als die entzündungshemmenden Hauptinhaltsstoffe (Della Loggia et al. 1994; Zitterl-Eglseer et al. 1997). Taraxasterol und insbesondere Faradiol und Helianol zeigten auch eine starke entzündungs- und tumorhemmende Wirkung am TPA-induzierten Mausohrödemtestmodell. Als potentielle Wirkstoffe für die Wundheilungsförderung gelten die Carotinoide, während für die antibakteriellen und an- tifungalen Wirkungen das ätherische Öl, Flavonoide und Saponine verantwortlich sind. Die immunstimulierende Wirkung wird der Polysaccharidfraktion und dem Calendulosid B zugeschrieben.

Anwendungsgebiete. Als Tinktur, Infus oder Fluidextrakt zur lokalen Anwendung bei entzündlichen Veränderungen der Mund- und Rachenschleimhaut sowie äußerlich als Tinktur und in Form von Salben bei schlecht heilenden Wunden und bei Ulcus cruris (Kommission E). Gemäß ESCOP sind die Indikationen: zur symptomatischen Behandlung leichter Entzündungen der Haut und der Schleimhaut sowie zur Unterstützung bei der Wundheilung.

\section{Kernaussagen}

Präparate der Ringelblumenblüten werden lokal bzw. äußerlich bei entzündlichen Veränderungen der Mund- und Rachenschleimhaut sowie zur Behandlung schlecht heilender Wunden verwendet. Als wirksamkeitsbestimmende Inhaltsstoffe für die entzündungshemmende Wirkung gelten die Triterpenalkohole. Die stärkste antiphlogistische Wirkung haben die freien Diole (z. B. Faradiol). Sie ist im Crotonöl-MausohrDermatitis-Testmodell vergleichbar mit der Wirkung von Indometacin. Allerdings gelten die Faradiol-3monoester (hauptsächlich Laurin-, Myristicin- und Palmitinsäureester), die bei den Triterpenen quantitativ vorherrschen, als die für die entzündungshemmende Wirkung verantwortlichen Hauptinhaltsstoffe.

\section{Schlüsselbegriffe}

Actaea racemosa

Actein

Apoptose

Betulinsäure

Bittermittel

Boswellia carteri, B. serrata

Boswelliasäuren

Brucea javanica

Calendula officinalis

Calendulae flos

Chemoprävention

Chronische Entzündung

Cimicifuga racemosa

Cimicifugae rhizoma

Cimicifuga-Triterpene

Cimicifugoside
Cucurbitacine
Östrogenrezeptormodulation, selektive
$\quad$ (SERM)
Faradiol
Faradiolmonoester
Hormone replacement therapy (HRT)
Klimakterische Beschwerden
Leukotriensynthesehemmung
Mesalazin
Mitochondrialer Weg
NF- $\kappa$ B
Olibanum indicum
Phyenlbutazon
Phyto-SERM-Theorie

Quassinoide

Raloxifen

Ringelblumenblüten

Salai Guggal

Sulfasalazin

Tamoxifen

Todesrezeptorweg

Triterpenalkohole

Triterpenglykoside

Wirkungen (antiplasmodial, antiproliferativ, antiviral, zytotoxisch, entzündungshemmend, östrogenartig, osteoprotektiv)

Wundheilung 


\subsection{Saponine}

\subsubsection{Begriffsbestimmung}

Unter Saponinen (Saponosiden) versteht man glykosidische Pflanzeninhaltsstoffe (und Inhaltsstoffe einiger mariner Invertebraten), die in Wasser gelöst - ähnlich wie Seifen beim Schütteln - einen haltbaren Schaum geben, auf Öle emulgierend und auf Suspensionen stabilisierend wirken. Die Glykosidnatur der Saponine lässt sich durch das Suffix „osid“ ausdrücken, weshalb man dem französischen Sprachgebrauch folgend treffender den Ausdruck Saponoside verwenden sollte. Dieser hat sich aber in der deutschen Literatur nicht eingebürgert.

Saponine sind optisch aktiv. Sie weisen eine besondere Affinität zu Cholesterol auf; die Spirostanol-Cholesterol-Komplexe sind in 96\%igem Ethanol sehr schwer löslich, sodass man wechselseitig Spirostanol oder Cholesterol aus alkoholischen Lösungen ausfällen kann. Viele Saponine vermögen noch in großer Verdünnung rote Blutkörperchen aufzulösen (hämolytische Aktivität). Für Fische, Kaulquappen und andere im Wasser lebende Tiere sind Saponine toxisch. Fische sterben an Hydrämie, weil es zu einer pathologischen Permeabilitätserhöhung der Kiemenepithelien kommt. Viele Saponine wirken antimikrobiell, vornehmlich gegen niedere Pilze.

Saponine schmecken kratzend und/oder bitter. Als Staub reizen sie zum Niesen; auch können sie Tränenfluss und Augenentzündungen hervorrufen. Viele Saponine haben zelltoxische Eigenschaften und wirken, intramuskulär oder subkutan appliziert, gewebsschädigend und lokal entzündungserregend.

Die aufgezählten Eigenschaften treffen nicht auf sämtliche Saponine in gleichem Maße zu. Es gibt zahlreiche Ausnahmen; in einigen Fällen, wie z. B. beim Glycyrrhizin, wird man nur sehr bedingt von einem Saponin sprechen können. Auf der anderen Seite gibt es Stoffe, wie Digitoxin und Digoxin, die mit den Saponinen viele Eigenschaften teilen, die aber wegen ihrer spezifischen Wirkungen nicht zu den Saponinen gezählt werden. Der Saponinbegriff ist somit nicht präzise definiert.

\subsubsection{Vorkommen, chemische und physikalische Eigenschaften, Einteilung}

Saponine sind im Pflanzenreich außerordentlich weit verbreitet, und zwar rechnet man, dass etwa 3 von 4 Pflanzenarten Saponine führen. Der Konzentrationsbereich von 0,1-30\%, ist, verglichen mit den Konzentrationen anderer sekundärer Pflanzenstoffe, sehr hoch. Lokalisiert sind sie in noch lebendem Gewebe als Lösungsbestandteil des Zellsaftes. In einer bestimmten Pflanzenart und einem bestimmten Pflanzenorgan treten Saponine oft als komplizierte Mischung zahlreicher, meist schwer trennbarer Einzelverbindungen auf.

Saponine sind in Wasser molekular- oder kolloidaldispers löslich; sie lösen sich gut in Mischungen von Wasser mit Methanol oder Ethanol; sie sind unlöslich in Lipidlösungsmitteln wie Ether, Chloroform oder Petrolether. Durch Kochen mit verdünnter Mineralsäure (Hydrolyse) zerfallen sie in einen Geninteil (= Sapogenin) und in 1-12 Mol Monosaccharide. Ein Teil der Saponine enthält, esterartig gebunden, aliphatische Carbonsäuren, die durch Verseifung abspaltbar sind.

Die Sapogenine sind, im Unterschied zu den Saponinen, unlöslich in Wasser und leicht löslich in absolutem Ethanol, zumeist auch in Ether und Chloroform.

Die chemische Konstitution der Sapogenine liefert für Saponine ein Einteilungsprinzip. Gemäß der Geninstruktur unterscheidet man die 3 Gruppen:

- Triterpensaponine (>Abb. 24.18 und 24.19),

- Steroidsaponine (= Spirostanolsaponine ( Abb. 24.35),

- Steroidalkaloidsaponine.

Man unterscheidet 3 verschiedene Typen:

- Monodesmoside ("Einketter"), Saponine, die nur eine einzige Zuckerkette tragen;

- Bisdesmoside (“Zweiketter”) mit 2 unabhängigen $\mathrm{Zu}$ ckerketten;

- Tridesmoside ("Dreiketter") mit 3 Zuckerketten (Anm.: Kommen bei den nachfolgend besprochenen Saponinen nicht vor).

Gebräuchlich ist auch die Einteilung der Saponine in neutrale, saure und basische Saponine. Dabei sind die Spirostanolsaponine immer neutral, die Steroidalkaloidsaponine immer basisch, während die Triterpensaponine entweder neutral oder sauer sein können. Der saure Charakter kann auf der Anwesenheit einer freien Carboxylgruppe 


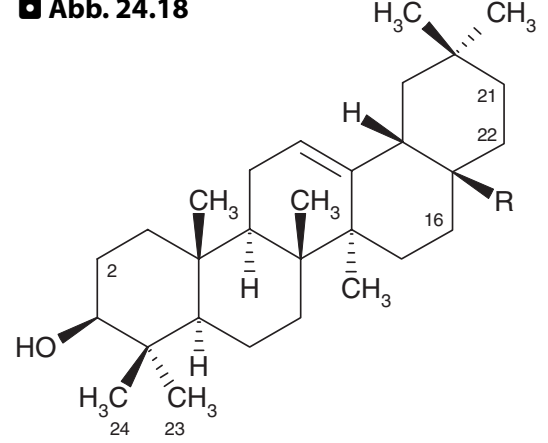

\begin{tabular}{|l|l|l|}
\hline $\mathrm{R}$ & Weitere OH-Gruppen & Trivialname \\
\hline $\mathrm{CH}_{3}$ & 24 & Sojasapogenol C \\
$\mathrm{CH}_{3}$ & $24,22 \beta$ & Sojasapogenol B \\
$\mathrm{CH}_{2} \mathrm{OH}$ & $16 \alpha$ & Primulagenin A \\
$\mathrm{CH}_{2} \mathrm{OH}$ & $2 \alpha, 23$ & Barringtogenol A \\
$\mathrm{CH}_{2} \mathrm{OH}$ & $16 \alpha, 21 \beta, 22 \alpha$ & Barringtogenol C \\
$\mathrm{CH}_{2} \mathrm{OH}$ & $16 \alpha, 21 \beta, 22 \alpha, 24$ & Protoaescigenin \\
$\mathrm{CHO}$ & $16 \alpha$ & Primulagenin D \\
$\mathrm{CHO}$ & $16 \alpha, 22 \alpha$ & Priverogenin A \\
\hline
\end{tabular}

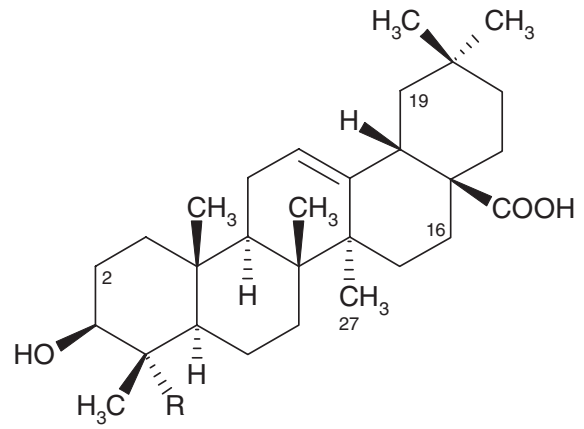

\begin{tabular}{|l|l|l|}
\hline $\mathrm{R}$ & Weitere OH-Gruppen & Trivialname \\
\hline $\mathrm{CH}_{3}$ & - & Oleanolsäure \\
$\mathrm{CH}_{3}$ & $16 \alpha$ & Echinocystsäure \\
$\mathrm{CH}_{3}$ & $19 \alpha$ & Siaresinolsäure \\
$\mathrm{CH}_{2} \mathrm{OH}$ & - & Hederagenin \\
$\mathrm{CH}_{2} \mathrm{OH}$ & $2 \beta, 16 \alpha$ & Polygalasäure \\
$\mathrm{COOH}$ & - & Gypsogensäure \\
$\mathrm{COOH}$ & $2 \beta$ & Medicagensäure \\
$\mathrm{COOH}$ & $2 \beta, 16 \alpha$ & 16 -Hydroxy- \\
& $2 \beta, 27$ & medicagensäure \\
$\mathrm{COOH}$ & $2 \beta, 27$ & Presenegenin \\
\hline
\end{tabular}

Übersicht über pentazyklische Triterpensapogenine vom Typus der 12,13-Dehydrooleanane (Oleanan-12-en): Linke Formel: neutrale, rechte Formel: saure Vertreter

im Triterpenteil beruhen oder darauf, dass der Zuckerteil eine Uronsäure enthält (Glycyrrhizin, (> Abb. 24.22).

Für Saponine, die niedere Carbonsäuren an das Aglykon gebunden enthalten, hat sich die Bezeichnung Estersaponin eingebürgert (z. B. Aescin, $>A b b$. 24.27).

In Saponinen wurden bisher folgende Monosaccharide als Bauelemente gefunden: D-Glucopyranose (Glcp), D-Galactopyranose (Galp), D-Xylopyranose (Xylp), D-Xylofuranose (Xylf), L-Arabopyranose (Arap), L-Arabofuranose (Araf), L-Rhamnopyranose (Rha $p$ ), L-Fucopyranose (Fucp) sowie die Uronsäuren D-Glucuronsäure (Glup) und D-Galacturonsäure (GalpA). Im Gegensatz zu den herzwirksamen Steroidglykosiden (? Kap. 24.7) enthalten Saponine somit keine seltenen Zucker. Art und Anzahl der Monosaccharide, Reihenfolge und Verknüpfungsart variieren in vielfältiger Weise. Je nach Anzahl der monomeren Zuckerbausteine charakterisiert man Saponine als Mono-, Di-, Tri- oder Tetraoside; ab der Tetraosidstufe man kennt Saponine mit bis zu 12 Zuckerbausteinen spricht man auch von Oligosiden (oligosidischen Saponinen). In Oligosiden ist das endständige Monosaccharid sehr häufig eine Pentose. Die Verknüpfungsart der Zucker untereinander und an das Sapogenin ist acetalisch, und zwar in der Regel $\alpha$-L- oder $\beta$-D-glykosidisch. Hinsichtlich der Bindung Zucker-Sapogenin lassen sich 2 Fälle unterscheiden: Bindung an eine (meist sekundäre) Hydroxylgruppe des Sapogenins oder esterglykosidisch an die OHGruppe eines Carboxyls (= Acylglykoside).

\subsubsection{Analytik von Saponindrogen}

Der qualitative Nachweis von Saponinen in Drogen wird heute in erster Linie mit Hilfe der Dünnschichtchromatographie durchgeführt. Andere Identitätsprüfungen, wie z. B. Farbreaktionen und insbesondere die früher übliche Schaumprobe sowie der Hämolyseversuch, finden in den modernen Arzneibüchern keine Anwendung mehr oder im besten Fall noch in einzelnen Fällen (z. B. Schaumprobe bei Seifenrinde in der Helv 10).

Prüfung auf Identität. Da es sich bei den Saponinen um vergleichsweise polare Stoffe handelt, kommen Trennbedingungen in Frage, die eine Verteilungschromatographie 


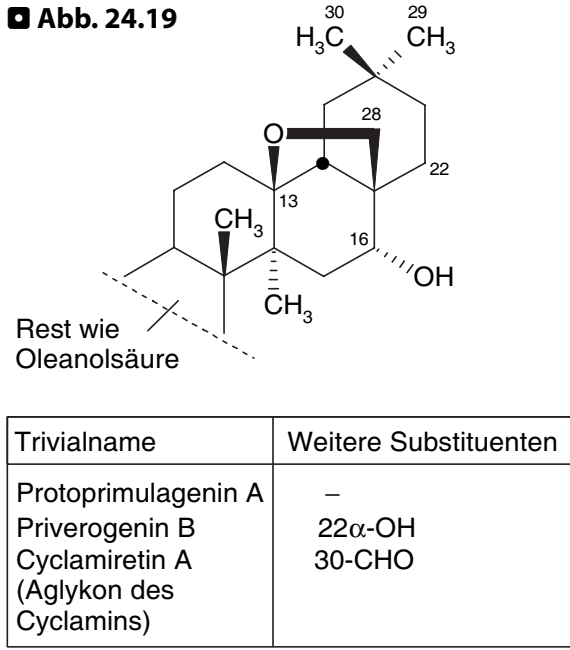

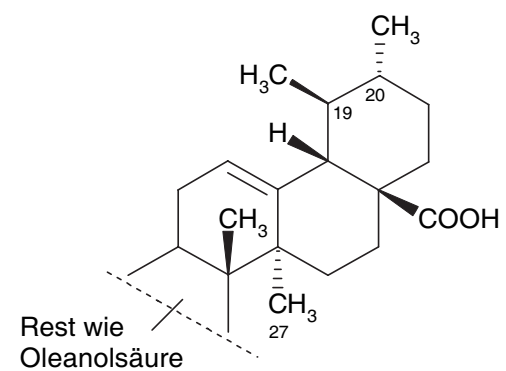

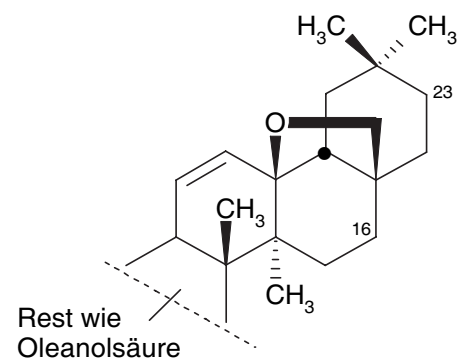

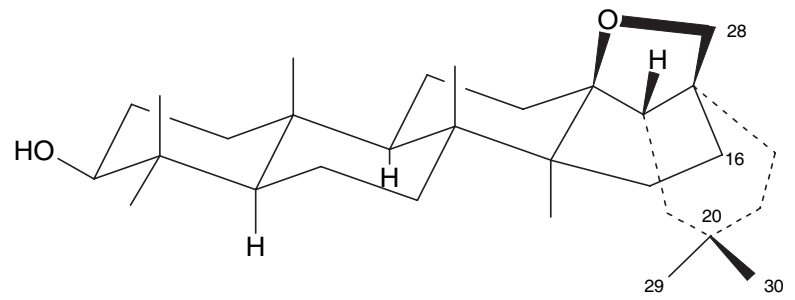

\begin{tabular}{|l|l|}
\hline Trivialname & Weitere Substituenten \\
\hline Saikogenin E & $16 \beta-\mathrm{OH}$ \\
Saikogenin F & $16 \beta-\mathrm{OH}, 23-\mathrm{CH}_{2} \mathrm{OH}$ \\
Saikogenin G & $16 \alpha-\mathrm{OH}, 23-\mathrm{CH}_{2} \mathrm{OH}$ \\
\hline
\end{tabular}

Konformationsformel (16-Desoxyprotoprimulagenin A)

Übersicht über pentazyklische Triterpensapogenine (Fortsetzung von $>A b b$. 24.18). Eine 13 $\beta$-OH-Gruppe kann mit der $28 \beta-\mathrm{CH}_{2} \mathrm{OH}-\mathrm{Gruppe}$ einen Tetrahydrofuranring bilden. Wenn die Ringe A, B und $\mathrm{C}$ als die Hauptebene des Moleküls betrachtet werden, dann steht der Tetrahydrofuranring $\beta$-ständig nahezu senkrecht zu dieser Ebene; der Ring $E$ ist a-ständig, vom Betrachter weg, angeordnet (die Konformationsformel ist die des 16-Desoxyprotoprimulagenin A). Die Saikosaponine aus der Wurzel von Bupleurum falcatum L. (Apiaceae [IIB25a]) enthalten im Ring D eine Doppelbindung. Die Ursolsäurederivate unterscheiden sich von denen der Oleanolsäure dadurch, dass anstelle der geminalen $\mathrm{CH}_{3}-\mathrm{Grup}_{-}$ pen an C-20 die Methylgruppen vicinal, als $19 \beta-\mathrm{CH}_{3}$ und als $20 \mathrm{a}-\mathrm{CH}_{3}$, angeordnet sind.

Cyclamiretin ist die Aglykonkomponente des Cyclamins, eines Saponins mit außerordentlich hoher Hämolysewirkung. Die an 3-OH angeheftete Zuckerkette ist verzweigt. Sie besteht aus Glucose (3 Mol), Xylose (1 Mol) und Arabinose (1 Mol)

darstellen, auf Kieselgelplatten vorzugsweise die Oberphase des Gemisches Essigsäure 99\%-Wasser-1-Butanol (10:40:50) als Fließmittel. Saure Saponine lassen sich besser in basischen Fließmittelsystemen trennen. Beispiel: DC der Süßholzwurzel nach PhEur: konzentrierte Ammoniaklösung-Wasser-Ethanol 96\%-Ethylacetat (1:9:25:65). Zum Sichtbarmachen der Zonen steht eine große Auswahl an Sprühreagenzien zur Verfügung: oxidierend wirkende Mineralsäuren, Lewis-Säuren, aromatische Aldehyde zusammen mit oxidierend wirkenden Säuren u. a. m. PhEur und DAB bevorzugen das Anisaldehydreagens. Die Saponinzonen färben sich im Tageslicht blau, blauviolett, rot oder gelbbraun bzw. sind im UV $365 \mathrm{~nm}$ blau, violett oder grün fluoreszierend. 
Gehaltsbestimmung. In den Pharmakopöen finden sich unterschiedliche Methoden: z. B. kolorimetrische, spektrophotometrische und vermehrt auch HPLC-Verfahren.

Die kolorimetrische Methode des DAB beruht auf der Farbreaktion mit Eisen(III)-chlorid-Essigsäure-Reagens (Rosskastaniensamen). Die Triterpene werden mit Methanol-Wasser aus der Droge extrahiert, durch Verteilen im System $0,1 \mathrm{~N}$ Salzsäure-Propanol-Chloroform angereichert und der Rückstand der organischen Phase in Essigsäure 99\% aufgenommen. Die Gehaltsbestimmung der Ginsenoside (Ginsengwurzel) und der Glycyrrhizinsäure (Süßholzwurzel) erfolgt in der PhEur 5 mit der HPLC.

Eine Übersicht zur Chromatographie der Saponine (DC, GC, HPLC, LC-MS, LC-NMR) befindet sich bei Oleszek (2002).

\subsubsection{Saponine als Hämolysegifte, hämolytischer Index, Struktur- spezifität}

\section{Hämolyse}

Man versteht unter Hämolyse die Zerstörung der roten Blutkörperchen: Hämoglobin und die anderen Bestandteile der Erythrozyten ergießen sich aus dem Zellinneren in das umgebende Medium. Man unterscheidet verschiedene Arten der Hämolyse:

- Mechanische Hämolyse. Sie erfolgt in physiologischer Weise im gesunden Organismus nach einer Lebensdauer von ca. 120 Tagen, bedingt durch die mechanische Beanspruchung des Zirkulierens in den Gefäßen. Artifiziell tritt mechanische Hämolyse immer dann auf, wenn Erythrozytenkonzentrat durch sehr feine Kanülen mit automatischen Pumpen transfundiert wird. Daraus resultieren bestimmte Risiken der Bluttransfusion und der Dialysatoren (künstliche Nieren).

- Osmotische Hämolyse. Zum Verständnis dieses Phänomens muss man wissen, dass die Proteinkonzentrationen im Erythrozyten höher ist als im umgebenden Plasma, ferner, dass die osmotische Wirkung der höheren Proteinkonzentration durch eine niedrigere Konzentration von $\mathrm{K}^{+}$-Ionen kompensiert wird, und schließlich, dass die Erythrozytenmembran für Ionen durchlässig, für die hochmolekularen Proteine aber undurchlässig ist. Nach Ausgleich der extra- und intrazellulären Konzentrationsunterschiede der Ionen wird der kolloidosmotische Druckgradient - der intrazelluläre höhere Proteingehalt bleibt bestehen - voll wirksam. Wasser strömt vermehrt in die Zelle, die zuvor bikonkaven Erythrozyten werden kugelförmig und platzen schließlich.

Osmoseänderung kann auch in vivo zur Hämolyse führen. Beim Ertrinken in Süßwasser wird das Wasser rasch resorbiert, verdünnt das Plasma und verursacht intravaskuläre Hämolyse (Meerwasser ist deutlich hyperton, zieht Flüssigkeit aus dem Gefäßsystem heraus und vermindert das Plasmavolumen). Die Toxizität gegenüber Fischen und anderen Kiementieren beruht auf einem vergleichbaren Phänomen. Saponine bewirken eine Permeabilitätserhöhung des Kiemenepithels, wodurch lebensnotwendige Ionen in das umgebende Milieu gelangen.

- Membranhämolyse. Sie tritt ein als Folge der Einwirkung stofflicher Faktoren. Stoffe, die die Erythrozytenmembran schädigen und hämolysierend wirken, bezeichnet man als Hämolysegifte. Zu den Hämolysegiften gehören $u$. a. bestimmte bakterielle Enzyme (Lysine von „hämolysierenden“ Strepto- und Staphylokokken), Insekten- und Schlangengifte, auch einige Pilzgifte (z. B. die des Knollenblätterpilzes). Eine ganze Reihe chemischer Substanzen, darunter auch Arzneistoffe (Sulfonamide, Chloramphenicol, Phenacetin, Penicilline, Cephalosporine u. a. m.), kann in vivo über unterschiedliche Mechanismen - immunologische und auch nichtimmunologische - eine Zerstörung von Erythrozyten hervorrufen.

In vivo und in vitro hämolysierend wirksam sind oberflächenaktive Stoffe, Seifen, synthetische Detergenzien und Saponine. Deren Wirkung beruht auf der Herabsetzung der Oberflächenspannung zwischen der wässrigen und der Lipidphase der Erythrozytenmembran. Die Lipide werden emulgiert und aus der Membran herausgehoben. Durch die Membranlücken strömen $\mathrm{Na}^{+}$-Ionen und Wassermoleküle in die Zelle hinein, $\mathrm{K}^{+}$-Ionen aus der Zelle heraus, so lange, bis die Membran platzt und Hämoglobin in das Plasma übertritt.

In ähnlicher Weise können Lipidlösungsmittel wie Chloroform oder Ether durch Herauslösen von Lipidanteilen der Membran zu Lecks und damit zur Hämolyse führen. Es ist wahrscheinlich, dass Saponine auch Bestandteile der Erythrozytenmembran - v. a. Cholesterol, möglicherweise auch Protein - durch Komplexbildung herauslösen. 
- Tabelle 24.3

Qualitative Angaben zur hämolytischen Aktivität der verschiedenen Saponintypen

\section{Saponintyp \\ Hämolytische Aktivität}

Triterpensaponine

Monodesmoside

- Neutrale

Sehr stark

- Saure

Sehr schwach

- Acylglykoside

Sehr schwach

Bisdesmoside

- Neutrale

Sehr schwach

- Saure

Mittel bis stark

\section{Steroide}

Monodesmosid

Sehr stark

Bisdesmoside

Sehr schwach

Alkaloide

Stark
Bestimmung der hämolytischen Wirkung. Die In-vitroHämolyse kann zur quantitativen Bestimmung von Saponinen als eine Art „Wertbestimmung, vielleicht besser biologische Standardisierung, ausgenutzt werden, die allerdings heute nur noch von wenigen Arzneibüchern vorgeschrieben wird (z. B. Helv, nicht aber PhEur oder DAB). Da vielerlei Faktoren den Hämolysevorgang beeinflussen, muss das Verfahren genormt werden; Tagesschwankungen werden ausgeschaltet durch Vergleich mit einer Standardsaponinlösung. Das Standardsaponin wird aus den Wurzeln von Gypsophila paniculata L. (Familie: Caryophyllaceae [IIB3a]) gewonnen; man teilt ihm per definitionem eine hämolytische Wirkung von $30.000 \mathrm{zu}$. Die Hämolyseversuche werden in Reagenzgläsern mit frischem Rinderblut (defibriniert, 1:50 verdünnt) durchgeführt. Durch Reihenverdünnung wird die Grenzkonzentration bestimmt, die eben noch eine Totalhämolyse bewirkt.

Die hämolytische Aktivität (H.I.) errechnet sich nach der Formel $30.000 \times \mathrm{a} / \mathrm{b}$. Dabei bedeutet $\mathrm{a}=$ die Menge an Standardsaponin in Gramm, b = die Menge an Droge in Gramm oder einer Zubereitung in Milliliter, die eine

- Tabelle 24.4

Hämolytische Aktivität einiger Saponine (Wulff 1968; verändert). Messparameter: Hämolytischer Index (H.I.) bestimmt nach Helv V, bezogen auf Schweizer Standard-Saponin (H.I. = 25.000) bei einer Blutverdünnung von 1:200

\begin{tabular}{|c|c|c|c|c|}
\hline Saponin & Saponintyp & Strukturformel & Vorkommen & $\begin{array}{l}\text { Hämolyti- } \\
\text { scher Index }\end{array}$ \\
\hline Gypsosid A & Triterpen, bisdesmosidisch, sauer & - & Gypsophila-Arten & 29.300 \\
\hline$\alpha$-Hederin & $\begin{array}{l}\text { Triterpen, monodesmosidisch, } \\
\text { sauer (durch Aglykon) }\end{array}$ & ( Abb. 24.25 & Hedera helix (Blätter) & 150.000 \\
\hline $\begin{array}{l}\text { Primulasaponin } \\
\text { (Gemisch) }\end{array}$ & $\begin{array}{l}\text { Triterpen, monodesmosidisch, } \\
\text { sauer (durch Zucker) }\end{array}$ & () Abb. 24.20 & $\begin{array}{l}\text { Primula elatior (Wurzel, } \\
\text { Rhizom) }\end{array}$ & 50.000 \\
\hline Aescin (Gemisch) & $\begin{array}{l}\text { Triterpen, monodesmosidisch, } \\
\text { Estersaponin (durch Aglykon) }\end{array}$ & (7bb. 24.27 & $\begin{array}{l}\text { Aesculus hippocastanum } \\
\text { (Samen) }\end{array}$ & 98.000 \\
\hline Glycyrrhizinsäure & $\begin{array}{l}\text { Triterpen, monodesmosidisch, } \\
\text { sauer (durch Zucker und Agly- } \\
\text { kon) }\end{array}$ & ( Abb. 24.22 & Glycyrrhiza-Arten (Wurzel) & $<2.000$ \\
\hline Cyclamin & $\begin{array}{l}\text { Triterpen, monodesmosidisch, } \\
\text { neutral }\end{array}$ & () Abb. 24.19 & $\begin{array}{l}\text { Cyclamen europaeum (Knol- } \\
\text { len) }\end{array}$ & 390.000 \\
\hline Sarsaparillosid & Steroid, bisdesmosidisch, neutral & Abb. 24.37 & Smilax-Arten (Wurzel) & $<2.000$ \\
\hline Digitonin & $\begin{array}{l}\text { Steroid, monodesmosidisch, } \\
\text { neutral }\end{array}$ & Abb. 24.36 & Digitalis purpurea (Samen) & 88.000 \\
\hline Tomatin & Steroidalkaloid, alkalisch & - & $\begin{array}{l}\text { Lycopersicon esculentum } \\
\text { (Tomatenpflanze: Blätter) }\end{array}$ & 170.000 \\
\hline
\end{tabular}


vollständige Hämolyse hervorrufen (PhEur II 1974). Die Helv 10 bestimmt die hämolytische Wirksamkeit saponinhaltiger Arzneidrogen und Arzneizubereitungen in PhHelv-Einheiten. Dabei bedeutet 1 PhHelv-Einheit die hämolytische Wirksamkeit von $10 \mathrm{mg}$ des Saponinstandards PhHelv.

Strukturspezifität. Die Hämolysefähigkeit der Saponine ist an das Aglykon gebunden und variiert stark in Abhängigkeit von der Struktur. Der Zuckeranteil hat nur einen verstärkenden oder auch abschwächenden Einfluss. Erhebliche hämolytische Aktivität weisen die monodesmosidischen Steroid- und Triterpensaponine auf (Ausnahmen sind z. B. Acylglykoside und Glycyrrhizin). Keine oder nur geringe Wirksamkeit findet sich bei den bisdesmosidischen Furostanolsaponinen und bei den neutralen Triterpensaponinen (> Tabellen 24.3 und 24.4). Durch die Anheftung einer 2. Zuckerkette am ,anderen“ Molekülende gehen demnach die Saponineigenschaften bei den Bisdesmosiden weitgehend verloren. Estersaponine haben oft eine starke hämolytische Aktivität. Bei den Triterpensaponinen ist die hämolytische Aktivität auch dann stark herabgesetzt, wenn die Ringe D und E freie polare Gruppen tragen, wie z. B. eine Carboxylgruppe oder mehrere alkoholische Hydroxylgruppen. Es ist allerdings schwierig, allgemein gültige Regeln zur Strukturwirkung der Saponine bei der Hämolyse zu machen, da in einzelnen Fällen z. B. Bisdesmoside die stärkere hämolytische Aktivität aufweisen als Monodesmoside [vgl. Übersichten von Tschesche u. Wulff 1973; Hostettmann u. Marston 1995; Lacaille-Dubois u. Wagner (2000) und darin zitierte Literatur].

Der zeitliche Verlauf der Hämolyse ist unterschiedlich für Steroid- und Triterpensaponine. Bei den Ersteren ist er schnell, bei den Letzteren langsam, was auf strukturelle Unterschiede zurückgeführt wird. Die Steroidsaponine haben eine höhere Affinität für Cholesterol an den Erythrozytenmembranen als die Triterpensaponine, da die Strukturen der Steroide denjenigen des Cholesterols ähnlicher sind als diejenigen der Triterpene (Takechi u. Tanaka 1995).

\subsubsection{Metabolismus, Pharmakokinetik und Toxikologie der Saponine}

Metabolismus und Pharmakokinetik. Die Untersuchung der Pharmakokinetik und des Metabolismus der Saponine ist bisher nur sehr lückenhaft erfolgt. Insbesondere gibt es wenig humanpharmakokinetische Studien und Untersuchungen über die Beziehung zwischen Struktur und Pharmakokinetik der Saponine. Die älteren Arbeiten wurden fast ausschließlich an Tieren (Ratte, Maus) durchgeführt. Dabei wurde festgestellt, dass nach der p.o.-Applikation die Saponinglykoside in der Regel bereits im Gastrointestinaltrakt chemischen bzw. enzymatischen Veränderungen unterliegen. Beispiele dazu bei Ginsenosiden, Saikosaponinen, Asiaticosid und Glycyrrhizinsäure sind Zuckerabspaltung durch Enzyme der intestinalen Mikroorganismen, Deacylierung, Oxidationsprozesse und Isomerisierung. Entgegen älteren Vorstellungen können Saponine nach p.o.-Zufuhr aus dem Magen-Darm-Trakt heraus absorbiert werden. Die Resorptionsquote ist allerdings in jedem Falle niedrig. Ginsengsaponine z. B. mit 3 Molekülen Zucker (Ginsenosid $\mathrm{Rb}_{1}$ ) werden aus dem Magen-Darm-Trakt der Ratte zu lediglich 0,1\% resorbiert. Zuckerärmere Ginsenoside mit nur 2 Molekülen Zucker (Ginsenosid $\mathrm{Rg}_{1}$ ) werden etwas besser, und zwar mit einem Anteil von 1,9-20\% der zugeführten Dosis (100 mg/kg KG) absorbiert. Daneben sind bei einzelnen Saponinen enterohepatische Kreisläufe beschrieben worden (z. B. Aescin, Asiatsäure), sodass sich möglicherweise aus diesem Grund keine hohen Blutspiegelwerte aufbauen können. Bei einzelnen Verbindungen (Aescin, Ginsenosid $\mathrm{Rb}_{1}$ und Glycyrrhizinsäure) wurden Plasmaproteinbindungen beobachtet (vgl. Bader 1994 und darin zitierte Literatur).

Im Falle von Aescin hängt die Bioverfügbarkeit beim Menschen von der gewählten galenischen Form der Produkte ab. Nach Gabe einer Retardform liegt sie bei 5\%, nach Applikation in Lösung bei 15\% (Oschmann et al. 1996). Absorption und Metabolismus sind nicht nur zwischen Mensch (falls Untersuchungen vorliegen) und Tier, sondern auch von Tierart zu Tierart unterschiedlich; auch sind sie stark vom individuellen Aufbau der Saponine abhängig. Recht häufig ist auch die Interpretation der vorliegenden Daten schwierig, da zufriedenstellend interpretierbare pharmakokinetische Daten erst durch moderne analytische Methoden ermöglicht werden, wie an einigen Beispielen (vgl. in Kap. 24.6.8 die Abschnitte zu Süßholzwurzel, Rosskastaniensamen und Ginsengwurzel) aufgezeigt werden kann.

Toxikologie. Wegen der schlechten Resorbierbarkeit der Saponine führen beim Menschen orale Gaben von Saponinen in Dosen, die bei intravenöser Zufuhr Intoxikationen hervorrufen würden, nicht zu akuten Vergiftungserscheinungen. Wunden oder Entzündungen im Bereich des 
Rachens, des Magens oder des Darms bringen jedoch die Gefahr mit sich, dass größere Dosen als beim Gesunden in die Blutbahn gelangen. Von besonderem Interesse ist es, ob eine Langzeitzufuhr von Saponinen unbedenklich ist, einmal, weil Saponine enthaltende Arzneimittel (z. B. Ginsengpräparate) oft über lange Zeiträume genommen werden, sodann deshalb, weil Saponine in einigen unserer Lebensmittel enthalten sind, beispielsweise in Erdnüssen, in grünem Tee $(0,04 \%)$ sowie in den Gemüsesortenn Spinat, rote Beete und Spargel. Bockshornkleesamen von Trigonella foenum-graecum L., die 0,1-0,2\% Steroidsaponine enthalten, sind ein viel verwendetes Gewürz - regelmäßiger Bestandteil von Curry und anderen scharfen Gewürzmischungen. In Äthiopien und in Ägypten setzt man Bockshornkleesamen dem Brot zu. Die Samen der Reismelde, Chenopodium quinoa WillD., die in den Regionen über $3500 \mathrm{~m}$ in Chile und Peru das Hauptnahrungsmittel für Millionen Menschen bilden, enthalten Saponine; allerdings entfernen die Indios die Hauptmenge der bitter schmeckenden Saponine durch Auswaschen der Meldesamen in alkalischen Lösungen. Ferner werden in verschiedenen Ländern saponinhaltige Extrakte wegen ihrer Eigenschaft, einen dauerhaften Schaum zu erzeugen, Limonaden und Bieren zugesetzt. Zu der Frage, ob kleine Saponinmengen bei lange dauernder Zufuhr Schädigungen hervorrufen, liegen somit seit Jahrhunderten durchgeführte Versuche vor, ohne dass je über schädigende Wirkungen berichtet wurde. Einschränkend muss allerdings hinzugefügt werden, dass eine chronische Giftwirkung durch bloße Empirie wesentlich schwieriger aufzudecken ist als eine akute Vergiftung.

\subsubsection{Wirkungen der Saponine}

Neben den schon in den Kapiteln 24.6.1 und 24.6.4 aufgeführten allgemeinen Saponineigenschaften (Schaumbildung, hämolytische Aktivität, Bildung von Cholesterolkomplexen) liegt heute eine Fülle von Untersuchungsergebnissen zur biologischen Aktivität und Pharmakologie der Saponine vor (> Tabelle 24.5 und dazu aufgeführte Literatur). Therapeutische Relevanz haben davon insbesondere die expektorierend-sekretolytische, antiödematös-exsudative, entzündungshemmend-antiulzerogene Wirkung sowie die Wirkung als allgemeines Tonikum, die in erster Linie auf einer Stimulierung von Lernfähigkeit, Gedächtnis und motorischer Aktivität basiert. Daneben tragen verschiedene der in der Tabelle für einzelne Rein- stoffe oder Saponinfraktionen aufgeführten Wirkungen zu einem Gesamtarzneimittelbild bei, sind aber für den therapeutischen Einsatz kaum entscheidend. Recht häufig lässt sich damit aber z. B. eine in der Volksmedizin übliche Indikation begründen.

Über die Bedeutung von Saponinen als Adjuvanzien zur Herstellung von Impfstoffen und zur Förderung der Resorption von Peptiden und Aminoglykosidantibiotika (() unter Quillajasaponine, S. 966).

Expektorierende Wirkung. Expektoranzien (= auswurffördernde Mittel) sollen das „Aushusten“ von Schleim oder Fremdstoffen aus dem Bronchialsystem erleichtern. Dabei unterteilt man in die Sekretomotorika, die den Abtransport des Schleimes fördern - dazu zählt das Ephedrin (es stimuliert die Zilienbewegung) - und in die Sekretolytika, die den Schleim verflüssigen. Von den Saponinen wird postuliert, sie würden, wie Emetin, eine Sezernierung von Sekret durch die serösen Zellen der Bronchialschleimhaut reflektorisch über den Parasympathikus, vom Magen aus, induzieren. Ein solcher Mechanismus impliziert, dass lokal irritierende Saponine in Dosen angewandt werden, die die sensiblen Nervenendigungen so stark erregen, dass tatsächlich das Vorstadium einer Nausea (= Nauseola) ausgelöst wird. Viele Fertigarzneimittel mit Saponindrogen dürften dafür zu schwach dosiert sein. Der Mechanismus für die expektorierende Wirkung ist bis heute nicht zweifelsfrei geklärt. $\alpha$-Hederin soll ein indirekter $\beta_{2}$-adrenerger Effekt zukommen (vgl. S. 965).

Entzündungshemmende Wirkung. Eine größere Gruppe von Saponinen (von etwa 50 Pflanzen) erwiesen sich im Carrageenan- oder Dextran-induzierten Rattenpfotenödemtest, im Crotonöl-induzierten Mäuseohrödemtest und/oder in anderen Testmodellen als entzündungshemmend. Für die antiphlogistische Wirkung scheinen eine verminderte Exsudation, eine direkte oder indirekte glucocorticoidartige Wirkung sowie die Hemmung der enzymatischen Bildung oder Freisetzung von Entzündungsmediatoren verantwortlich zu sein. Aus der Sicht der Phytotherapie können die wichtigeren Arzneidrogen/Saponine mit entzündungshemmenden Eigenschaften in die 2 Gruppen mit antiödematös/antiexsudativer und antiphlogistisch/antiulzerogener Wirkung eingeteilt werden

(จ Tabelle 24.5).

Die Saponine der ersten Gruppe haben die Fähigkeit, experimentelle Ödeme zu verhindern sowie auch bereits vorhandene Ödeme teilweise zu beseitigen. Diese ödem- 


\section{- Tabelle 24.5}

Saponinwirkungen mit therapeutischer Relevanz und in der Literatur beschriebene Wirkungen der Saponine (vgl. Übersichten von Bader 1994; Hostettmann u. Marston 1995; Lacaille-Dubois u. Wagner 2000; Francis et al. 2002)

Hauptwirkungen mit therapeutischer Relevanz

Expektorierend/sekretolytisch

Antiödematös/antiexsudativ

Entzündungshemmend/antiulzerogen

Stimulierung von Lernfähigkeit, Gedächtnis und motorischer Aktivität

Verschiedene Aktivitäten

\section{Antiviral}

Antibakteriell, antifungal

Zytotoxisch, antitumoral, chemopräventiv, antimutagen

Immunmodulierend bzw. als Immunoadjuvans

Hepatoprotektiv, zytoprotektiv

Antioxidativ, neuroprotektiv

Blutzuckersenkend

Molluscizid, piscizid

Blutplättchenaggregationshemmend

Wirkung auf Herz- und Kreislauf

Süßwirkung
Beispiele von Arzneidrogen bzw. wirksamen Saponinen

Efeublätter, Senegawurzel, Süßholzwurzel, Primelwurzel

Rosskastaniensamen, Mäusedornwurzelstock, Aescin

Süßholzwurzel, Glycyrrhizinsäure, Ginsenoside, Saikosaponine

Ginsengwurzel, Ginsenoside

\section{Beispiele von wirksamen Saponinen}

Glycyrrhizinsäure, Saikosaponine, Calendula-Saponine

$\alpha$-Hederin, Calendula-Saponine, Sapindoside

Glycyrrhizinsäure, Saikosaponine, Ginsenoside, $\alpha$-Hederin,

Tubeimosid 1, Virgaureasaponin E

Ginsenoside, Calendulosid B bzw. Quillajasaponine

Ginsenoside, Glycyrrhizinsäure

Ginsenoside

Ginsenoside, Aescin, Senegasaponine

Monodesmosidische Oleanolsäureglykoside

Ginsenoside

Ginsenoside

Glycyrrhizinsäure

Weiter nachgewiesene Aktivitäten sind: sedativ, analgetisch, antipyretisch, spermizid und empfängnisverhütend, anthelmintisch, insektizid, insektenwachstumshemmend, diuretisch, cholesterol- und triglyceridsenkend, Wirkung auf das endokrine System, Hemmung der Ethanolresorption, Hemmung bzw. Verstärkung der Süßempfindung, antipsychotisch.

protektiven Eigenschaften beanspruchen Interesse, weil sie dazu herangezogen werden, die Verwendung bestimmter Saponine in Venenmitteln pharmakologisch zu begründen. Substanzen mit antiexsudativen und ödemprotektiven Eigenschaften bilden eine Untergruppe der entzündungshemmenden Stoffe, indem sie die Initialstadien der Entzündung beeinflussen. Die Wirkungsweise wird heute in erster Linie damit erklärt, dass sie in vitro eine Hemmwirkung auf die lysosomalen Enzyme Elastase und Hyaluronidase ausüben, was zu einer verminderten Gefäßpermeabilität führt. Hyaluronidase ist für den Abbau der Hyaluronsäure (= Hauptsubstanz des die Gefäße umgebenden Bindegewebes) verantwortlich, und Elastase (eine Endopeptidase) für die hydrolytische Spaltung verschiedener Substanzen der extrazellulären Matrix (Elastin, Kollagen, Proteoglykane) sowie auch von Proteinen, die an den Endothelzellmembranen haften (u. a. Fibronectin;
Facino et al. 1995). Daneben spielt wahrscheinlich auch der Einfluss auf Enzyme des Prostaglandinmetabolismus eine nicht unwesentliche Rolle. Hier spielt vermutlich wie bei den Flavonoiden ( $(A b b$. 26.62) die Regulierung des Gleichgewichts zwischen Thromboxan $\mathrm{A}_{2}\left(\mathrm{TXA}_{2}\right)$ und Prostacyclin, das für die Thrombozyten-Gefäßwand-Interaktion in Richtung einer Hemmung der Thrombozytenaggregation von Bedeutung ist, eine Rolle.

Die entzündungshemmende Wirkung der 2. Gruppe basiert auf einer Freisetzung des adrenocorticotropen Hormons (ACTH) und der damit verbundenen verstärkten Ausschüttung und Biosynthese von Glucocorticoiden in der Nebennierenrinde (z. B. durch Saikosaponine) bzw. einer Hemmung von Enzymen, die für den Cortisolabbau in der Leber verantwortlich sind (durch Glycyrrhizinsäure). Beides stellen indirekte glucocorticoide Wirkungen dar (จ dazu auch Kap. 24.6.8, Abschnitt Süßholzwurzel). 
Von geringerer Bedeutung ist eine direkte Affinität zu Glucocorticoidrezeptoren, die für Saikosaponine und Ginsenoside nachgewiesen wurde. Diese Saponine hemmen auch die Freisetzung von Entzündungsmediatoren des Prostaglandinzyklus (z. B. TXA 2 ).

Die in der Literatur erwähnte „resorptionsfördernde Wirkung" der Saponine, die schon sehr früh an verschiedenen Arzneistoffen wie z. B. Cantharidin, Strophanthin, Curarealkaloiden, Magnesiumsulfat und Ferrosalzen, in Gegenwart von Saponingemischen gezeigt werden konnte, ist bis heute nicht eingehend studiert. Es handelt sich aber wohl kaum um eine echte Änderung der physiologischen Resorptionsvorgänge. Wahrscheinlich spielen zwei Effekte eine Rolle: die Änderung der Bioverfügbarkeit, indem die Teilchengröße von in Wasser schwer löslichen Arzneistoffen verkleinert wird, und der schleimhautirritierende Effekt, wodurch die Diffusion von Substanzen in die Blutbahn erleichtert wird. Ob Saponine als Begleitstoffe in Ganzdrogenzubereitungen zur Resorption von Stoffen führen, die, in reiner Form appliziert, nicht oder kaum resorbierbar sind, über diese für die Anwendung von Extrakten in der Phytotherapie so wichtige Frage, liegen keine systematischen Untersuchungen vor. Postuliert wird eine „Resorptionsverbesserung“ u. a. für Flavone, Phytosterole und Kieselsäure.

Die bedeutendste Entwicklung der letzten Dekade ist die Erkenntnis, dass Saponine in einer Reihe neu entwickelter Bioassays mit Enzymen oder Zellen insbesondere bei Tumoren, Entzündungen und Leberkrankheiten Wirkungen zeigen. Für diese und weitere Aktivitäten von Saponinen wird auf die $>$ Tabelle 24.5 und die zitierte Literatur verwiesen. Auf einzelne Wirkungen, die in der

\section{Schlüsselbegriffe}

Analytik von Saponindrogen

Bisdesmoside

Hämolyse

Hämolytischer Index (H.I.)

Metabolismus

\subsubsection{Arzneidrogen mit Saponinen}

In den Arzneibüchern sowie verschiedenen anderen Monographiesammlungen existiert eine große Anzahl von Arzneidrogen mit Saponinen als Hauptinhaltsstoffen. In der Mehrzahl davon kommen Triterpensaponine vor. Die wichtigeren Saponindrogen sind in $>$ Tabelle 24.6 aufgelistet.
Tabelle aufgeführt sind, wird näher im Kapitel 24.6.8, Abschnitte Süßholzwurzel, Seifenrinde, Quillaja-Saponine und Ginsengwurzel eingegangen.

Bisher sind nur in wenigen Fällen auch die der Wirkung zugrunde liegenden Mechanismen auf molekularer Ebene untersucht worden. Interessant ist die Tatsache, dass Saponine mit einer oder mehrerer Acylgruppen im Molekül die stärksten Wirkungen zeigen.

\section{! Kernaussagen}

Saponine sind glykosidische Pflanzeninhaltsstoffe mit einem Steroid- bzw. Triterpengrundgerüst, die aufgrund ihres amphiphilen Charakters Oberflächenaktivität aufweisen, in Wasser gelöst beim Schütteln einen haltbaren Schaum geben, mit Cholesterol Komplexe eingehen und eine hämolytische Aktivität aufweisen. Die Zucker sind in 1-3 Ketten über eine Hydroxylgruppe des Sapogenins oder esterglykosidisch an die $\mathrm{OH}-$ Gruppe eines Carboxyls verknüpft. Die Hämolysefähigkeit ist an das Aglykon gebunden und variiert stark in Abhängigkeit von der Struktur. Wegen der geringen Resorption der Saponine führen beim Menschen orale Gaben nicht zu akuten Vergiftungserscheinungen. Pharmakokinetik und Metabolismus der Saponine sind bisher nur sehr lückenhaft untersucht. Neben den typischen Saponineigenschaften ist heute eine ganze Reihe von Saponinwirkungen bekannt. Therapeutische Relevanz haben davon insbesondere die expektorierend-sekretolytische, antiödematösexsudative, entzündungshemmend-antiulzerogene Wirkung sowie die Wirkung als allgemeines Tonikum.

\subsubsection{Triterpensaponine}

Triterpensaponine sind bei den zweikeimblättrigen Pflanzen (Rosopsida $=$ Eudicotyledoneae) weit verbreitet, insbesondere aber in Arten der folgenden Pflanzenfamilien: Araliaceae, Caryophyllaceae, Polygalaceae, Primulaceae, Sapindaceae, Sapotaceae. Saponine können in höherer 


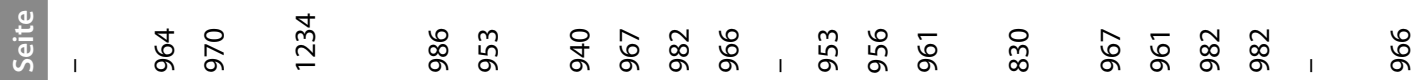

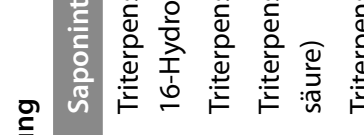

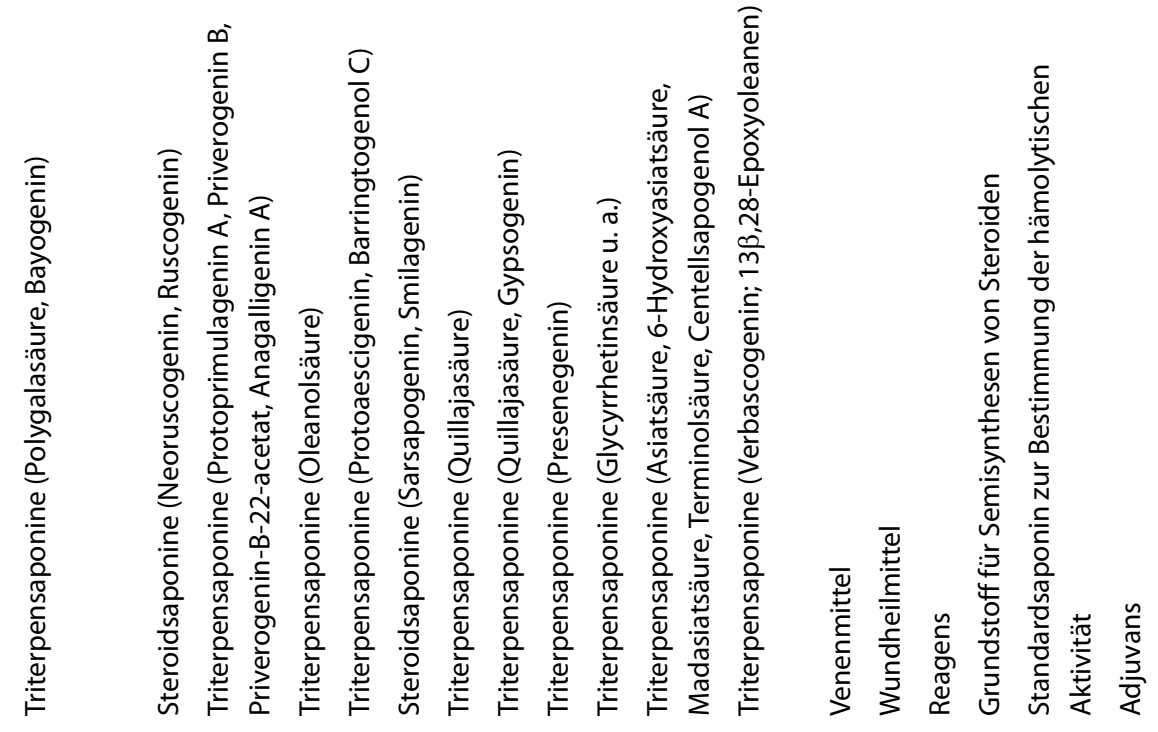

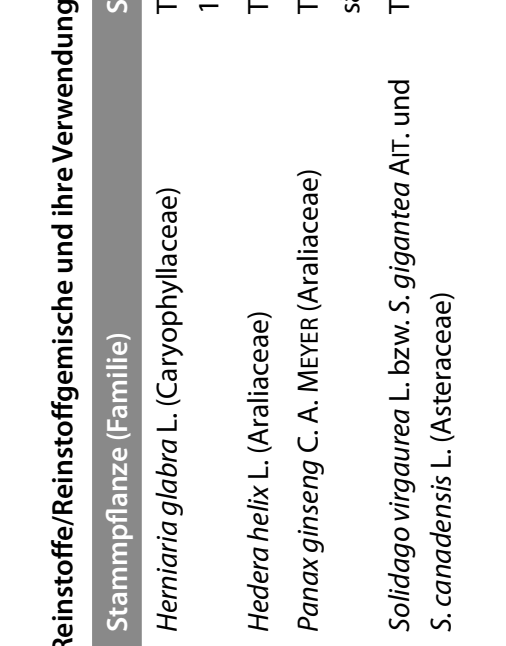

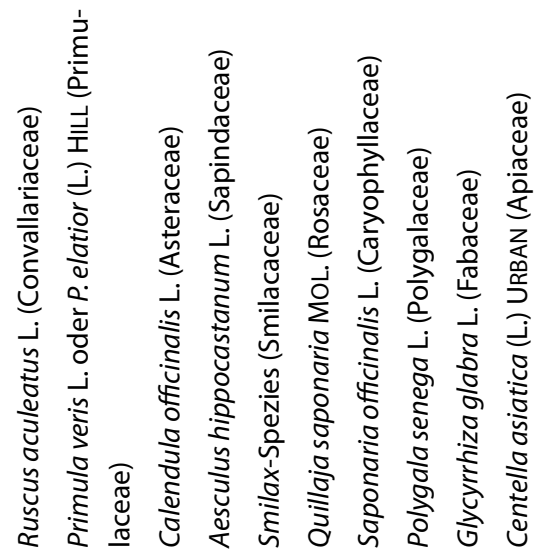

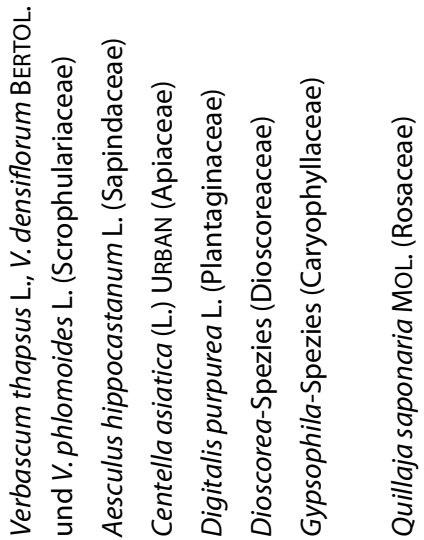

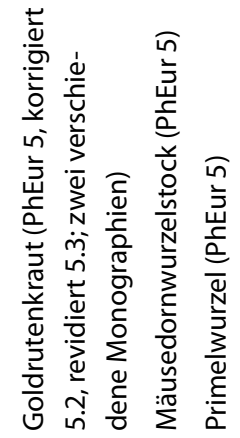

峁

$\stackrel{\complement}{\leftrightarrows}$

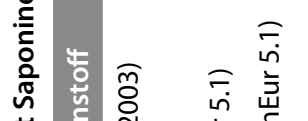

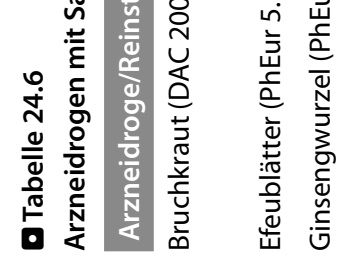

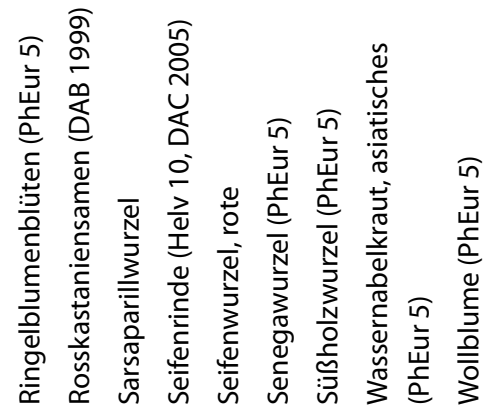

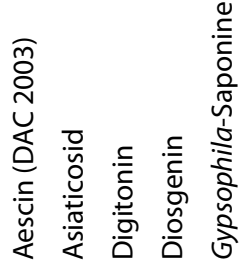

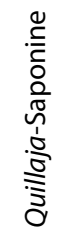


Konzentration in allen Organen auftreten, vorzugsweise in Wurzeln, Rinden und Samen. Bei der Ginsengwurzel sind die Saponine in eigenen Exkretgängen lokalisiert; doch ist dies eine Ausnahme von der Regel, da ansonsten Idioblasten, in denen Saponine abgelagert würden, fehlen, ein Hinweis vielleicht darauf, dass Saponine eine physiologische Funktion zu erfüllen haben.

Man vermutet, diese Funktion könne in einer Schutzwirkung pflanzenpathogenen Mikroorganismen, insbesondere Pilzen, gegenüber bestehen. Antibiotisch bzw. fungizid wirksam sind allerdings lediglich die monodesmosidischen Saponine. Die unwirksamen Bisdesmoside würden folglich die Transportform darstellen: Bei Infektion der Pflanze können sie rasch an die betroffene Gewebspartie herangeführt werden und dann auch schnell enzymatisch in die antibiotisch sehr wirksamen monodesmosidischen Saponine übergehen. Andererseits haben Mikroorganismen, z. B. die Pilze, Strategien gegen die Saponine entwickelt, u. a. in der Zusammensetzung ihrer Membranen (ein hoher Sterolgehalt erhöht die Resistenz) sowie saponinabbauende Enzyme (Hydrolasen) (vgl. Übersicht von Osbourn 1996).

\section{Primelwurzel}

Herkunft. Primelwurzel (Primulae radix PhEur 5) besteht aus dem getrockneten Wurzelstock mit den Wurzeln von Primula veris L. oder Primula elatior (L.) HILl (Familie: Primulaceae [IIB20b]). Beide Primula-Arten sind ausdauernde Pflanzen mit länglich eiförmigen, runzeligen Blättern in Rosetten. Die Blüten sitzen, als Dolde angeordnet, auf einem etwa 10-20 (30) cm hohen Stiel, der Kelch ist glockenförmig aufgeblasen, fünfkantig, hellgrün. Die Blumenkrone ist wenig länger als der Kelch, radförmig mit 5 Zipfeln; im radförmigen Teil bei $P$. veris (Frühlingsschlüsselblume) tief goldgelb mit orangefarbenen Flecken am Schlundrand (Blüte wohlriechend), bei P. elatior (Waldschlüsselblume) gleichmäßig schwefelgelb (Blüte geruchlos). Beide Arten sind in ganz Europa und Asien, mit Ausnahme des hohen Nordens, verbreitet.

Sensorische Eigenschaften. Primula-elatior-Wurzel ist entweder geruchlos oder sie riecht schwach nach Methylsalicylat; Primula-veris-Wurzel riecht schwach anisartig. Geschmack: stark kratzend. Das Drogenpulver reizt beim Verstäuben stark zum Niesen.

\section{Inhaltsstoffe}

- Triterpensaponine (3-10\%) mit unterschiedlichem Aglykonteil, je nachdem ob Primula-veris-Wurzel oder Primula-elatior-Wurzel vorliegt (>Abb. 24.20);

- Phenolglykoside (Primverosid, Primulaverosid), die bei der Trocknung durch enzymatischen Abbau zu den charakteristischen, an Methylsalicylat erinnernden Geruchsstoffen der Droge führen können;

- Methoxylierte Flavone (3', $4^{\prime}, 5^{\prime}$-Trimethoxyflavon in $P$. veris) Zucker und Zuckeralkohole.

Analytische Kennzeichnung. Fingerprint-DC (PhEur) auf Saponine [Fließmittel: obere Phase einer Mischung von Essigsäure 99\%-Wasser-1-Butanol (10:40:50); Referenzsubstanz: Aescin; Nachweis: UV bei 365 nm und Anisaldehydreagens]. Im ultravioletten Licht bei $365 \mathrm{~nm}$ dürfen keine hellblau oder grünlich fluoreszierenden Zonen sichtbar sein (Beimengungen von Vincetoxicum-hirundinaria-Wurzeln). Die Saponine erscheinen im Tageslicht nach Besprühen mit Anisaldehydreagens als verschieden gefärbte Zonen.

Verwendung. Als Teedroge, zur Herstellung von Extrakten und Tinkturen (Primulae radicis tinctura DAC 2005), die als Bestandteil von Fertigarzneimitteln Verwendung finden.

Wirkungen, Anwendungsgebiete. Sekretolytisch, expektorierend. Bei Katarrhen der Luftwege (Kommission E). Gemäß ESCOP sind die Indikationen: Husten mit Auswurf, Katarrh der Luftwege, chronische Bronchitis. Zur expektorierenden Wirkung $>$ Kap. 24.6.6.

Für dieselben Indikationen werden auch Schlüsselblumenblüten (Primulae flos cum calyce DAC 2005) verwendet, die allerdings nur wenig Saponine, dafür bis $3 \%$ Flavonoide enthalten.

Nebenwirkungen. Magenbeschwerden und Übelkeit können vereinzelt vorkommen.

\section{Senegawurzel}

Herkunft. Senegawurzel (Polygalae radix PhEur 5) besteht aus der getrockneten und meist zerkleinerten Wurzel sowie dem Wurzelkopf von Polygala senega L. (Familie: Polygalaceae [IIB9b]), aus bestimmten anderen Arten oder aus einer Mischung verschiedener Arten der Gat- 
- Abb. 24.20

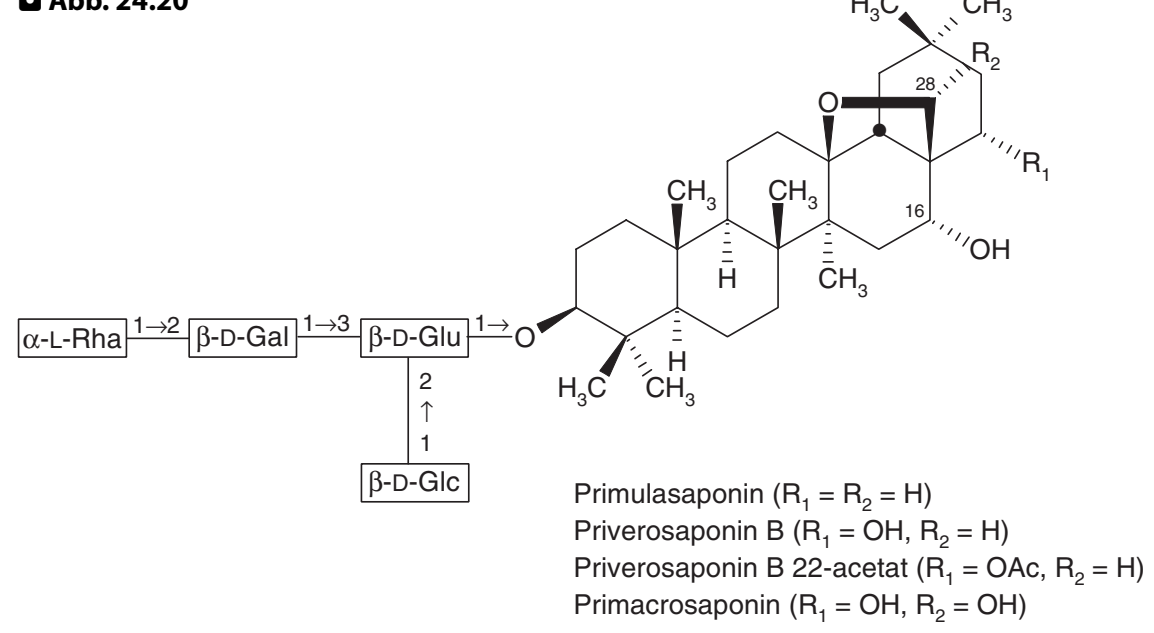

Hauptsaponin der Primula-elatior-Wurzel ist das Primulasaponin, dessen Aglykon Protoprimulagenin A an Glucuronsäure (Glu) gebunden ist. Somit liegt ein durch Uronsäure saures, monodesmosidisches Triterpensaponin vor. Die aus 4 Zuckern bestehende Kohlenhydratkette ist verzweigt. Nebensaponine unterscheiden sich in der Zuckerkette. Neben Primulasaponin kommen in Primula-veris-Wurzel Priverosaponin B, Priverosaponin B 22-acetat und Primacrosaponin mit derselben Zuckerkette, aber unterschiedlichen Aglykonen (Priverogenin B, Priverogenin-B-22-acetat und Anagalligenin A) vor (Calis et al. 1992). Aus einem kommerziell erhältlichen Primula-Wurzelextrakt (Herkunft: $P$. veris oder $P$. elatior) konnte kürzlich als zweites Hauptsaponin ein Primulasaponinderivat mit einer zusätzlichen Xylose (gebunden über die 4-OH-Gruppe der Glucose) isoliert werden (Siems et al. 1998)

tung Polygala. Bei P. senega handelt es sich um ein kleines, 20-30 cm hohes, ausdauerndes Kraut, das aus einem ganz kurzen Wurzelschopf mehrere Stängel treibt; die Blätter sind lanzettlich; die Blüten, die in ihrer Form etwas an Schmetterlingsblüten erinnern, sind weiß gefärbt. Beheimatet ist die Art in den Prärien und Wäldern Nordamerikas. Die Droge wird aus den nördlichen USA und Kanada importiert; die in Asien heimischen und in Japan verwendeten und kultivierten Arten P. tenuifolia WiLlD. und P. senega L. var. latifolia Torr. et GrAy können medizinisch-pharmazeutisch als gleichwertig angesehen werden.

Sensorische Eigenschaften. Geruch: schwach aromatisch (an Salicylsäuremethylester erinnernd), nach längerer Lagerung auch leicht ranzig. Geschmack: zunächst süßlich, später unangenehm, kratzend. Bei längerem Kauen den Speichelfluss anregend (sialagoger Effekt). Der Staub der pulverisierten Droge wirkt niesenerregend.

\section{Inhaltsstoffe}

- 6-12\% Triterpensaponine, die Presenegenin (>Abb. 24.18) als Aglykon enthalten. Die Saponine von P. se- nega werden als Senegine ( $(A b b .24 .21)$, diejenigen von P. tenuifolia als Onjisaponine und die Glykoside von P. senega var. latifolia als Senegasaponine a-c (neben den Seneginen II-IV) bezeichnet;

- Phenolglykoside: Senegosen A-O (P. senega var. latifolia) bzw. Tenuifoliosen A-Q (P. tenuifolia);

- Xanthone und Xanthonglykoside (u. a. verschiedene $O$ - und C-glykosidierte Polygalaxanthone; Jiang et al. 2005a und darin zitierte Literatur; P. tenuifolia);

- Mono- und Oligosaccharide;

- $5 \%$ fettes Öl mit Ölsäure als Hauptbestandteil (den leicht ranzigen Geruch einer überlagerten Droge bedingend).

Hinweis. In der frischen Pflanze kommt Primverosid vor, aus dem sich beim Trocknen durch die Einwirkung einer pflanzeneigenen Glucosidase Methylsalicylat bildet, das der nicht überlagerten Droge einen schwachen aromatischen Geruch verleiht.

Analytische Kennzeichnung. Fingerprint-DC (PhEur) der Saponine [Fließmittel: obere Phase einer Mischung von Essigsäure 99\%-Wasser-1-Butanol (10:40:50); Refe- 
D Abb. 24.21
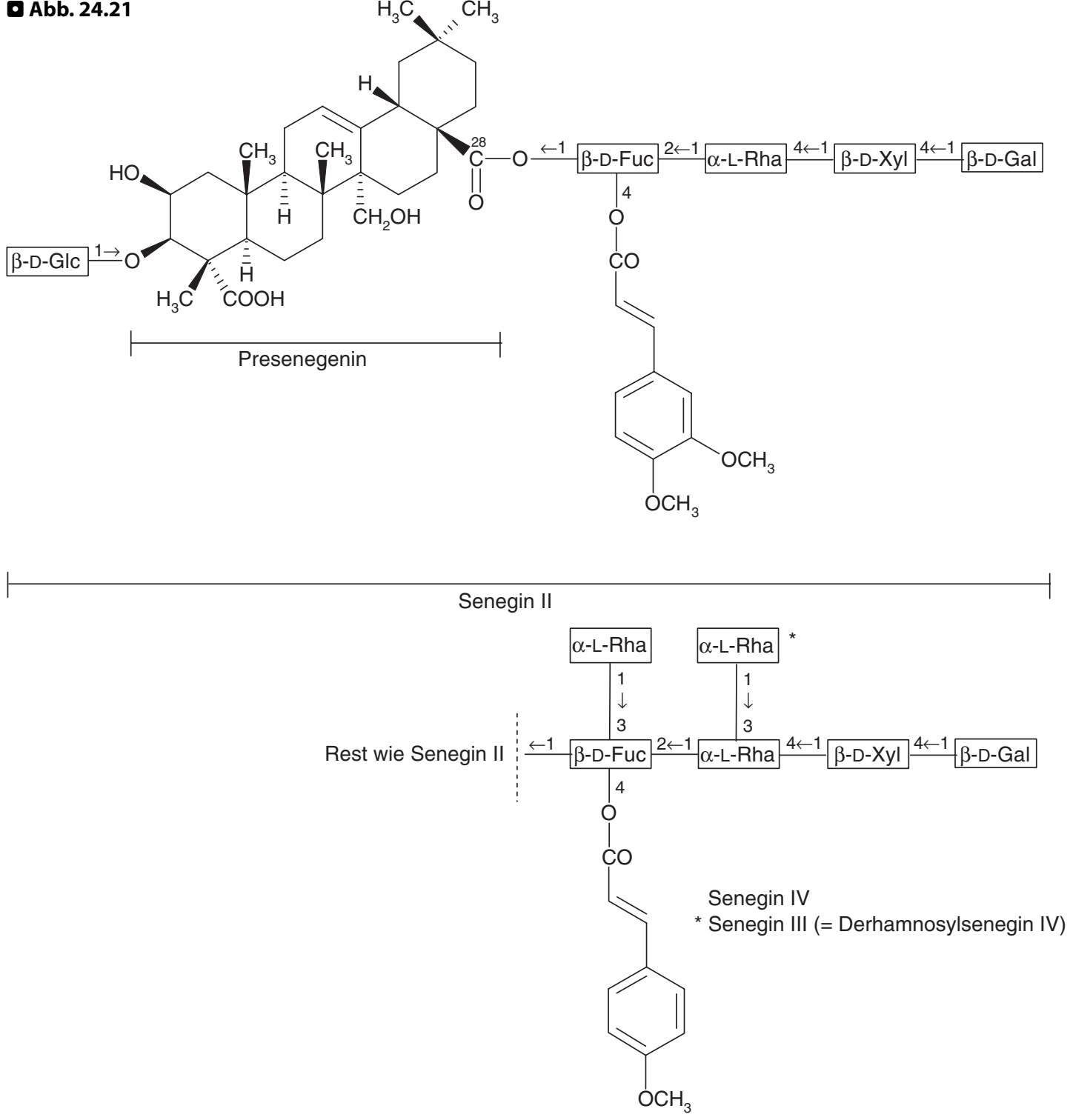

Hauptglykosid der Wurzel von Polygala senega ist das Senegin II, ein bisdesmosidisches Estersaponin. Das Aglykon Presenegenin ist mit der 3-OH-Gruppe an ein $\beta$-D-Glucosemolekül und mit dem 28-Carboxyl esterartig an ein lineares Tetrasaccharid gebunden. Die 4-OH-Gruppe des Fucosylrestes ist mit 3,4-Dimethoxyzimtsäure verestert. Die Senegine III (= Onjisaponin B) und IV enthalten einen verzweigten Penta- bzw. Hexasaccharidrest. Sie sind, abweichend vom Senegin II, im Fucoseteil nicht mit Dimethoxy-, sondern mit 4-Methoxyzimtsäure verestert. Die Onjisaponine (von P. tenuifolia) und die Senegasaponine (von P. senega var. latifolia) unterscheiden sich nur geringfügig im Zuckeranteil bzw. in der Substitution des Zimtsäurerests. Bei den Seneginen II-IV sowie den Senegasaponinen a-c kommen die Zimtsäurereste in der E- und Z-Form vor (Yoshikawa et al. 1995; 1996a) 
renzsubstanz: Aescin; Nachweis: Anisaldehydreagens]. Die Saponine erscheinen im Tageslicht als rote Banden, die sich bei der Nachbehandlung mit Molybdatophosphorsäure blau färben.

Verwendung. Als Teedroge (fein geschnittene oder grob pulverisierte Droge) und zur Herstellung von Sirup (z. B. Polygalae sirupus Helv 10) und Trockenextrakt (z. B. Polygalae extractum siccum normatum Helv 10). Viele Herstellungsverfahren für Senegaextrakte (auch diejenigen der Helv 10) schreiben einen Zusatz von Ammoniak vor, offenbar, um die Bildung von Niederschlägen zu verhindern. Als Estersaponine dürften die Senegawirkstoffe unter diesen Bedingungen kaum stabil sein, falls der $\mathrm{pH}$-Wert nicht genau überprüft wird.

Wirkungen und Anwendungsgebiete. Sekretolytisch, expektorierend. Bei Katarrhen der oberen Luftwege (Kommission E). Gemäß ESCOP sind die Indikationen: Husten mit Auswurf, Katarrh der Luftwege, chronische Bronchitis. Zur expektorierenden Wirkung $>$ Kap. 24.6.6.

Anmerkung. In der Kampo-Medizin in Japan sowie in der Traditionellen Chinesischen Medizin (TCM) werden die Wurzeln von P. tenuifolia $u$. a. wegen ihrer neuroprotektiven Wirkung zur Vorbeugung von Demenz verwendet. Neue Untersuchungen ergaben, dass der Wurzelextrakt von P. tenuifolia in vitro die Sekretion von $\beta$-Amyloid (vgl. dazu Infobox „Demenz“ und Text Wirkungsmechanismen; S. 1226 und 1228) hemmt (Jia et al. 2004 und darin zitierte Literatur).

Nebenwirkungen. Magen- und Darmreizung bei längerer Anwendung.

\section{Süßholzwurzel}

Herkunft. Süßholzwurzel (Liquiritiae radix PhEur 5, revidiert 5.5) besteht aus den getrockneten, ungeschälten oder geschälten Wurzeln und Ausläufern von Glycyrrhiza glabra L. und/oder G. inflata BATALin und/oder G. uralensis FIsch. (Familie: Fabaceae [IIB9a]). Die Droge stammt heute vorwiegend aus Kulturen.

Stammpflanzen. G. glabra, die bisher von der PhEur allein zugelassene Stammpflanze der Süßholzwurzel, ist eine mehrjährige, 1-1,5 m hohe, holzige Staude mit einem aus- gedehnten Wurzelsystem, das aus Pfahlwurzeln, Nebenwurzeln und zahlreichen, meterlangen Ausläufern besteht. Die Laubblätter sind unpaarig gefiedert mit deutlich fiedernervigen, kurz stachelspitzen Blättchen in 4-8 Paaren. Aus den Blattachseln entspringen die aufrechten, 10-15 cm langen Blütentrauben mit 20-30 Einzelblüten, die (je nach Varietät) unterschiedlich gefärbt sein können (blaulila, violett, weißrosa). Die Pflanze liebt sandige Böden und findet sich auf Ödland, in ausgetrockneten Flusstälern und Überschwemmungsgebieten. G. glabra ist im Mittelmeergebiet sowie in Teilen Russlands und Kleinasiens heimisch. Sie hat den Charakter einer Sammelart, die taxonomisch in mehrere Unterarten und Varietäten gegliedert wird. Dazu sowie bezüglich der verschiedenen geographischen Herkünfte machen die Arzneibücher allerdings keine Vorschriften. Der Handel unterscheidet:

- Spanisches Süßholz stammt von G. glabra var. typica Reg. et Herd.

- Russisches Süßholz stammt von G. glabra var. glandulifera WaLdst. et Kit. bzw. von G. uralensis Fisch.

- Chinesisches Süßßholz stammt von G. glabra und daneben insbesondere von G. inflata BATALIN und G. uralensis (beide seit dem Nachtrag 5.5 der PhEur als Stammpflanzen zugelassen).

- Türkisches Süßholz ist in seinen geschmacklichen Qualitäten dem besten spanischen Süßholz ebenbürtig. Es stammt überwiegend von G. glabra var. glandulifera.

Sensorische Eigenschaften. Geruch: schwach, aber charakteristisch mit einer schwer zu beschreibenden Geruchsnote. Geschmack: auffallend süß, mit leicht bitterem Nebengeschmack, oft auch etwas kratzend (in der PhEur nicht aufgeführt).

Inhaltsstoffe. Anmerkung: Die Süßholzwurzel gehört zu den am intensivsten untersuchten Drogen mit dem Ergebnis, dass ca. 400 Inhaltsstoffe beschrieben sind. Die Bedeutung vieler Untersuchungen ist schwer einzuordnen. Etliche dieser isolierten Stoffe sind wahrscheinlich Artefakte, die bei der Aufarbeitung entstehen; in anderen Fällen ist die botanische Herkunft nicht gesichert, sodass nicht abzuschätzen ist, ob die betreffende Substanz in allen Sorten auftritt; und schließlich fehlen sehr oft Konzentrationsangaben, sodass es sich um bloße Spurenstoffe handeln könnte. Im Folgenden sind nur mengenmäßig relevante Inhaltsstoffe berücksichtigt. Auf die Unterschiede des In- 


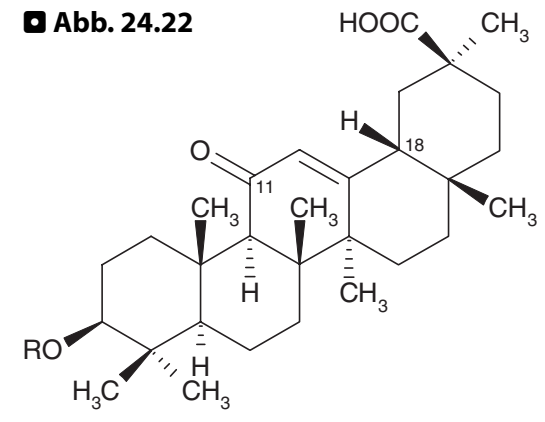<smiles>CCC(=O)CCC(=O)O</smiles><smiles>O=C1C[C@H](c2ccc(O)cc2)Oc2cc(O)ccc21</smiles><smiles>CCOc1ccc(/C=C/C(=O)c2ccc(O)cc2O)cc1</smiles>

Liquiritigenin $(\mathrm{R}=\mathrm{H})$

Liquiritin ( $R=\beta-D-G l u c o s e)$

Isoliquiritigenin $(\mathrm{R}=\mathrm{H})$
Isoliquiritin $(\mathrm{R}=\beta$-D-Glucose $)$

Charakteristischer Inhaltsstoff der Süßholzwurzel ist Glycyrrhizinsäure (GZ), die 170-mal stärker süß schmeckt als Rohrzucker (Mizutani et al. 1998) und eine dreibasische Säure darstellt, wobei zwei Carboxyle auf die beiden Glucuronsäuremoleküle (Glu) entfallen. Beide Glucuronsäuremoleküle liegen in der $\beta$-D-Form vor. Glycyrrhizinsäure zeigt kaum ausgeprägte Saponineigenschaften und besitzt praktisch keine hämolytische Aktivität. In der Pflanze liegt Glycyrrhizinsäure als Kalium- und Calciumsalz vor. Bei saurem pH fällt freie Glycyrrhizinsäure aus, der Hauptgrund dafür, warum bei der Extraktherstellung durch $\mathrm{NH}_{3}$ ZZusatz die nötige Basizität aufrechterhalten werden muss. Die stärkste Süßwirkung besitzt 3-Monoglucuronylglycyrrhizinsäure (941-mal süßer als Rohrzucker). Das Aglykon Glycyrrhetinsäure (GA) weist keinen süßen Geschmack mehr auf; andere Eigenschaften, wie antimikrobielle, mineralcorticoide und antiphlogistische Wirkung bleiben erhalten. Carbenoxolon, der Halbester der Bernsteinsäure mit GA, ist ein partialsynthetisches Produkt, das in Form des Dinatriumsalzes vorliegt. Seit Protonenpumpenhemmer und $\mathrm{H}_{2}$-Rezeptorantagonisten zur Ulcustherapie zur Verfügung stehen ( $>$ unter Risiken bei der Anwendung), hat die Substanz ihre medizinische Bedeutung weitgehend verloren. Im Carbenoxolon liegt wahrscheinlich ein Gemisch von $18 a-$ und $18 \beta-G A$ vor, in dem das $\beta$-Isomere überwiegt. Das Chalconderivat Isoliquiritigenin ist hauptverantwortlich für die spasmolytische Wirkung von Succus liquiritiae

haltsstoffspektrums der von der PhEur zugelassenen drei Arten wird nicht eingegangen.

- Triterpensaponine $[2-15 \%$; PhEur = mindestens $4,0 \%$ Glycyrrhizinsäure (GZ)], besonders Kalium- und Calciumsalze der Glycyrrhizinsäure (Glycyrrhizin) mit Glycyrrhetinsäure (GA) als Aglykon (จ Abb. 24.22); daneben kommen Saponine mit anderen Aglykonen vor;

- Flavonoide (1-2\%), darunter das gelb gefärbte Isoliquiritin und das isomere Liquiritin (? Abb. 24.22; (7) auch Kap. 26.5.3) sowie prenylierte Flavonoide und Isoflavonoide, u. a. Glabren, Glabridin, Licoricidin;
- saure Polysaccharide (Glycyrrhizan GA, Polysaccharide GP I und II); ferner

- Sterole, Cumarine, flüchtige Aromastoffe, mineralische Bestandteile, Zucker und Stärke.

\section{Analytische Kennzeichnung}

Identitätsprüfung. DC-Nachweis (PhEur) von GA und Isoliquiritigenin nach Hydrolyse mit verdünnter Salzsäure [Fließmittel: konzentrierte Ammoniaklösung-Wasser-Ethanol 96\%-Ethylacetat (1:9:25:65); Referenzsubstanzen: GA, Thymol; Nachweis UV $254 \mathrm{~nm}$ und Anisaldehydreagens]. Die GA wird durch Fluoreszenzminde- 
rung im UV $254 \mathrm{~nm}$ nachgewiesen. Sie erscheint nach Besprühen mit Anisaldehydreagens im Tageslicht als violette Zone, Isoliquiritigenin als gelbe Zone.

Gehaltsbestimmung. Der GZ-Gehalt wird in der PhEur mit der HPLC unter Verwendung von octadecylsilyliertem Kieselgel $(5 \mu \mathrm{m})$ als Säulenmaterial, Essigsäure 99\%-Acetonitril-Wasser (6:30:64) als Fließmittel und Monoammoniumglycyrrhizinat $C R S$ als Referenzsubstanz bestimmt.

\section{Verwendung}

- Als Teedroge - allein oder in industriell hergestellten Mischungen - zur Herstellung eines Infuses;

- zur Herstellung von Süßholzextrakten. Es lassen sich unterscheiden: Süßholztrockenextrakte [Liquiritiae extractum siccum normatum (DAC 2005); 5-7\% GZ], dickflüssige Süßholzextrakte (= Succus Liquiritiae) und Fluidextrakte. Der Süßholzwurzelfluidextrakt der PhEur 5 (Liquiritiae extractum fluidum ethanolicum normatum), herstellbar durch ein geeignetes Verfahren mit Ethanol 70\%, ist normiert und enthält mindestens 3,0 und höchstens 5,0\% GZ (HPLC). Trockenextrakte stellt man heute bevorzugt mittels Sprühtrocknung her;

- zur Herstellung von Lakritze. Bei traditioneller Herstellung wird das Erntegut zerkleinert und mit Wasser $\mathrm{zu}$ einem feinen, faserigen Brei zerrieben, der dann viele Stunden lang ausgekocht wird. Nach dem Kolieren und Absitzenlassen wird der Auszug in flachen Schalen über kleinem Feuer eingedickt. Heute erfolgt das Eindampfen in entsprechenden Verdampfern unter vermindertem Druck. Den noch warmen, zähflüssigen Extrakt gießt man in Formen, wo er erstarrt (Succus liquiritiae in Blockform). Zur Herstellung der Stangenform (Lakritzen) wird die halbfeste Masse maschinell durch Düsen verschiedener Größe gepresst und in Stücke geschnitten.

Über Feuer eingedickter Succus hat gegenüber den durch Vakuumeinengung gewonnenen Präparaten einen geringeren Gehalt an GZ (10-15\% gegenüber 20-25\%); auch ist der Anteil der glykosidisch gebundenen Flavonoide vermindert. Vakuumpräparate haben zudem eine hellere Farbe. Lakritzwaren bestehen nur zum geringen Teil aus Lakritze oder Süßholzextrakt (5-ca. 50\%; in der BRD mit einem Höchstgehalt an GZ von 0,2 g/100 g Lakritz). Zur Herstellung wird Mehl verkleistert und mit Zucker, Stärkesirup, Gelatine und eingedicktem Süßholzsaft vermischt und eingedickt. Nach Formgebung (durch Gießen oder maschinelles Pressen) zu Stangen, Bändern oder Figuren wird nachgetrocknet.

Metabolismus, Bioverfügbarkeit. Studien über den Metabolismus von GZ bei Mensch und Tier ergaben unterschiedliche Resultate. Nach oraler Verabreichung wird GZ beim Menschen durch die intestinale Flora, direkt oder via Glycyrrhetinsäuremonoglucuronid, zu GA abgebaut und in Form von GA resorbiert. Nach p.o.-Applikation von GZ an die Ratte wird GZ zum Teil resorbiert, allerdings ist die Bioverfügbarkeit niedriger als diejenige von GA (> Okamura et al. 2003 und darin zitierte Literatur). In Japan werden GZ-enthaltende Präparate entweder i.v. in Form von Injektionen oder p.o. in Form von Tabletten (Therapie chronischer Hepatitis) verwendet. Zur Verbesserung der Bioverfügbarkeit werden neben der parenteralen Verabreichung neue Anwendungsformen vorgeschlagen, z. B. die nasale oder rektale Verabreichung sowie die Zugabe von resorptionsfördernden Stoffen (z. B. Fettsäuren) zu Tabletten (Sasaki et al. 2003).

Wirkungen und Anwendungsgebiete. Für Süßholzextrakte sowie für einzelne Inhaltsstoffe sind im Laufe der Zeit in verschiedenen In-vitro- und In-vivo-Testmodellen eine ganze Palette von Wirkungen nachgewiesen worden, u. a. sekretolytische, expektorierende, antiulzerogene, antiphlogistische, spasmolytische, antimikrobielle, antivirale und antioxidative Wirkungen.

Aus der Sicht der Phytotherapie sind insbesondere die folgenden Wirkungen hervorzuheben: sekretolytisch/ expektorierend, antiulzerogen/antiphlogistisch, antiviral und spasmolytisch. Darauf basiert mindestens teilweise die Anwendung als Expektorans bei Husten und Bronchialkatarrh und als Adjuvans zur Therapie von Magen- und Duodenalgeschwüren sowie von Gastritis (ESCOP). Weitere Anwendungen von Süßholz und Süßholzextrakten sind der Einsatz als Geschmackskorrigenzien für Arzneimittel sowie in der Süßwarenindustrie.

Als Wirkstoffe für die sekretolytisch/expektorierende, antiphlogistisch/antiulzerogene und antivirale Wirkung gelten sowohl GZ als auch GA, während für die spasmolytische Aktivität die Flavonoide im Vordergrund stehen:

- Sekretolytisch/expektorierende Wirkung: Der Wirkungsmechanismus der sekretolytisch/expektorierenden und insbesondere der sekretomotorischen Wirkung ist wissenschaftlich nicht belegt. Er dürfte aber auf der Oberflächenaktivität der Saponine beruhen. 
- Antiulzerogene Wirkung: Die antiulzerogene Wirkung wird in erster Linie mit der antiphlogistischen Wirkung der GZ und GA erklärt. Nachweisbar sind eine Verminderung der Pepsinaktivität, eine Erhöhung der Viskosität des Magenschleimes sowie eine Verlängerung der Lebensdauer der Epithelzellen der Magenschleimhaut. Neben einer Hemmung von 5-Lipoxygenase, Radikalbildung und Lipidperoxidation steht hauptsächlich die Hemmung von Enzymen im Vordergrund, die den Steroidstoffwechsel beeinflussen. Die Hauptwirkung beruht darauf, dass GZ und GA die Inaktivierung von Nebennierenrindenhormonen in der Leber hemmen. Damit wird eine indirekte Corticoidwirkung entfaltet (> Abb. 24.23). Inwieweit die antiulzerogene Wirkung mit der wachstumshemmenden Wirkung gegenüber Helicobacter pylori (Fukai et al. 2002) zusammenhängt, muss durch weitere experimentelle Untersuchungen abgeklärt werden.

- Antivirale Wirkung: In neuerer Zeit steht insbesondere die antivirale Wirkung der GZ im Vordergrund des Interesses. GZ hemmt in vitro das Wachstum einer Reihe von DNA- und RNA-Viren, wie z. B. das HIV-1-, Hepatitis-C- (HCV), Herpes-simplex-Typ-1- (HSV-1-) und das Epstein-Barr-Virus (EBV), ferner Flaviviren (Gelb- und Dengue-Fieber, Hirnhautentzündung) und Coronaviren (SARS-CoV $=$ „SARS-associated coronavirus"). GZ erwies sich von fünf getesteten Substanzen (neben GZ = Ribavirin, 6-Aza-Uridin, Pyrazofurin, Mycophenolsäure) als diejenige mit der größten Wirksamkeit gegen die Vermehrung des SARS-CoV. GZ verminderte dabei nicht nur die Virusreplikation, sondern auch die Adsorption des Virus an und die Penetration in die Wirtszelle. Am wirksamsten war GZ, wenn die Substanz sowohl während wie auch nach der Adsorptionsphase an die Wirtszelle verabreicht wurde. Als Wirkungsmechanismus wird die Hemmung bzw. die Induktion von Botenstoffen des Zellstoffwechsels postuliert (Cinatl et al. 2003 und darin zitierte Literatur). Neben HSV-1 ist GZ in der Lage, die latente Infektion beim Kaposi-Sarkom assoziierten Herpesvirus (KSHV) zu beenden. GZ reduziert dabei die Synthese eines viralen Latenzproteins, was schlussendlich zur Apoptose der infizierten Zellen führt. Ob GZ oder GZ-Derivate zur Behandlung von Krankheiten eingesetzt werden können, die durch latente Virusinfektionen verursacht werden, ist im Augenblick nicht absehbar (vgl. Curreli et al. 2005). Das- selbe gilt für Derivate von GZ, z. B. GZ-Glykopeptide, die die Aktivität gegen SARS-CoV stark erhöhen (Hoever et al. 2005). Bisher wurde GZ an Patienten mit HIV-1 und chronischen HCV-Infektionen verabreicht.

- Spasmolytische Wirkung: Die spasmolytische Wirkung wird durch die Aglykone der Flavonoide, insbesondere durch das Isoliquiritigenin, verursacht.

$\mathrm{Zu}$ weiteren Wirkungen (z. B. östrogene, antihepatotoxische, antiproliferative (vgl. dazu Infobox „Tumorhemmendes Potential von Pflanzenstoffen“; S. 979), zytoprotektive, immunstimulierende) von Süßholzextrakten bzw. einzelner Inhaltsstoffe sowie den dazu postulierten Wirkungsmechanismen liegen Dutzende von neuen Arbeiten vor, auf die hier nicht näher eingetreten werden kann.

Risiken bei der Anwendung. Unerwünschte Wirkungen sind in erster Linie bei Missbrauch zu befürchten. Bei längerer Anwendung und höherer Dosierung können mineralocorticoide Wirkungen auftreten (vgl. () Abb. 24.23). Die gesteigerte Wasserretention führt zu einer vermehrten Wassereinlagerung mit Schwellungen im Bereich von Gesicht und Fußgelenken, nicht selten auch zu Bluthochdruck mit dem Warnsymptom Kopfschmerzen. Die gesteigerte Kaliumausscheidung bewirkt eine Hypokaliämie mit Folgeerscheinungen wie Müdigkeit und Muskelschwäche.

Die Anwendung von Süßholz und Süßholzpräparaten darf nicht langfristig und unkontrolliert erfolgen. Da die indirekte Corticoidwirkung bei längerer Einnahme ausgeprägt eintritt, muss die Therapiedauer auf 4-6 Wochen eingeschränkt werden. Zur Behandlung peptischer Ulzera sollten heute Protonenpumpenhemmer $\left(\mathrm{H}^{+} / \mathrm{K}^{+}\right.$-ATPase-Blocker) und $\mathrm{H}_{2}$-Rezeptorantagonisten eingesetzt werden.

Bei cholestatischen Lebererkrankungen, Leberzirrhose, Hypertonie, Hypokaliämie, schwerer Niereninsuffizienz und während der Schwangerschaft muss gänzlich von einer Anwendung abgesehen werden (Kommission $\mathrm{E}$ ).

Sowohl Carbenoxolon (Kommission B5) als auch GZ (Kommission B6) wurden von den entsprechenden Aufbereitungskommissionen negativ beurteilt.

Wechselwirkungen. Bei gleichzeitiger Einnahme von Saluretika oder von Digitalisglykosiden wird durch Kaliumverluste die Wirkung dieser Medikamente verstärkt. 
D Abb. 24.23

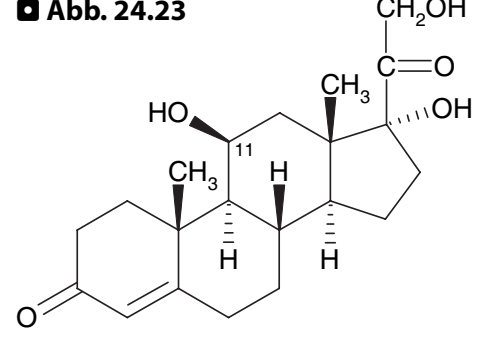

Cortisol

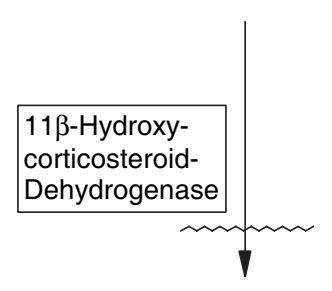<smiles>C[C@]12CC(=O)[C@H]3CCC4=CC(=O)CC[C@]4(C)[C@H]3[C@H]1CC[C@]2(O)C(=O)CO</smiles>

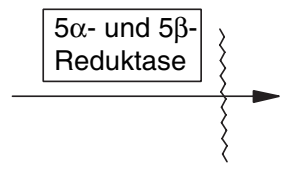

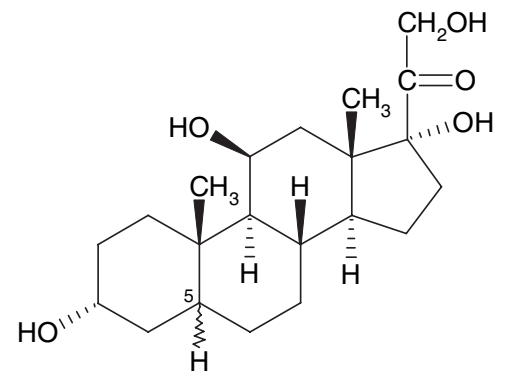

$5 \beta(+5 \alpha)$-Tetrahydrocortisol Biotransformation von Cortisol

\section{Cortison}

Glycyrrhizinsäure (GZ) und Glycyrrhetinsäure (GA) erzeugen bei längerer Einnahme von Süßholzpräparaten einen Pseudoaldosteronismus. Die dabei auftretende Natriumretention wird durch Veränderung des Cortisolmetabolismus erzeugt. Die Substanzen hemmen die Aktivität der 11 $\beta$-Hydroxycorticosteroid-Dehydrogenase, die für den Abbau von Cortisol zu Cortison verantwortlich ist. Daneben werden weitere Enzyme wie die $5 \alpha-/ 5 \beta$-Reduktasen sowie die $3 a-/ 3 \beta$-Hydroxysteroid-Dehydrogenasen gehemmt, was eine verzögerte Ausscheidung von Aldosteron und Cortisol zur Folge hat. Durch die Hemmung dieser Enzyme resultiert ein hoher Cortisolspiegel. Dieser erzeugt Natriumretention durch Bindung an den Typ 1 der renalen Mineralcorticoidrezeptoren und damit verbunden die bekannten Mineralcorticoideffekte (vgl. z. B. Kageyama et al. 1992 sowie Übersicht von Størmer et al. 1993). Unklarheiten existieren immer noch bezüglich der eigentlichen Wirkstruktur. Nach älteren Angaben ist GA wirksamer als GZ und wirkt insbesondere in der $\beta$-Form. Neuere Angaben tendieren dahin, dass 18a- und 18ß-GA eine unterschiedliche Hemmwirkung auf einzelne Enzyme aufweisen (z. B. Akao et al. 1992) bzw. dass weder GZ noch GA, sondern 3-Monoglucuronylglycyrrhizinsäure für die Erzeugung des Pseudoaldosteronismus hauptverantwortlich ist (Kato et al. 1995) 


\section{! Kernaussagen}

Süßholzpräparate werden als Expektorans und als Adjuvans zur Therapie von Magen- und Duodenalgeschwüren sowie von Gastritis verwendet. Als wirksamkeitsbestimmende Inhaltsstoffe für die sekretolytisch/ expektorierende sowie die antiphlogistisch/antiulzerogene Wirkung gelten Glycyrrhizinsäure (GZ) und Glycyrrhetinsäure (GA), für die spasmolytische insbesondere das Chalconderivat Isoliquiritigenin. GZ und GA erzeugen bei längerer Einnahme von Süßholzpräparaten aufgrund einer indirekten Corticoidwirkung einen Pseudoaldosteronismus, weshalb die Therapiedauer auf 4-6 Wochen eingeschränkt werden muss. Zur Behandlung peptischer Ulzera sollte daher heute der Verabreichung von Anticholinergika und $\mathrm{H}_{2}$-Antagonisten der Vorzug gegeben werden. GZ gilt dank einer ausgeprägten antiviralen Wirkung als Virustatikum. Aufgrund seiner starken Süßwirkung werden Süßholz und Süßholzextrakte als Geschmackskorrigenzien für Arzneimittel sowie in der Süßwarenindustrie verwendet.

\section{Asiatisches Wassernabelkraut}

Herkunft. Asiatisches Wassernabelkraut (Centellae asiaticae herba PhEur 5) besteht aus den getrockneten, oberir- dischen Teilen von Centella asiatica (L.) URbAN (Familie: Apiaceae [IIB25a]). C. asiatica (syn. Hydrocotyle asiatica L.) ist eine in tropischen Teilen Asiens (besonders Indiens, Indonesiens und Südchinas) sowie auf Madagaskar heimische Pflanze. Sie wächst an sumpfigen Stellen und an Bachläufen. Das immergrüne, kriechende Kaut hat einen auf dem Boden liegenden Stängel, der an den Knoten wurzelt und lang gestielte, nierenförmige Blätter sowie eine gestielte Blütendolde mit kleinen, hellvioletten Doldenblüten aufweist.

Centella-asiatica-Kraut wurde auf Madagaskar zur Behandlung lepröser Wunden verwendet; in Indien außerdem gegen Syphilis. Man verwendete den frischen Pflanzensaft innerlich und äußerlich. Asiaticosid wurde 1942 von J. Bontemps in reiner Form isoliert; die Konstitutionsaufklärung gelang ebenfalls einer französischen Arbeitsgruppe um J. Polonsky (1951-1959).

Sensorische Eigenschaften. Wassernabelkraut hat einen scharfen, würzigen Geschmack.

\section{Inhaltsstoffe}

- Triterpensaponine sowie freie Triterpensäuren [1 bis 8\% (vgl. Übersicht von Brinkhaus et al. 2000); PhEur $=$ mind. 6,0\% Gesamt-Triterpenderivate, berechnet als Asiaticosid; $>$ Abb. 24.24];

- Flavonoide [verschiedene Quercetin- (z. B. Petuletin) und Kämpferolderivate (z. B. Kämpferol-3-O- $\beta-\mathrm{D}-$ glucuronid)];

Wassernabelkraut enthält als therapeutisch wichtige Inhaltsstoffe pentacyclische Triterpensaponine. Bei den Hauptinhaltsstoffen Asiaticosid bzw. Madecassosid ist ein Trisaccharid esterartig mit der Säuregruppe eines Triterpens vom Ursantyp (Asiatsäure bzw. 6-Hydroxyasiatsäure) verknüpft. Je nach Herkunft der Pflanzen existieren verschiedene chemische Rassen, bei denen der Gehalt und die Zusammensetzung der Triterpene stark variieren kann (vgl. Übersicht von Brinkhaus et al. 2000). Neu beschriebene Esterglykoside aus in Sri Lanka und Vietnam kultivierten Pflanzen sind die Centellasponine A, B, C und D sowie Scheffoleosid A (Matsuda et al. 2001 a, 2001b). Die Asiaticoside C-F und Scheffursosid B konnten kürzlich aus in China gesammelten Pflanzen isoliert und in der Struktur aufgeklärt werden (Jiang et al. 2005b). Scheffeolosid A und Scheffursosid B wurden erstmals aus Schefflera octophylla (LOUR.) HARMS (Araliaceae [IIB25b]) von Maeda et al. (1994) isoliert. 6-Hydroxyasiatsäurearabinosid ist das erste Triterpenglykosid von C. asiatica, bei dem der Zucker (Arabinose) über das Hydroxyl an C-3 glykosidisch verknüpft ist (Shukla et al. 2000). Betulinsäure (> Abb. 24.16), ein Triterpen vom Lupantyp, ist bisher nur in Form der freien Säure isoliert worden. Da die Trennung und Reindarstellung der Esterglykoside aus C. asiatica früher schwierig war, finden sich in der älteren chemischen Literatur viele überflüssige Namen und widersprüchliche Angaben (vgl. dazu auch Hegnauer 1973). So müssen z. B. das Vorkommen und die Strukturen von Brahmosid, Brahminosid, Thankunisid und Isothankunisid überprüft werden. Der Name Asiaticosid A sollte gestrichen werden, da Madecassosid für diese Struktur Priorität hat. Anmerkung: Die Aglykone ohne Trivialnamen von Scheffoleosid A, Scheffursosid B, Centellasponin D, Asiaticosid C, D und F sind in der Abbildung nicht aufgeführt (vgl. dazu Maeda et al. 1994; Matsuda et al. 2001 b; Jiang et al. 2005b) 
D Abb. 24.24
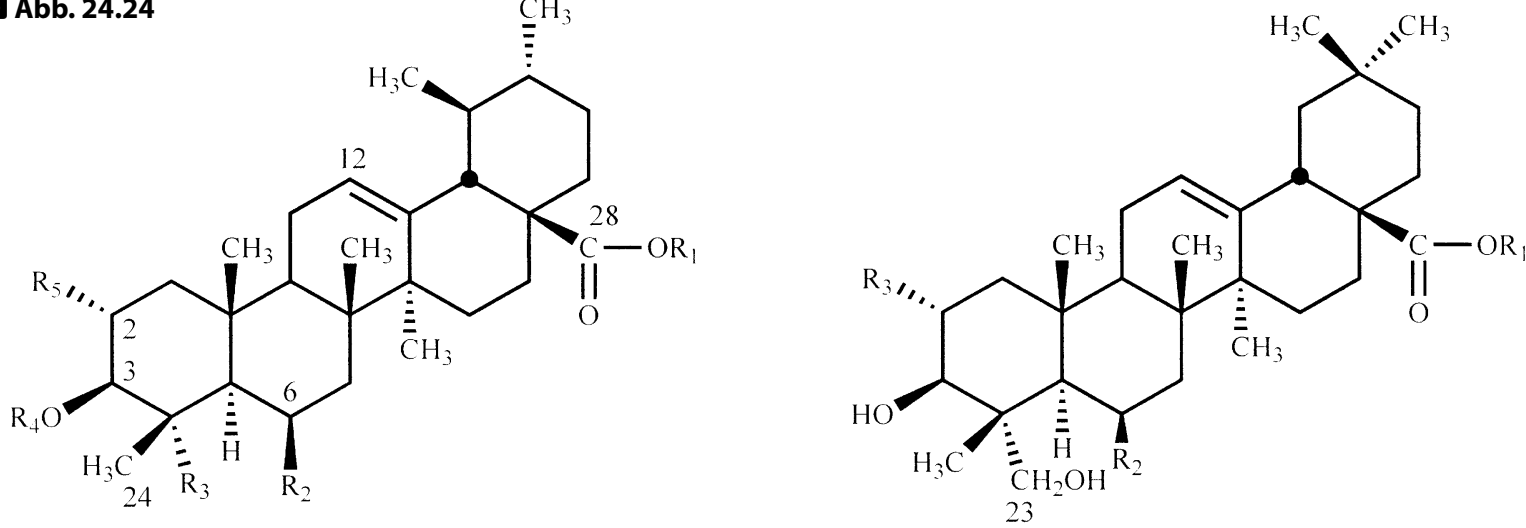

\begin{tabular}{|llllll|}
\hline & $\mathrm{R}_{1}$ & $\mathrm{R}_{2}$ & $\mathrm{R}_{3}$ & $\mathrm{R}_{4}$ & $\mathrm{R}_{5}$ \\
\hline Asiatsäure & $\mathrm{H}$ & $\mathrm{H}$ & $\mathrm{CH}_{2} \mathrm{OH}$ & $\mathrm{H}$ & $\mathrm{OH}$ \\
Asiaticosid & Glc-Glc-Rha & $\mathrm{H}$ & $\mathrm{CH}_{2} \mathrm{OH}$ & $\mathrm{H}$ & $\mathrm{OH}$ \\
Asiaticosid C & Glc-Glc-Rha & $\mathrm{H}$ & $\mathrm{CH}_{2} \mathrm{OAc}$ & $\mathrm{H}$ & $\mathrm{OH}$ \\
Asiaticosid D & Glc-Glc-Rha & $\mathrm{H}$ & $\mathrm{CH}_{3}$ & $\mathrm{H}$ & $\mathrm{OH}$ \\
Asiaticosid E & Glc-Glc & $\mathrm{H}$ & $\mathrm{CH}_{2} \mathrm{OH}$ & $\mathrm{H}$ & $\mathrm{OH}$ \\
Asiaticosid F & Glc-Glc-Rha & $\mathrm{H}$ & $\mathrm{CH}_{2} \mathrm{OH}$ & $\mathrm{H}$ & $\mathrm{H}$ \\
6-Hydroxyasiat-/Madecasssäure & $\mathrm{H}$ & $\mathrm{OH}$ & $\mathrm{CH}_{2} \mathrm{OH}$ & $\mathrm{H}$ & $\mathrm{OH}$ \\
Madecassosid (Asiaticosid A) & Glc-Glc-Rha & $\mathrm{OH}$ & $\mathrm{CH}_{2} \mathrm{OH}$ & $\mathrm{H}$ & $\mathrm{OH}$ \\
Centellasaponin B & Glc-Glc & $\mathrm{OH}$ & $\mathrm{CH}_{2} \mathrm{OH}$ & $\mathrm{H}$ & $\mathrm{OH}$ \\
6-Hydroxyasiatsäurearabinosid & $\mathrm{H}$ & $\mathrm{OH}$ & $\mathrm{CH}_{2} \mathrm{OH}$ & $\mathrm{Ara}$ & $\mathrm{OH}$ \\
Madasiatsäure & $\mathrm{H}$ & $\mathrm{OH}$ & $\mathrm{CH}_{3}$ & $\mathrm{H}$ & $\mathrm{OH}$ \\
Centellasaponin C & Glc-Glc-Rha & $\mathrm{OH}$ & $\mathrm{CH}_{3}$ & $\mathrm{H}$ & $\mathrm{OH}$ \\
Scheffursosid B & Glc-Glc-Rha & $\mathrm{H}$ & $\mathrm{CHO}_{3}$ & $\mathrm{H}$ & $\mathrm{OH}$ \\
\hline
\end{tabular}

\begin{tabular}{|llll|}
\hline & $\mathrm{R}_{1}$ & $\mathrm{R}_{2}$ & $\mathrm{R}_{3}$ \\
\hline Terminolsäure & $\mathrm{H}$ & $\mathrm{OH}$ & $\mathrm{OH}$ \\
Asiaticosid B & Glc-Glc-Rha & $\mathrm{OH}$ & $\mathrm{OH}$ \\
Scheffoleosid A & Glc-Glc-Rha H & $\mathrm{OH}$ \\
Centellasaponin D & Glc-Glc-Rha & $\mathrm{OH}$ & $\mathrm{H}$ \\
\hline
\end{tabular}

\begin{tabular}{|c|c|c|c|c|c|}
\hline Glc-Glc-Rha $=$ & $\leftarrow 1$ & $\beta-\mathrm{D}-\mathrm{Glc}$ & $6 \leftarrow 1$ & $\beta$-D-Glc & $4 \leftarrow 1 \alpha-\mathrm{a}-\mathrm{Rha}$ \\
\hline Glc-Glc $=$ & $\leftarrow 1$ & $\beta$-D-Glc & $6 \leftarrow 1$ & $\beta$-D-Glc & \\
\hline $\operatorname{Ara}=$ & $\leftarrow 1$ & $\alpha$-L-Ara & & & \\
\hline
\end{tabular}

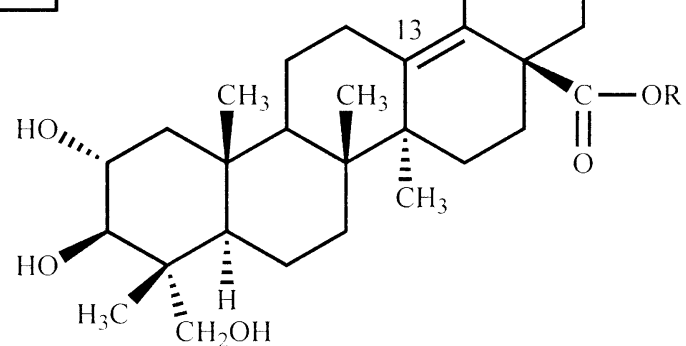

\begin{tabular}{|ll|}
\hline & $\mathrm{R}$ \\
\hline $\begin{array}{ll}\text { Centellasapogenol A } \\
\text { Centellasaponin A }\end{array}$ & H \\
\hline
\end{tabular}


- ätherisches Öl (0,1\% mit Mono- und Sesquiterpenkohlenwasserstoffen; Hauptkomponenten sind $\beta$-Caryophyllen, trans- $\beta$-Farnesen, Germacren D);

- Stigmasterol, Sitosterol, 2,5-Dihydroxybenzoesäure, verschiedene Aminosäuren, wenig $\alpha$-Tocopherol.

\section{Analytische Kennzeichnung}

Prüfung auf Identität. Fingerprint-DC der Triterpenderivate (PhEur) [Fließmittel: Essigsäure-AmeisensäureWasser-Ethylacetat (11:11:27:100), Referenzsubstanz: Asiaticosid; Nachweis: Anisaldehyd-Reagens]. Nach dem Besprühen mit dem Reagens erscheinen die Zonen für die beiden Saponine Asiaticosid und Madecassosid im Tageslicht grünlichblau bzw. violett und diejenigen für die freien Triterpensäuren Asiatsäure und Madecasssäure hellblau bzw. rosaviolett gefärbt.

Gehaltsbestimmung. Quantitative HPLC-Bestimmung (PhEur) von Asiaticosid unter Verwendung von octadecylsilyliertem Kieselgel $(5 \mu \mathrm{m})$ als Säulenmaterial, einem Gemisch aus Acetonitril und 0,25\% Phosphorsäure als mobile Phase, und Asiaticosid als Referenzsubstanz.

Verwendung. Zur Herstellung von alkoholischen und wässrigen, meistens Triterpen angereicherten Extrakten (TTF), die zu Phytopharmaka in Form von Kapseln, Tabletten, Tropfen, Salben und Puder, insbesondere für die Indikationen Wundheilung und chronische venöse Insuffizienz [vgl. Infobox "Chronische venöse Insuffizienz (CVI)“; S. 969], verarbeitet werden.

Metabolismus und Pharmakokinetik. Eine Studie zum Metabolismus und zur Pharmakokinetik einer angereicherten Triterpenfraktion von C. asiatica nach p.oVerabreichung an den Menschen ergab, dass Asiaticosid in Asiatsäure umgewandelt wird (Grimaldi et al. 1990). Eindeutig interpretierbare Resultate zur Pharmakokinetik sind erst nach einer noch ausstehenden Untersuchung der Reinstoffe Asiaticosid und Madecassosid zu erwarten.

Wirkungen und Wirkungsmechanismen. Für Extrakte von C. asiatica sind insbesondere antiulzeröse (ulkusprotektive), antimikrobielle, wundheilungsfördernde und antiphlogistische Wirkungen nachgewiesen worden. Als Wirkstoffe gelten die Triterpene (Esterglykoside und freie Säuren; vgl. Übersicht von Brinkhaus et al. 2000). Als mögliche Mechanismen der Wirkung von Asiaticosid
(0,2\%, topische Anwendung) bei der Wundheilung, werden u. a. die Anregung der Kollagenbiosynthese, die Erhöhung der antioxidativen Kapazität des Gewebes, die Stimulierung der Angiogenese durch Anregung von Wachstumsfaktoren sowie die Hemmung der Expression und Aktivität von iNOS diskutiert (Guo et al. 2004 und darin zitierte Literatur). Die Behandlung von Psoriasis wird einer antiproliferativen Wirkung von Asiaticosid und Madecassosid (vergleichbar mit Dithranol) zugeschrieben (Sampson et al. 2001).

In einer kürzlich durchgeführten Arbeit wurde die Veränderung der Expression von 1053 Humangenen an menschlichen Fibroblasten (Zellkultur) mit der Gen-Microarray-Technologie und der „,real-time reverse transcription polymerase chain reaction" (Real-time-RT-PCR) unter Verwendung einer definierten Triterpenfraktion [,tritrated extract" von C. asiatica (TECA $=40 \%$ Asiaticosid, $30 \%$ Asiatsäure, $30 \%$ Madecasssäure)] sowie den Reinstoffen Asiaticosid, Asiatsäure, Madecassosid und Madecasssäure untersucht. Die Behandlung mit TECA beeinflusste Gene verschiedener Wachstumsfaktoren sowie solche, die an der Angiogenese und der Modulation der extrazellulären Matrix beteiligt sind. Von den 1053 analysierten Genen wurden 7,8\% (82) durch TECA moduliert, am stärksten TNFAIP6 (= Tumor-Nekose-Faktor-Alpha-induziertes Protein 6). TNFAIP6 spielt eine zentrale Rolle bei der Modulation der extrazellulären Matrix und im Entzündungsgeschehen (antiinflammatorische Eigenschaften). Die Resultate ergaben, dass die reine Asiatsäure und etwas weniger die Madecasssäure die stärkste Genmodulation erzeugten und dass die Veränderungen der Genexpression die klinischen und biochemischen Daten zur Anwendung von Centalla-asiatica-Triterpenen bei CVI, Mikroangiopathie und Ödemen unterstützen (Coldren et al. 2003).

Anwendungsgebiete. Klinik: p.o. zur Behandlung der CVI, topisch zur Beschleunigung der Wundheilung, bei Verbrennungen, Ekzemen, Geschwüren sowie bei Psoriasis.

Die bisher durchgeführten klinischen Studien sind mit Extrakten bzw. TTF-Präparaten durchgeführt worden, insbesondere bei Patienten mit CVI. Die Dosierung lag zwischen 30 und $60 \mathrm{mg} /$ Tag. Neben Plazebo wurde als Vergleichspräparat Venoruton ${ }^{\circledR}$ (Hydroxyethylrutinpräparat) eingesetzt. Zur Beurteilung des Behandlungserfolgs wurden plethysmographische Messungen sowie Messungen des Knöchelumfangs, des vaskulären Tonus, des Ve- 
nendrucks, der Kapillarpermeabilität und der Mikrozirkulation verwendet. In den meisten Fällen waren die Studienergebnisse signifikant besser als mit Plazebo. Die Studien sind allerdings nicht miteinander vergleichbar, da sie mit unterschiedlich hergestellten und zusammengesetzten, oft nichtstandardisierten Präparaten erfolgt sind. Neue, GCP-konforme Studien sind erforderlich, bevor die therapeutische Anwendung bei CVI vertreten werden kann.

Untersuchungen zur besseren Wundheilung wurden mit dem Präparat Madecassol ${ }^{\circledR}$ durchgeführt. Es handelt sich dabei um einen Extrakt aus C. asiatica mit 40\% Asiaticosid, 29-30\% Asiat-, 29-30\% Madecasssäure und $1 \%$ Madasiatsäure. Die wundheilungsfördernde Wirkung wird dem Asiaticosid bzw. dem Triterpengemisch zugeschrieben. Die Substanzen sollen über die Regulation der Fibroblastenaktivität direkt in den Vernarbungsprozess eingreifen und regulierend auf die Bildung neuen Bindegewebes einwirken (vgl. Übersicht von Brinkhaus et al. 2000).

Unerwünschte Wirkungen. Vereinzelt sind Magenbeschwerden und Übelkeit, nach topischer Anwendung seltene Fälle von Kontaktdermatitis beobachtet worden.

\section{! Kernaussagen}

Asiatisches Wassernabelkraut enthält als wirksamkeitsbestimmende Inhaltsstoffe Triterpensaponine sowie freie Triterpensäuren. Die Anwendung geschieht in Form von Triterpen angereicherten Extrakten entweder p.o. zur Behandlung der chronischen venösen Insuffizienz oder topisch zur Beschleunigung der Wundheilung. Die Triterpene wirken ulkusprotektiv, wundheilungsfördernd und antiphlogistisch, wobei der Asiatsäure die stärkste Wirkung zugeschrieben wird.

\section{Efeublätter}

Herkunft. Efeublätter (Hederae folium PhEur 5.1) bestehen aus den im Frühling geernteten, getrockneten Blättern von Hedera helix L. (Familie: Araliaceae [IIB25b]). Der Efeu ist eine in Europa heimische, bis $20 \mathrm{~m}$ hoch werdende und mit Haftwurzeln kletternde immergrüne Holzpflanze. Die Laubblätter der Pflanze sind verschieden gestaltet: die unteren, jugendlichen, dunkelgrünen, ledrigen Blätter sind gelappt; die oberen, länglich-eiförmigen, hellgrünen, an blühenden Zweigen sitzenden Blätter, sind ganzrandig.

Sensorische Eigenschaften. Die Droge weist einen schwachen, eigenartigen Geruch auf; sie schmeckt bitter und etwas kratzend.

\section{Inhaltsstoffe}

- Triterpensaponine [4-5\%); vorwiegend bisdesmosidische Glykoside mit Hederagenin und Oleanolsäure als Aglykone (\$ Abb. 24.25); PhEur = mindestens 3,0\% Hederacosid C]. Aus Frischmaterial hergestellte Auszüge enthalten im Wesentlichen Hederacosid $\mathrm{C}$, daneben kommen in kleinen Mengen Hederacosid B, die Hedera-Saponine D-I sowie Monodesmoside [u. a. $\alpha$-Hederin (vgl. Legende zu $>A b b$. 24.25)] vor;

- Flavonoidglykoside mit Rutin, Kämpferol-3-O-rhamnoglucosid, Isoquercitrin, Astragalin; daneben die Aglykone Quercetin und Kämpferol;

- Phenolcarbonsäuren (Chlorogen-, Neochlorogen-, 4,5- und 3,5-o-Dicaffeoylchinasäure, Rosmarin-, Kaffee- und Protocatechusäure); ferner

- Polyacetylene (Falcarinon, Falcarinol), ätherisches Öl mit hauptsächlich Mono- und Sesquiterpenen, Sterole und Cumarine.

\section{Analytische Kennzeichnung}

Identitätsprüfung. DC-Nachweis (PhEur) von Hederacosid $\mathrm{C}$ und $\alpha$-Hederin [Fließmittel: wasserfreie Ameisensäure-Methanol-Aceton-Ethylacetat (4:20:20:30); Referenzsubstanzen: Hederacosid C und $\alpha$-Hederin; Nachweis: ethanolische Schwefelsäure]. Hederacosid C erscheint nach dem Besprühen im Tageslicht als violette, $\alpha$-Hederin als sehr schwache violette Zone.

Gehaltsbestimmung. Quantitative HPLC-Bestimmung (PhEur) von Hederacosid C unter Verwendung von octadecylsilyliertem Kieselgel $(5 \mu \mathrm{m})$ als Säulenmaterial, einem Gradienten bestehend aus Acetonitril-Wasser (140:880; eingestellt mit Phosphorsäure auf einen $\mathrm{pH}$ von 2,0) sowie Phosphorsäure-Acetonitril (2:998) als mobile Phase und Hederacosid C als Referenzsubstanz.

Verwendung. Zur Herstellung insbesondere eines Efeublättertrockenextrakts (Prospan ${ }^{\circledR}, 30 \%$ Ethanol, DEV 5-7,5:1), der in Form von Hustensaft, Tropfen, Tabletten und Suppositorien Anwendung findet. 
- Abb. 24.25

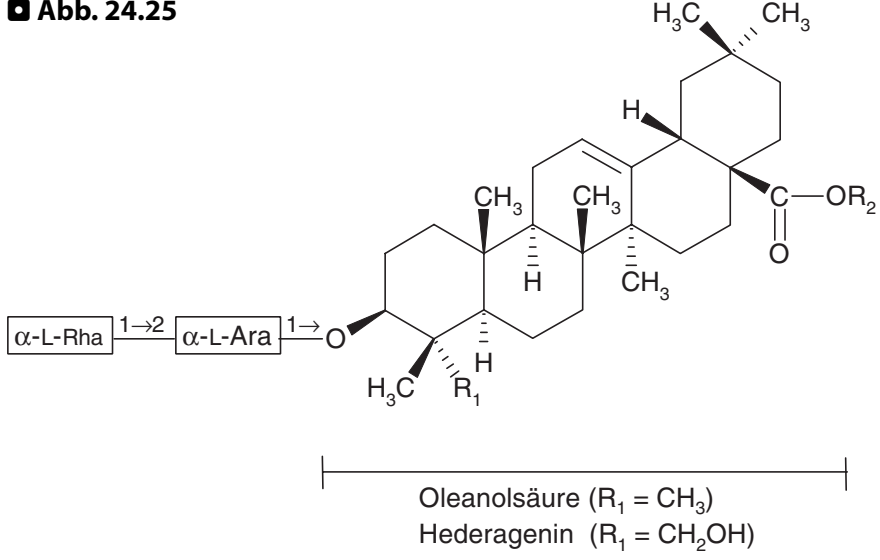

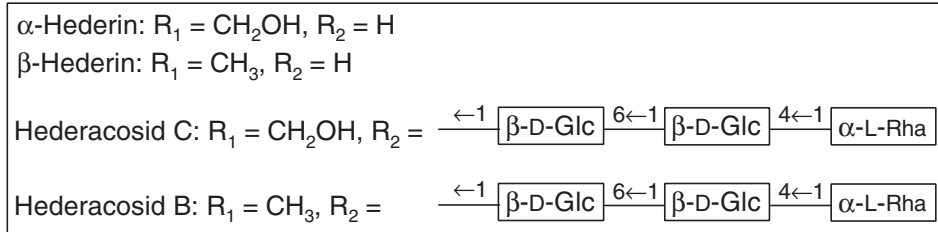

Die genuinen Saponine des Efeublatts gehören zu den Bisdesmosiden. Die Glykosidesterbindung an C-28 ist relativ locker; bereits beim Trocknungsvorgang sowie bei der Aufarbeitung von frischen Efeublättern kann die Kette abgespalten werden: Es entstehen die sauren Monodesmoside $\alpha$ - und $\beta$-Hederin. Lässt man z. B. bei der Aufarbeitung frische Efeublätter im zerkleinerten Zustand über Nacht im Wasser stehen, findet man kein Hederacosid C mehr, sondern nur noch a-Hederin (Wagner u. Reger 1986). In geringen Mengen ist neben weiteren Hederasaponinen Hederacosid B vorhanden, das beim enzymatischen Abbau $\beta$-Hederin liefert

Wirkungen. Efeublätterextrakt wirkt expektorierend und leicht spasmolytisch. Daraus hergestellte Fertigarzneimittel sollten in erster Linie die genuinen bisdesmosidischen Triterpensaponine enthalten. Neue In-vitro-Untersuchungen ergaben, dass dem Monodesmosid $\alpha$-Hederin ein indirekter $\beta_{2}$-adrenerger Effekt zukommt, wodurch sich gemäß Runkel et al. (2005) die in klinischen Studien nachgewiesene sekretolytische und bronchospasmolytische Wirkung des Extrakts plausibel erklären lässt. Folge der Stimulation der $\beta_{2}$-adrenergen Rezeptoren ist eine vermehrte Bildung von Surfactant in den Alveolarepithelzellen (sekretolytischer Effekt) sowie eine Reduktion des intrazellulären $\mathrm{Ca}^{2+}$-Spiegels in den Bronchialmuskelzellen (bronchospasmolytischer Effekt). Über den Gehalt an $\alpha$-Hederin in den Handelspräparaten existieren keine wissenschaftlichen Mitteilungen. Er sollte allerdings aus toxikologischen Gründen ( $>$ unten) nur gering sein. Die Forderung der PhEur nach einem Mindestgehalt von 3,0\% Hederacosid C ist sinnvoll, obwohl die Substanz selbst keinen Einfluss auf die regulatorischen Prozesse der $\beta_{2}$-adrenergen Rezeptoren hat. Hederacosid kann als Prodrug aufgefasst werden, da es in vivo durch Esterasen in $\alpha$-Hederin umgewandelt wird (Übersicht von Runkel et al. 2005). Biopharmazeutische Untersuchungen zu den Efeutriterpenen am Menschen liegen bisher nur in Form einer Pilotstudie (Schmidt 2003) vor. Erst detaillierte pharmakokinetische Studien werden mehr Klarheit über die Bioverfügbarkeit der Saponine und den postulierten Wirkungsmechanismus ergeben.

Natives Hederacosid C und das Folgeglykosid $\alpha-\mathrm{He}$ derin unterscheiden sich in ihren Eigenschaften außerordentlich: $\alpha$-Hederin ist wesentlich toxischer sowie wesentlich stärker hämolytisch wirkend (H.I. $=150.000$, vgl. $>$ Tabelle 24.4); es weist (im Tierexperiment) ferner antiexsudative (ödemausschwemmende) Eigenschaften auf, die dem Hederacosid C völlig fehlen; es wirkt ferner schleimhautreizend und ist zytotoxisch. Die Aglykone der Hedera-Saponine erwiesen sich in vitro als potente Inhibitoren der lysosomalen Enzyme Elastase und Hyaluronidase (Facino et al. 1995) [vgl. dazu auch Abschnitt Ross- 
kastaniensamen und Aescin (S. 967) und Abschnitt Mäusedornwurzelstock (S. 986)].

Anwendungsgebiete. Efeublätterextrakte werden bei Katarrhen der oberen Luftwege sowie symptomatischer Behandlung chronisch-entzündlicher Bronchialerkrankungen angewendet (Kommission E). Gemäß ESCOP sind die Indikationen Husten mit übermäßig starker Sekretion von viskösem Schleim; Adjuvans zur Behandlung entzündlicher Bronchialerkrankungen. Efeuextrakte und Hederine enthaltende Präparate eignen sich aufgrund der antiödematösen Wirkung zur äußerlichen Anwendung, z. B. zur Behandlung von Cellulitis. Es wird postuliert, dass im Falle der topischen Anwendung von Extraktpräparaten auch die Saponinglykoside auf der Haut zur Wirkung kommen, da die Aglykone durch Hydrolasen in der Zellmembran freigesetzt werden (Facino et al. 1995). Eine Besprechung der mit Efeuextraktpräparaten (insbesondere mit Prospan ${ }^{\circledR}$ ) durchgeführten kontrollierten klinischen Studien (versus Ambroxol als Standard bzw. plazebokontrolliert) findet sich bei Schulz u. Hänsel 2004. Gemäß einer dieser Studien ist der Efeublätterextrakt in seiner Wirksamkeit dem synthetischen Mukolytikum Ambroxol ebenbürtig.

Unerwünschte Wirkungen. Allergische Kontaktdermatitis ist insbesondere bei intensivem Kontakt mit Efeupflanzen beobachtet worden. Die Sensibilisierungspotenz ist mittelstark. Hauptallergen ist das Falcarinol.

\section{Seifenrinde, Quillaja-Saponine}

Herkunft, Eigenschaften. Ausgangsmaterial zur Herstellung der Quillaja-Saponine ist die Quillaja-, Panama- oder Seifenrinde (Quillaiae cortex Helv 10, Quillajae cortex DAC 2005), die 9-10\% Saponine enthält. Die QuillajaRinde besteht aus der getrockneten, von Kork und Außenrinde weitgehend befreiten Rinde von Stämmen und Ästen von Quillaja saponaria Mol. (Familie: Rosaceae [IIB11a]), das sind immergrüne, stattliche, in Chile, Peru und Bolivien heimische Bäume. Die Quillaja-Saponine (7) Abb. 24.26) stellen ein weißes, stark zum Niesen reizendes Pulver von anfangs süßem, dann bitterem Geschmack dar. Sie bilden mit Wasser noch in großer Verdünnung sehr stabile Schäume.
Wirkungen, Anwendungsgebiete. Die Seifenrinde wird nur noch selten als Expektorans verwendet. Heute werden vorwiegend Quillaja-Saponine dank ihrem starken Schäumungsvermögen u. a. als Suspensionsstabilisator verwendet, z. B. bei der Herstellung der Steinkohlenteerlösung (Tinctura oder Liquor carbonis detergens) bzw. in der kosmetischen Industrie als Zusatz zu Haarwässern und Shampoos, um das Nachfetten der Haare zu verzögern.

Die Quillaja-Saponine haben eine Bedeutung als Adjuvanzien zur Herstellung von Impfstoffen und zur Förderung der Resorption von Peptiden und Aminoglykosidantibiotika erlangt. Quillaja-Saponine wie QS-21 verstärken, Impfstoffen in geringen Mengen zugesetzt, deren Immunogenität. Insbesondere bei der Entwicklung eines erfolgreichen Impfstoffes gegen das HIV-1-Virus ist ein wirksamer Hilfsstoff, der die humorale und zellvermittelte Immunantwort induziert, erforderlich. Für die Erzeugung einer Immunantwort sind die intakten genuinen Saponine erforderlich. Deacylierte Verbindungen wie die Saponine DS-1 und DS-2 (vgl. $>$ Abb. 24.26) zeigen diese Wirkung nicht mehr (Cleland et al. 1996).

DS-1 eignet sich aber zur Resorptionsförderung von Arzneistoffen, die wie die Peptide bei oraler oder topischer Anwendung nicht wirksam sind. Im Gegensatz zu Detergenzien und Cholaten haben Saponine wie DS-1 keine Reizwirkung bei topischer Anwendung. DS-1 erzeugt keine Immunantwort, fördert aber die systemische Aufnahme von Aminoglykosidantibiotika bei nasaler Applikation und von Peptiden wie Insulin bei topischer Anwendung an der Nase und am Auge in sehr kleinen Konzentrationen (Pillion et al. 1995). Der Wirkungsmechanismus ist bisher nicht im Detail aufgeklärt. Es wird angenommen, dass die von QS-21 und DS-1 erzeugten Wirkungen durch eine Interaktion der Substanzen mit biologischen Membranen (Oberflächenaktivität der Saponine) zustande kommen, was zur Stimulierung einer Immunantwort bzw. zur Förderung der Resorption führt (Pillion et al. 1996; Kensil et al. 1996). In neueren Arbeiten wurde die Stimulierung verschiedener Zytokine nachgewiesen (Villacres-Eriksson et al. 1997; Behboudi et al. 1999; Boyaka et al. 2001).

Kernaussagen

Quillaja-Saponine haben neben ihrem technischen Einsatz als Suspensionsstabilisator eine Bedeutung als Adjuvanzien von Impfstoffen sowie zur Förderung der Resorption von Peptiden und Aminoglykosidantibiotika. 


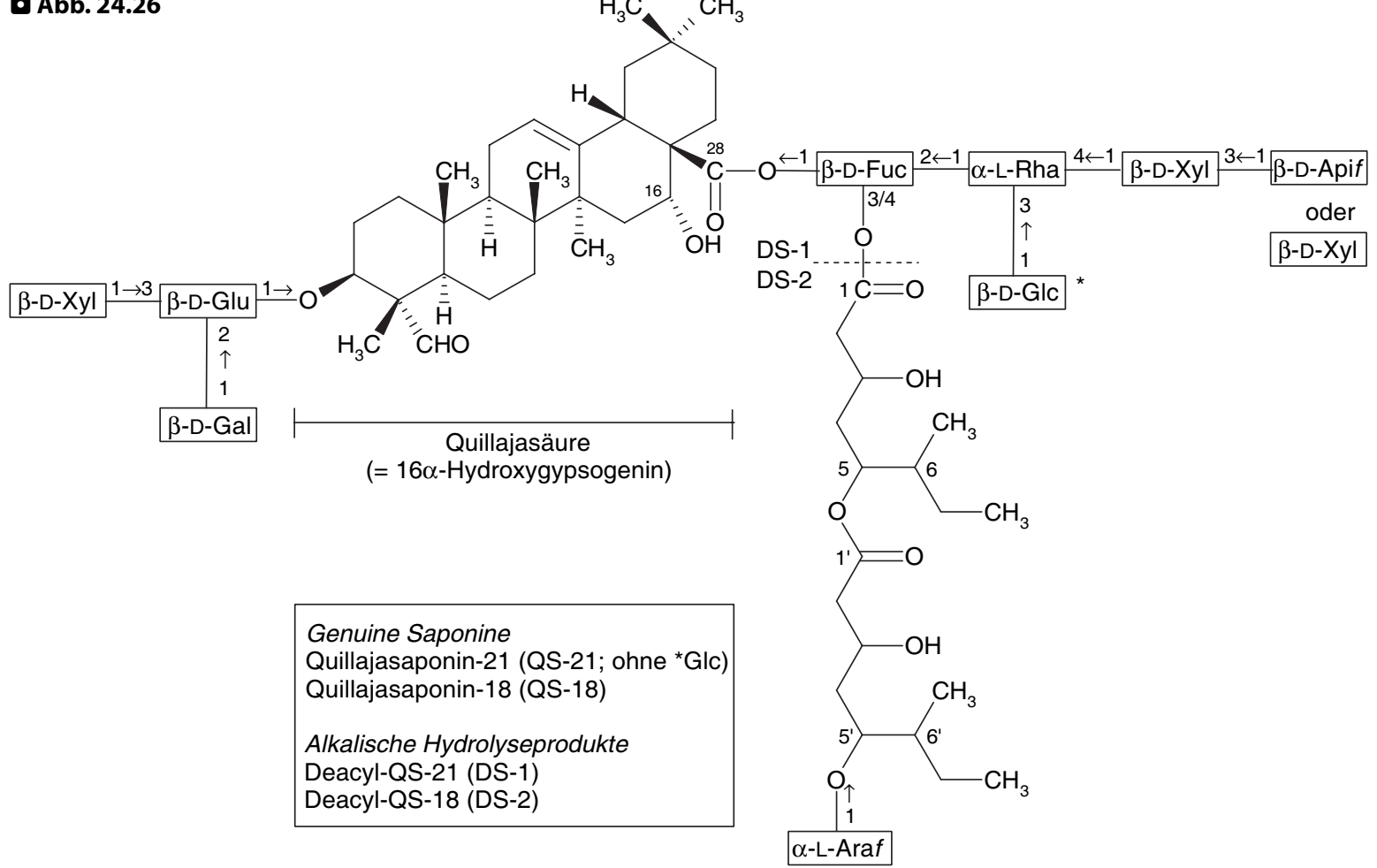

Die Saponine der Seifenrinde stellen ein komplexes Gemisch dar. Bei den Hauptsubstanzen handelt es sich um bisdesmosidische Saponine, deren Aglykon Quillajasäure mit der 3-OH-Gruppe an ein verzweigtes Trisaccharid (über Glucuronsäure; Glu) und mit dem 28-Carboxyl esterartig an ein lineares Tetra- bzw. verzweigtes Pentasaccharid verknüpft ist. Die 3- bzw. 4-OH-Gruppe des Fucosylrestes ist über eine Fettsäurekette, bestehend aus 2 Molekülen (3S, 5S, 6S)-3,5-Dihydroxy-6-methyloctansäure (C-9-Säure), verknüpft, deren Kettenabschluss Arabinose darstellt. In Lösung findet an der Fucose ein Acyltransfer statt. Bei der Hauptkomponente (QS-21A; 94\%) ist die Fettsäurekette über die 4-OH-Gruppe, bei der Nebenkomponente (QS-21B; 6\%) über die 3-OH-Gruppe der Fucose gebunden. Als Endzucker der Acylsaccharidkette liegt zu 65\% Apiose bzw. zu 35\% Xylose vor (Cleland et al. 1996). QS-21 A mit einer Apiose als Endzucker kann heute synthetisch hergestellt werden (Wang et al. 2005a). Neben den in der Abbildung formelmäßig wiedergegebenen Quillajasaponinen QS-18 und QS-21 kommen weitere Saponine in der Seifenrinde vor. Zwischen 1998 und 2003 sind ca. 50 Saponine mit einer ähnlichen Struktur bekannt geworden (vgl. Nyberg et al. 2003 und darin zitierte Literatur). Häufig handelt es sich um regioisomere Verbindungen, bei denen eine Acylwanderung stattgefunden hat. Einzelne Saponine haben an C-3 bzw. C-4 der Fucose eine O-Acetylgruppe, was die Acylwanderung verunmöglicht, bei anderen konnte Phytolaccagensäure als Aglykon nachgewiesen werden, wiederum bei anderen wurde anstelle der C-9- eine C-5-Acylgruppe [(S)-2-Methylbuttersäure] bzw. eine Disaccharidkette an der 3-OH-Gruppe gefunden. Neben den Bisdesmosiden kommen auch Monodesmoside (ohne C-28-Substitution) vor

\section{Rosskastaniensamen}

Herkunft. Rosskastaniensamen (Hippocastani semen DAB 1999) bestehen aus den getrockneten Samen von Aesculus hippocastanum L. (Familie: Sapindaceae [IIB18e], bisher Hippocastanaceae). Die Rosskastanie ist auf dem
Balkan, im Kaukasus und in Vorderasien beheimatet. Die großen Blätter des bis $30 \mathrm{~m}$ hoch werdenden Baumes sind 5- bis 7-zählig gefiedert und die Teilblätter am Rande gezähnt. Die Blüten sind zygomorph und vereinigen sich zu aufrechten Rispen. Die Frucht ist eine mit Stacheln besetzte, grüne Kapselfrucht, die sich bei der Reife mit 2 oder 3 
Klappen öffnet. Sie enthält i. d. R. nur einen Samen mit einer glänzend rotbraunen Samenschale und einer weißen, vom Nabel herrührenden Stelle. Eine Monographie Hippocastani semen für die PhEur ist in Bearbeitung.

Sensorische Eigenschaften. Rosskastaniensamen haben einen anfangs mehligen, dann kratzend und anhaltend bitteren Geschmack.

\section{Inhaltsstoffe}

- Triterpensaponine (3-6\%; DAB = mindestens 3,0\%) mit Protoaescigenin und Barringtogenol $\mathrm{C}$ als Aglykone (จ Abb. 24.27);
- Flavonoide, v. a. Glykoside des Quercetins und Kämpferols (Hübner et al. 1999);

- Gerbstoffe und Cumarine (in der Samenschale), Vitamine B und C, Sterole, wenig ätherisches Öl; ferner

- Zucker, Stärke und andere Polysaccharide, fettes Öl, Purine, Proteine, Mineralstoffe.

\section{Analytische Kennzeichnung}

Prüfung auf Identität. DC-Nachweis von Aescin (DAB) [Fließmittel: die obere Phase einer Mischung von Essigsäure 98\%-Wasser-1-Butanol (10:40:50); Referenzsubstanz: Aescin; Nachweis: UV 254 nm, Anisaldehydreagens]. Das Aescin ist im UV $254 \mathrm{~nm}$ als Fluoreszenz mindernde Zone

- Abb. 24.27

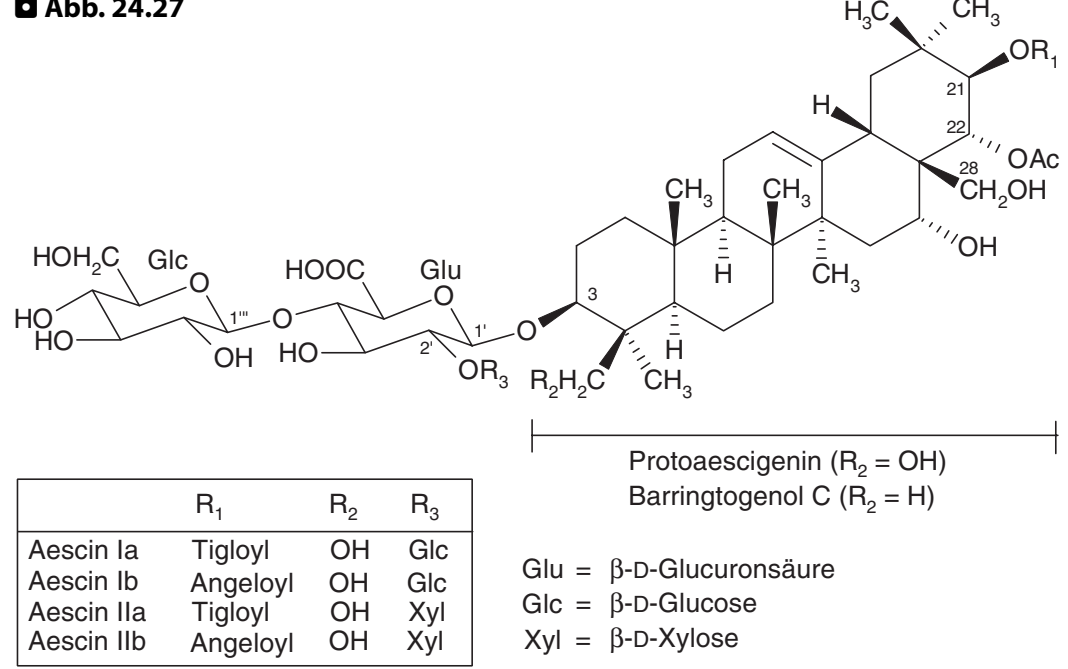

Rosskastaniensamen enthalten ein komplex zusammengesetztes Gemisch von Triterpensaponinen. Nach Untersuchungen der Arbeitsgruppe von Yoshikawa (Yoshikawa et al. 1996b u. 1998; Übersicht von Yoshikawa u. Matsuda 2000) konnten aus den Rosskastaniensamen 9 Aescine $(\mathrm{la}, \mathrm{lb}, \mathrm{Ila}$, Il $\mathrm{lb}, \mathrm{Illa}, \mathrm{Ill} b, \mathrm{IV}, \mathrm{V}, \mathrm{VI})$ und drei Isoaescine $(\mathrm{la}, \mathrm{lb}, \mathrm{V})$ isoliert und in der Struktur aufgeklärt werden. Die in der Formel wiedergegebenen Aescine la/b und lla/b stellen die Hauptsubstanzen dar. Die Aglykone der Aescine sind Diester des Protoaescigenins und Barringtogenols C, die über die OH-Gruppe an C-3 mit einem verzweigten Trisaccharid aus Glucuronsäure und 2 Glucosen oder Glucose und Galactose bzw. Xylose verknüpft sind. Die OH-Gruppe an C-21 ist mit kurzkettigen Fettsäuren (Tiglin-, Angelica-, Isobutter- oder 2-Methylbuttersäure), die OH-Gruppe an C-22 mit Essigsäure verestert (Ausnahme: Isoaescine, vgl. unten).

Nach einer früher durchgeführten Lösungsmittelfraktionierung wurde zwischen den drei Aescinfraktionen $\beta$-Aescin, a-Aescin und Kryptoaescin unterschieden. Mit $\beta$-Aescin wird ein leicht erhältliches, in Wasser schwer lösliches Mischkristallisat bezeichnet. Nach Griffini et al. (1997) entsprechen die Aescine la/b und lla/b den bei der LC-MS-Analyse erhaltenen Hauptprodukten von $\beta$-Aescin. Mit $\alpha$ - und Kryptoaescin werden gut wasserlösliche Substanzgemische bezeichnet, bei denen die Essigsäure durch Acylwanderung von C-22 an C-28 verschoben ist. Die genaue Zusammensetzung von a- und Kryptoaescin ist allerdings bisher nie mit modernen spektroskopischen Methoden abgeklärt worden. Möglicherweise sind sie mit den Isoaescinen identisch, bei denen es sich wahrscheinlich um Artefakte handelt, die durch Acylwanderung der Essigsäure (C-22 $\rightarrow$ C-28) während des Isolierungsprozesses (in schwach saurer Lösung) entstehen (vgl. Übersicht von Yoshikawa u. Matsuda 2000) 
und nach Besprühen mit Anisaldehydreagens im Tageslicht als blauviolett gefärbte Zone erkennbar.

Die DAB-Vorschrift hat keine Aussagekraft über die Zusammensetzung des Aescingemisches, da sich die Saponine nicht auftrennen lassen. Dazu eignet sich heute am besten die HPLC in Kombination mit der Massenspektrometrie (LC-MS). Die LC-MS ermöglicht ein Fingerprintchromatogramm der Haupt- und Nebensubstanzen von Aescin (Griffini et al. 1997).

Gehaltsbestimmung. Die Triterpensaponine werden nach Abtrennung der Saponine aus einer salzsauren Lösung durch Ausschütteln mit 1-Propanol-Chloroform und Reaktion mit Eisen(III)-chlorid-Essigsäure photometrisch bei $540 \mathrm{~nm}$ bestimmt.

Wegen der komplexen Zusammensetzung von Aescin sind chromatographische Methoden zur Gehaltsbestimmung weniger geeignet. Für die Aescinbestimmung bei pharmakokinetischen Studien ist es gelungen, spezifische Antikörper gegenüber den Säuresubstituenten an C-21, C-22 und C-28 des Triterpenteils herzustellen und daraus eine RIA-Methode (Radioimmunosorbent-Assay) zu entwickeln (vgl. Oschmann et al. 1996 und darin zitierte Literatur). Mit dieser Methode ist die Bestimmung von Aescin im Plasma im Bereich von 10-200 ng/ml möglich.

Verwendung. Rosskastaniensamenkerne oder Samenschrot ist Ausgangsmaterial zur Herstellung von Aescin ( $\beta$-Aescin; DAC 2003) und zur Herstellung von Extrakten, z. B. des eingestellten Rosskastaniensamentrockenextrakts (Hippocastani extractum siccum normatum DAB 2003). Maximale Aescinausbeuten werden durch Extraktion mit Ethanol-Wasser- oder Methanol-Wasser-Gemischen (Ethanol- bzw. Methanolgehalt etwa 40-60\%) erzielt. Aescin enthaltende Präparate bzw. Rosskastaniensamenextrakte werden in verschiedenen galenischen Formen als Monopräparate (Aescin) oder als Bestandteil von Kombinationspräparaten (Extrakte) für die Indikationsgruppe chronische venöse Insuffizienz (vgl. Infobox) angeboten; ferner zur äußerlichen Anwendung als Gel und Salbe.

Hinweise zur Bioverfügbarkeit und Pharmakokinetik. Aescin, als Extrakt gegeben, wird zu etwa 10\% aus dem Magen-Darm-Trakt aufgenommen. Die Absorptionsquote der Reinsubstanz, die in röntgenamorpher Form vorliegt, ist wenig höher. Die Plasmahalbwertszeit ist kurz. Eine Besonderheit des Aescins besteht darin, dass die vol-

\section{Infobox}

Chronische venöse Insuffizienz (CVI). Venenerkrankungen zählen zu den häufigsten Krankheitsbildern in der mitteleuropäischen Bevölkerung. Unter dem Begriff CVI werden unterschiedliche Störungen des venösen Abflusses zusammengefasst. Sie wird heute meist nach ihrer Erscheinungsform in drei Schweregrade eingeteilt, wobei Grad I charakterisiert wird durch tagsüber auftretende Knöchelund Unterschenkelödeme, Schwere- und Spannungsgefühl oder Schmerzen in den Beinen sowie die Erweiterung subkutaner Venen (Corona phlebectatica). Dauerhafte Ödeme, zusätzliche Hyper- und Depigmentierung der Haut und/oder Induration (Verhärtung und Verdichtung) des Unterhautgewebes zeigen den Grad II der CVI an. Floride bzw. abgeheilte Geschwüre sind die Zeichen für den III. Schweregrad. Nichtoperative Therapieansätze sind Kompressionstherapie, physikalische und medikamentöse Therapie, u. a. mit Extrakten aus asiatischem Wassernabelkraut, Mäusedornwurzelstock, Rosskastaniensamen, Steinkleekraut, Buchweizenkraut, rotem Weinlaub sowie mit isolierten Flavonoiden wie Diosmin, Hesperidin, Rutin und Rutinderivaten.

le Wirkung einer Dosis erst nach $15-20 \mathrm{~h}$ erreicht wird. Aescin haftet lang am Gefäßendothel (Halbwertszeit der Wirkung zwischen 3 und 5 Tagen; Felix 1992). Humanpharmakokinetische Resultate, die auf dem RIA (vgl. unter Gehaltsbestimmung) beruhen, ergaben, dass nach p.o.Verabreichung von Rosskastaniensamenextrakt entsprechend $50 \mathrm{mg}$ Aescin nach $2 \mathrm{~h}$ maximale Serumspiegel von 9-10 $\mathrm{ng} / \mathrm{ml}$ erhalten wurden, was einer Bioverfügbarkeit um 5\% entspricht. Die terminale Halbwertszeit lag bei ca. $20 \mathrm{~h}$, diejenige in der $\alpha$-Phase bei $8 \mathrm{~h}$. Zwischen Retardformulierungen (z. B. Retard-Filmtablette, Pellet) und schnell freisetzenden Formulierungen (Lösung) waren nur minimale Unterschiede (im maximalen Serumspiegel, Streuung der Serumspiegelwerte) feststellbar. Daher besteht keine Veranlassung, für eine Therapie mit Rosskastanienextrakt den Einsatz eines Retardpräparates zu fordern, wie es in der Monographie der Kommission E erfolgt ist (Dittgen et al. 1996; Oschmann et al. 1996; Bässler et al. 2003). Zur Pharmakokinetik und Bioäquivalenz von Rosskastanienzubereitungen vgl. auch Übersicht von Loew u. Schrödter 1999. 
Wirkungen. Aescin wirkt in verschiedenen experimentellen Modellen (z. B. Rattenpfotenödem) antiexsudativ und gefäßabdichtend. Durch Senkung der Gefäßpermeabilität wird die Filtration kleinmolekularer Proteine, Elektrolyte und Wasser in das Interstitium verhindert (Kommission E). Rosskastaniensamenextrakte besitzen ödemprotektive, venentonisierende, entzündungshemmende und antioxidative Wirkungen (vgl. Übersicht von Bombardelli et al. 1996). Aescin hemmt in vitro ähnlich wie Hedera-helix- und Ruscus-aculeatus-Saponine (> S. 964 und 986) lysosomale Enzyme. Dadurch wird die Gefäßwand wieder abgedichtet und der Übertritt von Flüssigkeit in das Gewebe verhindert. Aescin hemmt allerdings nur die Hyaluronidase, während die Aktivität der Elastase nicht beeinflusst wird (Facino et al. 1995).

Anwendungsgebiete. Fertigarzneimittel auf Extrakt- und Aescinbasis (Tagesdosis $100 \mathrm{mg}$ Aescin) werden zur Behandlung von Beschwerden bei Erkrankungen der Beinvenen (CVI), z. B. Schmerzen und Schweregefühl in den Beinen, nächtliche Wadenkrämpfe, Juckreiz und Beinschwellungen verwendet (Kommission E; ESCOP). Es liegen dazu verschiedene randomisierte, kontrollierte Doppelblindstudien vor (vgl. systematischer Review von Pittler u. Ernst 1999, 2004), die die kurzfristige klinische Wirksamkeit belegen.

Gemäß den Empfehlungen der Kommission E sollten bei einer Therapie mit Rosskastanienpräparaten weitere vom Arzt verordnete nichtinvasive Maßnahmen wie z. B. Wickel an den Beinen, Stützstrümpfe oder kalte Wassergüsse unbedingt eingehalten werden. Eine neuere Studie ergab, dass die Einnahme von Rosskastaniensamenextrakt bei CVI genauso gut gegen Ödeme wirkt wie eine Behandlung mit Kompressionsstrümpfen, mit einer zudem besseren Compliance (Diehm et al. 1996).

Topische Zubereitungen werden bei traumatischen Schwellungen (z. B. Sportverletzungen) sowie bei Veneninsuffizienz eingesetzt.

\section{! Kernaussagen}

Rosskastaniensamen enthalten als wirksamkeitsbestimmende Inhaltsstoffe Triterpensaponine (Aescin). Aescin hat antiexsudative und gefäßabdichtende, Rosskastaniensamenextrakte besitzen ödemprotektive, venentonisierende und entzündungshemmende Wirkungen. Hauptanwendungsgebiet ist die CVI.
Nebenwirkungen. Aescin weist als Saponin schleimhautreizende Eigenschaften auf. Daher können nach Einnahme Aescin enthaltender Präparate Magenbeschwerden auftreten.

\section{Ginsengwurzel}

Herkunft. Ginsengwurzel (Ginseng radix PhEur 5, revidiert 5.1) besteht aus den getrockneten (weißer Ginseng) oder den mit Dampf behandelten und getrockneten (roter Ginseng) Wurzeln von Panax ginseng C. A. Meyer (Familie: Araliaceae [IIB25b]). P. ginseng ist eine mehrjährige Staudenpflanze, die in den Bergwäldern der Mandschurei und Nordkoreas wild vorkommt. Die in Europa angebotene Handelsware kommt ausschließlich aus Kulturen; Hauptproduzent ist Südkorea, daneben kommt heute immer mehr Droge auch aus China.

Stammpflanze und Ginsengkulturen. Panax-ginsengPflanzen werden etwa $60 \mathrm{~cm}$ hoch, der Stängel trägt 3-4 Verzweigungen, die jeweils 4-5 Blätter besitzen, die wie Kastanienblätter angeordnet sind. Die grünlich-gelben Blüten bilden eine Dolde; der Fruchtknoten ist unterständig und entwickelt sich zu einer roten, etwa erbsengroßen Beere, die 2 Samen enthält. Von der Aussaat der Samen bis zur Ernte der Wurzel liegt ein Zeitraum von 4-6 Jahren. Die Pflanzen gedeihen ihrem natürlichen Vorkommen entsprechend nur im Halbschatten und müssen deshalb künstlich beschattet werden. Die Wurzeln sind bei der Ernte 8 bis maximal $20 \mathrm{~cm}$ lang und etwa $2 \mathrm{~cm}$ dick; sie weisen Verzweigungen auf. Zur Gewinnung der Ganzdroge werden die dünneren Enden von Haupt- und Nebenwurzeln abgeschnitten. Die abgeschnittenen Teile bilden als „slender tails“ ein eigenes Handelsprodukt.

Sensorische Eigenschaften. Die Droge hat einen schwachen, eigenartigen Geruch und schmeckt schwach würzig, anfangs leicht bitter, dann süßlich und etwas schleimig.

Handelssorten. Abhängig von der Art der Drogenverarbeitung nach der Ernte unterscheidet man weißen und roten Ginseng.

- Weißer Ginseng: Die frisch geernteten Wurzeln werden gewaschen, die Nebenwurzeln entfernt. Nach dem Abschaben und einem Bleichprozess mit $\mathrm{SO}_{2}$ erfolgt Trocknen an der Sonne oder auch künstlich bei 100$200{ }^{\circ} \mathrm{C}$. Bei dieser Prozedur gehen die äußeren dunkel- 
- Tabelle 24.7

Verteilung der Ginsenoside in Panax ginseng C.A. MEYER (nach Soldati u. Sticher 1980)

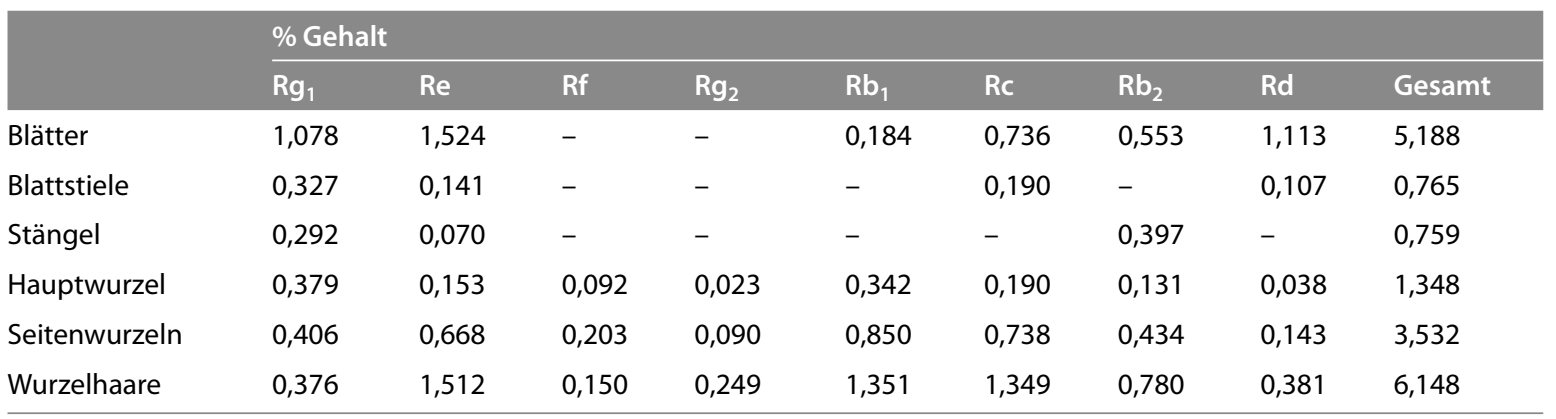

gefärbten Schichten des Korkgewebes verloren. Eine Wurzel wiegt durchschnittlich 8-10 g.

- Roter Ginseng: Bei dieser Zubereitungsart handelt es sich im Grund um eine uralte, empirisch gefundene Konservierungsmethode. Die geernteten Wurzeln werden noch frisch mit Wasserdampf von $120-130^{\circ} \mathrm{C}$ $2-3 \mathrm{~h}$ lang behandelt und danach getrocknet. Sie erhalten dadurch ein glasiges und rötliches Aussehen. Die Farbentwicklung lässt sich als Maillard-Reaktion deuten.

Durch einen besonders hohen Ginsenosidgehalt zeichnen sich die Seitenwurzeln und die Wurzelhaare, die sog. „slender tails" aus (\$ Tabelle 24.7). Sie enthalten im Vergleich mit der Hauptwurzel höhere Anteile an Rindenparenchym, in denen die Ginsenoside lokalisiert sind. Eigenartigerweise werden die Seitenwurzeln in der Traditionellen Chinesischen Medizin (TCM) von der Hauptwurzel entfernt; offensichtlich aber nicht aus rationalen Gründen, sondern vermutlich deshalb, um im Sinne der Signaturenlehre die menschenähnliche Gestalt der Hauptwurzel besser zur Geltung zu bringen. Zur Herstellung von Ginsengextrakten andererseits sind die Seitenwurzeln mit ihren hohen Ginsenosidgehalten natürlich verwertbar.

Neben den Wurzeln von P. ginseng (Koreanischer Ginseng) werden auch Wurzeln anderer Panax-Arten medizinisch verwendet. Die Hauptbedeutung kommt dabei P. quinquefolium L. (Amerikanischer Ginseng; USA, Kanada und von dort auch Export nach Ostasien), P. notoginseng (Burk.) F. H. Chen (Sanchi Ginseng; China) und P. japonicus C. A. Meyer (Chikusetsuninjin; Japan) zu.

\section{Inhaltsstoffe}

- Triterpensaponine (Ginsenoside) [2-3\%; PhEur = mindestens 0,4\% einer Mischung von Ginsenosid $\operatorname{Rg}_{1}$ und Ginsenosid $\mathrm{Rb}_{1}$ ], deren Aglykone vorwiegend zum tetrazyklischen Dammarantyp (? Abb. 24.28 und 24.29), teilweise zum pentazyklischen Oleanolsäuretyp (z. B. Ro; Formel von Oleanolsäure $>A b b$. 24.18) gehören;

- Polysaccharide, hauptsächlich die Panaxane A-U (= Peptidoglykane) und die Ginsenane PA, PB, S-IA und S-IIA. Die Struktur der Polysaccharide ist erst teilweise bekannt. Panaxan A weist eine Hauptkette aus $\alpha$-1 $\rightarrow 6$-verknüpften $D$-Glucoseeinheiten auf, während Ginsenan A aus einer Hauptkette mit $\beta-1 \rightarrow$ 3-verknüpften D-Galactoseresten besteht;

- Polyacetylene mit Panaxytriol, Panaxynol und Panaxydol als Hauptsubstanzen (> Abb. 24.30);

- ätherisches Öl mit den Sesquiterpenkohlenwasserstoffen Eremophilen und $\beta$-Elemen, die zum eigentümlichen Geruch der Droge beitragen; ferner

- phenolische Substanzen, Triglyceride, Fettsäuren, Zucker, Stärke, Pektine, Aminosäuren, Peptide, Proteine, Mineralstoffe.

\section{Analytische Kennzeichnung}

Prüfung auf Identität und Reinheit. DC-Nachweis der Ginsenoside $\operatorname{Rg}_{1} / \operatorname{Rg}_{2}$, Rf, Re, Rd, Rc, $\mathrm{Rb}_{1} / \mathrm{Rb}_{2}$ (PhEur) [Fließmittel: Ethylacetat-Wasser-1-Butanol (25:50:100); Referenzsubstanzen: Aescin, Arbutin; Nachweis: Anisaldehydreagens]. Die Ginsenoside erscheinen nach dem Besprühen mit Anisaldehydreagens im Tageslicht als violette Zonen. Die PhEur lässt auf eine eventuelle Substitution von P. ginseng durch P. quinquefolium (Fehlen von Ginsenosid Rf) prüfen (HPLC).

Gehaltsbestimmung. Die Gehaltsbestimmung (PhEur) erfolgt mit Hilfe der HPLC unter Verwendung von octadecylsilyliertem Kieselgel $(5 \mu \mathrm{m})$ als Säulenmaterial, 


\section{- Abb. 24.28}

Glykoside

$R b_{1}, R b_{2}$, $\mathrm{Rb}_{3}, \mathrm{Rc}, \mathrm{Rd}$

Säurehydrolyse

Panaxadiol

$\mathrm{Re}, \mathrm{Rf}, \mathrm{Glc}-\mathrm{Rf}$, $\mathrm{Rg}_{1}, \mathrm{Rg}_{2}$

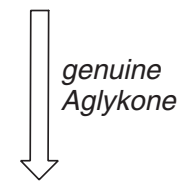

(S)

Protopanaxadiol $(\mathrm{R}=\mathrm{H})$

Protopanaxatriol $(\mathrm{R}=\mathrm{OH})$

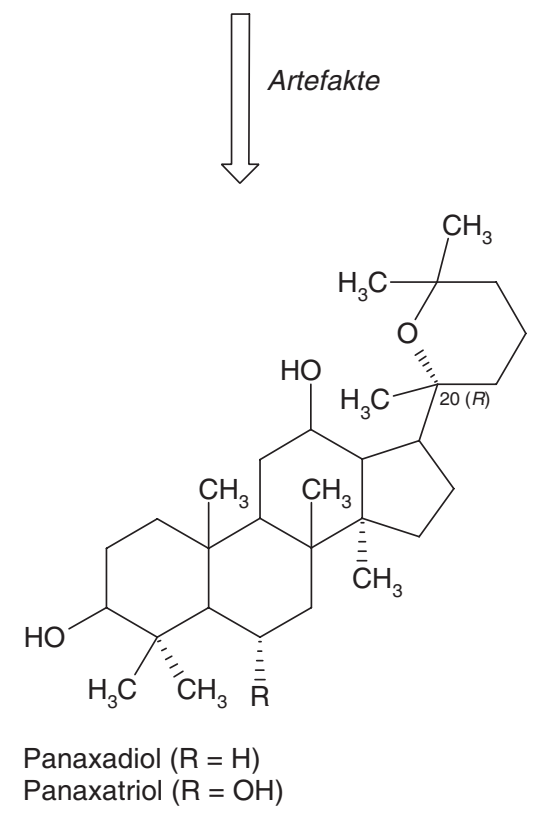

Die Saponine der Ginsengwurzel basieren, ihrem chemischen Aufbau nach, auf dem Dammarenol, einem tetrazyklischen Triterpen ( $($ auch $>$ Abb. 24.1). Die Benennung der Saponine - als Ginsenoside Ra, Rb, bis Rh - nimmt Bezug auf deren Rf-Folge auf Dünnschichtchromatogrammen, wobei die Polarität vom Index a zum Index $h$ abnimmt, was sich bereits an der Zahl der Zucker ablesen lässt, die mit dem Triterpen verbunden sind. Die intermediär nach Abspaltung der Zucker aus den Ginsenosiden frei werdenden genuinen Aglykone Protopanaxadiol und Protopanaxatriol zyklisieren spontan durch Addition der sekundären 20-OH-Gruppe an die 23,24-Doppelbindung zu den Pyranderivaten Panaxadiol und Panaxatriol. Dabei erfolgt eine Konfigurationsumkehr von der 20(S)-zur 20(R)-Verbindung. Panaxadiol und Panaxatriol sind folglich sekundäre Aglykone und als Artefakte aufzufassen

einem Acetonitril-Wasser- (mit Phosphorsäure auf pH 2 eingestellten) Gradienten als Fließmittel und der Ginsenoside $\mathrm{Rg}_{1}$, Re, $\mathrm{Rf}$ und $\mathrm{Rb}_{1}$ als Referenzsubstanzen.

Anmerkung. Art und Mengenverhältnis der Ginsenoside erlauben Rückschlüsse auf eine Verarbeitung minderwertiger oder verfälschter Ginsengdroge in Extrakten und Fertigarzneimitteln. Die Ginsenosidspektren von rotem und weißem Ginseng, aber auch diejenigen von Wurzeln anderer Panax-Arten oder von Ginsengblättern sind unterschiedlich. Zur Abklärung solcher Unterschiede eignet sich heute am besten die HPLC. Es existieren verschiedene HPLC- bzw. HPLC-MS-Methoden, mit denen bis über 20 Ginsenoside in einem Run getrennt werden können. Sie erlauben sowohl qualitatitv (z. B. Vorliegen von weißem oder rotem Ginseng) als auch quantitativ (Einzelbestimmung der 8 wichtigsten Ginsenoside) detaillierte Aussagen über die Qualität der Ginsengwurzel und daraus herge- 
- Abb. 24.29

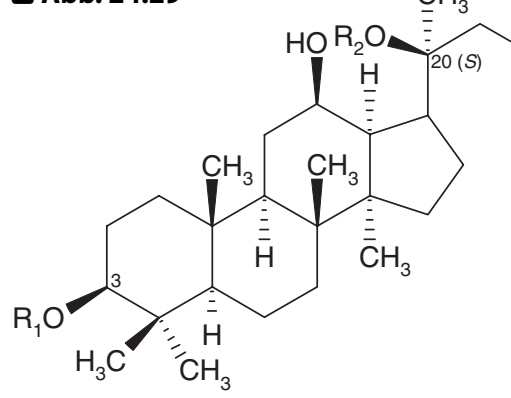

Protopanaxadiolderivate

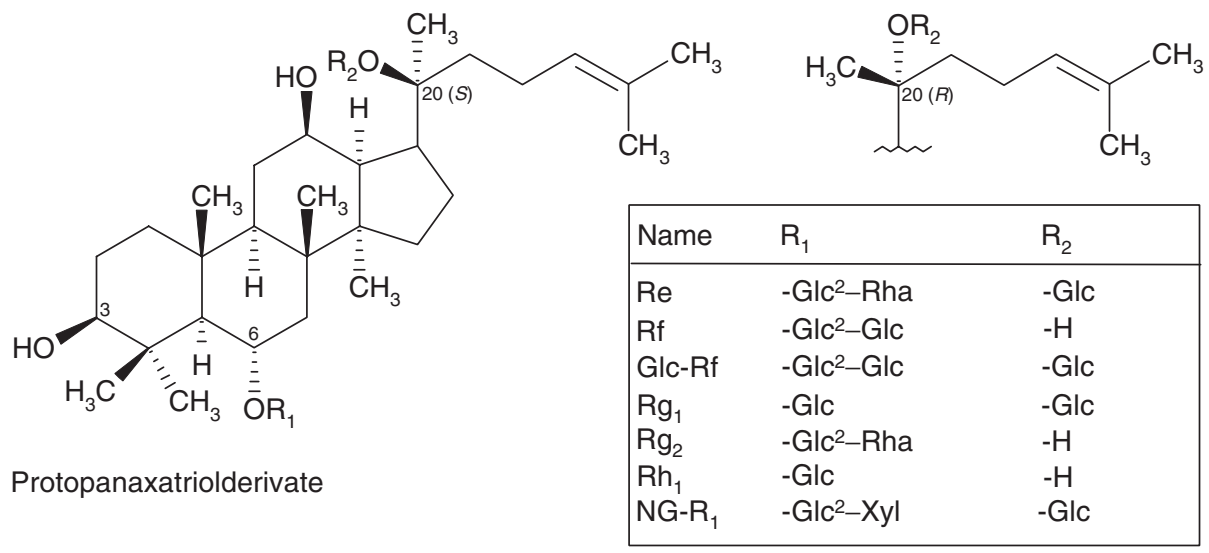

Aus der Ginsengwurzel konnten bisher über 30 Ginsenoside isoliert werden. Sie gehören mehrheitlich zu den neutralen bisdesmosidischen Saponinen (z. B. die im weißen Ginseng mengenmäßig vorherrschenden Ginsenoside $R b_{1}, R c$, $R e$, $\mathbf{R g}_{1}$ ), einige hingegen zu den monodesmosidischen Vertretern ( $\mathbf{z}$. B. $\mathbf{R f}, \mathbf{R g}_{2}$ ); die Zuckerketten liegen jeweils unverzweigt vor. Bei den vom Protopanaxadiol sich ableitenden Ginsenosiden sind die Zucker sowohl mit der 3-OH- als auch mit der 20-OH-Gruppe verknüpft; ungewöhnlich ist die Stellung der Glykosidbindung bei den Protopanaxatriolglykosiden, indem die 3-OH-Gruppe frei bleibt und die Zucker außer am C-20 auch am C-6 gebunden sind.

Mit einigen Ausnahmen $\left[\mathrm{Rg}_{3}, \mathrm{Rg}_{2}, \mathrm{Rh}_{1}=\mathbf{2 0}(S+R)\right]$ sind alle Ginsenoside Derivate von 20(S)-Protopanaxadiol und 20(S)Protopanaxatriol. 20(R)-Verbindungen stellen Artefakte dar, die beim Herstellungsprozess entstehen. Sie sind daher, mit Ausnahme von $20(R)-\mathrm{Rg}_{3}$, dessen Vorkommen im weißen Ginseng überprüft werden muss (vgl. Sticher 1998 und darin zitierte Literatur), charakteristische Ginsenoside für roten Ginseng. Malonylginsenoside (z. B. $m R b_{1}$, $m R b_{2}$, etc.) kommen nur im weißen Ginseng vor. Die Malonylgruppe wird beim Erhitzen mit Wasserdampf abgespalten. Es scheint, dass in der frischen Ginsengwurzel noch weitere Ginsenoide als Malonylderivate (z. B. Rb ${ }_{3}, \mathrm{Ra}_{1}, \mathrm{Ra}_{2}$ ) vorkommen (Fuzzati et al. 1999) 


\section{- Abb. 24.30}

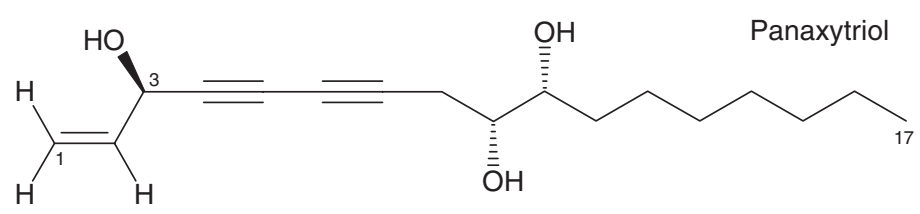<smiles>C=CC(O)C#CC#CCC=CCCCCCCBr</smiles><smiles>C=CC(O)C#CC#CCC1OC1CCCCCCC</smiles>

Während früher vorwiegend die Ginsenoside als wirksamkeitsbestimmende Inhaltsstoffe der Ginsengwurzel betrachtet worden sind, konnte in neuerer Zeit gezeigt werden, dass auch andere Inhaltsstoffe (Polyacetylene und Polysaccharide) zur Gesamtwirkung beitragen. Bei den lipophilen Polyacetylenen sind das insbesondere Panaxytriol, Panaxynol und Panaxydol. Sie gehören zur Gruppe der $\mathrm{C}_{17}$-Acetylenderivate mit einer oder mehreren sekundären Alkoholgruppen im Molekül. Sie sind offensichtlich eng mit entsprechenden Acetylenderivaten bestimmter Apiaceen verwandt, wie überhaupt die zwischen Araliaceen und Apiaceen bestehende taxonomische Verwandtschaft sich auch in deren stofflichen Zusammensetzung widerspiegelt (vgl. Frohne u. Jensen 1998)

stellter Produkte (vgl. Übersicht von Sticher 1998; Fuzzati et al. 1999; Li et al. 2000).

Verarbeitung, Arzneiformen. In den Ursprungsländern wurde traditionell die zerkleinerte Droge des roten Ginseng als solche oder in Form der Teezubreitung verwendet. Heute findet man in den „Ginseng-Shops“ in Korea, China oder Japan sämtliche nur denkbaren Präparate in den Bereichen von Kosmetik, Lebensmitteln und Pharmazeutika.

In Europa werden mehrheitlich Präparate angeboten, für die weißer Ginseng als Ausgangsmaterial dient. Fein pulverisierte Droge wird entweder direkt zu Kapseln oder Dragees verarbeitet oder weit häufiger zu Flüssig-, Spissum- bzw. Trockenextrakten, die in den verschiedensten Formen von Fertigarzneimitteln auf den Markt gelangen. Die meisten Fertigarzneimittel enthalten Trocken- (in Bearbeitung für PhEur) oder Sprühextrakt. Spissum- und Fluidextrakte eignen sich zur Herstellung von Ginsengwein und anderen Alkohol enthaltenden Tonika.
Metabolismus und Pharmakokinetik. Viele der älteren Untersuchungen über die Pharmakokinetik und den Metabolismus der Ginsenoside sind unkritisch und mit unrealistisch hohen Dosierungen durchgeführt worden. Aus diesem Grund werden in den $>$ Abbildungen 24.31-24.33 nur einige in neuerer Zeit erhaltene Resultate (Tier und Mensch) zusammengefasst (vgl. Übersicht von Sticher 1998 und darin zitierte Literatur; Bae et al. 2000, 2002; Abdel Tawab et al. 2003). Die im Plasma und im Urin identifizierten Substanzen entstehen im Gastrointestinaltrakt entweder durch Darmbakterien oder -enzyme bzw. durch den Magensaft. Die wesentliche Erkenntnis dabei ist, dass Protopanaxadiol- und Protopanaxatriolsaponine verschieden metabolisiert und nach p.o.-Verabreichung in erster Linie in Form von Metaboliten absorbiert und ausgeschieden werden. Es ist erwähnenswert, dass sowohl bei den Protopanaxadiol- als auch den Protopanaxatriolsaponinen hauptsächlich monoglucosidierte Abbauprodukte (Substanz K, Ginsenosid $\mathrm{Rh}_{1}$, Ginsenosid $\mathrm{F}_{1}$ ) zur Resorption gelangen und nicht die entsprechenden Aglykone. Sie können daher innerhalb der Ginsenoside als die eigentlichen Wirkstoffe angesehen werden. Substanz K 
- Abb. 24.31

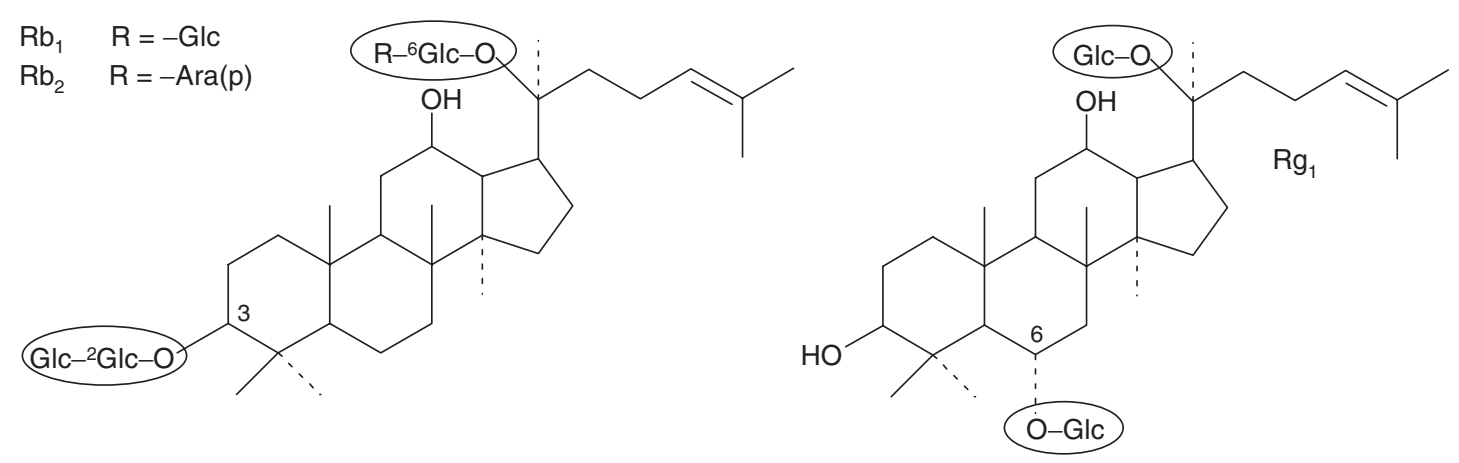

Halbwertszeit von Protopanaxadioltyp- und Protopanaxatrioltyp-Ginsenosiden im Serum

\begin{tabular}{|c|c|c|c|c|}
\hline \multirow{2}{*}{ Ginsenosid } & \multicolumn{3}{|c|}{ Versuchstier (intravenöse Applikation) } & \\
\hline & Ratte & Kaninchen & Minischweinchen & \\
\hline $\mathrm{Rb}_{1}$ & $14,5 \mathrm{~h}$ & & $16 \mathrm{~h}$ & $\mathrm{Rb}_{1}=$ hoher \\
\hline $\mathrm{Rb}_{2}$ & & $8 \mathrm{~h}$ & & Plasmaprotein- \\
\hline $\mathrm{Rg}_{1}$ & $6,3 \mathrm{~min}$ & $69,5 \mathrm{~min}$ & $27 \mathrm{~min}$ & bindungsgrad \\
\hline
\end{tabular}

Pharmakokinetische Studien mit Diol- und Triol-Typ-Ginsenosiden. Die Halbwertszeit der Protopanaxadiol- und der Protopanaxatrioltyp-Ginsenoside ist unterschiedlich. $\mathrm{Rg}_{1}$ (Trioltyp) hat eine sehr kurze Halbwertszeit von 27 min nach

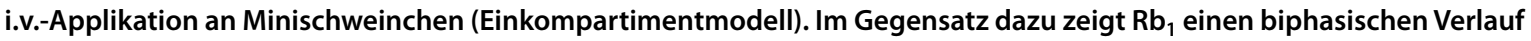
der Blutspiegelkurve mit einer Halbwertszeit in der $\beta$-Phase von $16 \mathrm{~h}$ (Zweikompartimentmodell). Diese Resultate korrelieren mit den pharmakokinetischen Daten bei Ratten und Kaninchen. Die lange Verweildauer von $\mathrm{Rb}_{1}$ im Serum wird einem hohen Plasmabindungsgrad zugeschrieben (vgl. Sticher 1998 und darin zitierte Literatur)

(vgl. ( ) Abb. 24.33) ist gemäß Tohda et al. (2004) in vitro und in vivo für die Reaktivierung neuronaler Funktionen verantwortlich. Nach Hasegawa et al. (2000) werden die resorbierten Substanzen in der Leber mit Fettsäuren verestert (ähnlich dem Cholesterolmetabolismus).

Wirkungen und Toxizität. Die Ginsenoside zeigen nur sehr schwach ausgeprägte Hämolysewirkung. Ihre Toxizität ist sehr gering: Nach p.o.-Zufuhr ist tierexperimentell eine $\mathrm{LD}_{50}$ nicht messbar ( $>5 \mathrm{~g} / \mathrm{kg} \mathrm{KG}$, Maus); intraperitoneal liegt die $\mathrm{LD}_{50}$ (Maus) zwischen $305 \mathrm{mg} / \mathrm{kg} \mathrm{KG}$ im Falle des Ginsenosids $\mathrm{Rb}_{2}$ und $1340 \mathrm{mg} / \mathrm{kg} \mathrm{KG}$ im Falle des Ginsenosids Rf. Die Ginsenoside gehören zu den wenigen Naturstoffen, die tierexperimentell (Maus, BeagleHunde) auf chronische Toxizität geprüft worden sind: Es ergaben sich keine Anhaltspunkte für pathologische Veränderungen.

Die Hauptwirkungen von Ginsengextrakten und Ginsengpräparaten sind in der $>$ Tabelle 24.8 zusammen- gefasst. Aus den schon längere Zeit zurückliegenden Untersuchungen, von denen allerdings recht häufig eine Relevanz für die medizinische Anwendung fehlt oder mangelhaft ist (z. B. durch unrealistisch hohe Dosierung, i.v. oder i.p. anstelle der p.o.-Applikation, Tierexperimente ohne Bezug zum therapeutischen Wert am Menschen), geht hervor, dass hauptsächlich die Ginsenoside $\mathrm{Rb}_{1}$ und $\mathrm{Rg}_{1}$ an der Wirkung beteiligt sind. $\mathrm{Rg}_{1}$ stimuliert das ZNS, steigert die Protein-, DNA- und RNA-Synthese, während $\mathrm{Rb}_{1}$ beruhigende Wirkung auf das ZNS ausübt und zerebrale Funktionen des kognitiven Bereichs (Aufmerksamkeit, Konzentration, Merkfähigkeit, Gedächtnis) aktiviert. Unter weiter beschriebenen Ginsengwirkungen sind $\mathrm{u}$. a. die Hemmung von Thrombozytenaggregation und Lipidperoxidation, antioxidative Wirkung, Radikalfängereigenschaften, Neuroprotektion und Vasorelaxation besonders erwähnenswert. Diese Aktivitäten werden in der englischen Sprache unter der Bezeichnung ",anti-aging activity“ zusammengefasst. Damit werden Wirkungen beschrie- 
- Abb. 24.32
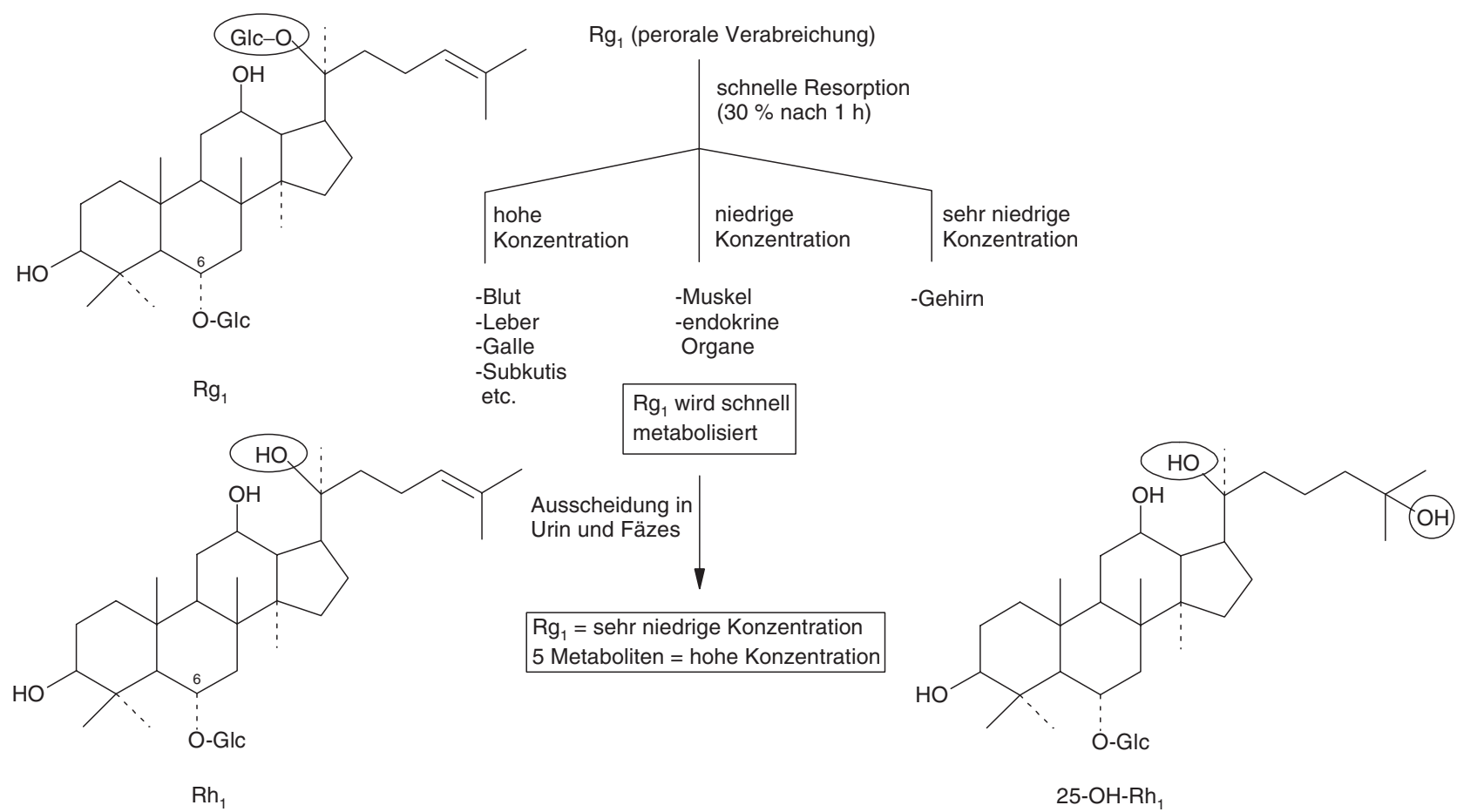

Metabolismus von Ginsenosid $\mathbf{R g}_{1}$. Ginsenosid $\mathrm{Rg}_{1}$ wird nach p.o.-Verabreichung an Mäuse schnell resorbiert. Die Konzentration von $\mathrm{Rg}_{1}$ und seinen Metaboliten ist hoch im Blut, in Leber, Galle, Unterhaut und Bindehaut, im Epithel von Mundund Nasenhöhle sowie in der Speiseröhre, während sie im Muskelgewebe und in endokrinen Organen bzw. im Gehirn tief bzw. sehr tief ist. $\mathbf{R g}_{1}$ wird schnell metabolisiert und nur in geringen Mengen unverändert ausgeschieden. Der Hauptanteil wird via Urin und Fäzes in Form von 5 Metaboliten $\left(\mathrm{Rh}_{1}, 25-\mathrm{OH}-\mathrm{Rh}_{1}\right.$ und andere) ausgeschieden (vgl. Sticher 1998 und darin zitierte Literatur). Nach neuen Untersuchungen beim Menschen (p.o.-Verabreichung eines Extrakts) wird das Ginsenosid $R_{1}$ ebenfalls vorwiegend in $R h_{1}$ und $25-\mathrm{OH}-\mathrm{Rh}_{1}$ umgewandelt. Daneben gelangt ein Teil von $\mathrm{Rg}_{1}$ unverändert in den Dickdarm, wo es zu Ginsenosid $\mathrm{F}_{1}$ (Glucoserest an OH-C-20 anstelle von OH-C-6) hydrolysiert wird. Die Ginsenoside $R h_{1}$ und $F_{1}$ entstehen auch nach p.o.-Verabreichung von Ginsenosid $R e$, hier allerdings über die $Z$ wischenstufen von $\mathbf{R g}_{2}$ und $\mathrm{Rg}_{1}$ (Abdel Tawab et al. 2003)

ben, die sich insbesondere in der späteren Lebensphase positiv auf die Gesundheit auswirken können. In Kombination mit der Hemmwirkung auf die Proliferation von Krebszellen und den Effekten auf das Immunsystem kann die Verwendung von Ginseng in Ostasien zur Erlangung eines langen Lebens in Gesundheit eine gewisse Plausibilität beanspruchen (vgl. Übersicht von Sticher 1998 und darin zitierte Literatur).

In neueren Untersuchungen sind vermehrt einzelne Inhaltsstoffe von Ginseng (Ginsenoside, Polyacetylene, Polysaccharide) auf ihre Wirkungen untersucht worden. Polyacetylene zeigten in vitro zytotoxische, entzündungs- hemmende und blutplättchenaggregationshemmende Wirkungen, während für Polysaccharide vorwiegend immunmodulierende (gesteigerte Aktivität natürlicher Killerzellen, eine vermehrte Interferon- und Komplementproduktion, eine Zunahme der Phagozytoseaktivität des retikuloendothelialen Systems sowie eine Hemmung der alkalischen Phosphatase), zytoprotektive und zytotoxische Wirkungen nachgewiesen werden konnten. In den letzten Jahren wurden vermehrt einzelne Ginsenoside und Polyacetylene in verschiedensten In-vitro-Assays (z. B. Rezeptorbindungsstudien, Zelllinien) auf mögliche Wirkungsmechanismen untersucht, auf die hier nicht nä- 


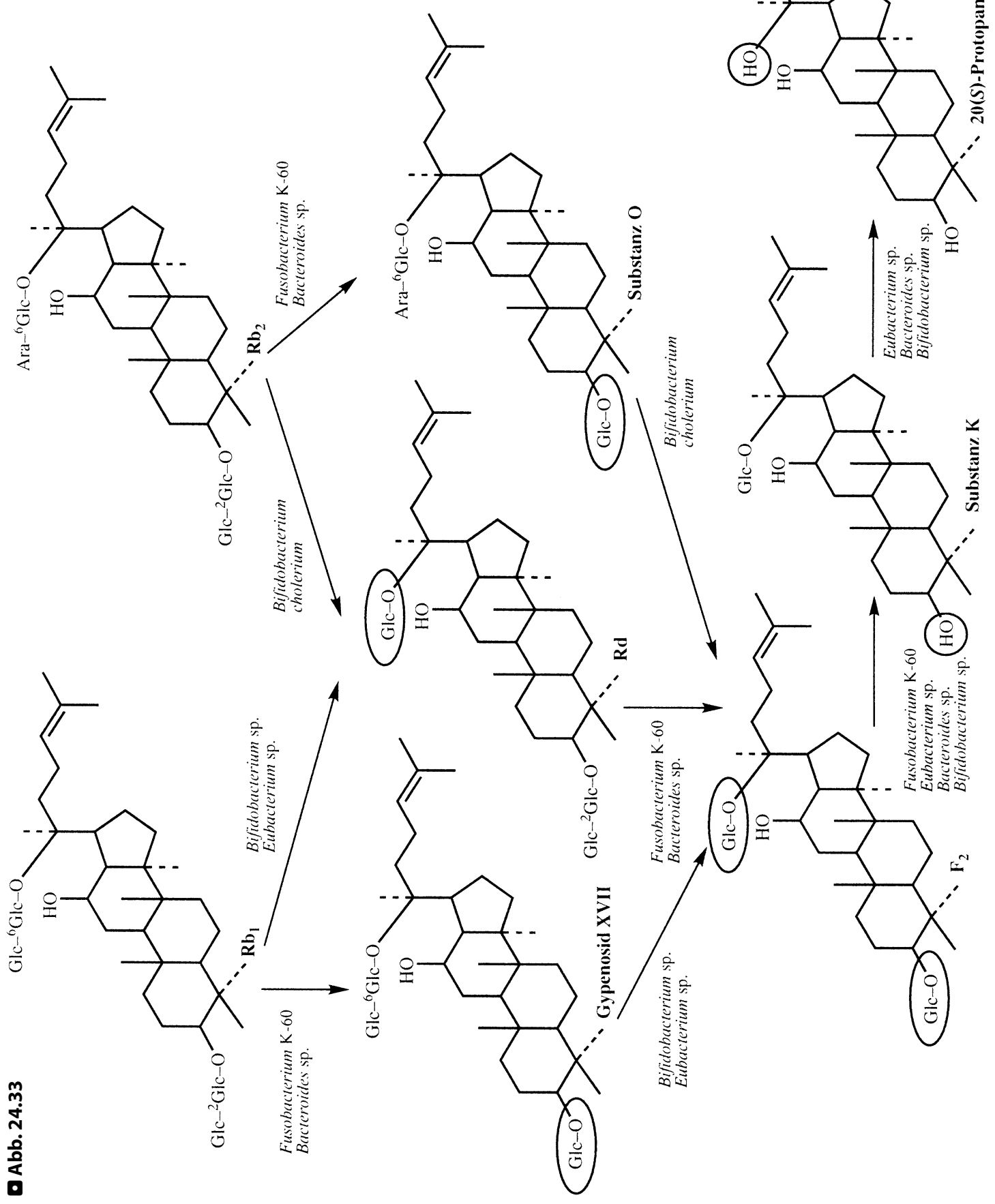


- Tabelle 24.8

In der Literatur beschriebene Hauptwirkungen von Ginseng und Beispiele nachgewiesener Aktivitäten einzelner Inhaltsstoffe

Hauptwirkungen

- Wirkung als allgemeines Tonikum

- Wirkung auf Immun- und Kreislaufsystem

- Wirkung auf Fett- und Alkoholmetabolismus

- Blutzuckersenkende Wirkung

- Wirkung auf Hypophyse und Nebennierenrinde

- Tumorhemmende Wirkung

Aktivitäten

Hemmung der Thrombozytenaggregation

Antioxidative Wirkung

Neuroprotektive Wirkung

Zytotoxische Wirkung

Immunmodulierende Effekte

Zytoprotektive Wirkung

Blutzuckersenkende Wirkung

Hemmung von lonenkanälen
Verantwortliche Inhaltsstoffe

$\mathrm{Ro}, \mathrm{Rg}_{1}, \mathrm{Rg}_{2}$, Polyacetylene

$\mathrm{Rg}_{1}, \mathrm{Rb}_{1}, \mathrm{Rc}$

Saponingemisch, $\mathrm{Rb}_{1}$ (Substanz K), $\mathrm{Rg}_{1}, \mathrm{Rg}_{3}$

Polyacetylene, Polysaccharide, $\mathrm{Rg}_{3}, \mathrm{Rh}_{2}$, Substanz K

und andere Ginsenosidmetaboliten

$\mathrm{Rg}_{1}$, Polysaccharide

Polysaccharide

Peptidoglykane

$\mathrm{Rf}, \mathrm{Re}, \mathrm{Rg}_{3}$ her eingegangen werden kann. In Ostasien scheint die in verschiedenen In-vitro- und in Tiermodellen nachgewiesene tumorhemmende Wirkung, insbesondere des Metaboliten Substanz K, eine bevorzugte Stellung einzunehmen (vgl. dazu folgende Infobox „Tumorhemmendes Potential von Pflanzenstoffen“).

Anwendungsgebiete. Als Tonikum zur Stärkung und Kräftigung bei Müdigkeits- und Schwächegefühl, nachlassender Leistungs- und Konzentrationsfähigkeit sowie in der Rekonvaleszenz (Kommission E, ESCOP).
Die Anwendung als Tonikum bei Erschöpfungszuständen basiert weitgehend auf dem stimulierenden Effekt einzelner Ginsenoside, der sich in der Verbesserung der körperlichen und geistigen Leistungsfähigkeit äußert, während die Beschleunigung von Genesungsvorgängen wahrscheinlich der immunmodulierenden Wirkung von Ginsenosiden und Polysacchariden im Sinne einer Erhöhung der Abwehrkräfte des menschlichen Körpers zugeschrieben werden muss. Da die experimentell nachgewiesenen Effekte vollständig nur mit einem Gesamtextrakt erhalten werden können, sind bisher keine Ein-

- Metabolismus der Ginsenoside $\mathrm{Rb}_{1}$ und $\mathrm{Rb}_{2}$ durch die menschliche Intestinalflora. Das Abbauschema kann für Ginsenoside vom Diol-Typ als Modellbeispiel gelten, wobei in Betracht gezogen werden muss, dass der Metabolismus je nach der Zusammensetzung der menschlichen Intestinalflora abweichend verlaufen kann.

Anaerobe Inkubation der Ginsenoside $\mathrm{Rb}_{1}, \mathrm{Rb}_{2}$ und $\mathrm{Rc}$ (Struktur nicht abgebildet) mit menschlicher Darmflora ergibt als Hauptmetaboliten die Substanz K, daneben 20(S)-Protopanaxadiol. Eubacterium- und Bifidobacterium-Spezies können Gentiobiose (Glc- ${ }^{6} \mathrm{Glc}-$ ) besser als Sophorose (Glc- ${ }^{2} \mathrm{Glc}-$ ) spalten. Der Metabolismus von Ginsenosid $\mathrm{Rb}_{1}$ führt daher über Ginsenosid Rd zu Substanz K. Andererseits können Fusobacterium-K-60- und Bacteroides-Spezies Sophorose leichter spalten als Gentiobiose. Der Metabolismus führt daher via Gypenosid XVIII. Ähnliche Verhältnisse finden sich beim Metabolismus von Ginsenosid $\mathrm{Rb}_{2}$. Eubacterium- und Bifidobacterium-Spezies metabolisieren Ginsenosid $\mathrm{Rb}_{2}$ via Ginsenosid Rd, Fusobacterium-K-60- und Bacteroides-Spezies via Substanz O zu Substanz K (Bae et al. 2000, 2002). Das Ginsenosid $\mathrm{Rb}_{1}$ konnte im Plasma und im Urin auch unverändert nachgewiesen werden (Abdel Tawab et al. 2003) 
Infobox

Tumorhemmendes Potential von Pflanzenstoffen. In der traditionellen Medizin sämtlicher Kulturen werden Pflanzenextrakte zur Vorbeugung, aber auch zur Therapie von malignen Krankheiten verwendet. Es ist deshalb nicht verwunderlich, dass insbesondere in der neueren Literatur Hunderte von wissenschaftlichen Arbeiten publiziert wurden, in denen unter Einsatz moderner In-vitro-Assays und von verschiedenen In-vivo-Modellen sowie in epidemiologischen Studien beim Menschen antikarzinogene Wirkungen von Extrakten bzw. von einzelnen isolierten Reinstoffen nachgewiesen wurden. Beispiele von Arzneidrogen mit einem chemopräventiven Potential sind Süßholz- und Ginsengwurzel, Javanische Gelbwurz und Curcumawurzelstock sowie Teeblätter von Camellia sinensis. Beispiele von Reinstoffen sind einzelne Flavonoide und Polyphenole (z. B. Epigallocatechingallat), Betulinsäure, Boswelliasäuren, Cannabinoide, Carnosol, Curcumin, [6]-Gingerol, Ginsenosidmetaboliten (Substanz K), Hypericin, Sesquiterpenlactone (z. B. Parthenolid), Silibinin, Xanthohumol u. a. Viele dieser Substanzen sind Hemmstoffe verschiedener Enzyme, die mit der Entstehung von Krebs in Zusammenhang stehen. Auf biochemischer Ebene stehen die Hemmung der Zellproliferation, von Zellzyklen und verschiedener Signaltransduktionswege, z. B. von Wachstumsfaktoren, NF- $\kappa B$ („,nuclear factor" $\kappa B$ ), AP-1 (Aktivatorprotein-1) und Jak/STAT (Janus-Kinase $1 /$ "signal transducer and activator of transcription"), die Hemmung der Angiogenese und von COX-2 (Cyclooxygenase-2) sowie die Induktion der Apoptose im Vordergrund (vgl. dazu Dorai u. Aggarwal 2004). Ebenfalls spielt die antioxidative Wirkung häufig eine wichtige Rolle (vgl. Infobox „Antioxidanzien“, Kap. 26.5.8). Obwohl im Falle einiger Beispiele chemopräventive Effekte in experimentellen wie auch in epidemiologischen Studien nachgewiesen werden konnten, gibt es bis heute keine schlüssigen Beweise für eine chemopräventive Wirkung komplementärer bzw. alternativer Therapien beim Menschen. Das Potential unkonventioneller Therapien liegt vielmehr in einer unterstützenden Prävention und in der palliativen Pflege (vgl. dazu auch Ernst u. Cassileth 1999; Shin et al. 2000). Ob sich dereinst einzelne dieser Reinstoffe für eine Tumortherapie eignen, wird die Zukunft zeigen. Auszuschließen ist das nicht, finden doch Naturstoffe wie Taxol, Vinca-Alkaloide oder Lignanderivate seit längerer Zeit eine therapeutische Anwendung. zelsubstanzen als Monopräparate im Handel. Alle kommerziell erhältlichen Fertigarzneimittel sind Extraktpräparate.

Kontrollierte klinische Studien bestätigen verschiedene der in den pharmakologischen Untersuchungen erhaltenen Erkenntnisse und damit die oben erwähnten Anwendungsgebiete. So konnten die im Tierversuch gefundene Leistungssteigerung sowie schützende und regenerierende Effekte nachgewiesen werden (vgl. Übersicht von Sonnenborn u. Proppert 1990). Zur Verbesserung zerebraler Funktionen des kognitiven Bereichs wie Aufmerksamkeit, Konzentration, Merkfähigkeit und Gedächtnis werden heute vermehrt Kombinationspräparate mit Extrakten von Ginsengwurzeln und Ginkgoblättern verabreicht (vgl. z. B. Scholey u. Kennedy 2002).

\section{! Kernaussagen}

Hauptinhaltsstoffe der Ginsengwurzel sind die Ginsenoside, deren Aglykone vorwiegend zum tetrazyklischen Dammarantyp gehören. Die intermediär nach Abspaltung der Zucker aus den Ginsenosiden frei werdenden genuinen Aglykone Protopanaxadiol und Protopanaxatriol zyklisieren spontan unter Konfigurationsumkehr [20(S)- $\rightarrow$ 20(R)-] durch Addition der sekundären 20-OH-Gruppe an die 23,24-Doppelbindung zu den Pyranderivaten Panaxadiol und Panaxatriol. Metabolismus und Pharmakokinetik der Hauptginsenoside $\mathrm{Rb}_{1}, \mathrm{Rb}_{2}, \mathrm{Rc}, \mathrm{Rg}_{1}$, Re sind relativ gut untersucht. Protopanaxadiol- und Protopanaxatriolsaponine werden verschieden metabolisiert und nach p.o.-Verabreichung in erster Linie in Form von Metaboliten absorbiert [monoglucosidierte Ginsenoside (Substanz K, Ginsenosid Rh ${ }_{1}$, Ginsenosid $F_{1}$ )]. Die Ginsenoside weisen ein breites Wirkungsspektrum auf mit den Hauptwirkungen ZNS-stimulierend $\left(\mathrm{Rg}_{1}\right)$ und ZNS-dämpfend $\left(\mathrm{Rb}_{1}\right)$. Neben den Ginsenosiden tragen Polyacetylene und Polysaccharide zur Wirkung bei. Die Hauptanwendung geschieht als Tonikum und Geriatrikum zur Stärkung und Kräftigung bei Müdigkeits- und Schwächegefühl, nachlassender Leistungsund Konzentrationsfähigkeit sowie in der Rekonvaleszenz. Das Arzneimittelbild von Ginseng entspricht der ostasiatischen Vorstellung zur Erlangung eines langen Lebens in Gesundheit ( $>$ Hinweis). 
Nebenwirkungen. Bei hoher Dosierung oder Anwendung über sehr lange Zeit sind Schlaflosigkeit, Nervosität, Hypertonie und Durchfall beobachtet worden.
Hinweis. Die Anwendung von Ginseng zur Förderung der Lebensqualität wird in der westlichen Medizin kontrovers diskutiert (vgl. dazu auch Coleman et al. 2003).

\section{Schlüsselbegriffe}

$\begin{array}{ll}\alpha \text {-Hederin } & \text { Glycyrrhizinsäure (GZ) } \\ \text { Aescin } & \text { Hedera helix } \\ \text { Aesculus hippocastanum } & \text { Hederacosid C } \\ \text { Ambroxol } & \text { Hederae folium } \\ \text { Asiaticosid } & \text { Husten } \\ \text { Asiatisches Wassernabelkraut } & \text { Impfstoff Adjuvans } \\ \text { Asiatsäure } & \text { Isoliquiritigenin } \\ \text { Atemwegserkrankungen } & \text { Lakritze } \\ \text { Bronchitis } & \text { Lebensqualität } \\ \text { Centella asiatica } & \text { Liquiritiae radix } \\ \text { Centellae asiaticae herba } & \text { Magen- und Duodenalgeschwüre } \\ \text { Chronische venöse Insuffizienz (CVI) } & \text { Onjisaponine } \\ \text { Cortisol-Metabolismus } & \text { Panax ginseng } \\ \text { Dammarangrundgerüst } & \text { Polyacetylene } \\ \text { Efeublätter } & \text { Polygala senega } \\ \text { Expektorans } & \text { Polygala tenuifolia } \\ \text { Gastritis } & \text { Polygalae radix } \\ \text { Geriatrikum } & \text { Polysaccharide } \\ \text { Geschmackskorrigens } & \text { Primelwurzel } \\ \text { Ginseng radix } & \text { Primula elatior } \\ \text { Ginsengwurzel } & \text { Primula veris } \\ \text { Glycyrrhetinsäure (GA) } & \text { Primulae radix } \\ \text { Glycyrrhiza glabra } & \text { Protopanaxadiolsaponine } \\ & \end{array}$

Protopanaxatriolsaponine
Pseudoaldosteronismus
Quillaiae cortex
Quillaja saponaria
Quillaja-Saponine
Rosskastaniensamen
Roter Ginseng
Seifenrinde
Senegawurzel
Senegine
Süßholzwurzel
Tonikum
Triterpensaponine
Weißer Ginseng
Wirkungen (anti-aging, antiexsudativ,
antioxidativ, immunmodulierend,
$\quad$ ödemprotektiv, resorptionsför-
dernd, Süßwirkung, tumorhem-
mend, venentonisierend)
Wundheilung

\subsubsection{Steroidsaponine}

\section{Struktur und Vorkommen}

Die Steroidsaponine gehören zu den $\mathrm{C}_{27}$-Steroiden; sie lassen sich als Abkömmlinge des Cholesterols auffassen, dessen $\mathrm{C}_{8}$-Seitenkette so modifiziert ist, dass sich $\mathrm{O}$-Heterozyklen ausbilden können. Nach der Ausgestaltung der Seitenkette unterscheidet man den Furostan- und den Spirostantyp (>Abb. 24.34). Furostanderivate geben mit Ehrlichs-Reagens (Dimethylaminobenzaldehyd in 20\%iger Salzsäurelösung) eine Rotfärbung; Spirostanderivate reagieren nicht.

Bei den Spirostanen ergeben sich zahlreiche Isomeriemöglichkeiten, bedingt durch die Chiralitätszentren 20, 22 und 25 (> $A b b$. 24.35). Alle nativen Sapogenine scheinen übereinstimmend die $20(S), 22(R)$-Konfiguration aufzuweisen; hingegen kommen beide 25 -epimeren Va- rianten in der Pflanze vor, ja sie treten in der Regel gemeinsam auf. Die Vertreter der $25(S)$-Reihe bezeichnet man als „normale“ Sapogenine oder als Neosapogenine, die epimeren Vertreter der $25(R)$-Reihe als Isosapogenine.

Bei den Rosopsida (Eudicotyledoneae) hat man bisher nur in wenigen Familien und Gattungen Vertreter mit Steroidsaponinen gefunden. $\mathrm{Zu}$ diesen seltenen Vorkommen zählen Arten der Gattung Digitalis (Familie: Plantaginaceae [IIB23 h], bisher Scrophulariaceae) sowie Trigonella foenum-graecum L. (Familie: Fabaceae [IIB9a]). Gehäuft treten Steroidsaponine bei Familien auf, die zu den Liliopsida (Monocotyledoneae) zählen, insbesondere Familien aus der Ordnung der Dioscoreales, Asparagales und Liliales. Zu nennen sind hier v. a. die Gattungen Smilax (Smiliacaceae [IIA5a], bisher Liliaceae), Dioscorea (Dioscoreaceae [IIA3a]) sowie Agave und Yucca (Agavaceae [IIA6f]). 
D Abb. 24.34

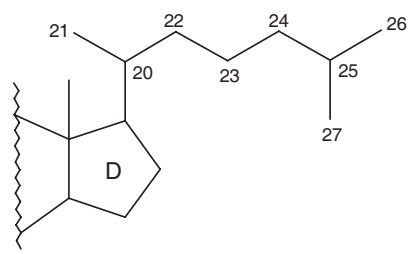

Rest wie im Cholesterol (Abb. 24.1)

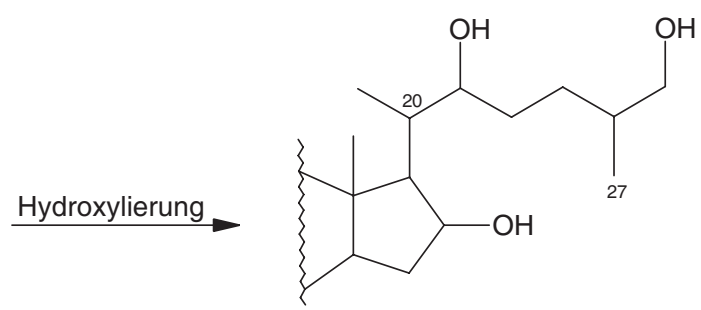<smiles>CC(C)C=O</smiles>

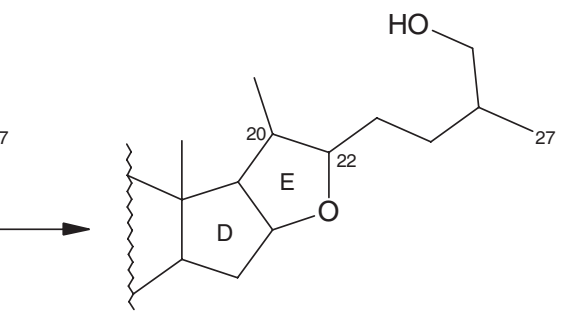

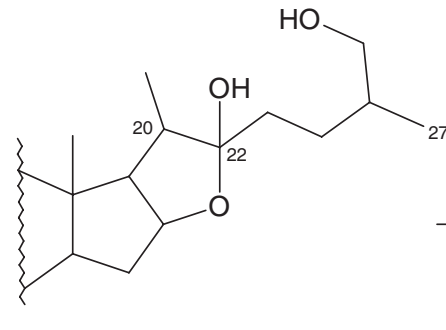

$\mathrm{H}_{2} \mathrm{O}$
Furostantyp

Spirostantyp (Spiroketal)

Die Steroidsapogenine sind formal Derivate des Cholesterols, dessen $C_{8}$-Seitenkette modifiziert ist. Es kommen 2 Typen vor: der Furostan- und der Spirostantyp; Letzterer ist durch eine Spiroketalgruppierung charakterisiert

- Abb. 24.35

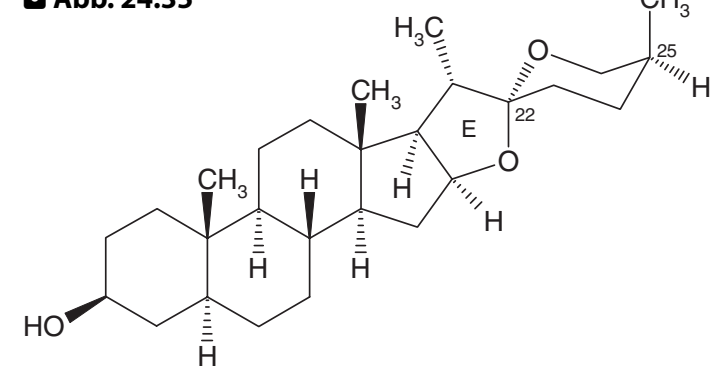

ein Neosapogenin: $25(S)-S p i r o s t a n$

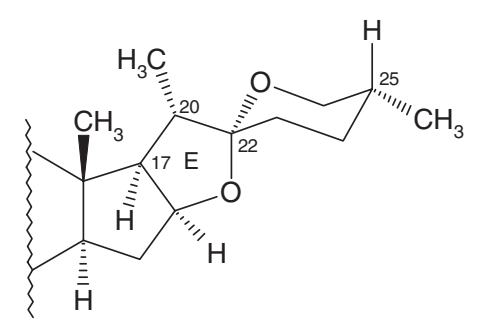

ein Isosapogenin: $25(R)$-Spirostan
Konfiguration von Spirostanen. In den nativen Spirostanen wird an den Chiralitätszentren 17 und 20 die Konfiguration beibehalten, wie sie im Cholesterol vorliegt (17-a-H und 20-a- $\mathrm{CH}_{3}$ ). Die Ringe D/E sind cis-verknüpft; das bedeutet, dass der Ring $E$ über die Molekülebene, die durch Ring A bis D gebildet wird, herausragt. Der Pyranring $\mathrm{F}$ ist etwas senkrecht gegen $\mathrm{E}$ verdreht zu denken: der durch die C-Atome 22, 23 und 24 gebildete Teil des Pyranringes ist dem Betrachter zugewendet zu denken, gleichermaßen wie die Methylgruppen an C-10 und C-13. Die natürlich vorkommenden Spirostane teilt man, entsprechend der Konfiguration am C-25, in die Neosapogenine und die Isosapogenine ein. Sapogenine mit abweichenden Merkmalen kennzeichnet man als Pseudosapogenine 


\section{Digitonin}

Digitonin ( $(A b b .24 .36)$ bedeutet zweierlei: Einmal kennzeichnet es einen chemisch definierten Stoff und sodann verschieden zusammengesetzte Handelsprodukte (> Tabelle 24.9), von denen das Digitonin oftmals nur $40 \%$ ausmacht. Gute Handelsprodukte sind wie folgt $\mathrm{zu}-$ sammengesetzt: $70-80 \%$ Digitonin, $10-20 \%$ Tigonin plus Gitonin und weitere Begleitsaponine (wie z. B. Deglucodigitonin).

Trotz ihrer uneinheitlichen Zusammensetzung stellen die Handelspräparate rein weiße, sehr schön kristallisierende Produkte dar. Ausgangsprodukt zur Gewinnung sind die Blätter von Digitalis purpurea L. Digitonin ist ein nützliches Reagens aufgrund seiner bemerkenswerten Eigenschaft, mit Cholesterol einen unlöslichen, stöchiometrisch (1:1) zusammengesetzten Komplex zu bilden. Cholesterolester lassen sich mit Digitonin nicht ausfällen, hingegen zahlreiche andere $\beta$-Hydroxysteroide.

Dass im Handelsdigitonin eine Saponinmischung vorliegt, ist für die Verwendung als Reagens zur quantitativen Bestimmung ohne Belang, da die Fällbarkeit der Begleitsaponine mit Cholesterol sehr ähnlich ist. Lediglich bei der Berechnung muss der Molgewichtsunterschied berücksichtigt werden; man setzt einen um 10\% erniedrigten Faktor ein.

\section{Smilax-Saponine}

Man kennt zurzeit an die 200 Smilax-Arten (Familie: Smilacaceae [IIA5a], bisher Liliaceae). Es handelt sich um Kletterpflanzen mit einem ausdauernden holzigen Wurzelstock, stacheligen Stängeln und herzeiförmigen oder pfeilförmigen Blättern. Beheimatet sind Smilax-Arten in den Tropen und in den wärmeren Gegenden der nördlichen Hemisphäre.

\section{- Tabelle 24.9}

Bestandteile von Digitoninhandelsprodukten

\begin{tabular}{lll} 
Glykoside & Aglykon & Zucker \\
Digitonin & Digitogenin & 2 Gal, $2 \mathrm{Glc}, 1 \mathrm{Xyl}$ \\
Tigonin & Tigogenin & $2 \mathrm{Gal}, 2 \mathrm{Glc}, 1 \mathrm{Xyl}$ \\
Gitonin & $\begin{array}{l}\text { Gitogenin (=15-Des- } \\
\text { oxydigitogenin) }\end{array}$ & $3 \mathrm{Gal}, 1 \mathrm{Xyl}$ \\
& \\
\hline
\end{tabular}

Als Drogen verwendet man die getrockneten Wurzeln bestimmter Smilax-Arten.

- Sarsaparille oder Sarsaparillwurzel besteht aus den oft meterlangen Wurzeln einiger mittelamerikanischer S.-Arten, insbesondere der Smilax aristolochiaefolia Mill. (Veracruzsorte), Smilax regelii KILL. et C. V. Morton (Hondurassorte), Smilax febrifuga KnUth neben unbekannten Smilax-Arten (Guayaquil- und Costa-Rica-Sorten);

- In der chinesischen Medizin verwendet man Wurzeln und/oder Rhizome der folgenden in China heimischen Arten: S. sieboldi MIQ., S. stans MAXIM, S. scobinicaulis C. H. Wright, S. glabra Roxb.

Wurzeln und Rhizomteile von Smilax-Arten enthalten, soweit sie bisher untersucht wurden, 1-3\% Steroidsaponine, in denen Sarsapogenin und Smilagenin ( $(A b b .24 .36$ ) als Aglykone auftreten. Wenn man die im Falle der Veracruz-Sarsaparille gefundenen Ergebnisse verallgemeinern darf, so liegen primär bisdesmosidische Saponine vor; die monodesmosidischen Spirostanole dürften Folgeglykoside darstellen (> Abb. 24.37).

In der rationalen Pharmakotherapie spielen weder Sarsaparille noch andere Smilax-Arten eine Rolle. Hingegen sind sie wichtige Arzneistoffe in der Volksmedizin, und zwar auffallenderweise in der Volksmedizin sehr unterschiedlicher Kulturkreise (Neue Welt, Indien, China) für je gleiche Indikationen. So gehörte Sarsaparille während Jahrhunderten in Europa zu den Basismitteln der Luestherapie; in China verwendete man das Rhizom von S. glabra gegen das Primärstadium der Syphilis. Weitere volksmedizinische Indikationsgebiete sind: Psoriasis, chronische Hautausschläge, Furunkulose und Rheumatismus, überhaupt Krankheiten mit chronisch-entzündlichem Verlauf. Sarsaparillwurzel soll den Stoffwechsel anregen und deshalb eine günstige Wirkung bei gewissen Hauterkrankungen und bei Rheumatismus haben. Ihre heutige Anwendung im Rahmen einer oralen Reizkörpertherapie bezweckt die Anregung der unspezifischen Abwehr. Die damit verbundene immunologische Wirkbasis muss allerdings wissenschaftlich noch belegt werden (vgl. Hänsel 1984).

\section{Glykoside des Diosgenins und verwandter Spirosta-5-ene}

Von den vorhergehend beschriebenen Steroidsapogeninen unterscheidet sich das Diosgenin (vgl. () Abb. 24.36) 
24.6 Saponine

983
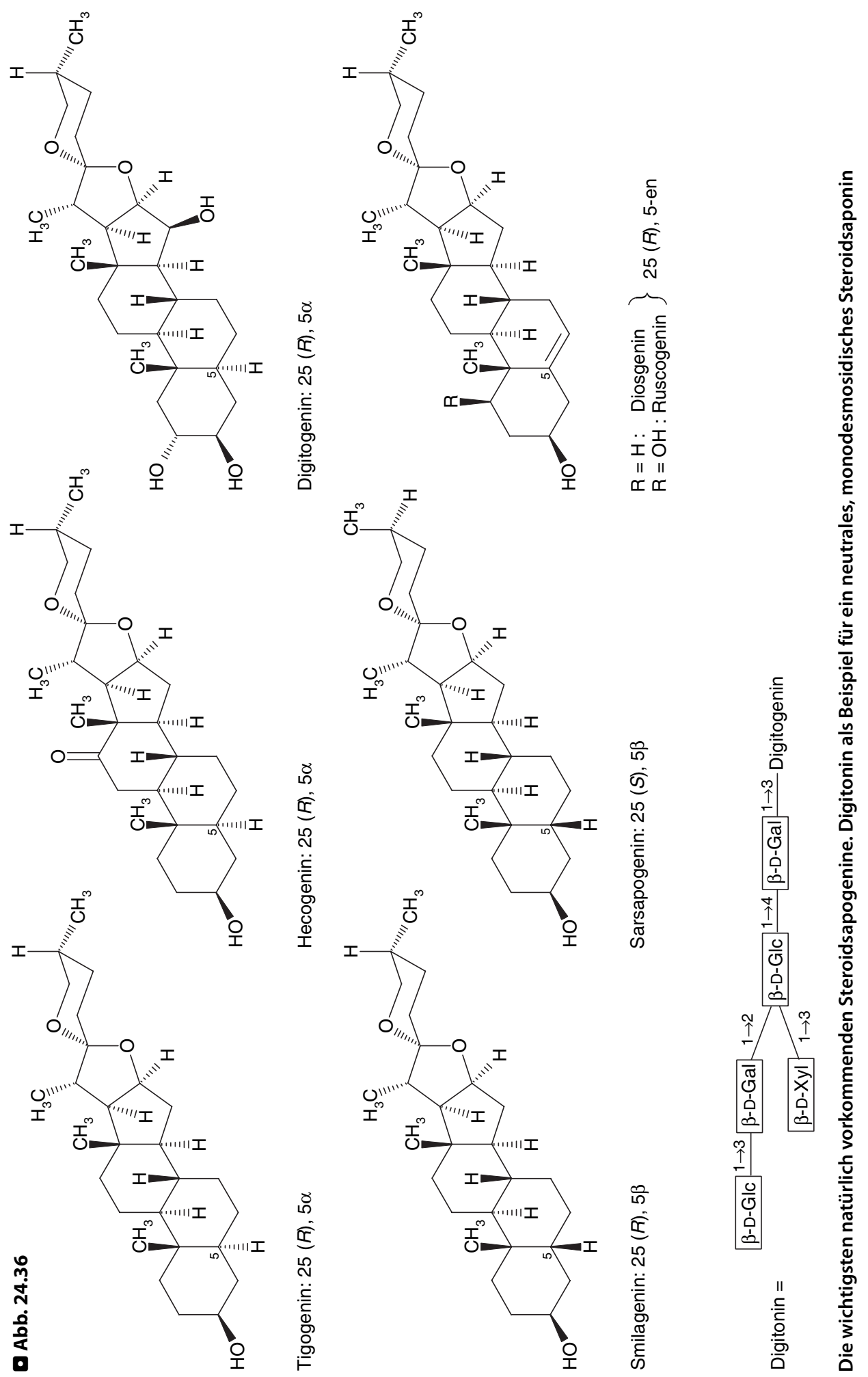
D Abb. 24.37

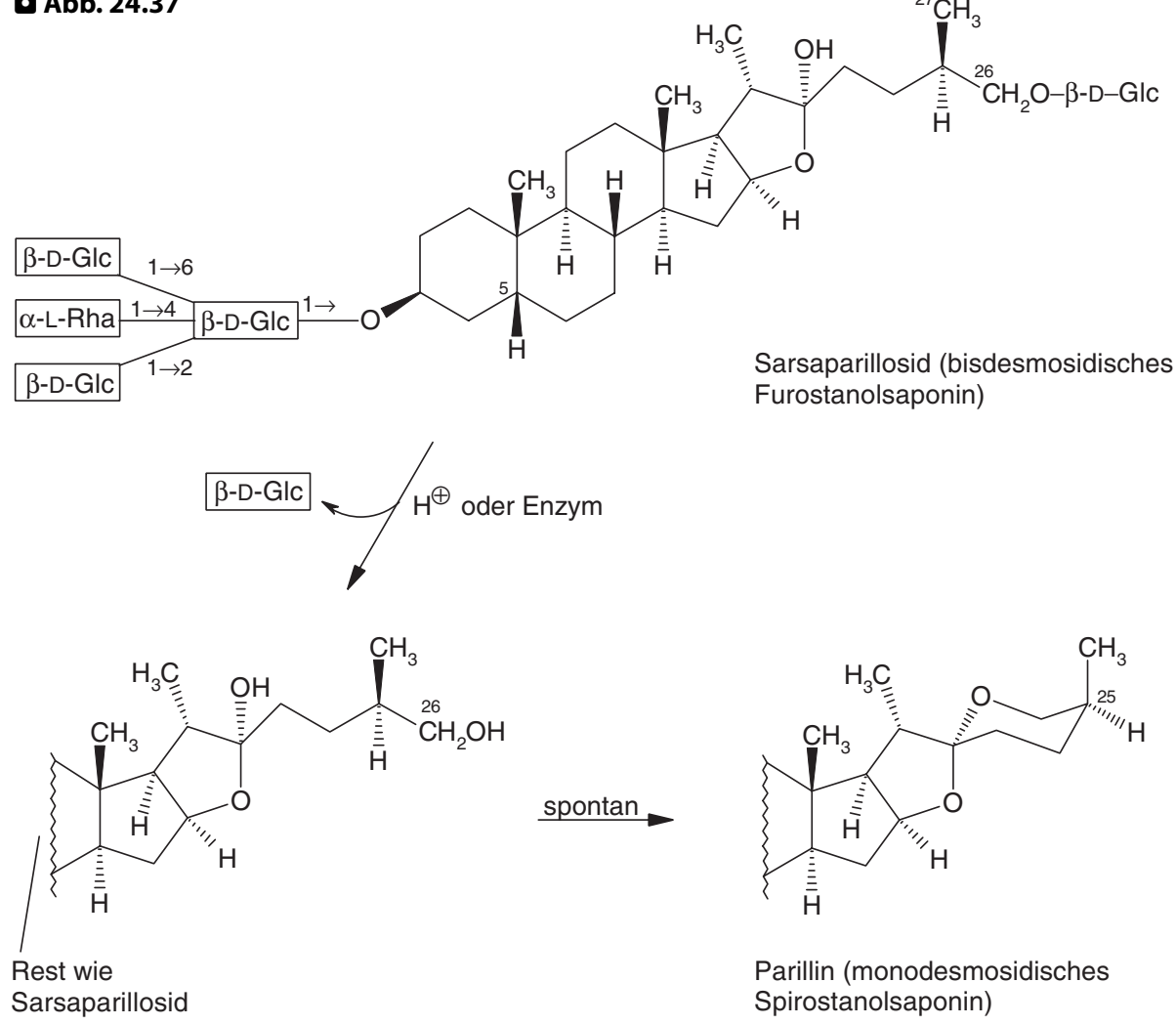

Biosynthetischer Zusammenhang zwischen bis- und monodesmosidischen Steroidsaponinen. Die Bisdesmoside stellen gleichsam die Vorstufen für die Monodesmoside dar: Der Zucker der Seitenkette wird enzymatisch, aber auch durch Säuren, sehr viel leichter abgespalten als die Zucker an $3-\mathrm{OH}$; die dabei entstehende Verbindung mit einer Diolseitenkette stabilisiert sich sofort zum Spiroketal.

Die biologischen Unterschiede zwischen den beiden Saponinen sind beträchtlich: Parillin wirkt hämolysierend und fungistatisch; Sarsaparillosid ist hämolytisch und antimikrobiell weitgehend inaktiv

wesentlich dadurch, dass im Ring B eine Doppelbindung vorliegt. Weitere Vertreter der Spirosta-5-en-Reihe sind in $>$ Tabelle 24.10 aufgeführt.

Spirosta-5-ene lassen sich leicht von den sie begleitenden 5,6-Dihydroderivaten durch eine Farbreaktion mit Antimontrichlorid in Nitrobenzol-Methanol unterscheiden. Die selektive Rot- oder Rosafärbung der Spirosta-5ene mit Antimon (III)-Ionen dient zugleich als Basis einer möglichen photometrischen Bestimmung.

In zahlreichen Dioscorea-Arten kommt Diosgenin in Form der beiden Trioside Dioscin und Gracillin vor. Dioscin enthält $1 \mathrm{Mol}$ D-Glucose und $2 \mathrm{Mol}$ L-Rhamnose, während Gracillin $2 \mathrm{Mol} \mathrm{D}$-Glucose und $1 \mathrm{Mol} \mathrm{L}$-Rhamnose enthält.
Dioscorea ist eine zu Ehren des griechischen Arztes Dioskurides (40-90 n. Chr.) benannte tropische Pflanzengattung. Bisher sind 250 Arten beschrieben. Wenn man von einigen der Stärke wegen kultivierten DioscoreaArten (Yamswurzel) absieht, die Rhizomknollen bilden, sind die anderen Dioscorea-Arten durch Wurzelknollen gekennzeichnet, die aus sprossbürtigen Wurzeln der Stängelbasis hervorgehen; sie sind von keuliger Gestalt, $30-70 \mathrm{~cm}$ lang und bis zu $20 \mathrm{~kg}$ schwer. Dioscorea-Arten haben einjährige, windende Stängel mit meist großen herzförmigen Blättern und getrenntgeschlechtlichen Blüten, die in lockeren Trauben stehen und 2-häusig oder 1-häusig verteilt sind; die Früchte sind 3-fächerige Kapseln. 
- Tabelle 24.10

Sapogenine der Spirosta-5-en-Reihe

$\begin{array}{lll}\text { Trivialname } & \begin{array}{l}\text { Konfiguration } \\ \text { an C-25 }\end{array} & \text { Ringsubstitution } \\ \text { Diosgenin } & 25(R) & 3 \beta \text {-ol } \\ \begin{array}{l}\text { Yamogenin } \\ \text { (Neodiosgenin) }\end{array} & 25(S) & 3 \beta \text {-ol } \\ \text { Ruscogenin } & 25(R) & 1 \beta, 3 \beta \text {-diol } \\ \text { Neoruscogenin } & 25 \text {-en } & 1 \beta, 3 \beta \text {-diol } \\ \text { Yuccagenin } & 25(R) & 2 \alpha, 3 \beta \text {-diol } \\ \text { Lilagenin } & 25(S) & 2 \alpha, 3 \beta \text {-diol } \\ \text { (Neoyuccagenin) } & & \\ \text { Botogenin } & 25(R) & 3 \beta \text {-ol,12-on } \\ \text { Neobotogenin } & 25(S) & 3 \beta \text {-ol,12-on } \\ \text { (Correlogenin) } & & \end{array}$

Einige Arten werden in Gewächshäusern ihrer schönen Blüten wegen als Zierpflanzen gezogen; andere haben in tropischen Gegenden Bedeutung als Nahrungsmittel (Yams), vergleichbar unserer Kartoffel, so D. alata L., D. bulbifera L., D. cayennensis LAM., D. esculenta (Lour.) Burk., D. opposita Thunb. (Synonym: D. batatas DeCne.).

Andere Dioscorea-Arten spielen in der Volksmedizin als Arzneidrogen eine Rolle, insbesondere die getrockneten unterirdischen Teile von $D$. villosa $\mathrm{L}$., einer in den östlichen und mittleren Regionen der USA beheimateten Art. Infuse gelten als spasmolytisch, entzündungswidrig, antirheumatisch und cholagog wirksam. Als Indikationen werden genannt: rheumatoide Arthritis, Muskelrheuma, Cholezystitis, Dysmenorrhoe.

Wurzeln von Dioscorea-Arten, die zur Diosgeningewinnung gesammelt werden (\$ Tabelle 24.11), bezeichnet man in Mexiko als Barbasco. Ursprünglich versteht man

- Abb. 24.38

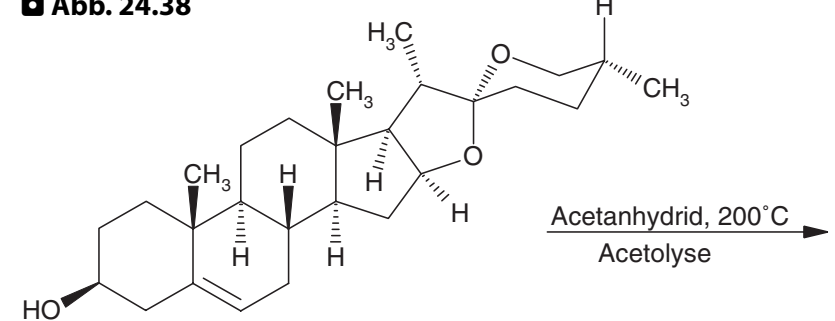<smiles>CC(=O)OCC(C)CCC1=C[C@]2(C)[C@@H](C[C@H]3[C@@H]4CC=C5C[C@@H](OC(C)=O)CC[C@]5(C)[C@H]4CC[C@]32C)O1</smiles><smiles>CC(=O)C1=CC[C@H]2[C@@H]3CC=C4C[C@@H](O)CC[C@]4(C)[C@H]3CC[C@]12C</smiles>

16-Dehydropregnenolon (4)

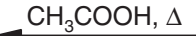

Abbau von Diosgenin (1) zum 16-Dehydropregnenolon (4), einer Muttersubstanz, die partialsynthetisch zu Corticosteroiden, Pregnenen, Androstenen und 19-Norsteroiden umwandelbar ist. Diosgenin wird im Druckkessel bei $200^{\circ} \mathrm{C}$ mit Acetanhydrid gekocht. Dabei bricht der Spiroketalring unter Ausbildung einer 20,22-Doppelbindung auf: es bildet sich das als Pseudodiosgenin (c-Diosgenin) bezeichnete Furostanderivat 2, das bei niederen Temperaturen mit Chromsäure zum Diketon 3 (= Dioson) abbaubar ist. Erhitzen mit Essigsäure führt zu 4 bzw. 4-Acetat. 4 wird in mehreren Schritten in Cortexolon umgewandelt und anschließend durch $11 \beta$-Hydroxylierung mit Hilfe von Mikroorganismen in Cortisol übergeführt 
- Tabelle 24.11

Dioscorea-Arten mit industrieller Bedeutung als Rohstoff zur Diosgeningewinnung

\begin{tabular}{ll} 
Art & Geographische Herkunft \\
D. composita HEMSL. & Mexiko, Guatemala \\
D. deltoidea WALL. & Indien, Pakistan, Nepal \\
D. floribunda M. MART. et GAL. & Mexiko, Mittelamerika \\
D. mexicana GUILL. & Mexiko, Mittelamerika \\
D. panthaica PRAIN. et Burk. & China \\
D. prazeri PRAIN. et BURK. & Indien \\
D. spiculiflora HEMSL. & Mexiko, Mittelamerika \\
D. zingiberensis C.H. WRIGHT & China \\
\hline
\end{tabular}

in den spanisch sprechenden Ländern der neuen Welt unter Barbasco jede als Fischgift zum Fischfang verwendbare Wurzel, gleichgültig, um welche Pflanzenart es sich handelt.

Einen Teil der auf dem Weltmarkt angebotenen Arzneistoffe vom Typus der Steroide - Corticosteroide, Sexualhormone und Ovulationshemmer - stellt man partialsynthetisch aus Diosgenin (\$ Abb. 24.38), andere aus Sitosterol, Gallensäuren und weiteren Naturstoffen her. Bei allen Verfahren werden Mikroorganismen für stereospezifische Reaktionsschritte eingesetzt.

\section{Mäusedornwurzelstock}

Herkunft. Mäusedornwurzelstock (Rusci rhizoma PhEur 5, korrigiert 5.3) besteht aus den unterirdischen Teilen von Ruscus aculeatus L. (Familie: Convallariaceae [IIA6a], bisher Asparagaceae). Die Stammpflanze, ein bis $1 \mathrm{~m}$ hoch werdender, immergrüner Halbstrauch ist in Frankreich und im Mittelmeergebiet (inklusive Nordafrika) heimisch. Charakteristisch sind die eigentümlich gestalteten, blattförmigen Kurztriebe (Phyllokladien), die in den Achseln stark reduzierter Blätter sitzen und in eine scharfe Spitze auslaufen. Von dieser Eigentümlichkeit leitet sich die botanische Artbezeichnung ab (aculeatus = stachelig).

\section{Inhaltsstoffe}

- Steroidsaponine (4-6\%; PhEur = mindestens $1,0 \%$ Sapogenine) mit den Aglykonen Neoruscogenin und Ruscogenin (> Abb. 24.39 und 24.40);
- Sterole und Sterolglykoside, Triterpene, 2,5-Diacetyl6-hydroxybenzofuran (Euparon), Chrysophansäure;

- wenig ätherisches $\mathrm{O} l, \mathrm{C}_{22}-\mathrm{C}_{26}$-Fettsäuren.

\section{Analytische Kennzeichnung}

Prüfung auf Identität. DC-Nachweis (PhEur) der Ruscogenine nach Hydrolyse mit verdünnter Salzsäure [Fließmittel: Methanol-Methylenchlorid (7:93); Referenzsubstanzen: Ruscogenine CRS und Stigmasterol; Nachweis: Vanillin-Schwefelsäure-Reagens]. Die Ruscogenine erscheinen nach Besprühen mit dem Vanillin-Schwefelsäure-Reagens im Tageslicht als gelbe Zone.

Gehaltsbestimmung. Die Gehaltsbestimmung der Ruscogenine (PhEur) erfolgt mit der HPLC unter Verwendung von octadecylsilyliertem Kieselgel $(5 \mu \mathrm{m})$ als Säulenmaterial, einem Wasser-Acetonitril-Gradienten und einer Mischung der Ruscogenine [Ruscogenine CRS (Ruscogenin + Neoruscogenin)] als externer Standard.

Verwendung. Aus dem Mäusedornwurzelstock werden hydroalkoholische Extrakte sowie Neoruscogenin/ Ruscogenin-Reinstoffpräparate, deklariert als „Ruscogenine“, hergestellt, die durch hydrolytischen Abbau der Saponine gewonnen werden. Deglucoderhamnoruscin und weitere zuckerarme Saponine werden durch Behandlung mit geeigneten Enzymen hergestellt (Di Lazzaro et al. 2001).

Pharmakokinetik. Zur Pharmakokinetik der Saponine von R. aculeatus am Menschen liegt bisher nur eine Pilotstudie vor. Dabei wurde an 3 Probanden je $1 \mathrm{~g}$ RuscusExtrakt p.o. verabreicht. Die höchste Plasmakonzentration an Deglucoruscin $(\sim 2 \mu \mathrm{g} / \mathrm{ml})$ konnte mit der HPLC zwischen 90-120 min nachgewiesen werden. Dieser Versuch zeigt, dass Spirostanolglykoside vom Menschen nach p.o.-Verabreichung resorbiert werden (Rauwald $\mathrm{u}$. Grünwidl 1991). Diese vorläufigen Resultate müsssen durch eine größere Studie und unter Berücksichtigung der heute bekannten genuinen Hauptinhaltsstoffe bestätigt werden.

Wirkungen. Im Tierexperiment konnten eine Erhöhung des Venentonus, kapillarabdichtende, antiphlogistische und diuretische Wirkungen nachgewiesen werden (Kommission E). Als Wirkstoffe gelten insbesondere Deglucoderhamnoruscin und weitere zuckerarme Saponine sowie die Aglykone Neoruscogenin und Ruscogenin. Die Agly- 
D Abb. 24.39

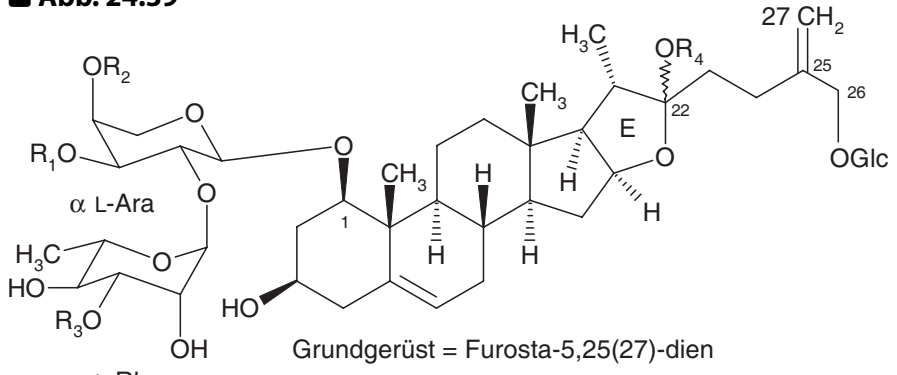

$\alpha$ L-Rha

\begin{tabular}{|lllll|}
\hline & $\mathrm{R}_{1}$ & $\mathrm{R}_{2}$ & $\mathrm{R}_{3}$ & $\mathrm{R}_{4}$ \\
\hline 1 (Ruscosid) & $\mathrm{H}$ & $\mathrm{H}$ & $\mathrm{Glc}$ & $\mathrm{H}$ \\
2 (Deglucoruscosid) & $\mathrm{H}$ & $\mathrm{H}$ & $\mathrm{H}$ & $\mathrm{H}$ \\
\hline
\end{tabular}

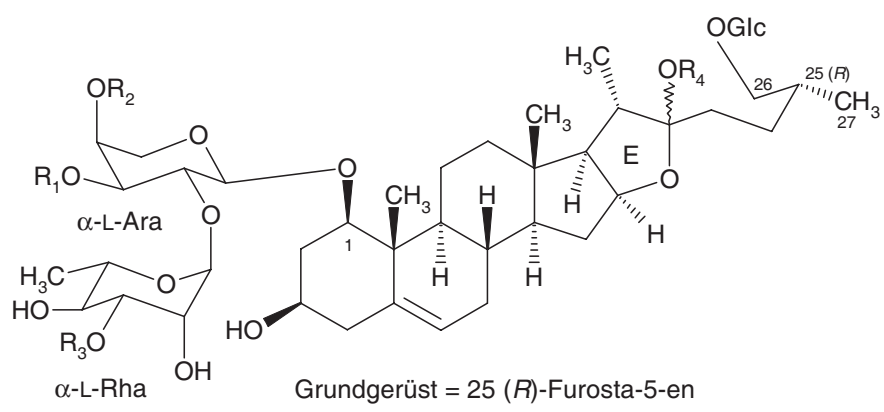

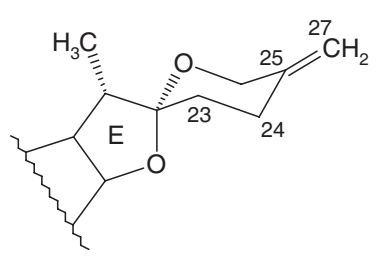

Grundgerüst = Spirosta-5,25(27)-dien; Aglykon = Neoruscogenin, $\mathrm{C}_{27} \mathrm{H}_{40} \mathrm{O}_{4}$

\begin{tabular}{|llll|}
\hline & $\mathrm{R}_{1}$ & $\mathrm{R}_{2}$ & $\mathrm{R}_{3}$ \\
\hline 3 (Ruscin) & $\mathrm{H}$ & $\mathrm{H}$ & $\mathrm{Glc}$ \\
4 (Deglucoruscin) & $\mathrm{H}$ & $\mathrm{H}$ & $\mathrm{H}$ \\
\hline
\end{tabular}

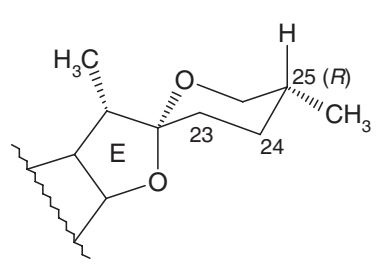

Grundgerüst $=25(\mathrm{R})$-Spirosta-5-en; Aglykon = "Ruscogenin" (1 $\beta$-Hydroxydiosgenin), $\mathrm{C}_{27} \mathrm{H}_{42} \mathrm{O}_{4}$

Mäusedornwurzelstock enthält als charakteristische und pharmakologisch aktive Inhaltsstoffe ein sehr komplexes Gemisch von ca. 30 Steroidsaponinen mit Furosta-5,25(27)-dien-, Spirosta-5,25(27)-dien-, (25R)-Furosta-5-en- und (25R)-Spirosta-5-en-Grundstrukturen (vgl. Mimaki et al. 1998a,b,c,d; Mimaki et al. 1999 und darin zitierte Literaturen). Die Zuckerkette ist bei allen Ruscus-aculeatus-Saponinen nicht über das 3-OH, sondern über das 1-OH an das jeweilige Genin gebunden, die Ringe A-E (C-1 bis C-21) sind identisch (Ringverknüpfung: $B / C, C / D=$ trans; $D / E=c i s$ ). Bei den mengenmäßig vorherrschenden Hauptsaponinen handelt es sich um die bisdesmosidischen Furostanolglykoside Ruscosid (1) und Deglucoruscosid (2) sowie die monodesmosidischen Spirostanolglykoside Ruscin (3), Deglucoruscin (4) und Deglucoderhamnoruscin (Aglykon: Neoruscogenin) (vgl. de Combarieu et al. 2002). Als Nebenglykoside kommen die (25R)-25,27-Dihydroderivate der aufgeführten Verbindungen vor (in der Abbildung = Formeln unten; ohne Trivialnamen), ferner Steroidsaponine, die am OH-C-22 methyliert, 23-Hydroxy- bzw. 23,24-Dihydroxyneoruscogenin als Aglykon aufweisen, Arabinose durch $\beta$-D-Galactose ersetzt ist, der Substitutent $R_{1} \beta$-D-Xylose darstellt, die an einem der Zuckerbausteine sulfatiert, acetyliert oder mit einer 2-Hydroxy-3-methylpentanoyl-Gruppe substituiert bzw. am Aglykon (1-OH) mit einem Sulfatrest verestert sind. Es ist nicht abgeklärt, ob 22-Oxyfurostanol als 22-OH wie in Ruscosid/Deglucoruscosid oder als 22-OCH 3 genuin in der Pflanze vorkommt.

Enzymatische oder säurehydrolytische Abspaltung der Zucker führt bei den Furostanolglykosiden unter Zyklisierung der Seitenkette nicht zum freien Furostandientetraol, sondern zu Neoruscogenin. Gemäß Rauwald u. Janßen (1988) werden bei der Hydrolyse eines Ruscus-Extrakts 75\% Neoruscogenin und 25\% Ruscogenin als Aglykone erhalten. Die Bezeichnung „Neoruscogenin“ für das Spirosta-25(27)-dien-Grundgerüst ist verwirrend, da der Name Neoruscogenin für das Aglykon mit einem 25(S)- $\Delta^{5}$-Spirostaengerüst verwendet werden sollte (vgl. $>A b b .24 .35$ ) 


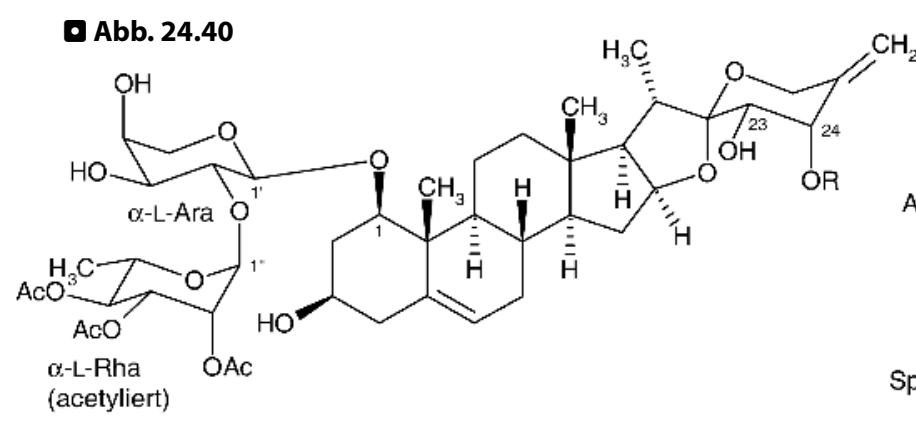

Aculeosid A (Aglykon = 23,24-Dihydroxyneoruscogenin), $\mathrm{C}_{50} \mathrm{H}_{72} \mathrm{O}_{21}$

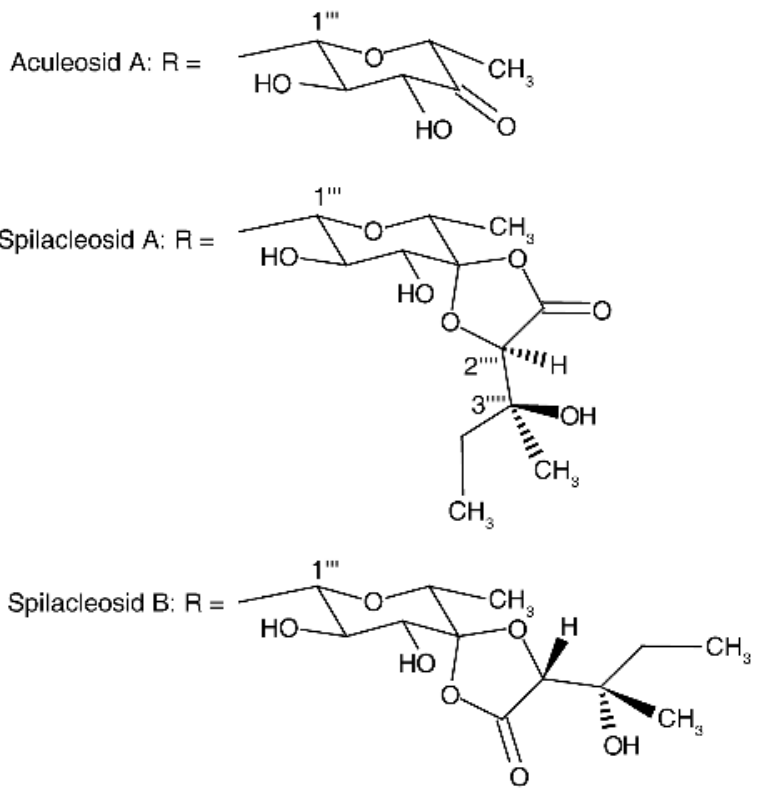

Von besonderem Interesse ist das Aculeosid A. Es handelt sich dabei um ein bisdesmosidisches Spirostanolglykosid mit einer seltenen Deoxyaldoketose (6-Deoxy-D-glycero-L-threo-4-hexosulose), die über das 24-OH des 23,24-Dihydroxyneoruscogenins verknüpft ist (Horikawa et al. 1994; Mimaki et al. 1998d). Es zeigt eine starke zytostatische Aktivität an menschlichen $\mathrm{HL}-60$-Leukämiezellen $\left(\mathrm{IC}_{50}\right.$-Wert $\left.=0,48 \mu \mathrm{g} / \mathrm{ml}^{-1}\right)$. Kürzlich wurden zwei strukturell interessante AculeosidA-Derivate mit einer 1,3-Dioxolan-Spirostruktur isoliert, die Spilacleoside A und B. Sie sind aus Aculeosid A und (2R, 3S)2,3-Dihydroxy-3-methylpentansäure zusammengesetzt (Kameyama et al. 2003)

kone der Ruscus-Saponine („Ruscogenine“) erwiesen sich in vitro als Hemmstoffe der Elastase (vgl. dazu auch Kap. 24.6.8, Abschnitte Efeublätter und Rosskastaniensamen; Facino et al. 1995). Übersichten über die bis 1997/98 vorliegenden pharmakologischen und klinischen Untersuchungen finden sich bei van Rensen (2000) und bei Noé (2000). In den vorliegenden Anwendungsbeobachtungen und meist offenen, nicht GCP-konformen klinischen Studien sowie den pharmakologischen Untersuchungen wurden Extrakte von Mäusedornwurzelstock fast immer als Bestandteil von Kombinationspräparaten untersucht (z. B. Ruscusextrakt, Hesperidinmethylchalkon, Ascorbinsäure; für neue Literatur dazu vgl. Bouaziz et al. 1999; Jäger et al. 1999; Parrado u. Buzzi 1999; Beltramino et al. 2000 und darin zitierte Literatur). Eine erst kürzlich durchgeführte randomisierte, plazebokontrollierte Doppelblindstudie (Vanscheidt et al. 2002) ergab signifikante Unterschiede zwischen dem Ruscusextrakt (mind. 4,5 mg Gesamtrus- cogenine pro Dosis) und Plazebo in der Behandlung von Patienten mit chronischer venöser Insuffizienz [vgl. Infobox „Chronische venöse Insuffizienz (CVI)“; S. 969].

Anwendungsgebiete. Zur unterstützenden Therapie von Beschwerden bei CVI wie Schmerzen und Schweregefühl in den Beinen, nächtliche Wadenkrämpfe, Juckreiz und Schwellungen. Unterstützende Therapie von Beschwerden bei Härmorrhoiden wie Juckreiz und Brennen (Kommission E, ESCOP).

Hydroalkoholische Trockenextrakte, die Saponine enthalten, werden vergleichbar mit Rosskastanienextrakten in verschiedenen Zubereitungsformen als Venenmittel angeboten, während Ruscogeninpräparate zu Hämorrhoidalmitteln verarbeitet werden.

Nebenwirkungen. In seltenen Fällen können Magenbeschwerden und Übelkeit auftreten. 


\section{! Kernaussagen}

Mäusedornwurzelextrakte werden zur unterstützenden Behandlung von Beschwerden bei CVI verwendet. Hauptinhaltsstoffe sind Steroidsaponine mit den Aglykonen Ruscogenin und Neoruscogenin, bei denen die Zuckerkette nicht über das 3-OH, sondern über das 1-OH an das Aglykon gebunden ist. Zuckerarme Steroidsapo- nine wie Deglucoderhamnoruscin und die Aglykone Neoruscogenin und Ruscogenin haben insbesondere kapillarabdichtende und antiphlogistische Wirkungen. Metabolismus und Pharmakokinetik der Steroidsaponine müssen am Menschen in einer größeren Studie untersucht werden, bevor zuverlässige Aussagen über die Wirkstoffe gemacht werden können.

\section{Schlüsselbegriffe}

Chronische venöse Insuffizienz (CVI)

Deglucoderhamnoruscin

Digitonin

Dioscorea-Arten

Diosgenin

Furostanole

Isosapogenin

Mäusedornwurzelstock
Mikrobielle Steroidhydroxylierung

Neosapogenin

Parillin

Paritalsynthese von Corticosteroiden

Reizkörpertherapie

Ruscogenine

Ruscus aculeatus

Sarsaparillosid

\author{
Sarsapogenin \\ Smilagenin \\ Smilax-Arten \\ Smilax-Saponine \\ Spirostanole \\ Steroidsaponine
}

\subsection{Herzwirksame Steroide}

\subsubsection{Begriffsbestimmung, Geschichtliches}

Unter herzwirksamen Steroiden versteht man eine Gruppe meist glykosidischer Pflanzeninhaltsstoffe, die spezifische Wirkungen auf den Herzmuskel von Kalt- und Warmblütlern entfalten. Der üblicherweise verwendete Begriff "herzwirksame Glykoside" für diese Stoffgruppe ist ungenau, da in der Natur auch nichtglykosidische Steroide sowie Glykoside ohne Steroidgerüst mit einer Wirkung auf das Herz vorkommen.

Niedrige (therapeutische) Dosen der herzwirksamen Steroidglykoside wirken kardiotonisch. Ein isoliertes Froschherz beispielsweise, das unter zunehmender Belastung langsam größer wird und in Diastole stehen bleibt, nimmt nach Gabe von einem Tropfen einer Glykosidlösung seine Arbeit wieder auf und verkleinert sich bereits nach wenigen Schlägen. Ähnlich kann beim Menschen der insuffiziente Herzmuskel aus einem Zustand chronischer Erschöpfung erneut zur notwendigen physiologischen Leistung stimuliert werden. Höhere (toxische) Dosen haben eine spezifisch toxische Wirkung auf das Herz: Es kommt zu einer dauernden Erhöhung des Herztonus, wobei die diastolische Erschlaffung zunehmend geringer wird. Hinzu treten Rhythmusstörungen und eine Blockierung des Reizleitungssystems mit ungeordnetem Funktionieren des Herzens. Schließlich steht das Herz in halbkontrahiertem Zustand (Säugetierherz) oder in maximaler Systole (Froschherz) still.

Beide Wirkungen, die kardiotonische als auch die toxische, waren in der vornaturwissenschaftlichen Ära bekannt. Die Meerzwiebel, Scillae bulbus, wird in allen größeren medizinisch-botanischen Werken der Antike erwähnt; Dioskurides empfiehlt sie Wassersüchtigen, ebenso Celsus und Scribonius Largus. Das Maiglöckchen, Convallaria majalis, spielt im Mittelalter eine vergleichbare Rolle. Der purpurrote Fingerhut (Digitalis purpurea) wurde zuerst in der Volksmedizin der britischen Inseln verwendet. Durch das Wirken des englischen Arztes William Withering - seine bekannte Schrift „An account of the foxglove, and some of its medical uses with practical remarks on dropsy, and other diseases" erschien im Jahre 1785 - wurden die therapeutischen Effekte der Digitalis-Blätter in der Medizin allgemein bekannt. Getrocknetes Sekret der Haut- und Ohrspeicheldrüsen von Kröten (Bufonidae) - eine tierische Droge mit typischer Digitaliswirkung - war ein wichtiges Herzmittel der chinesischen Medizin lange vor Christi Geburt.

Auch die toxischen Wirkungen von herzwirksamen Steroiden waren bekannt. Man verwendete entsprechende Pflanzenextrakte zur Herstellung von Pfeilgiften, so auf Borneo von Antiaris toxicaria (Pers.) Lesch. (Familie: Moraceae [IIB11c]), in Westafrika von Strophanthuskombé-Samen. 


\subsubsection{Aufbau der herzwirksamen Steroidglykoside}

Herzwirksame Steroidglykoside sind $\mathrm{C}_{23}$ - oder $\mathrm{C}_{24}$-Steroide, die über die alkoholische 3-Hydroxylgruppe in glykosidischer Bindung mit der zyklischen Halbacetalform eines Mono-, Di-, Tri- oder Tetrasaccharidrestes verknüpft sind.

Aglykon. Als Prototyp kann das Digitoxigenin gelten: Bei ihm sind alle Struktureigentümlichkeiten, die zur Herzwirksamkeit erforderlich sind, voll ausgebildet (> Abb. 24.41). Die Ringe A/B/C des Steroidgerüstes
(> Abb. 24.42) weisen cis-trans-Verknüpfung auf, wie sie auch für die Gallensäuren (Coprostanreihe) typisch ist. Die cis-Verknüpfungsweise der Ringe C/D hingegen kommt außerhalb der herzwirksamen Steroidglykoside fast nicht vor (Ausnahme: Holarrhena-Alkaloide). An funktionellen Gruppen trägt das Steroidgerüst $2 \beta$-ständige Hydroxylgruppen an $\mathrm{C}-3$ und $\mathrm{C}-14$ sowie einen Butenolidring $\beta$-ständig an C-17.

Die Variation dieses Prototypmoleküls umfasst im Wesentlichen 2 Typen:

a) Abwandlung des Butenolidringes und

b) Abwandlung durch Oxidation (Substitutionsmuster).

Abb. 24.41

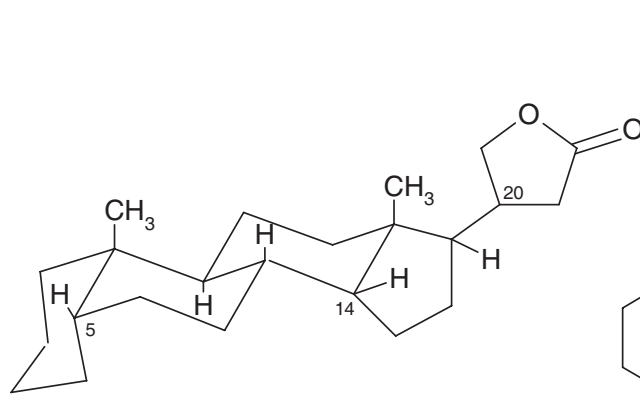

$5 \beta, 14 \beta-C a r d a n o l i d$

Konformationsformel

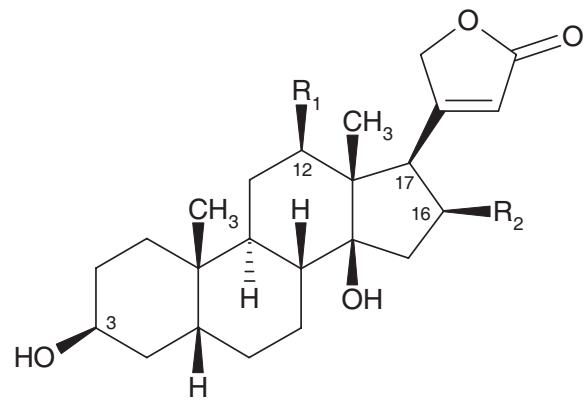

\begin{tabular}{|l|l|l|}
\hline $\mathrm{R}_{1}$ & $\mathrm{R}_{2}$ & \\
\hline $\mathrm{H}$ & $\mathrm{H}$ & Digitoxigenin \\
$\mathrm{OH}$ & $\mathrm{H}$ & Digoxigenin \\
$\mathrm{H}$ & $\mathrm{OH}$ & Gitoxigenin \\
$\mathrm{OH}$ & $\mathrm{OH}$ & Diginatigeni \\
\hline
\end{tabular}

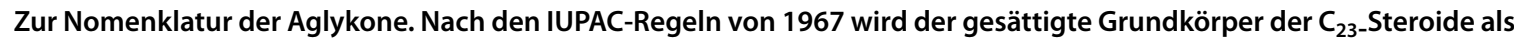
Cardanolid bezeichnet; die Bezeichnung Bufanolid wird für $\mathrm{C}_{24}$-Steroide verwendet, die an C-17 einen 6-gliedrigen Lactonring tragen. Damit die von den beiden Grundkörpern sich ableitenden Derivate die typische Herzwirkung aufweisen, müssen bestimmte strukturelle und räumliche Merkmale vorliegen: 1) $\beta$-ständige ungesättigte Lactonringe an C-17; 2 ) mindestens $2 \beta$-ständige Hydroxylgruppen an C-3 und C-14 
- Abb. 24.42

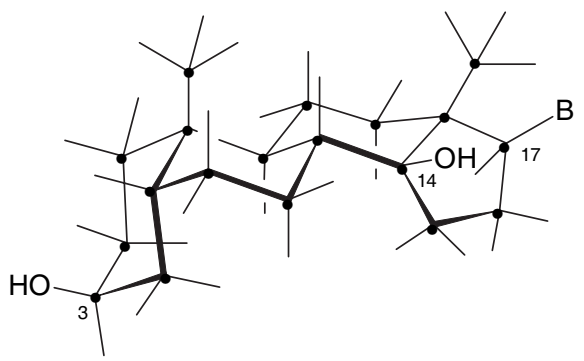

Digitoxigenin

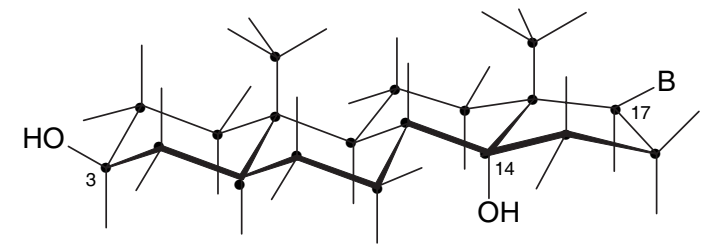

Schattenriss von Dreiding-Modellen. Die Ringe A mit B sowie $C$ mit $D$ sind bei den herzwirksamen Steroiden cisverknüpft, die Ringe $B$ mit $C$ hingegen trans-verknüpft. Dies bedeutet für den räumlichen Bau des Cyclopentanoperhyodrophenanthrenteils, dass nur die Ringe $B$ und $C$ annähernd flächig-eben gebaut sind, die Ringe $A$ und $D$ hingegen beide stark abgewinkelt sind. Zum Vergleich: ein mit Digitoxigenin isomeres Molekül mit durchgehender trans-Verknüpfung sämtlicher Ringe. $B$ Butenolidring

Vergleich: alle Ringe trans-verknüpft

- Abb. 24.43

Cholesterol (C27)

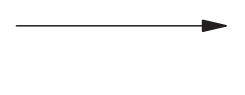

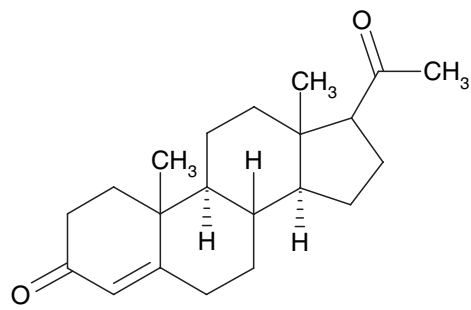

Progesteron (1)

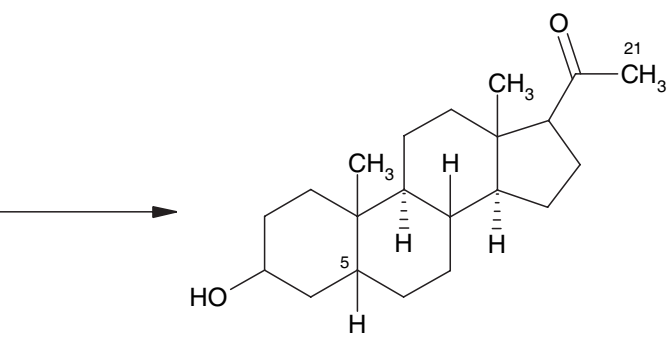

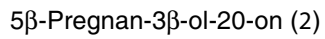

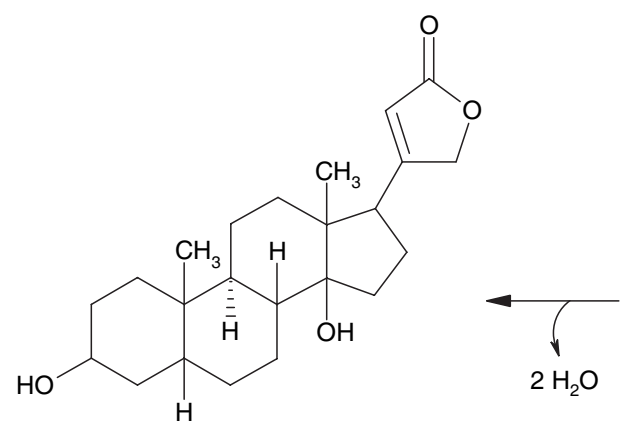

Digitoxigenin

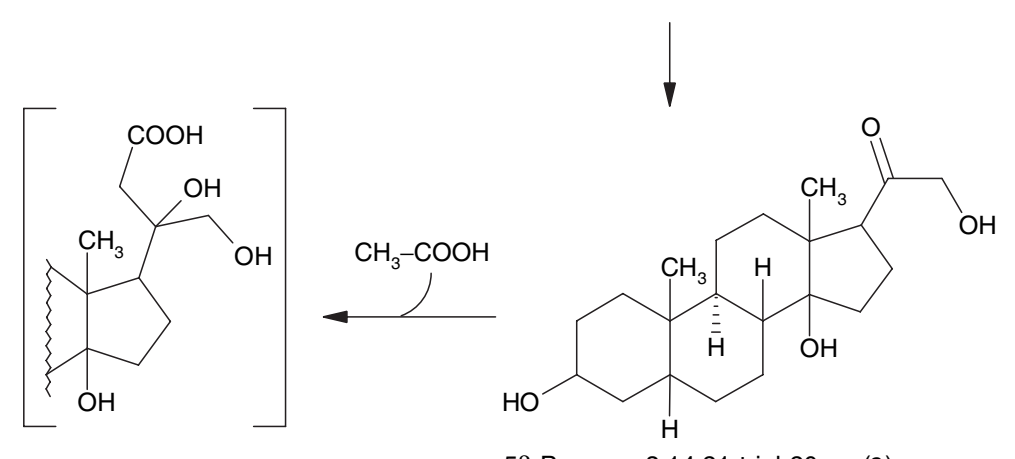

5 $\beta$-Pregnan-3,14,21-triol-20-on (3)

Biosynthetisch lassen sich die Cardenolide als Derivate des Cholesterols auffassen. Wie der tierische Organismus, so sind auch Pflanzen befähigt, Cholesterol zum $C_{21}$-Progesteron abzubauen. Hydroxylierung an C-14 und C-21 der Zwischenstufe 2 führt zum Triol 3. Die beiden Kohlenstoffatome der $C_{23}$-Cardenolide stammen aus Acetyl- bzw. Malonyl-CoA. Die $\mathrm{C}_{3}$-Kette der Bufadienolide stammt aus Propionyl- oder Methylmalonyl-CoA 
$\mathrm{Zu}$ a): Anstelle des 5-gliedrigen Lactonringes kann auch ein $\alpha$-Pyron-Ring (Cumalinring; Pentadienolidring) vorkommen. Dementsprechend teilt man die herzwirksamen Steroide in die Gruppe der Cardenolide und in die der Bufadienolide ein.

$\mathrm{Zu} \mathrm{b):} \mathrm{Das} \mathrm{Steroidgerüst} \mathrm{kann} \mathrm{an} \mathrm{zahlreichen} \mathrm{weiteren}$ Stellen hydroxyliert (und sekundär acyliert) sein; v. a. betroffen sind dabei die Positionen C-1, C-5, C-11, C-12 und C-16. Sodann kann anstelle der Methylgruppe an C-10 eine Hydroxymethyl- oder eine Aldehydgruppe vorliegen, wie das für die Cardenolide aus Strophanthus- und Convallaria-Arten charakteristisch ist.

Von den etwa 100 bekannten Aglykonen unterscheiden sich einzelne auch durch das Auftreten von Doppelbindungen im Ringsystem, zusätzlichen Epoxy- oder Oxogruppen und seltener durch trans-trans-cis-Verknüpfung der Ringe. Auf weitere Abweichungen bei seltener vorkommenden und therapeutisch nicht verwendeten Glykosiden kann hier nicht eingegangen werden.

Der biosynthetischen Verwandtschaft nach sind die Aglykone zwischen dem Cholesterol und den Pregnanen einzuordnen. Stammverbindung ist das $\mathrm{C}_{27}$-Cholesterol, das zunächst zu einem $\mathrm{C}_{21}$-Steroid abgebaut und durch Verknüpfung mit Acetyl- bzw. Malonyl-CoA bzw. einem $\mathrm{C}_{3}$-Donator zu den $\mathrm{C}_{23}$-Cardenoliden und den $\mathrm{C}_{24}$-Bufadienoliden wieder aufgebaut wird (> Abb. 24.43).

Zuckerteil der herzwirksamen Steroidglykoside. Es kommt neben D-Glucose, L-Rhamnose und D-Fucose eine Reihe sonst sehr seltener 2,6-Didesoxyzucker sowie deren 3-Methylether vor ( $(A b b$. 24.44). In allen bisher bekannten Glykosiden ist das Aglykon entweder $\beta$-D-glykosidisch oder $\alpha$-L-glykosidisch mit der Zuckerkette verbunden, was bedeutet, dass in allen Glykosiden die Absolutkonfiguration am Anomeriezentrum C-1 stets die gleiche ist. Die Zucker der $\beta$-D-Reihe liegen in $\operatorname{der}{ }^{4} \mathrm{C}_{1^{-}}$, die der $\alpha$-LReihe in $\operatorname{der}{ }^{1} \mathrm{C}_{4}$-Konformation vor ( $(A b b$. 24.44). Wenn seltene Desoxyzucker und „normale“ Zucker, wie D-Glucose nebeneinander in der Zuckerkette auftreten, dann ist das Aglykon an einen seltenen Zucker gebunden, wohingegen die D-Glucosemoleküle endständig angeordnet sind. Enzyme spalten bevorzugt die $\beta$-D-Glucose ab. Bereits während der Aufarbeitung der Droge können sich aus den genuinen Primärglykosiden die glucosefreien Sekundärglykoside bilden.

Glykosidnatur. Die glykosidische Verknüpfung der herzwirksamen Steroide mit Zuckern ist für die Herzwirk- samkeit nicht unbedingt notwendig, die Aglykone allein sind auch wirksam. Sie sind allerdings therapeutisch nicht brauchbar, da sie im Organismus sehr rasch metabolisiert werden. Die Zucker beeinflussen nicht nur die physikochemischen Eigenschaften der Glykoside (Resorption, Proteinbindung, Verteilung im Organismus, Biotransformation und Ausscheidung) wesentlich, sie sind auch für die Affinität der Substanzen mit dem Digitalisrezeptor essentiell (vgl. Kap. 24.7.6). Erst der Umstand, dass die Aglykone mit seltenen Zuckern verknüpft sind, die im Organismus nicht oder nur sehr langsam abgebaut werden, ermöglicht die therapeutische Verwendung dieser Pflanzenstoffe. Die am 3-OH glykosidisch gebundene $\mathrm{Zu}$ ckerkette verhindert nicht nur die Inaktivierung des Genins, sie erschwert auch dessen Hydroxylierung - einen entscheidenden metabolischen Schritt zur rascheren Elimination aus dem menschlichen Organismus. Wären die Genine beispielsweise direkt an D-Glucose, einen im menschlichen und tierischen Organismus vorkommenden Zucker, gebunden, so wäre höchst wahrscheinlich die Metabolisierung dieser herzwirksamen Steroide nicht allzusehr verzögert und ihre therapeutische Wirksamkeit somit höchst flüchtig.

\subsubsection{Einige chemische Eigenschaften, Farbreaktionen}

Die herzwirksamen Steroidglykoside sind farblose, kristallisierbare Substanzen, die einen bitteren Geschmack aufweisen. Sie sind leicht löslich in Ethanol, Chloroform und Pyridin, mäßig löslich in Ethylacetat. In Wasser sind sie, sobald sie in reiner Form vorliegen, nur schwer löslich; doch sind sie aus pflanzlichem Material durchaus mit Wasser extrahierbar.

In wässriger oder alkoholischer Lösung sind sie nur bei neutralem sowie sehr schwach basischem und sehr schwach saurem $\mathrm{pH}$-Bereich beständig. In stark saurem Bereich, v. a. bei höherer Temperatur (Hydrolysebedingungen), erfolgt leicht Dehydratisierung zu den unwirksamen 14-Anhydroverbindungen. Alkalieinwirkung führt zunächst zur Öffnung des Lactonringes; unter Verschiebung einer Doppelbindung bildet sich eine Aldehydcarbonsäure, die nach Wiederansäuern zu den unwirksamen Isocardanoliden rezyklisiert (?) Abb. 24.45).

Herzwirksame Steroidglykoside geben mit vielen Reagenzien Farbreaktionen, wobei der Steroidteil, der Zu- 
- Abb. 24.44
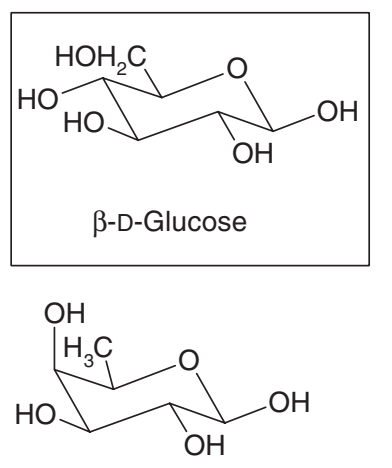

$\beta$-D-Fucose<smiles>CC1OC(O)CC(O)C(O)C1O</smiles>

$\beta$-D-Digitoxose<smiles>CO[C@H]1C(C)O[C@H](O)[C@H](O)[C@H]1O</smiles>

$\beta$-D-Digitalose<smiles>COC1CC(O)OC(C)C1O</smiles>

$\beta$-D-Cymarose<smiles>CO[C@H]1C(O)[C@H](C)O[C@H](O)C[C@@H]1O</smiles>

$\beta$-D-Diginose<smiles>CC1OC(O)C(O)C(O)C1O</smiles><smiles>COC1OC(O)C(O)C(O)C1C</smiles>

$\alpha$-L-Oleandrose

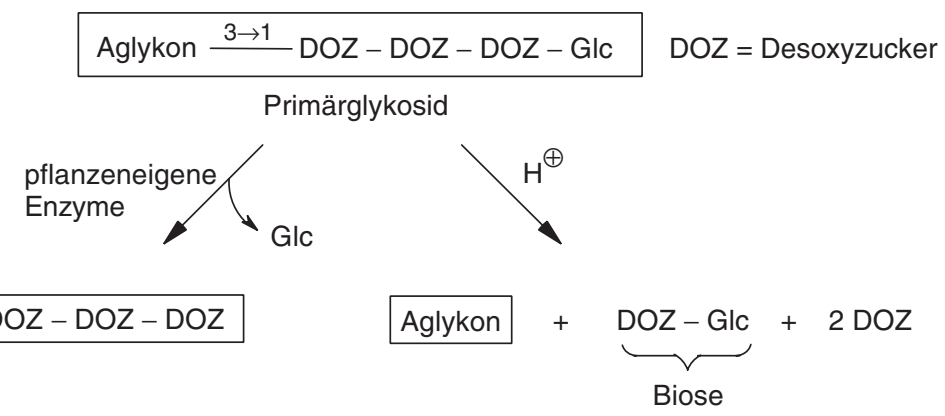

Obere Hälfte: Beispiele von Zuckern der herzwirksamen Steroidglykoside. Die Zucker der D-Reihe sind $\beta$-glykosidisch, die Zucker der L-Reihe a-glykosidisch mit dem Aglykon verknüpft. Dabei liegen die Zucker bei den $\beta$-D-Glykosiden in der ${ }^{4} C_{1}$-Konformation vor, die der $\mathbf{a}$-L-Reihe überraschenderweise bevorzugt in der ${ }^{1} C_{4}$-Konformation. Dies bedeutet, dass in der $a$-L-Reihe der raumerfüllende Cardenolidrest eine axiale Position einnimmt. Untere Hälfte: In der Pflanze liegen die herzwirksamen Steroidglykoside genuin in einer zuckerreichen Form, als Tetra- oder Pentaoside, vor. Wenn die Zuckerkette Desoxyzucker (DOZ) neben „normalen“ Hexosen enthält, so sind die DOZ unmittelbar mit dem Genin verknüpft. Pflanzen, die herzwirksame Glykoside führen, enthalten zugleich Enzyme, die selektiv die endständigen „normalen“ Hexosen in der Regel handelt es sich um $\beta$-D-Glucose - abspalten: Die Primärglykoside gehen in Sekundär- oder Folgeglykoside über. Gegen Säurehydrolyse erweist sich die Bindung Aglykon-DOZ als ziemlich empfindlich, sodass neben dem Aglykon intakte Bioside nachgewiesen werden können 
D Abb. 24.45<smiles>CC1(C)CCCCC1(C)O</smiles>

1<smiles>[3H][C@@H]1[CH][CH]C1</smiles><smiles>CCCC1(C)C2CCCC1(C)C(C(=CC(=O)O)CO)C2</smiles>

3

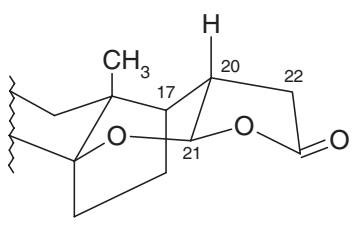

Isocardanolid 7, unwirksames Acylal<smiles>CC1(C)C2CCC1(C)C(C1=CC(=O)OC1)C2</smiles>

2a unwirksame Anhydroderivate<smiles>CC12CCCC(CC1)C2(C)C1=CC(=O)OC1</smiles>

2 b<smiles>CC12CCCC(O)(CC1)C2C(=CO)CC(=O)O</smiles>

4<smiles>CCC12CCC3(C)CCC(O1)C(C3O)[C@H]2CC(=O)O</smiles>

6<smiles>CC12CCCC(C)(CCC1)C2C(=O)CC(=O)O</smiles>

5

In stark saurer Lösung, insbesondere bei erhöhter Temperatur (Hydrolysebedingungen) erfolgt unter Abspaltung der tertiären 14-OH-Gruppe Dehydratisierung zu unwirksamen 14-Anhydroverbindungen (2a und 2b). Durch Einwirkung von Alkali wird der Lactonring zerstört unter Bildung der unwirksamen Acylale (7). Man nimmt an, dass die Reaktion mit einer Hydrolyse des Butenolidringes ( $1 \rightarrow 3$ ) und einer Umlagerung der Doppelbindung von C-20(22) nach C-20(21) (3 $\rightarrow 4)$ beginnt, der sich eine Tautomerisierung des intermediär gebildeten Vinylalkohols zum Aldehyd anschließt (4 $\rightarrow 5)$. Der Aldehyd 5 reagiert mit der 14-OH-Gruppe zum 6-gliedrigen, zyklischen Halbacetal 6, das zum Isocardenolid 7 lactonisiert

ckerteil oder der Lactonring für die Reaktion verantwortlich sein kann. Die Farbreaktionen sind nützlich:

- zur Charakterisierung isolierter Glykoside bzw. entsprechender Arzneistoffe;

- zum DC-Nachweis bei der Prüfung von Arzneistoffen, Arzneimitteln und Drogen auf Identität und Reinheit;

- zur quantitativen photometrischen Bestimmung in Drogen und daraus hergestellten Arzneimitteln.
Gebräuchliche Nachweis- und Bestimmungsreaktionen sind die folgenden:

- Kedde-Reaktion: Versetzt man die alkoholische Lösung eines Cardenolids mit 3,5-Dinitrobenzoesäureund Natriumhydroxidlösung, so entsteht eine intensive Färbung: z. B. violett beim Digoxin und Digitoxin (PhEur 5).

- Raymond-Reaktion: Wie Kedde-Reaktion, jedoch anstelle von Dinitrobenzoesäure 1,3-Dinitrobenzol: z. B. blau beim Ouabain (PhEur 5). 
- Baljet-Reaktion: Sie besteht in einer orangeroten Färbung, die $\alpha, \beta$-ungesättigte Lactone beim Umsetzen mit einer alkalischen Pikrinsäurelösung zeigen. Anwendungsbeispiele: Gehaltsbestimmung von Ouabain (g-Strophanthin), Digitoxin und Digoxin nach PhEur 5.

Die Kedde-, Raymond- und Baljet-Reaktionen zeigen aktivierte Methylengruppen an. Sie fallen daher bei Cardenoliden, nicht aber bei Bufadienoliden positiv aus. Das
Carbeniat-Anion der aktivierten (aciden) Methylengruppe reagiert mit dem aromatischen Reagens, wobei gefärbte Komplexanionen entstehen (> Abb. 24.46)

- Die Farbreaktion nach Keller-Kiliani besteht im Erscheinen einer grünen, später blauen Färbung beim Unterschichten des in Essigsäure 99\% gelösten Cardenolids mit dem gleichen Volumen Schwefelsäure unter Zusatz von 1 Tropfen Fe(III)-chloridlösung.

Anwendung: Prüfung auf Identität von Digitoxin und Digoxin nach PhEur 5.

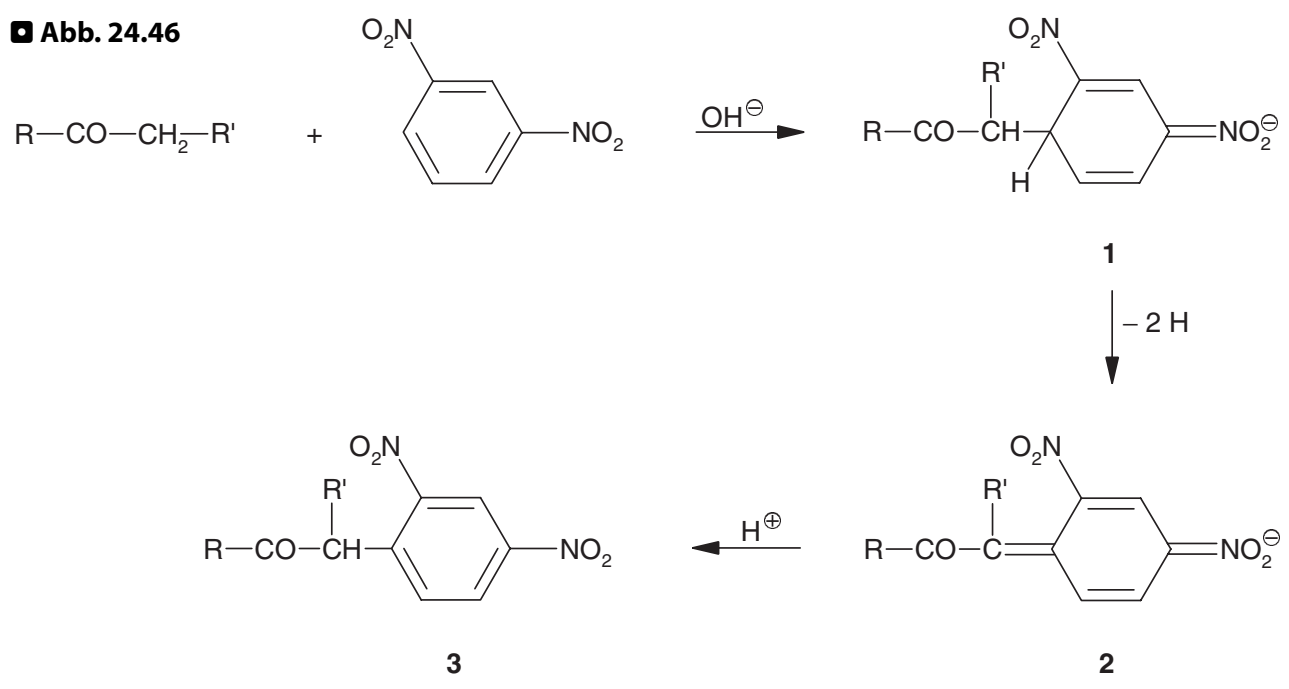<smiles>CC(C)(C)C1=CC(=O)OC1C1C(C(=O)[O-])=CC(=[N+]([O-])[O-])C=C1[N+](=O)[O-]</smiles>

Meisenheimer-Komplex (farbig)<smiles>COC1=CC(=O)OC1=C1C([N+](=O)[O-])=CC(=[N+]([O-])[O-])C(O)=C1[N+](=O)[O-]</smiles>

Zimmermann-Verbindung (farbig)

Wie bereits im Jahre 1886 erstmals beschrieben (Janovsky u. Erb 1886), reagieren Verbindungen, die eine aktivierte Methylengruppe enthalten, mit $m$-Dinitrobenzol in Lauge unter Bildung farbiger Chinoide 2; bei der Bildung von 2 über die Zwischenstufe 1 wirkt das im Übermaß vorhandene Nitroderivat als Oxidationsmittel (Kakáč u. Vejdělek 1974). Die Methylengruppe des Butenolidrings herzwirksamer Steroide reagiert in ähnlicher Weise mit aromatischen Nitroderivaten: mit 1,3-Dinitrobenzol (Raymond-Reaktion), mit 3,5-Dinitrobenzoesäure (Kedde-Reaktion) oder mit Pikrinsäure (1,3,5-Trinitrophenol; Baljet-Reaktion). Mit Pikrinsäure verläuft die Reaktion über einen Meisenheimer-Komplex oxidativ zur farbigen Zimmermann-Verbindung. Mit Raymond- und Kedde-Reagens erfolgt keine Oxidation. Die Farbreaktionen erfordern basisches Milieu; im sauren Bereich findet Entfärbung statt unter Bildung substituierter Nitroderivate 3 
Mit dem Keller-Kiliani-Reagens wird sowohl der 2-Desoxyzucker als auch der Steroidteil nachgewiesen. Die Reaktionsmechanismen sind nicht im Detail erforscht. Die 2-Desoxyzucker werden durch die Einwirkung starker Säuren zu Furfuralderivaten abgebaut, wobei die $\mathrm{Fe}(\mathrm{III})$-Ionen den Abbau bis zu einfachen Aldehyden (z. B. Malonaldehyd) weiter treiben. Die reaktionsfähigen Aldehyde gehen Kondensations- und Polymerisationsreaktionen ein, die zur Bildung blauer Farbprodukte führen. Zur Reaktion des Steroidteils () Zlatkis-Zak-Reaktion (Kap. 24.2).

- Farbreaktion auf Desoxyzucker mit Xanthydrol und Essigsäure. 2-Desoxy- und 2,6-Didesoxyzucker sowie Glykoside mit diesen Desoxyzuckern als Komponente bilden bei Umsetzung mit Xanthydrol in Gegenwart von Säuren - man verwendet meist Salzsäure oder 4-Toluolsulfonsäure in Essigsäure 99\% - eine Rotfärbung mit einem Absorptionsmaximum bei $530 \mathrm{~nm}$. Die Reaktion eignet sich zur Identitätsprüfung von Cardenoliden in Drogenauszügen; sie ist auch Basis für quantitative Bestimmungen. Der Reaktionsverlauf ist nicht geklärt.

- Rosenheim-Reaktion: Löst man etwas Substanz in 90\%iger Trichloressigsäure, so färben sich Steroide, die in ihrem Ringsystem ein Diensystem aufweisen (z. B. Ergosterol) oder die ein solches leicht zu bilden vermögen (z. B. Scilla-Glykoside), zunächst rosa, dann violett und schließlich tiefblau. Modifizierte Reaktionen dienen als allgemeines Steroidreagens. Trichloressigsäure in Ethanol ist ein Reagens zum Nachweis von Steroiden auf Dünnschichtchromatogrammen.

- Reagens nach Jensen-Kny (Kny 1963). Es besteht im Wesentlichen aus Trichloressigsäure, der jedoch Chloramin T (Tosylchloramid-Na) zugesetzt ist. Nach PhEur 5 wird es als Sprühreagens bei der DC-Prüfung von Digitalis-purpurea-Blättern herangezogen. Es bilden sich im UV-Licht charakteristisch blau oder gelb fluoreszierende Verbindungen. Der Reaktionsmechanismus ist nicht abschließend geklärt: Durch die wasserentziehende Wirkung der Trichloressigsäure werden vermutlich die Aglykone in Anhydroverbindungen übergeführt. Aus dem Gitoxigenin entsteht beispielsweise ein Dianhydroderivat mit einem System von 4 konjugierten Doppelbindungen (Trienonsystem), das bereits mit Trichloressigsäure allein blau fluoresziert. Digitoxin- und Digoxinderivate zeigen hingegen erst nach Zusatz des Oxidationsmittels gelbe bzw. weiß-blaue Fluoreszenzen.

\subsubsection{Verbreitung im Pflanzenreich, verwendete Extrakte/Reinstoffe}

Herzwirksame Steroidglykoside sind im Pflanzenreich weit verbreitet, und zwar sowohl bei den Rosopsida (= Eudicotyledoneae) als auch bei den Liliopsida (= Monocotyledoneae). Pflanzenfamilien, in denen glykosidführende Gattungen vertreten sind, sind die folgenden: Convallariaceae [IIA6a] (Convallaria), Hyacynthaceae [IIA6d] (Urginea), Ranunculaceae [IIB1a] (Adonis, Helleborus), Brassicaceae [IIB15a] (Cheiranthus, Erysimum), Apocynaceae [IIB22c] (Acokanthera, Apocynum, Nerium, Strophanthus, Thevetia, ferner Asclepias, Gomphocarpus, Marsdenia, Xysmalobium, bisher Asclepiadaceae), Plantaginaceae [IIB23 h] (Digitalis, bisher Scrophulariaceae), Scrophulariaceae [IIB23i] (Penstemon). Viele Hunderte von Pflanzenarten wurden auf ihre Glykosidführung hin untersucht mit dem Ergebnis, dass heute über 500 verschiedene Varianten bekannt sind. Durchwegs handelt es sich um Glykoside, die hinsichtlich ihres Hydroxylierungsgrades dem Strophanthin näher stehen als dem Digitoxin: Glykoside des Digitoxigenins wurden nur höchst selten gefunden. Als Arzneimittel verwendet man 3 Gruppen:

- Extrakte oder Extraktfraktionen aus den folgenden Drogen: Adonis vernalis (Kraut), Convallaria majalis (Kraut), Digitalis purpurea (Blätter), Nerium oleander (Blätter), Urginea maritima (Zwiebel);

- Reinglykoside: Digitoxin, Digoxin, Proscillaridin, $\mathrm{Cy}$ marin, g-Strophanthin (Ouabain), k-Strophanthin;

- partialsynthetische Glykoside: $\alpha$-Acetyldigoxin, $\beta$-Acetyldigoxin, Pentaacetylgitoxin, Meproscillarin, $\beta$-Methyldigoxin.

\subsubsection{Pharmakokinetik und Metabolismus}

Der Polaritätsgrad eines Arzneistoffes und seine enterale Resorptionsgeschwindigkeit stehen in engem Zusammenhang. Die wesentliche Barriere, die ein Stoff bei seiner Resorption zu überwinden hat, bilden die Zellmembranen des Mukosaepithels, an deren Aufbau in großem Maße Lipide beteiligt sind. Die Absorptionsgeschwindigkeit eines herzwirksamen Steroids wird daher um so größer sein, je besser lipidlöslich (d. h. je apolarer) das Glykosid ist, wobei man voraussetzen muss, dass Diffusion (nichtaktiver Transport) für die Überwindung der Lipidbarriere 
- Tabelle 24.12

Korrelation zwischen Polaritätsgrad und Resorptionsquote herzwirksamer Steroidglykoside. Ein grobes Maß für den Polaritätsgrad ist der relative Gehalt an freien Hydroxylgruppen im Molekül, d. h. das Verhältnis der Anzahl der Kohlenstoffatome pro freie Hydroxylgruppe im Molekül (C/OH). Abnehmende Polarität bzw. zunehmende Lipophilie äußert sich in größerer Wanderungsgeschwindigkeit im Dünnschichtchromatogramm (mod. nach Lauterbach 1977)

\begin{tabular}{llllll} 
Glykosid & Bruttoformel & $\begin{array}{l}\text { Freie OH- } \\
\text { Gruppen } n\end{array}$ & C/OH & Rf-Bereich & $\begin{array}{l}\text { Resorptions- } \\
\text { quote [\%] }\end{array}$ \\
k-Strophanthosid & $\mathrm{C}_{42} \mathrm{H}_{64} \mathrm{O}_{19}$ & 12 & 3,5 & 0,1 & $\sim 4$ \\
Convallosid & $\mathrm{C}_{35} \mathrm{H}_{52} \mathrm{O}_{15}$ & 8 & 4,2 & 0,2 & $\sim 10$ \\
Lanatosid C & $\mathrm{C}_{49} \mathrm{H}_{76} \mathrm{O}_{20}$ & 9 & 5,4 & 0,4 & $35-40$ \\
Digoxin & $\mathrm{C}_{41} \mathrm{H}_{64} \mathrm{O}_{14}$ & 6 & 6,8 & 0,5 & $70-80$ \\
Digitoxin & $\mathrm{C}_{41} \mathrm{H}_{64} \mathrm{O}_{13}$ & 5 & 8,2 & 0,7 & 100 \\
\hline
\end{tabular}

a Kieselgel, Dichlormethan-Methanol-Formamid (80:9:1).

ausschlaggebend ist. Ein Maß für den Polaritätsgrad ist die Zahl an polaren Gruppen im Aglykon- und Zuckerteil des Glykosids. Ein besseres Maß für den Polaritätsgrad bzw. den Lipophilitätsgrad ergibt sich aus den Wanderungsgeschwindigkeiten in chromatographischen Verteilungssystemen. Aus $>$ Tabelle 24.12 lässt sich entnehmen, dass Rf-Werte, C/OH-Quotienten und Resorptionsquoten miteinander korrelieren.

Die pharmakologischen Eigenschaften eines bestimmten herzwirksamen Steroids werden aber nicht allein von der Lipophilie determiniert. Wichtig sind auch die absolute Löslichkeit in Wasser sowie die Lösungsgeschwindigkeiten (aus der Arzneiform heraus) während der MagenDarm-Passage. Der Diffusionsvorgang durch die Lipidmembran hindurch setzt voraus, dass sich das Glykosid zuvor in wässrigen Verdauungssäften molekulardispers löst. Bei den lipophilen Glykosiden (Digitoxin, Digoxin) kann eine zu geringe Lösungsgeschwindigkeit der die $\mathrm{Ab}$ sorption begrenzende Faktor sein. Die Löslichkeiten in Wasser lassen sich nicht aus der Konstitution vorhersagen. Digoxin und Gitoxin sind isomer und enthalten eine sekundäre OH-Gruppe mehr als Digitoxin: Digoxin löst sich besser, Gitoxin aber schlechter in Wasser als Digitoxin. Verschließt man im Digoxin eine OH-Gruppe durch Methylierung, so steigt überraschend die Wasserlöslichkeit stark an (> Tabelle 24.13).

Ähnlich wie zwischen Lipophilie und Resorptionsquote, so besteht auch ein Zusammenhang zwischen Lipophilie (Verteilungskoeffizient) und Elimination aus dem Körper. Nimmt man als Maß die Abklingquote, so ergeben sich die in $>A b b .24 .47$ graphisch dargestellten Zusammenhänge. Abklingquote bedeutet die Glykosidmenge in

- Tabelle 24.13

Löslichkeiten einiger herzwirksamer Steroidglykoside in Wasser (Schaumann 1978; Megges et al. 1977). Als grobes Maß der Lipophilie wird der aus der Bruttoformel zu entnehmende Quotient aus der Zahl der Kohlenstoffatome und der Zahl der Sauerstoffatome gebildet

\begin{tabular}{llllr} 
Nr. & Glykosid & Bruttoformel & Quotient C/O & Löslichkeit in Wasser [mg/l] \\
1 & Digitoxin & $\mathrm{C}_{41} \mathrm{H}_{64} \mathrm{O}_{13}$ & 3,15 & 8 \\
2 & B-Methyldigoxin & $\mathrm{C}_{42} \mathrm{H}_{66} \mathrm{O}_{14}$ & 3,00 & 640 \\
3 & Digoxin & $\mathrm{C}_{41} \mathrm{H}_{64} \mathrm{O}_{14}$ & 2,92 & 40 \\
4 & Gitoxin & $\mathrm{C}_{41} \mathrm{H}_{64} \mathrm{O}_{14}$ & 2,92 & 2 \\
5 & Pentaacetylgitoxin & $\mathrm{C}_{51} \mathrm{H}_{74} \mathrm{O}_{19}$ & 2,68 & 12 \\
6 & Lanatosid C & $\mathrm{C}_{49} \mathrm{H}_{76} \mathrm{O}_{20}$ & 2,45 & 86 \\
7 & Ouabain & $\mathrm{C}_{29} \mathrm{H}_{44} \mathrm{O}_{12}$ & 2,40 & 11.100 \\
\hline
\end{tabular}


- Abb. 24.47

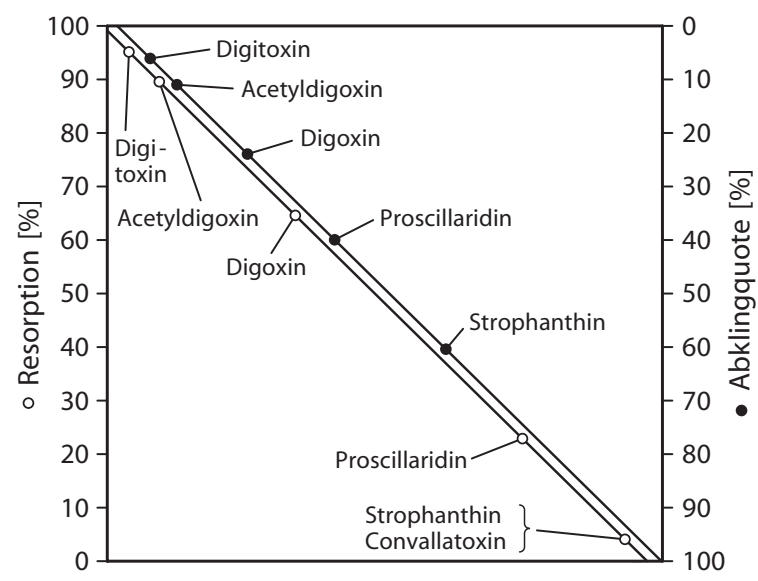

Abhängigkeit von Resorption und Abklingquote einiger gebräuchlicher Glykoside. Entsprechend der zunehmenden Größe des Verteilungskoeffizienten n-Octanol/Wasser (= Lipophilie) nimmt die orale Resorptionsquote zu, die Abklingquote ab (mod. nach Niedner 1973)

Prozent, die täglich durch Inaktivierung oder Ausscheidung eliminiert wird.

Ein Begriff der Praxis ist die so genannte Steuerbarkeit eines Glykosids: Steuerbarkeit ist in etwa gleichbedeutend mit der Eliminationshalbwertszeit. Bei Überdosierung liefert die Eliminationshalbwertszeit einen Anhaltspunkt dafür, wie rasch mit dem Abklingen der Vergiftungserscheinungen zu rechnen ist. Im Falle einer Intoxikation durch ein stärker polares Glykosid gelangt der Patient rascher aus dem Bereich eines toxischen in den Bereich eines therapeutischen Wirkspiegels als bei einer Digitoxinüberdosierung: Das betreffende Glykosid ist „besser steuerbar“. Die Eliminationshalbwertszeiten sind in 8 Tabelle 24.14 zusammengestellt.

- Tabelle 24.14

Eliminationshalbwertszeiten einiger Cardenolide

\begin{tabular}{ll} 
Glykosid & Tage \\
Digitoxin & Etwa 5 \\
Digoxin & Etwa 2 \\
Acetyldigoxin & Etwa 2 \\
k-Strophanthin & Etwa 1,8 \\
Proscillaridin & Etwa 1,5 \\
Oleandrosid & Etwa 1 \\
\hline
\end{tabular}

Abklingquote und Eliminationshalbwertszeit hängen mit dem Metabolismus der Substanzen zusammen. Die polaren Glykoside werden beim Menschen zum größten Teil unverändert mit dem Urin ausgeschieden (z. B. Strophanthin nach i.v.-Applikation) bzw. vor der Ausscheidung bis zu etwa $30 \%$ durch Biotransformation umgewandelt (z. B. bei Digoxin nach p.o.-Applikation). Die apolaren Glykoside (z. B. Digitoxin) werden bis zu 60\% der nach p.o.-Verabreichung resorbierten Menge metabolisiert. Ein Teil der Metaboliten wird der Ausscheidung durch Eintritt in den enterohepatischen Kreislauf entzogen (vgl. Scheline 1991).

Der Metabolismus ist je nach Substanz unterschiedlich. Abspaltung der Desoxyzucker, Epimerisierung der

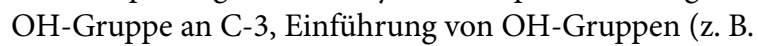
an C-12), Hydrierung der Doppelbindung im Lactonring sowie Konjugation mit Glucuron- und Schwefelsäure sind Schritte, die häufig vorkommen.

\subsubsection{Wirkungen auf biochemischer Ebene und Anwendungsgebiete}

Wirkungen. Die wesentlichste Wirkung der herzwirksamen Steroidglykoside am Herzen beruht auf einer Steigerung der Kontraktionskraft (positiv-inotrope Wirkung), die zur Senkung der Schlagfrequenz und einer Verbesserung des Wirkungsgrades führt. Die für diese Wirkung auf biochemischer Ebene verantwortlichen Mechanismen scheinen viel komplexer zu sein, als bisher angenommen wurde. Es ist davon auszugehen, dass die direkten positivinotropen Effekte auf das Herz durch einen mehrfachen Mechanismus verursacht werden, und dass je nach Testbedingung verschiedene Wirkungsmechanismen vorliegen.

Nach allgemeiner Übereinkunft wird die positiv-inotrope Wirkung der herzwirksamen Steroidglykoside durch einen Effekt ausgelöst, der zu einem Anstieg von $\mathrm{Ca}^{2+}$ Ionen im sarkoplasmatischen Retikulum des Myokards führt. Dafür in Frage kommen verschiedene Mechanismen wie die Hemmung der $\mathrm{Na}^{+} / \mathrm{K}^{+}$-ATPase, die Hemmung der $\mathrm{Ca}^{2+} / \mathrm{Mg}^{2+}$-ATPase, die Stimulierung des $\mathrm{Na}^{+} /$ $\mathrm{K}^{+} / \mathrm{Cl}^{-}$-Cotransportsystems und die Freisetzung von membrangebundenem $\mathrm{Ca}^{2+}$. Sowohl die $\mathrm{Na}^{+} / \mathrm{K}^{+}$-ATPase als auch der $\mathrm{Na}^{+} / \mathrm{K}^{+} / \mathrm{Cl}^{-}$-Cotransporter sind für den aktiven Transport von $\mathrm{Na}^{+}$in den Extrazellularraum und $\mathrm{K}^{+}$ in den Intrazellularraum verantwortlich. Der Anstieg der intrazellulären $\mathrm{Na}^{+}$-Konzentration führt zu einer Aktivierung des $\mathrm{Na}^{+} / \mathrm{Ca}^{2+}$-Austauschproteins und damit zu einer 
- Abb. 24.48

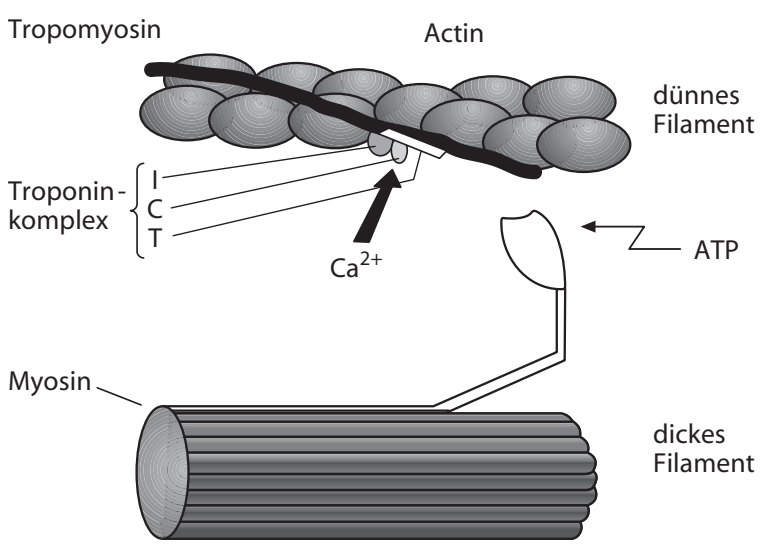

Schematische Darstellung der Herzmuskelfilamente. $\mathrm{Ca}^{2+}$ Ionen spielen für die Kontraktion des Herzmuskels eine zentrale Rolle. In Abwesenheit von $\mathrm{Ca}^{2+}$-Ionen verhindern die Proteine Tropomyosin und Troponin aufgrund ihrer räumlichen Anordnung im dünnen Filament die Interaktion von Actin und Myosin. $\mathrm{Ca}^{2+}$-lonen binden an Troponin $C$, eines von 3 Polypeptiden des Troponinkomplexes, wodurch die oben beschriebene hemmende Wirkung von Tropomyosin/Troponin auf die Muskelkontraktion aufgehoben wird. Es wird angenommen, dass die globulären Teile des Troponinkomplexes ihre Konformation ändern. Sie bleiben dabei über Troponin T mit dem dünnen Filament verbunden, lösen aber eine Veränderung der räumlichen Anordnung des Tropomyosins aus. Dadurch wird unter ATP-Verbrauch die Wechselwirkung zwischen Actin und Myosin und somit die teleskopartige Verschiebung der beiden Filamente ermöglicht (vgl. Übersicht von Buschauer 1989)

Erhöhung der intrazellulären $\mathrm{Ca}^{2+}$-Konzentration. Beim insuffizienten Herz verursacht dieser Anstieg an $\mathrm{Ca}^{2+}$ Ionen die positiv-inotrope Wirkung (> Abb. 24.48 und 26.59). Die therapeutischen und die toxischen Effekte z. B. von Digoxin werden beim Menschen in Konzentrationen in der Größenordnung von $1-2 \times 10^{-9} \mathrm{~mol} / \mathrm{l}$ erreicht, während bei Versuchen am isolierten Myokard vom Tier mit ähnlicher Empfindlichkeit wie beim Menschen viel höhere Konzentrationen notwendig sind. Diese Tatsache lässt vermuten, dass „klinische“ Konzentrationen einen positiv-inotropen Effekt durch einen Mechanismus auslösen (z. B. durch Stimulierung des $\mathrm{Na}^{+} / \mathrm{K}^{+} / \mathrm{Cl}^{-}$-Cotransporters) und Laboratoriumsversuche durch einen anderen (z. B. durch Hemmung der $\mathrm{Na}^{+} / \mathrm{K}^{+}$-ATPase).
Obwohl der Wirkungsmechanismus umstritten ist, gibt es keinen Zweifel an der Existenz eines sehr spezifischen Rezeptors (Digitalisrezeptor) an der extrazellulären Seite der $\mathrm{Na}^{+} / \mathrm{K}^{+}$-ATPase. Bei der $\mathrm{Na}^{+} / \mathrm{K}^{+}$-ATPase handelt es sich um ein Membranprotein mit 2 Untereinheiten: eine große katalytische Untereinheit $\alpha$ mit einem Molekulargewicht von ca. 110.000 und eine kleinere glykosidierte Untereinheit $\beta$ mit einem Molekulargewicht von ca. 35.000. Die Digitalisrezeptoren („binding sites for cardiac glycosides") befinden sich extrazellulär an der $\alpha$-Untereinheit, die aus verschiedenen Isoformen $\left(\alpha_{1}, \alpha_{2}\right.$, $\alpha_{3}$ u. a.) besteht. Die einzelnen Bindungsdomänen (z. B. $\left.\mathrm{H}_{1}-\mathrm{H}_{2}, \mathrm{H}_{3}-\mathrm{H}_{4}\right)$ sind bis heute nur teilweise näher beschrieben. SAR-Studien ergaben, dass die Steroidglykoside in 3 Bindungsregionen eingeteilt werden können: $\beta$ ständiger Lactonring, Steroidgerüst und Zuckerteil. Alle 3 Regionen scheinen sich an der Bindung an den Rezeptor zu beteiligen. Die anfängliche Bindung erfolgt durch eine Interaktion zwischen dem $\beta$-ständigen Lactonring des Steroidgerüsts („lactone binding site“) und einem Tryptophanring der $\mathrm{H}_{3}-\mathrm{H}_{4}$-Domäne. Dieser Schritt führt zu einem Konformationswechsel in dieser Region, der die Hemmung des Enzyms zur Folge hat. Es scheint, dass ein 2. Bindungsprozess nach dem anfänglichen Kontakt mit dem Rezeptor notwendig ist. Dieser erfolgt zwischen einem Zucker („sugar binding site“) und wahrscheinlich der $\mathrm{H}_{1}-\mathrm{H}_{2}$-Domäne. Für eine detailliertere Erklärung zu diesem hypothetischen Rezeptorbindungsmodell sowie einzelner Varianten dazu $(>$ Übersichten von Thomas 1992, 1996, sowie darin zitierte Literatur.

An die Digitalisrezeptoren können Steroide mit bestimmten strukturellen Voraussetzungen, wie sie bei den herzwirksamen Steroidglykosiden vorliegen, aber auch andere Substanzen (z. B. Erythrophleum-Alkaloide) mit entsprechenden strukturellen Merkmalen, binden. Bei den herzwirksamen Steroiden zeigen Verbindungen die größte Affinität zum Rezeptor, die über das Hydroxyl an C-3 direkt mit einer $\alpha$-L-Rhamnose verknüpft sind (z. B. Digitoxigenin- $\alpha$-L-rhamnosid). Es konnte gezeigt werden, dass der direkt mit dem Genin verknüpfte Zucker am meisten zur Bindung beiträgt und dass Steroidglykoside mit 6-Desoyzuckern (d. h. mit einer C-5-Methylgruppe) die stärkste Wirkung aufweisen. Es wird daraus geschlossen, dass die Methylgruppe eine Schlüsselrolle bei der Bindung des Zuckers zum Rezeptor aufweist. Das ist auch der Grund dafür, dass die Wirkung von Steroidgeninen nur kurz und weniger stark ist als diejenige der Glykoside. Daneben scheinen auch die 3- oder 4-OH-Gruppen dieses 
Zuckers und die $\alpha$-glykosidische Bindung von Bedeutung zu sein. Die bisher angenommene cis-Verknüpfung der Ringe A/B scheint für die positiv-inotrope Wirkung nicht essentiell zu sein. So weist z. B. 5 $\alpha$ H-Digitoxigenin (Uzarigenin) dieselbe Wirkung wie Digitoxigenin auf. Sobald diese Genine an der 3-OH-Gruppe glykosidiert sind, ergeben sich allerdings andere Wirkungsstärken. Monoglucosidierung von Digitoxigenin verstärkt die Wirkung um das 300 fache, bei Uzarigenin wird sie um das 60 fache verringert. Andererseits ist das Monorhamnosid des Uzarigenins 7,8-mal stärker wirksam als das entsprechende Genin (vgl. Übersichten von Thomas 1992, 1996).

Neben dem beschriebenen direkten oder extrazellulären Wirkungsmechanismus werden in den letzten Jahren vermehrt auch indirekte bzw. intrazelluläre Mechanismen diskutiert. Intrazelluläre Wirkungen wurden lange Zeit ignoriert, tragen wahrscheinlich aber entscheidend zur inotropen Wirkung bei. Diskutiert werden verschiedene Aspekte:

- eine Beteiligung von Phospholipasen (Phospholipase $\mathrm{A}_{2}$, Phospholipase C, Proteinkinase C),

- eine Zunahme der Glykosidsensitivität der $\mathrm{Na}^{+} / \mathrm{K}^{+}$ATPase bei chronischer Glykosidaussetzung,

- eine zelluläre Aufnahme der Steroidglykoside, und ein damit zusammenhängender Effekt auf das sarkoplasmatische Retikulum (vgl. Übersicht von Levi et al. 1994) und

- eine Beeinflussung des autonomen Nervensystems (vgl. Übersicht von Thomas 1996).

Mit zunehmender Hemmung der Membran-ATPase (= abnehmende Energiezufuhr für die Natriumpumpe) kommt es zu einer toxischen Wirkung. Intrazelluläres $\mathrm{Na}^{+}$ steigt an, was aus Gründen der Aufrechterhaltung des osmotischen Gleichgewichts eine Ausschleusung des intrazellulär vorhandenen $\mathrm{K}^{+}$zur Folge hat und zu Kaliumverlusten führt. Die Abflachung des $\mathrm{Na}^{+}$- und $\mathrm{K}^{+}$-Gradienten wiederum bedingt einen Abfall des Membranruhepotentials und führt in der Folge davon zur Erniedrigung der Reizschwelle und zur Abnahme der Leitungsgeschwindigkeit. Störungen der Herzrhythmik stehen im Vordergrund von Vergiftungserscheinungen. Bedingt durch die Hemmung der $\mathrm{Na}^{+} / \mathrm{K}^{+}$-ATPase in den Darmepithelien kommt es zu Störungen des Elektrolyttransports auch im Dünnund Dickdarm, womit sich die Durchfälle erklären, die als unerwünschte Wirkung, wenn auch selten, auftreten können. Lipophile Glykoside (Digitoxin und Meproscillarin) wirken eher laxierend als polare Glykoside.
Anwendungsgebiete. Die ideale positiv-inotrope Substanz gibt es bisher nicht. Herzwirksame Steroidglykoside haben eine geringe therapeutische Breite und müssen deshalb sehr exakt dosiert und sollten nur bei klaren Indikationen angewandt werden. Diese sind die chronische Herzmuskelinsuffizienz (NYHA-Stadien II und III) und Arrhythmien (Vorhofflimmern, Vorhofflattern), insbesondere wenn Arrhythmien von einer Herzinsuffizienz begleitet sind. Der Wirkungsmechanismus bei Arrhythmien ist bisher nicht bekannt.

Grundpfeiler der medikamentösen Behandlung der chronischen Herzinsuffizienz ist heute eine Gabe von ACE-Hemmern. Bei schweren Fällen umfasst eine optimale Therapie häufig die Kombination von herzwirksamen Steroidglykosiden, Diuretika und ACE-Hemmern (Erdmann 1995). Bei akuter Herzinsuffizienz und anderen Herzkrankheiten sind die herzwirksamen Steroide nicht mehr Mittel der ersten Wahl. Hier finden andere Kardiaka wie z. B. $\beta$-Blocker, Calciumantagonisten, Vasodilatatoren oder ACE-Hemmer Verwendung.

\subsubsection{Analytische Kennzeichnung}

Die PhEur und das DAB kennen die Monographien Adoniskraut, Digitalis-purpurea-Blätter, Maiglöckchenkraut und Meerzwiebel. Die Prüfung auf Identität dieser 4 Arzneidrogen ist in $>$ Tabelle 24.15 zusammengestellt. Daneben sind Digitalis-lanata-Blätter als Ausgangsmaterial zur Glykosidgewinnung von Bedeutung.

Zur quantitativen Bestimmung von Reinstoffen und cardenolidhaltigen Drogen und Extrakten existieren photometrische und HPLC-Methoden. Die PhEur verwendet:

- alkalische Pikrinsäurelösung (Baljet-Reagens) zur Gehaltsbestimmung von Digitoxin und Ouabain;

- alkalische Dinitrobenzoesäurelösung (Kedde-Reagens) zur Gesamtglykosidbestimmung der Cardenolide in Digitalis-purpurea-Blättern.

- HPLC bei Digoxin und $\beta$-Acetyldigoxin (PhEur 5.5)

Zur Anreicherung werden die Glykoside bei Digitalis-purpurea-Blättern nach PhEur mit Wasser bei Raumtemperatur extrahiert; Ballaststoffe entfernt man durch Zusatz von Blei(II)-acetat, den Überschuss an Bleiionen mit Natriummonohydrogenphosphat. Im Filtrat werden die Glykoside hydrolysiert und die Aglykone mit Chloroform ausgeschüttelt. Der Rückstand der Chloroformlösung wird mit 
- Tabelle 24.15

Prüfung auf Identität nach DAB 1999 bzw. PhEur 5

\begin{tabular}{|c|c|c|c|c|}
\hline & Adoniskraut (DAB) & $\begin{array}{l}\text { Maiglöckchenkraut } \\
\text { (DAB) }\end{array}$ & Meerzwiebel (DAB) & $\begin{array}{l}\text { Digitalis-purpurea-Blätter } \\
\text { (PhEur) }\end{array}$ \\
\hline Extraktion & Ethanol $70 \%$ & Ethanol $70 \%$ & Ethanol $70 \%$ & Ethanol $50 \%$ \\
\hline $\begin{array}{l}\text { Ballaststoff- } \\
\text { entfernung }\end{array}$ & Blei(II)-acetat & Blei(II)-acetat & Blei(II)-acetat & Blei(II)-acetat \\
\hline Fließmittel & $\begin{array}{l}\text { Wasser-Methanol- } \\
\text { Ethylacetat }(8: 11: 81)\end{array}$ & $\begin{array}{l}\text { Wasser-Methanol- } \\
\text { Ethylacetat }(8: 11: 81)\end{array}$ & $\begin{array}{l}\text { Wasser-Methanol- } \\
\text { Ethylacetat }(8: 11: 81)\end{array}$ & $\begin{array}{l}\text { Wasser-Methanol-Ethylacetat } \\
(7,5: 10: 75)\end{array}$ \\
\hline $\begin{array}{l}\text { Referenz- } \\
\text { substanzen }\end{array}$ & $\begin{array}{l}\text { Cymarin, Convalla- } \\
\text { toxin }\end{array}$ & Convallatoxin & $\begin{array}{l}\text { Lanatosid C, Proscilla- } \\
\text { ridin }\end{array}$ & $\begin{array}{l}\text { Digitoxin, Gitoxin, Purpureaglyko- } \\
\text { sid A und B }\end{array}$ \\
\hline Reagens & Kedde & Kedde & $\begin{array}{l}\text { Chloramin T/Trichlor- } \\
\text { essigsäure }\end{array}$ & Chloramin T/Trichloressigsäure \\
\hline $\begin{array}{l}\text { Nachweis } \\
\text { von }\end{array}$ & $\begin{array}{l}\text { Cymarin als rot- } \\
\text { violette Zone im } \\
\text { Tageslicht }\end{array}$ & $\begin{array}{l}\text { Convallatoxin als } \\
\text { rotviolette Zone im } \\
\text { Tageslicht }\end{array}$ & $\begin{array}{l}\text { Proscillaridin und } \\
\text { Scillaren A als gelb } \\
\text { fluoreszierende Zone } \\
\text { im UV bei } 365 \mathrm{~nm}\end{array}$ & $\begin{array}{l}\text { Purpureaglykosid B und Gitoxin } \\
\text { als hellblau fluoreszierende Zone, } \\
\text { Purpureaglykosid A und Digitoxin } \\
\text { als bräunlichgelb fluoreszierende } \\
\text { Zone im UV bei } 365 \mathrm{~nm}\end{array}$ \\
\hline
\end{tabular}

Kedde-Reagens umgesetzt. Die bei $540 \mathrm{~nm}$ gemessene Extinktion wird mit der Extinktion eines Hydrolysats einer bekannten Digitoxinmenge in Bezug gesetzt.

Die erwähnten photometrischen Methoden sollten durch die HPLC ersetzt werden. Wie von Wiegrebe u. Wichtl (1993) gezeigt werden konnte, lassen sich damit unter Verwendung eines internen Standards ( $\beta$-Methyldigoxin) bei Digitalis-lanata-Blättern über 50 Cardenolide in etwa $2 \mathrm{mg}$ pulverisiertem Blattmaterial schnell und exakt bestimmen. Allerdings scheint auch mit der HPLC eine Probenaufbereitung mit Reversed-phase-Material zur Entfernung von Ballaststoffen nicht immer möglich, sodass man bei einzelnen Drogen wie z. B. bei Maiglöckchenkraut nach wie vor Blei(II)-acetat dafür einsetzen muss (Krenn et al. 1996).

Das DAB kennt keine Gehaltsbestimmung bei den Cardenoliddrogen, sondern schreibt noch immer eine biologische Methode der Wirkwertbestimmung vor, obwohl ihre praktische Relevanz sehr gering ist. Als Kriterium wird eine charakteristische toxische Wirkung dieser Stoffgruppe, der systolische Herzstillstand, bestimmt. Bezugsgröße ist ein Reinglykosid. Die Bestimmung des Wirkwertes ist in einer allgemeinen Vorschrift beschrieben (2.7.N1; DAB) und wird jeweils in einer eigenen Monographie „Eingestelltes Adonis-, Digitalis-purpurea-, Maiglöckchen- und Meerzwiebelpulver" vorgeschrieben, wobei der Wirkwert am Meerschweinchen sich aus dem Vergleich der letalen Do- sen von Droge und Referenzglykosid (Cymarin, Digitoxin, Convallatoxin bzw. Proscillaridin) ergibt, z. B. bei Adonis vernalis im Bereich 1,67-2,40 mg/g liegen muss. Das DAB hält an der heute überholten und auch unethischen (pro Testserie werden 20 Meerschweinchen benötigt) Wirkwertbestimmung fest, obwohl bei einzelnen Drogen eine Korrelation zwischen photometrischer Gehaltsbestimmung und Wirkwert besteht. Eine solche könnte mit HPLC-Methoden, wie sie z. B. für das Maiglöckchen entwickelt worden sind (Krenn et al. 1996), ebenfalls erreicht werden, da auch zwischen den Resultaten der HPLC und der Photometrie eine gute Korrelation besteht.

Heute muss nicht nur die biologische Wirkwertbestimmung als obsolet angesehen werden, sondern generell auch die Verwendung von Extraktpräparaten cardenolidhaltiger Drogen. Reinstoffpräparate verdienen zur Einstellung auf einen Vollwirkspiegel im Interesse einer Dosierungsgenauigkeit den Vorzug.

\subsubsection{Digitalis lanata und Lanataglykoside}

Herkunft der Digitalis-lanata-Blätter. Digitalis-lanataBlätter (Digitalis lanatae folium DAB 10) bestehen aus den getrockneten Laubblättern von Digitalis lanata EHRH. (Familie: Plantaginaceae [IIB23 h], bisher Scrophulariaceae). 
Stammpflanze. D. lanata ist ein 2- bis mehrjähriges Kraut. Im ersten Jahr bildet sich eine dem Boden angedrückte Blattrosette, deren Blätter auch im Winter grün bleiben. Im 2. Jahr entwickelt sich der etwa $120 \mathrm{~cm}$ hohe aufrechte Stängel mit sitzenden Blättern, die in ihrer Form den Spitzwegerichblättern ähneln, und mit glockigen Blüten, die in einer lockeren Traube angeordnet sind. Blüten: gelbockerfarbene Kronröhre mit braunen Adern

- Abb. 24.49

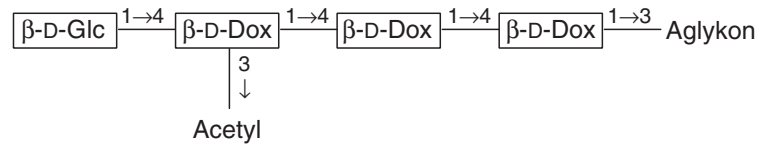

\begin{tabular}{|l|l|l|}
\hline Aglykon & Primärglykosid & Gehalt [\%] \\
\hline Digitoxigenin & Lanatosid A & $0,05-0,25$ \\
Digoxigenin & Lanatosid C & $0,1-0,3$ \\
Gitoxigenin & Lanatosid B & $0,01-0,05$ \\
\hline
\end{tabular}

Aufbau der Lanatoside, der wichtigsten Primärglykoside der Digitalis-lanata-Blätter durchzogen; große Unterlippe, weißlich, nach abwärts gebogen. Die Blütenteile und Blütenstandsachsen sind drüsigwollig behaart (,wolliger" Fingerhut $=D$. lanata) . Als „pontisches Florenelement“ ist D. lanata in Südosteuropa beheimatet; zur Drogengewinnung wird sie in zahlreichen Ländern - u. a. in den Niederlanden, in Italien, in Nordafrika sowie in Nord- und Südamerika - kultiviert.

Hinweis. Ausgangsmaterial zur Drogengewinnung sind die im Herbst geernteten Blätter des ersten Kulturjahres (Rosettenpflanzen).

Sensorische Eigenschaften. Die Droge schmeckt stark bitter.

\section{Inhaltsstoffe}

- Über 70 Cardenolidglykoside mit den fünf Aglykonen Digitoxigenin (A-Reihe), Gitoxigenin (B-Reihe), Digoxigenin (C-Reihe), Diginatigenin (D-Reihe) und Gitaloxigenin (E-Reihe) und einem Gesamtgehalt von 0,5-1,5\% (จ Abb. 24.49-24.52); ferner

D Abb. 24.50

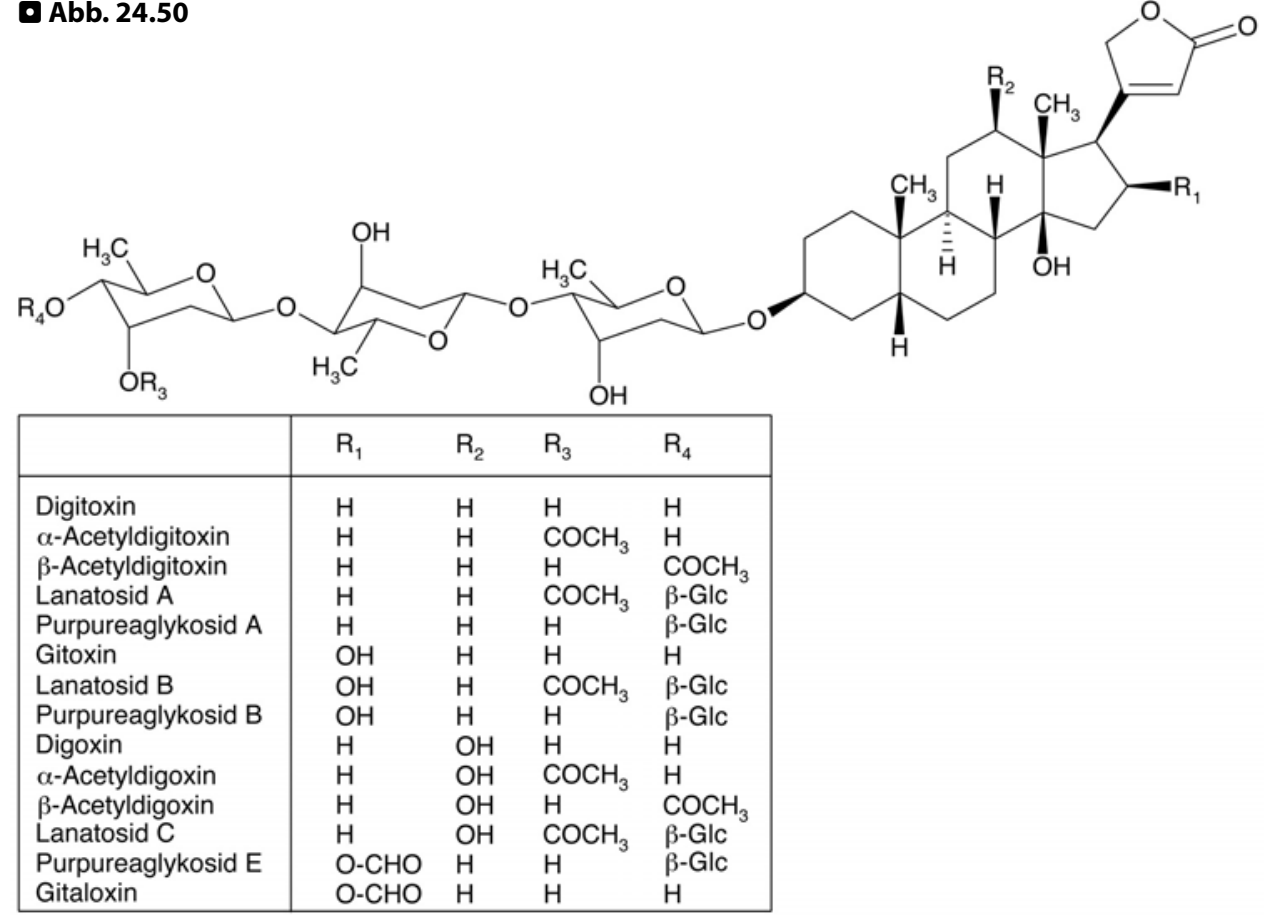

Die pharmakologisch bedeutsamen herzwirksamen Steroide, die in den Blättern von Digitalis lanata und/oder D. purpurea vorkommen bzw. aus diesen Drogen als Ausgangsmaterial darstellbar sind. $\beta$-Glc $\beta$-D-Glucoserest 


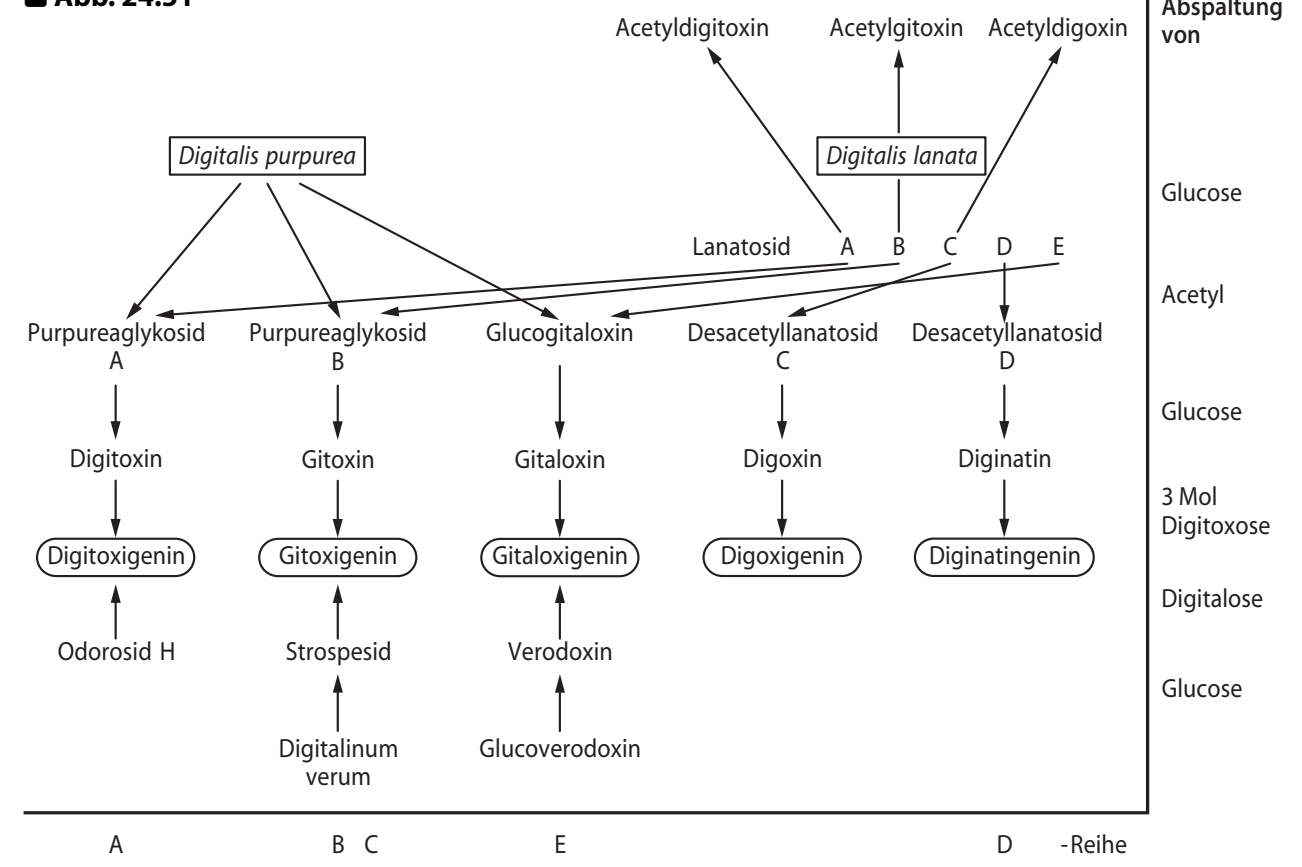

Glykosidstufen der Hauptsteroidglykoside von Digitalis lanata und D. purpurea und gegenseitige Beziehungen. Vergleicht man das Glykosidspektrum von $D$. lanata mit dem von $D$. purpurea, so fallen verschiedene Unterschiede auf. D. purpurea: a) Glykoside der C- und D-Reihe fehlen; b) Acetyldigitoxose als Zuckerkomponente tritt nicht auf. D. lanata: a) Enzymatische Abspaltung der endständigen Glucose durch pflanzeneigene $\beta$-Glucosidase führt bei den Lanatosiden A-C zu den acetylierten Sekundärglykosiden Acetyldigitoxin, Acetylgitoxin und Acetyldigoxin. Als Folge der Abspaltung der endständigen $\beta$-D-Glucose findet eine partielle Isomerisierung der nunmehr endständigen 3-O-Acetyldigitoxose zur 4-O-Acetyldigitoxose statt (vgl. $>$ Abb. 24.52); b) Die genuinen Lanatoside können durch Verseifung in die genuinen D.-purpurea-Glykoside sowie Desacetyllanatosid C und $D$ überführt werden

- herzunwirksame Pregnanglykoside (Digitanolglykoside; $>$ Abb. 24.53), Steroidsaponine, Flavonoide u. a.

Verwendung. Als Ausgangsmaterial zur Gewinnung von Reinstoffen, insbesondere von Digoxin, Acetyldigoxin und Lanatosid C. Digoxin wiederum liefert partialsynthetische Acetyl- und Methylderivate.

Digoxin (PhEur 5, revidiert 5.5; vgl. ( Abb. 24.50) ist ein Abbauprodukt des ursprünglich in der Pflanze genuin enthaltenen Lanatosid C (vgl. (7) Abb. 24.51). Die Abspaltung der endständigen D-Glucose und des Acetylrestes erfolgt ezymatisch durch pflanzeneigene Glucohydrolasen und Acetylesterasen. Diese sind nicht - wie früher angenommen wurde - fest an die Zellmembran gebunden, sondern in der Zellwand lokalisiert (Kreis u. May 1990). Zur Extraktion von Digoxin werden die pul- verisierten Blätter in Wasser bei $30-37^{\circ} \mathrm{C}$ der Mazeration unterworfen. Dann extrahiert man die Glykosidfraktion mit Wasser-Ethanol und fällt die Ballaststoffe vom Typus phenolischer Verbindungen (Flavone, Phenolcarbonsäuren, Gerbstoffe) mittels Bleihydroxid aus. Nach Extraktion des Glykosidgemisches mit einem organischen Lösungsmittel (Chloroform-Methanol) erfolgt die Isolierung mittels Säulenchromatographie oder Gegenstromverteilung. Eine völlige Reindarstellung ist sehr kompliziert und unwirtschaftlich: Daher enthält das handelsübliche Digoxin stets noch Nebenglykoside, hauptsächlich Digitoxin und Gitoxin. Die PhEur erlaubt Beimengungen bis zu 6\%. Zum Lösen von $1 \mathrm{~g}$ Digoxin benötigt man 251 Wasser. Relativ gut löst es sich in $80 \%$ igem Ethanol; darin ist es besser löslich als das isomere Gitoxin. 
- Abb. 24.52
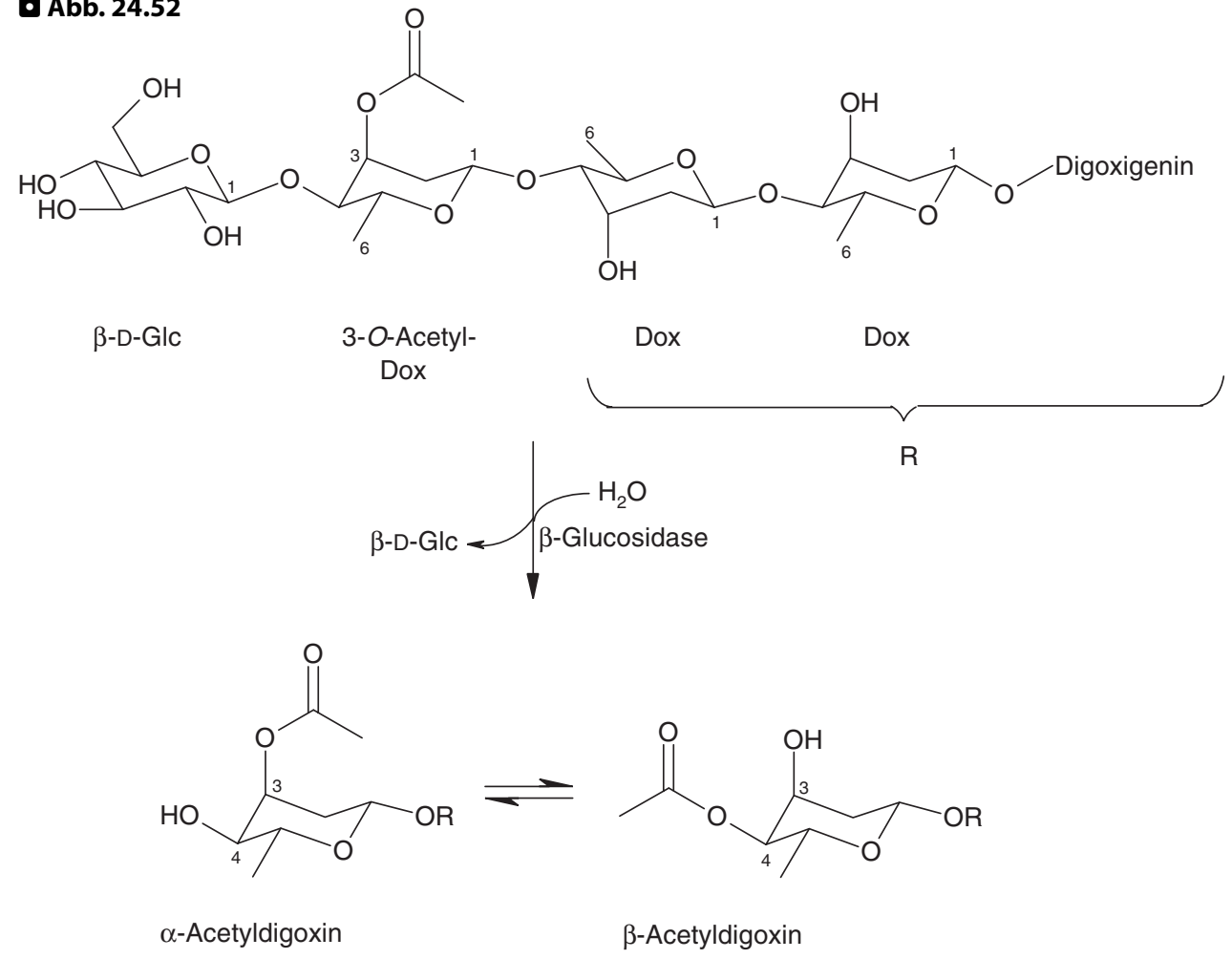

Die Umwandlung von a-Acetyldigoxin in das mit ihm stellungsisomere $\beta$-Acetyldigoxin wird verständlich, wenn die Konformationseffekte der 3-O-Acetyldigitoxose berücksichtigt werden. Die 3-Acetyl-4-glucosyldigitoxose liegt in der ${ }^{1} \mathrm{C}_{4}$-Konformation vor, sodass die raumerfüllenden Substituenten (Digitoxose an 1-OH; Glucose an 4-OH) eine äquatoriale Position einnehmen. Kommt es zur enzymatischen Abspaltung der endständigen Glucose, so wird die zum axialen 3-Acetoxysubstituenten benachbarte äquatoriale OH-Position frei. Die Energiedifferenz zwischen e-OH plus a-O-Acetyl einerseits und $\mathrm{a}-\mathrm{OH}$ plus e-O-Acetyl andererseits ist die treibende Kraft für die Wanderung des Acetylsubstituenten von der 3-zur 4-Position. Es stellt sich eine Gleichgewichtslage ein. Methylgruppen sind als bloße Valenzstriche gezeichnet

$\beta$-Acetyldigoxin (PhEur 5.5) wird partialsynthetisch durch selektive Acetylierung der 4-OH-Gruppe der terminalen Digitoxose im Digoxinmolekül erhalten, beispielsweise durch Umsetzung mit Essigsäure in Gegenwart von Dicyclohexylcarbodiimid.

$\alpha$-Acetyldigoxin erhält man partialsynthetisch durch enzymatische Hydrolyse des Lanatosid C (Abspaltung der endständigen Glucose) unter $\mathrm{pH}$-Wertbedingungen, die die Acetylgruppe intakt lassen. Es stellt sich ein Gleichgewicht zwischen der $\alpha$ - und der $\beta$-Form ein (vgl. ( $A b b$. 24.52). Einfacher ist die Acetylierung von Digoxin mit Orthoessigsäureethylester in Tetrahydrofuran unter Verwendung kleiner Mengen $p$-Toluolsulfonsäure als Katalysator.
$\beta$-Methyldigoxin (Medigoxin) erhält man durch selektive Methylierung von Digoxin. Analog wie im Falle des $\beta$-Acetyldigoxins wird die terminale 4-OH-Gruppe der endständigen Digitoxose verschlossen. Im Allgemeinen führt die Methylierung von alkoholischen Gruppen zu Derivaten mit geringer Löslichkeit in Wasser. Sehr überraschend steigt aber im Falle des Digoxins die Wasserlöslichkeit stark an: Es lösen sich $460 \mathrm{mg}$ Medigoxin in 11 Wasser, aber nur 40 mg Digoxin.

Metabolismus der Lanataglykoside. Digoxin und die Digoxinderivate zeichnen sich durch eine gute orale Bioverfügbarkeit aus. Sie werden in den heute üblichen galenischen Zubereitungsformen zu etwa 70-90\% resorbiert. Die 
<smiles>CC(=O)C1C[C@@H](O)[C@]2(O)C3CC=C4CC(O)CCC4(C)[C@H]3CC12C</smiles>

Purprogenin, 5-Pregnen-3 $\beta, 14 \beta, 15 \alpha$-triol-12,20-dion<smiles></smiles>

Digacetigenin

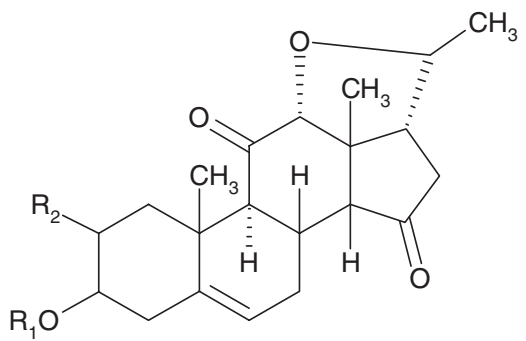

\begin{tabular}{|l|l|l|}
\hline $\mathrm{R}_{1}$ & $\mathrm{R}_{2}$ & \\
\hline $\mathrm{H}$ & $\mathrm{H}$ & Diginigenin \\
Digitalosyl & $\mathrm{H}$ & Digitalonin \\
Diginosyl & $\mathrm{H}$ & Diginosid \\
Diginosyl & $\mathrm{OH}$ & Digifolein \\
\hline
\end{tabular}

Außer den herzaktiven Steroiden vom Cardenolidtyp finden sich im Digitalis-lanata- und Digitalis-purpurea-Blatt $\mathrm{C}_{21}$-Pregnanglykoside, die unter der Bezeichnung Digitanolglykoside zusammengefasst werden. Als Zuckerkomponente tragen sie dieselben seltenen Desoxyzucker wie die Cardenolidglykoside (Struktur der Zucker $\gg$ Abb. 24.44). Sie zeigen keine Herzwirkung (Lactonring fehlt), werden aber bei der Gehaltsbestimmung, sofern keine Abtrennung erfolgt, miterfasst

Abklingquote beträgt ca. 20\%. Die Metaboliten von Digoxin entstehen zur Hauptsache durch Zuckerabspaltung, Hydrierung der Doppelbindung im Lactonring und Konjugation. Die Acetyldigoxine werden in der Leber deacetyliert und dann weiter wie Digoxin metabolisiert. Im Unterschied zum Digitoxin (vgl. Kap. 24.7.9) spielt beim Digoxin der enterohepatische Kreislauf nur eine untergeordnete Rolle (vgl. Scheline 1991). Im Falle von $\beta$-Methyldigoxin wird die Methylgruppe im Organismus nur langsam abgespalten. Im Vergleich zu Digoxin weist Medigoxin eine etwas längere Halbwertszeit der Elimination auf, auch scheint die erhöhte Lipophilie eine unerwünschte Tendenz zur Anreicherung im Zentralnervensystem zu haben.

\subsubsection{Digitalis purpurea und Purpureaglykoside}

Herkunft der Digitalis-purpurea-Blätter. Die Droge (Digitalis purpureae folium PhEur 5) besteht aus den ge- trockneten Blättern von Digitalis purpurea L. (Familie: Plantaginaceae [IIB23 h], bisher Scrophulariaceae). Sie enthalten mindestens 0,3\% Cardenolidglykoside, berechnet als Digitoxin.

Stammpflanze. Der rote Fingerhut ist ein 2- bis mehrjähriges Kraut; im 1. Jahr bildet sich eine mächtige Blattrosette aus und erst im 2. Jahr ein etwa $100 \mathrm{~cm}$ hoher, meist unverzweigter, blütentragender Stängel. Der Stängel trägt eiförmig-längliche, am Rande gekerbte und unterseits behaarte Blätter mit hervortretender Nervatur. Die in einseitswendigen Trauben stehenden Blüten sind monosymmetrisch; die Blumenkrone ist glockig mit nur wenig ausgezogener Unterlippe, leuchtend karminrot gefärbt (zuweilen hellrot, seltener weiß), innen gefleckt.

Heimat. Westeuropa bis westliches Mitteleuropa. Die Droge stammt ausschließlich aus Kulturen in Holland, England, Deutschland und Afrika. 
Hinweis. Ausgangsmaterial zur Drogengewinnung sind hauptsächlich die im Herbst geernteten Blätter des ersten Kulturjahres (Rosettenblätter).

Sensorische Eigenschaften. Die Droge hat einen bitteren Geschmack.

\section{Inhaltsstoffe}

- Bisher wurden an die 30 Cardenolidglykoside isoliert. Sie leiten sich von den Aglykonen Digitoxigenin (A-Reihe), Gitoxigenin (B-Reihe) und Gitaloxigenin (16-Formylgitoxigenin; E-Reihe) ab (vgl. \$ Abb. 24.50 und 24.51; 24.54); ferner

- herzunwirksame Pregnanglykoside (Digitanolglykoside; vgl. ( Abb. 24.53), Steroidsaponine, Flavonoide, Phenolglykoside u. a.

Verwendung. Digitalis-purpurea-Blätter sind Ausgangsmaterial zur Isolierung von Digitoxin und Gitoxin; Letzteres wird partialsynthetisch durch Acetylierung in Pengitoxin und durch Formylierung in Gitiformat übergeführt. Galenische Zubereitungen aus der Droge, wie die Tinktur oder das Infus, werden so gut wie nicht mehr verwendet und sind als obsolet zu betrachten; gegebenenfalls ist das standardisierte eingestellte Digitalis-purpurea-Pulver DAB 1999 abzugeben.

Digitoxin. Digitoxin (PhEur 5) lässt sich als Abbauprodukt zweier genuiner Glykoside auffassen: des Lanatosids A der Digitalis-lanata-Blätter und des Purpureaglykosids A der Digitalis-purpurea-Blätter (vgl. ( Abb. 24.51). Somit können die Blätter beider Digitalis-Arten als Rohstoff zur Digitoxingewinnung herangezogen werden, wobei heute die Lanata-Blätter industriell die wesentlich wichtigere Quelle darstellen. Die als Arzneistoffe dienen-

\section{- Abb. 24.54}

$\beta$-D-Glc ${ }^{1 \rightarrow 4} \beta$-D-Dox ${ }^{1 \rightarrow 4} \beta$-D-Dox ${ }^{1 \rightarrow 4} \beta$-D-Dox ${ }^{1 \rightarrow 3}$ Aglykon

\begin{tabular}{|l|l|l|}
\hline Aglykon & Primärglykosid & Gehalt [\%] \\
\hline Digitoxigenin & Purpureaglykosid A & $0,02-0,12$ \\
Gitoxigenin & Purpureaglykosid B & $0,02-0,08$ \\
Gitaloxigenin & Purpureaglykosid E & $0,01-0,1$ \\
(16-Formylgitoxigenin) & & \\
\hline
\end{tabular}

Aufbau der wichtigen Primärglykoside der Digitalis-purpurea-Blätter den Digitoxinpräparationen sind in der Regel nicht 100\%ig rein. Sie enthalten Begleitglykoside, wobei die jeweiligen Pharmakopöen einen unterschiedlichen Spielraum lassen: nach PhEur 5 8\%, nach USP 28 (2005) 11\%. Die „Verunreinigungen“ können durchaus akzeptiert werden, da die Lösungsgeschwindigkeit verbessert wird. Zum Lösen von $1 \mathrm{~g}$ Digitoxin bei $20^{\circ} \mathrm{C}$ benötigt man $40 \mathrm{ml}$ Chloroform oder $60 \mathrm{ml}$ Ethanol oder 771 Wasser.

Metabolismus von Digitoxin. Digitoxin wird nach p.o.Applikation praktisch zu 100\% resorbiert. Die Abklingquote beträgt ca. 7\%. Die Metaboliten von Digitoxin entstehen in erster Linie durch schrittweise Zuckerabspaltung. Daneben laufen alle in Kap. 24.7.5 beschriebenen Reaktionsschritte wie 12-Hydroxylierung, 3-OH-Epimerisierung und Konjugation ab. In kleinen Mengen finden auch $5 \beta$-, $1 \beta$ - und $16 \beta$-Hydroxylierungen statt. Interessanterweise ist die Hydrierung der C-20,22-Doppelbindung im Lactonring, ein wesentlicher Schritt bei Digoxin, bei Digitoxin nur von untergeordneter Bedeutung (vgl. Scheline 1991). Digitoxin wird entweder unverändert oder in Form der Metaboliten mit dem Urin bzw. in Form von Konjugaten (Hauptkonjugat ist das Glucuronid von Digitoxigeninmonodigitoxosid) biliär ausgeschieden. Die anschließend durch die Tätigkeit der Darmbakterien wieder freigesetzten Glykoside können dann erneut resorbiert und in den Kreislauf eingeschleust werden (enterohepatischer Kreislauf). Die lange Wirkdauer von Digitoxin wird dadurch verständlich.

Gitoxin (16-Hydroxydigitoxin) ist an und für sich ein therapeutisch interessantes Glykosid, weil seine zentrale Toxizität gering ist und daher bei der therapeutischen Verwendung weniger mit dem Auftreten unerwünschter Nebenwirkungen von Seiten des Zentralnervensystems zu rechnen ist. Der peroralen Anwendung steht jedoch die schlechte Bioverfügbarkeit entgegen. Die Löslichkeit in Wasser ist noch geringer als die des Digitoxins - sie beträgt nur etwa ein Viertel; und zugleich ist auch die Lipidlöslichkeit gering - sie beträgt ein Fünftel derjenigen des Digitoxins. Folglich sind sowohl Lösungsgeschwindigkeit als auch Resorptionsquote außerordentlich niedrig. Durch Acetylierung des Gitoxins zum Pentaacetylderivat (Pengitoxin) steigt die Wasserlöslichkeit um das 4 fache, die Lipidlöslichkeit um das 20fache. Die Bioverfügbarkeit von Pengitoxin ist entsprechend gut. Die kardiotonische Wirkung bleibt voll erhalten, da das Glykosid nach Resorption rasch zu Gitoxin desacetyliert wird. Pengitoxin ist somit ein Arzneistoff mit typischem „Prodrug- 
charakter", hat aber keine Vorteile gegenüber den besser charakterisierten Glykosiden wie Digoxin oder Digitoxin.

\subsubsection{Strophanthin und andere Rein- glykoside mit großer Abklingquote}

\section{Ouabain (g-Strophanthin)}

Ouabain (PhEur 5) oder g-Strophanthin (\$ Abb. 24.55) kommt in den Samen der im tropischen Westafrika verbreiteten Liane Strophanthus gratus (WALL. et Hook.) FrANCH. vor (Familie: Apocynaceae [IIB22c]). Die ausgereiften Samen sind 11-19 mm lang und 3-5 mm breit, im Gegensatz zu den Samen der meisten anderen Strophanthus-Arten kahl, von leuchtend goldgelber bis gelbbrauner Farbe. Der Geschmack ist ganz außerordentlich und lange anhaltend bitter. Strophanthus-gratus-Samen enthalten 4-5\% Cardenolidglykoside; das Gemisch besteht zu 9095\% aus g-Strophanthin, das sich daher aus dieser Droge sehr leicht kristallin darstellen lässt.

Historische Anmerkung: Aus den Samen von Strophanthus gratus gewannen die Pahuins, ein Volksstamm des westlichen Äquatorialafrika, ein Pfeilgift. Den ostafrikanischen Somalis diente ein Extrakt aus der Rinde des Ouabaiobaumes, Acokanthera ouabaio BoIss. (Familie: Apocynaceae [IIB22c]) in gleicher Weise als Ingredienz für Pfeilgifte. Das aus der Ouabaiorinde isolierte Gift - der französische Wissenschaftler Arnaud belegte es mit dem Namen Ouabain - erwies sich als mit g-Strophanthin identisch.

Eigenschaften und Prüfung auf Identität. Ouabain ist eine farblose, kristalline Substanz von stark bitterem Geschmack. Etwas löslich in Wasser (1:70) und Ethanol (1:100), in lipophilen Lösungsmitteln praktisch unlöslich. Die wässrige Lösung ist linksdrehend. Wenig beständig in Gegenwart von Säuren, Alkalien oder Oxidationsmitteln. Die Substanz färbt sich in Schwefelsäure rot bis rotbraun; die Lösung fluoresziert bei $365 \mathrm{~nm}$ grün. Ermöglicht die Unterscheidung von k-Strophanthin, das sich grün färbt. Weitere Reaktionen nach PhEur 5:

- Prüfung mit Raymond-Reagens,

- hydrolytische Spaltung und Nachweis der L-Rhamnose durch die Reduktionsprobe,

- DC-Vergleich mit authentischem Ouabain.
- Abb. 24.55

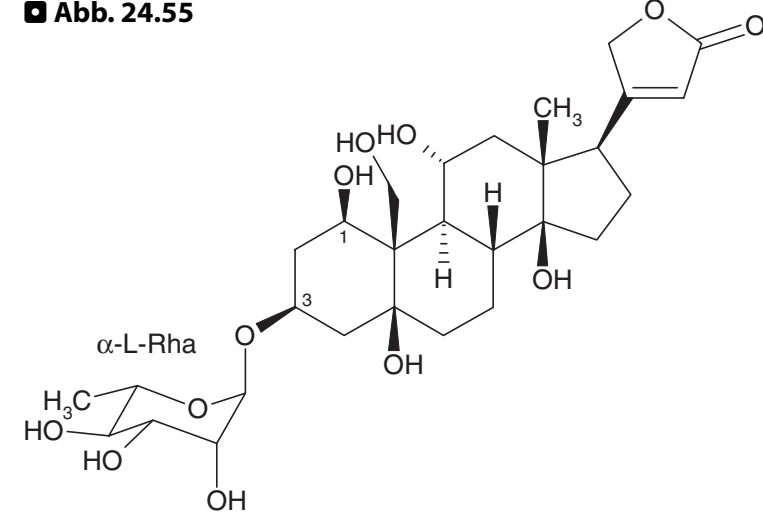

Ouabain ( = g-Strophanthin, $\mathrm{C}_{29} \mathrm{H}_{44} \mathrm{O}_{12}$ )

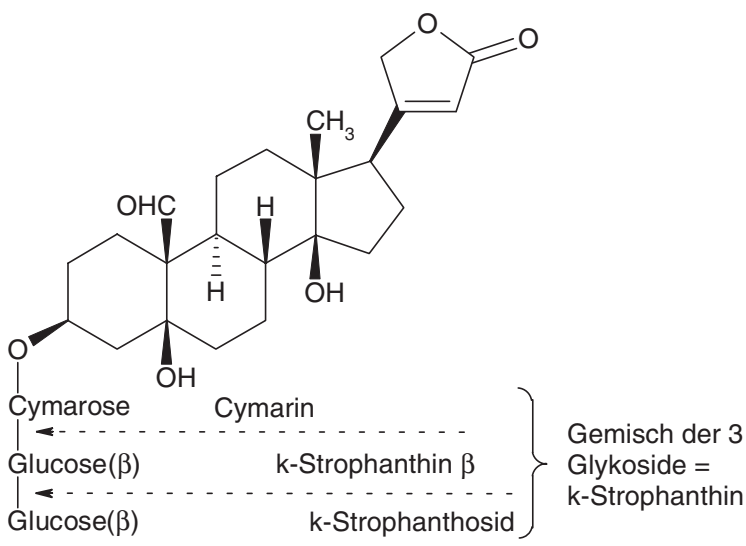

Strophanthus-Glykoside. Von allen therapeutisch verwendeten Cardenoliden enthält Ouabain (g-Strophanthin) das Aglykon mit der größten Zahl an Hydroxylgruppen. Die a-L-Rhamnose nimmt die ${ }^{1} \mathrm{C}_{4}$-Konformation ein. Unter k-Strophanthin versteht man ein Gemisch, das zur Hauptsache aus dem triosidischen $k$-Strophanthosid, dem biosidischen k-Strophanthin $\beta$ und dem monoglykosidischen Cymarin besteht

Hinweise zur Bioverfügbarkeit. Die Resorptionsquote bei p.o.-Verabreichung von Ouabain liegt unter 5\%. Die Substanz kann daher rationell nur durch intravenöse Injektion zugeführt werden. Die Wirkung von i.v. verabreichtem Ouabain beim Menschen setzt innerhalb weniger Minuten ein; die Vollwirkung wird nach etwa $60 \mathrm{~min}$ erreicht. Die Haftfähigkeit des Ouabains am Herzmuskel ist gering; es wandert rasch in periphere Kompartimente $\mathrm{ab}$ und diffundiert von dort relativ langsam ins Blut $\mathrm{zu}$ rück. Die Wirkungsdauer beträgt 2-3 Tage, was einer Ab- 
klingquote von etwa $40 \%$ entspricht. Die Elimination erfolgt beim Menschen ausschließlich über die Nieren; im Harn lässt sich der Hauptteil des zugeführten Ouabains in unveränderter Form wiederfinden.

Anwendung. In Ampullenform i.v. zur Behandlung schwerer Formen der Herzinsuffizienz, bei denen eine rasch einsetzende Wirkung erwünscht ist. Die Strophanthintherapie hat allerdings die ursprüngliche Bedeutung heute weitgehend verloren. Die i.v.-Injektion von Ouabain kann in den meisten Fällen durch eine orale Applikation von Digitalisglykosiden ersetzt werden.

Für die Arzneimittel zur peroralen Strophanthustherapie gelten hypoxische Herzkrankheiten sowie Prophylaxe des Herzinfarkts als Indikationsgebiete. Man vermutet als Wirkungsbasis eine spezielle Wirkung auf den Herzmuskelstoffwechsel; dieser Effekt müsse nicht notwendigerweise mit der Aufrechterhaltung eines bestimmten Wirkspiegels, wie er für die positiv-inotrope Wirkung essentiell ist, verbunden sein. Die perorale Strophanthintherapie ist umstritten.

\section{k-Strophanthin}

k-Strophanthin ist keine einheitliche Substanz, vielmehr handelt es sich um ein standardisiertes Gemisch dreier Glykoside, die sich durch die Zuckerkomponente unterscheiden; gemeinsam ist ihnen das Aglykon Strophanthidin. Geringe Mengen weiterer Glykoside, die sich vom Strophanthidol und Periplogenin ableiten, können im Gemisch enthalten sein (vgl. ( Abb. 24.55). Zur Gewinnung dienen die Strophanthus-kombé-Samen, vielleicht auch Samen verwandter Strophanthus-Arten. Strophanthus kombé OLIv. (Familie: Apocynaceae [IIB22c]) ist ein kletternder, im Raum der ostafrikanischen Seen heimischer Strauch. k-Strophanthin wird in gleicher Weise angewendet wie Ouabain. Nachteilig ist die leichte Autoxidierbarkeit der Aglykonkomponente in wässriger Lösung, bedingt durch die Aldehydgruppe an C-10 (Oxidation zur Carboxylgruppe und Decarboxylierung zum unwirksamen $\mathrm{C}_{20}$-Steroid).

\section{Cymarin}

Cymarin ist eine Teilkomponente des k-Strophanthins. Es lässt sich ebenfalls aus Strophanthus-kombé-Samen ge- winnen. Da die bi- und triosidischen Glykoside abgebaut sind, wird Cymarin auch nach oraler Gabe besser resorbiert. Ansonsten wirkt es strophanthinartig.

\section{Proscillaridin}

Proscillaridin (DAC 2005) bildet sich aus Glucoscillaren und aus Scillaren A durch ein in der Meerzwiebel vorkommendes Enzym, die Scillarenase (? Abb. 24.56). Technisch gewinnt man folglich Proscillaridin aus feingeschnittenen Meerzwiebeln erst nach vorhergehender Fermentation (wässrige Suspension $2 \mathrm{~h}$ bei etwa $40^{\circ} \mathrm{C}$ sich selbst überlassen) durch Extraktion mit Ethylacetat.

Weißes bis schwach gelbliches, kristallines, hygroskopisches Pulver. Die Substanz schmilzt zwischen 190 und $225^{\circ} \mathrm{C}$ unter Zersetzung; sie reizt stark die Schleimhäute.

Proscillaridin besitzt grundsätzlich die gleichen Herzwirkungen wie die Digitalis- und Strophanthusglykoside. Die Resorptionsquote (30-35\%) ist bedeutend höher als die der Strophanthine. Als Vorzug gegenüber Digitoxin und Digoxin gilt die „gute Steuerbarkeit“: toxische Erscheinungen bei Überdosierung verschwinden bereits nach einem Tag. Nachteilig dürfte sein, dass Diarrhöen etwas häufiger aufzutreten pflegen. Proscillaridin ist auch Ausgangsmaterial zur Überführung in das halbsynthetische Meproscillarin (4'-O-Methylproscillaridin).

\subsubsection{Weitere Drogen mit herz- wirksamen Steroiden}

Das DAB führt die Monographien Adoniskraut, Maiglöckchenkraut und Meerzwiebel sowie die entsprechenden eingestellten Pulver als Drogen mit herzwirksamen Steroiden auf. Alle 3 Arzneidrogen sind bezüglich Wirkung und Anwendungsgebieten mehr oder weniger gleich zu werten.

Wirkungen und Anwendungsgebiete. Als Hauptwirkung aller 3 Drogen wird in den entsprechenden Monographien der Kommission E die positiv-inotrope Wirkung aufgeführt. Alle 3 Drogen (als Pulvis normatus) werden zur Herstellung von alkoholischen Fluidextrakten und von Trockenextrakten und diese wiederum zur Herstellung phytotherapeutischer Kombinationspräparate verwendet. 
- Abb. 24.56

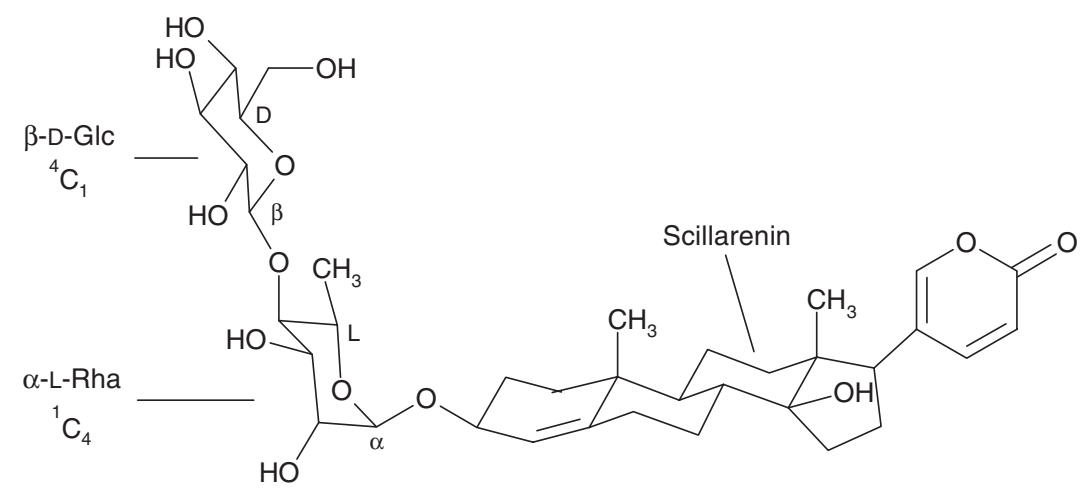

Scillaren A<smiles>CC(C)CC(C)(C)CO[Ga]O</smiles>

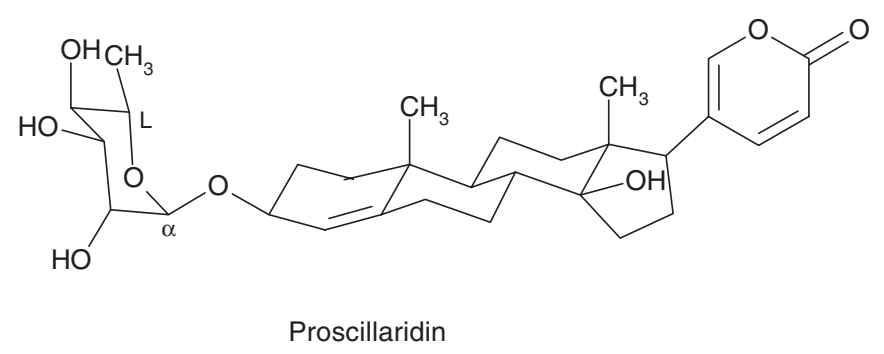

In der Meerzwiebel liegt zunächst als Primärglykosid Glucoscillaren A vor (nicht eingezeichnet); bereits beim Trocknen tritt weitgehende Hydrolyse durch die pflanzeneigene $\beta$-Glucosidase zum Scillaren A ein. Scillaren A ist somit als Sekundärglykosid anzusehen. Enzymatische Spaltung durch die pflanzeneigene Scillarenase oder (künstlich) durch Zusatz von Pilzhydrolasen führt zum Tertiärglykosid Proscillaridin

Die Anwendung der Phytopharmaka geschieht bei leichteren Formen der Herzinsuffizienz sowie beim Altersherz. Da weder für Monodrogenpräparate noch für Kombinationspräparate kontrollierte klinische Studien zur Wirksamkeit vorliegen und pharmakokinetische Daten nur partiell von einzelnen Inhaltsstoffen, nicht aber von Kombinationspräparaten vorliegen, kommt die Kommission $\mathrm{E}$ zum Schluss, dass aufgrund dieser fehlenden Untersuchungen Wirksamkeit, Unbedenklichkeit und Risiko solch fixer Kombinationen nicht beurteilbar seien. Es liegen auch keine klinischen Studien vor, die Aufschluss darüber geben würden, ob solche Drogen/Drogengemische aufgrund des Glykosidgemisches (inkl. Zusatzstoffe) ein qua- litativ oder auch quantitativ partiell unterschiedliches Wirkungsspektrum im Vergleich zu Monosubstanzen (einzelne Cardenolide/Bufadienolide) aufweisen (vgl. dazu Saller et al. 1995).

\section{Adoniskraut}

Adoniskraut (Adonidis herba DAB 1999) besteht aus den zur Blütezeit gesammelten und getrockneten oberirdischen Teilen von Adonis vernalis L. (Familie: Ranunculaceae [IIB1a]). Die Stammpflanze ist ein 10-30 cm hohes, ausdauerndes Kraut mit stark zerschlitzten Blättern 


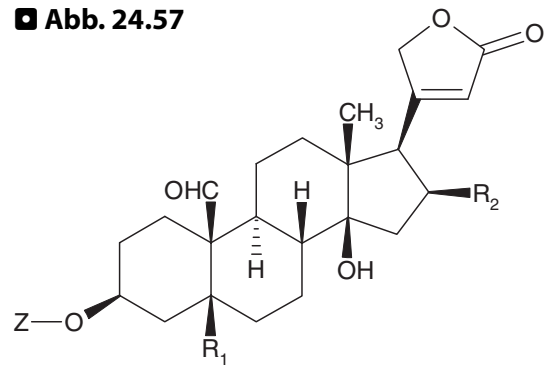

\begin{tabular}{|l|l|l|l|l|}
\hline Glykosid & Aglykon & $\mathrm{R}_{1}$ & $\mathrm{R}_{2}$ & Zucker (Z) \\
\hline $\begin{array}{l}\text { Cymarin } \\
\text { Adonitoxin }\end{array}$ & $\begin{array}{l}\text { k-Strophanthidin } \\
\text { Adonitoxigenin }\end{array}$ & $\begin{array}{l}\mathrm{OH} \\
\mathrm{H}\end{array}$ & $\begin{array}{l}\mathrm{H} \\
\mathrm{OH}\end{array}$ & $\begin{array}{l}\beta \text {-D-Cymarose } \\
\alpha \text {-L-Rhamnose }\end{array}$ \\
\hline
\end{tabular}

Adonis-vernalis-Kraut enthält über 25 Cardenolidglykoside. Die beiden Hauptglykoside sind Cymarin und Adonitoxin. Die Aglykone dieser beiden Glykoside, k-Strophanthidin und Adonitoxigenin, sind stellungsisomere Cardenolide mit einer $\beta$-Hydroxyl-Gruppe am C- 5 bzw. am C-16. Cymarose (vgl. ( Abb. 24.44) ist gleich wie Digitoxose ein 2,6-Didesoxyzucker und großen, goldgelben, radiären Blüten. Die Pflanze steht in Mitteleuropa fast überall unter Naturschutz. Adoniskraut enthält $0,2-0,8 \%$ Cardenolidglykoside mit 5 verschiedenen Aglykonen ( $>$ Abb. 24.57), daneben Flavonoide, Pflanzensäuren, Zuckeralkohole. Hinweis: Wird Adoniskraut verordnet, so ist, wenn aus der Verordnung nichts anderes hervorgeht, eingestelltes Adonispulver (Adonidis pulvis normatus DAB 1999) zu verwenden.

\section{Maiglöckchenkraut}

Maiglöckchenkraut (Convallariae herba DAB 1999) besteht aus den während der Blütezeit gesammelten und getrockneten, oberirdischen Teilen von Convallaria majalis L. oder nahestehender Arten. Die Gattung Convallaria (Familie: Convallariaceae [IIA6a]) umfasst lediglich 3 Arten. Unter "nahestehend“ ist die in Japan heimische $C$. kreiskei MrQ. gemeint. Es handelt sich um krautige Pflanzen mit kriechenden Wurzelstöcken, einem mit ganzrandigen Blättern besetzten Stängel und traubig angeordneten Blüten mit oberständigem Fruchtknoten, aus dem sich eine kugelige, 3- bis 6-samige Beere entwickelt. Maiglöckchenkraut enthält $0,2-0,5 \%$ Cardenolidglykoside mit

- Abb. 24.58<smiles>[Z]O[C@H]1CC[C@]2([R5])[C@H]3[C@H](CC[C@]2(O)C1)[C@@]1(O)CC[C@H](C2=CC(=O)OC2)[C@@]1(C)C[C@H]3[2H]</smiles>

\begin{tabular}{|l|l|l|l|l|}
\hline Glykoside & Aglykone & $\mathrm{R}_{1}$ & $\mathrm{R}_{2}$ & Zucker $(\mathrm{Z})$ \\
\hline Convallosid & Strophanthidin & $\mathrm{H}$ & $\mathrm{CHO}$ & $\beta$-D-GlC- $(1 \rightarrow 4)-\alpha-$-L-Rha- $(1 \rightarrow)$ \\
Convallatoxin & Strophanthidin & $\mathrm{H}$ & $\mathrm{CHO}$ & $\alpha$-L-Rha- $(1 \rightarrow)$ \\
Desglucocheirotoxin & Strophanthidin & $\mathrm{H}$ & $\mathrm{CHO}$ & $\beta$-D-Gulomethylosyl- $(1 \rightarrow)$ \\
Convallatoxol & Strophanthidol & $\mathrm{H}$ & $\mathrm{CH}{ }_{2} \mathrm{OH}$ & $\alpha$-L-Rha- $(1 \rightarrow)$ \\
Lukundjosid & Bipindogenin & $\mathrm{OH}$ & $\mathrm{CH}_{3}$ & $\alpha$-L-Rha- $(1 \rightarrow)$ \\
\hline
\end{tabular}

Die mengenmäßig vorherrschenden Glykoside des Maiglöckchenkrauts. Je nach Herkunft der Droge macht Convallatoxin bis $40 \%$ des Gesamtglykosidgehaltes aus, die weiteren 4 in der Abbildung aufgeführten Glykoside bis ca. die Hälfte davon. Man beachte die seltene 11a-Hydroxylgruppe im Lukundjosid, die auch für das Ouabain typisch ist. 6-Desoxy-DGulose (Synonym: Gulomethylose; Struktur nicht abgebildet) ist ein Vertreter der seltenen Zucker 
8 verschiedenen Aglykonen ( $(A b b .24 .58)$. Die von C. kreiskei stammende Droge hat bis zu 1\% Gesamtglykoside. Weitere Inhaltsstoffe sind Saponine vom Furostanoltyp, Flavonoide und Pflanzensäuren (u. a. Chelidonsäure). Hinweis: Wird Maiglöckchenkraut verordnet, so ist, wenn aus der Verordnung nichts anderes hervorgeht, eingestelltes Maiglöckchenpulver (Convallariae pulvis normatus DAB 1999) zu verwenden.

\section{Meerzwiebel}

Meerzwiebel (Scillae bulbus DAB 1999) stammt von der nach der Blütezeit gesammelten Zwiebel der weißzwiebligen Rasse von Urginea maritima (L.) BAK. (Synonyme: Drimia maritima (L.) STEARN und Scilla maritima L. (Familie: Hyacinthaceae [IIa6d]). Die Meerzwiebel ist in den Mittelmeerländern beheimatet. U. maritima ist als Sam-
- Abb. 24.59

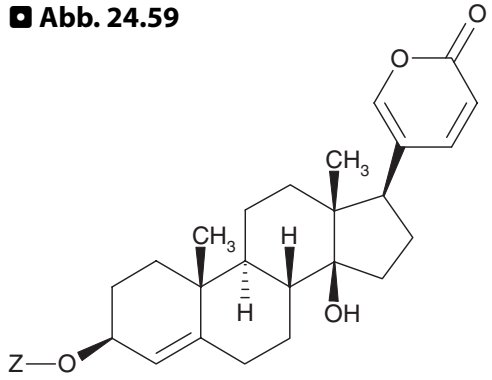

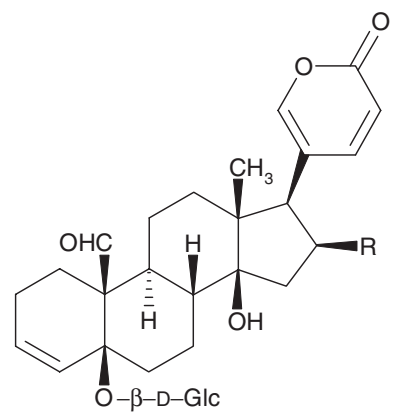

\begin{tabular}{|l|l|}
\hline Glykoside & R \\
\hline $\begin{array}{l}\text { Scilliglaucosid } \\
\text { Scillicyanosid }\end{array}$ & $\mathrm{H}$ \\
$\mathrm{OCOCH}$ & \\
\hline
\end{tabular}

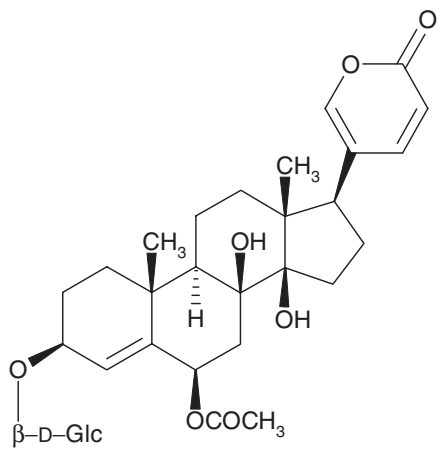

Scillirosid

Die in der Meerzwiebel vorkommenden Glykoside sind $C_{24}$-Steroide mit einem C-17-Pentadienolidring, sie gehören der Bufadienolidreihe an. Bis heute sind über 80 Verbindungen bekannt. Die mengenmäßig vorherrschenden Glykoside Scillaren A, Proscillaridin A und Glucoscillaren A (Struktur nicht abgebildet) leiten sich vom Aglykon Scillarenin ab. Alle 3 Glykoside sind herzwirksam, obwohl das für die Wirkung als obligat betrachtete Merkmal cis-ständiger Substituenten an C-5 und C-10 (d. h. Ringe A/B cis-verknüpft) nicht vorliegt. Begleitsteroide sind u. a. Glykoside, die durch eine 5 $\beta$-Glucosylgruppe gekennzeichnet sind; dadurch liegt cis-Verknüpfung der Ringe $A / B$ vor. Ungewöhnlich ist das Fehlen der $3 \beta-\mathrm{OH}$-Gruppe; sie ist durch eine 3,4-Doppelbindung ersetzt (formale Bildung nach Austritt von $1 \mathrm{Mol}_{2} \mathrm{O}$ ). Die Monographie des Arzneibuchs muss revidiert werden, da die Annahme, dass bestimmte Inhaltsstoffe wie Scillirosid (Acetoxygruppe am C-6) nur von der sog.,,rotzwiebligen“ Varietät gebildet wird, nicht mehr zutrifft. Varietäten mit einem hohen Proscillaridin-A- und Scillaren-A-Gehalt können für pharmazeutische Zwecke, jene mit einer hohen Konzentration an Scillirosid dagegen für die Verwendung als Rodentizid verwendet werden (Kopp et al. 1990) 
melart aufzufassen, die aus mindestens 6 Arten besteht (vgl. Kopp et al. 1990). Die Pflanze wird ca. 50-100 cm hoch. Ihre Zwiebel ragt teilweise aus dem Boden und besteht aus zahlreichen (etwa 40) fleischig-schleimigen, weißen Schuppen, die außen von braunen, trockenhäutigen Schuppen umgeben sind. Die Droge besteht lediglich aus den mittleren, fleischigen Zwiebelschuppen, die zur Beschleunigung des Trocknungsvorgangs in Streifen geschnitten werden. Die äußeren Schuppen sind hautig und wertlos; die inneren wegen ihres hohen Schleimgehalts sehr schwer zu trocknen. Meerzwiebel enthält 0,1-4\% Bufadienolide mit den Hauptglykosiden Scillaren A und Proscillaridin A, auf die annähernd zwei Drittel der Glykosidfraktion entfallen (\$ Abb. 24.59), ferner Schleim- stoffe, vorwiegend Glucogalactane und andere Polysaccharide, (Fructosane), fettes Öl, Flavonoide, organische Säuren (u. a. Chelidonsäure). Hinweis: Wird Meerzwiebel verordnet, so ist, wenn aus der Verordnung nichts anderes hervorgeht, eingestelltes Meerzwiebelpulver (Scillae pulvis normatus DAB 1999) zu verwenden.

Der heute gültige Name der Stammpflanze ist Drimia maritima (L.) STEARN. Die Droge müsste daher eigentlich Drimiae bulbus heißen. Man hat jedoch den traditionellen Namen beibehalten, der aus einer Zeit stammt, als die Meerzwiebelpflanze zur Gattung Scilla gestellt wurde. Die Gattungen stehen sich taxonomisch sehr nahe. Ein gutes Unterscheidungsmerkmal sind die zusammengedrückten oder kantigen Samen.

\section{! Kernaussagen}

Herzwirksame Steroide sind glykosidische Pflanzeninhaltsstoffe mit einer spezifischen Wirkung auf den Herzmuskel (positiv-inotrope Wirkung). Aufgrund der Struktur des Lactonringes werden sie in die Cardenolide (5-gliedriger Lactonring) und die Bufadienolide (6-gliedriger Lactonring) eingeteilt. Der Zuckerteil der herzwirksamen Steroidglykoside besteht neben ubiquitären Zuckern wie Glucose und Rhamnose aus seltenen 2,6-Desoxyzuckern. Die Herzwirksamkeit kommt durch die Aglykone zustande, die Zucker beeinflussen die physikochemischen Eigenschaften der Glykoside (Resorption, Proteinbindung, Verteilung, Biotransformation, Ausscheidung). Die positiv-inotrope Wirkung wird durch Effekte ausgelöst, die zu einem Anstieg von $\mathrm{Ca}^{2+}$-Ionen im sarkoplasmatischen Retikulum des Myo- kards führen (Hemmung von $\mathrm{Na}^{+} / \mathrm{K}^{+}$-ATPase bzw. $\mathrm{Ca}^{2+} /$ $\mathrm{Mg}^{2+}$-ATPase, Stimulierung des $\mathrm{Na}^{+} / \mathrm{K}^{+} / \mathrm{Cl}^{-}$-Cotransportsystems, Freisetzung von membrangebundenem $\mathrm{Ca}^{2+}$ ). Die Wirkung kommt durch die Bindung der Steroide an Digitalisrezeptoren („binding site for cardiac glycosides“) zustande. Die in der Therapie verwendeten Reinstoffe stammen von Digitalis lanata (Digoxin und Derivate), Digitalis purpurea (Digitoxin, Gitoxin) und Strophanthus gratus (g- und k-Strophanthin). Die therapeutische Bedeutung der herzwirksamen Steroide hat gegen Ende des letzten Jahrhunderts durch den möglich gewordenen Einsatz von ACE-Hemmern, $\beta$-Blockern, Calciumantagonisten und Vasodilatatoren stark abgenommen. Indikationen sind in erster Linie die chronische Herzmuskelinsuffizienz und Arrhythmien (Vorhofflimmern, Vorhofflattern).

\section{Schlüssselbegriffe}

Abklingquote

Adonidis herba

Adonis vernalis

Adoniskraut

Adonitoxin

Baljet-Reaktion

Bufadienolide

$\mathrm{Ca}^{2+} / \mathrm{Mg}^{2+}$-ATPase

Cardenolide

Convallaria majalis

Convallariae herba

Convallatoxin

Coprostanreihe
Cymarin

Desoxyzucker

Digitalis lanata

Digitalis lanatae folium

Digitalis purpurea

Digitalis purpureae folium

Digitalis-lanata-Blätter

Digitalis-purpurea-Blätter

Digitalisrezeptor

Digitoxin

Digoxin und Derivate

Eliminationshalbwertszeit

Enterohepatischer Kreislauf
Gitoxin

Herzwirksame Steroide

Herzmuskelfilamente

Kedde-Reaktion

Keller-Kiliani-Reaktion

${ }^{1} \mathrm{C}_{4}$-Konformation

${ }^{4} \mathrm{C}_{1}$-Konformation

Lanatoside

Maiglöckchenkraut

Meerzwiebel

$\mathrm{Na}^{+} / \mathrm{K}^{+}$-ATPase

$\mathrm{Na}^{+} / \mathrm{K}^{+} / \mathrm{Cl}^{-}$-Cotransportsystem

Proscillaridin A 
Purpureaglykoside

Quabain

Raymond-Reaktion

Reagens nach Jensen-Kny

Resorptionsquote

Rosenheim-Reaktion
Scillae bulbus

Scillaren A

Scillirosid

Steroidglykoside

g-Strophanthin

k-Strophanthin
Strophanthus gratus

Strophanthus kombé

Urginea maritima

Verteilungskoeffizient

Wirkung (positiv inotrop)

\subsection{Verschiedene Substanzen mit einem Steroidgerüst}

\subsubsection{Uzarawurzel}

Herkunft. Uzarawurzel (Uzarae radix) besteht aus den getrockneten, meist 2-jährigen Wurzeln verschiedener in Südafrika heimischer Xysmalobium- und Pachycarpus(Gomphocarpus-)Arten (Familie: Apocynaceae [IIB22c], bisher Asclepiadaceae). Die Wurzeln werden von den Medizinmännern Südafrikas zur Uzara-Medizin verarbeitet und gegen Dysenterie, als Antidiarrhoikum sowie als „uterines Sedativum“ verwendet. Zum Einsatz kommen die Wurzeln von Pachycarpus schinzianus (Schltr.) N. E. BR. und von Xysmalobium undulatum R. BR., wobei offenbar je nach Gegend nur eine oder auch beide Pflanzen als Ausgangsmaterial zur Drogengewinnung dienen. Demgegenüber wird für die Gewinnung des bereits 1911 in die hiesige Phytotherapie eingeführten alkoholisch-wässrigen Extraktes ausschließlich Xysmalobium undulatum als Stammpflanze eingesetzt, deren Kultivierung aus klimatischen Gründen bis heute in Südafrika erfolgt.

Sensorische Eigenschaften. Die Droge besitzt einen ganz schwachen, eigenartigen Geruch und einen rein bitteren Geschmack, der nach längerem Kauen schwach brennend sein kann.

\section{Inhaltsstoffe}

- Steroidglykoside vom Uzarigenintyp (> Abb. 24.60 und 24.61), die von den Wurzeln überwiegend als polare Glykoside [1-3 Mol Glucose; mit Ausnahme von Asclepiosid (= Uzarigenin-3-O- $\beta$-D-allomethylosid)] mit einem Gehalt von mindestens $6 \%$ akkumuliert werden; ferner biogenetisch eng verwandte, an C-19 oxidierte Steroidglykoside wie Coroglaucigenin- $\beta$-Dglucosid und Pachygenol- $\beta$-D-glucosid (Pauli u. Fröhlich 2000);

- Pregnanderivate.

\section{Analytische Kennzeichnung}

Prüfung auf Identität. Die Prüfung auf Identität erfolgt mit DC [Fließmittel: Ethylmethylketon-Toluol-Methanol-Wasser-Essigsäure 98\% (80:10:6:5:2); Referenzsubstanzen: Uzarin und Uzarigenin; Nachweis: Chloramin T-Trichloressigsäure-Reagens; UV $365 \mathrm{~nm}$ ]. Die Steroidglykoside ergeben eine gelbe Fluoreszenz (Schmitz et al. 1992).

Gehaltsbestimmung. Die Gehaltsbestimmung erfolgt durch Auswertung der Kedde-Reaktion, deren Berechnung wegen der Schwierigkeiten bei der Gewinnung von epimerenreinem Uzarin besser auf Uzarigenin bezogen werden sollte.

Wirkungen und Toxikologie. Uzara wirkt über eine Hemmung der Darmmotilität und durch Normalisierung der Darmpassage antidiarrhoisch (vgl. Schmitz et al. 1992). Die ausgeprägte spasmolytische Wirkung, wie sie in der jahrzehntelangen Therapie beobachtet und im Tierversuch vielfach nachvollzogen wurde, geht einher mit einer Verringerung der Pendel- und Mischbewegungen der Darmmuskulatur. Paradoxerweise reagieren isolierte glattmuskuläre Organe in vitro auf Uzara-Extrakte durch spontane Erregung oder Kontraktion. Gegenüber den klassischen herzwirksamen Steroidglykosiddrogen, deren Inhaltsstoffe sich vom Digitoxigenin ableiten, zeichnet sich Uzara bei oraler Applikation durch eine deutlich verringerte Herzwirkung und das Fehlen einer toxischen Wirkung aus. Sowohl bei der Zuordnung der Wirkstoffe als auch bei der toxikologischen Beurteilung von Uzara und seinen Cardenoliden verbleiben allerdings einige Unklarheiten: $\mathrm{Zu}$ berücksichtigen sind insbesondere die neu bekannt gewordenen Struktur-Wirkungs-Beziehungen von Cardenoliden (vgl. Übersicht von Thomas 1992), wonach Uzarigeninderivate auch in glykosidischer Bindung grundsätzlich als inotrop-aktive Wirkstoffe mit z. T. hoher Potenz anzusprechen sind. Als Grund für eine Verringerung der inotropen Aktivität von 
- Abb. 24.60

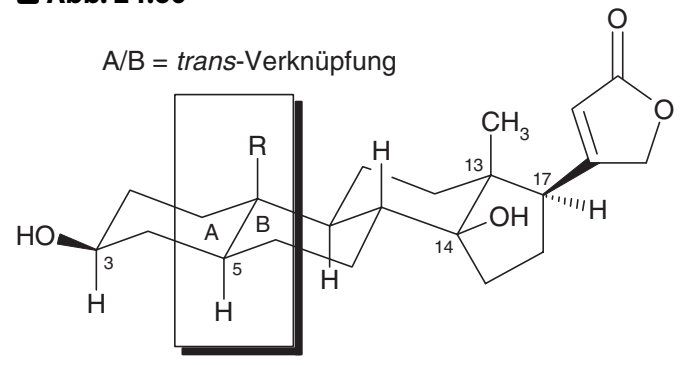

Uzarigenin $\left(\mathrm{R}=\mathrm{CH}_{3}\right)$

Coroglaucigenin $\left(\mathrm{R}=\mathrm{CH}_{2} \mathrm{OH}\right)$

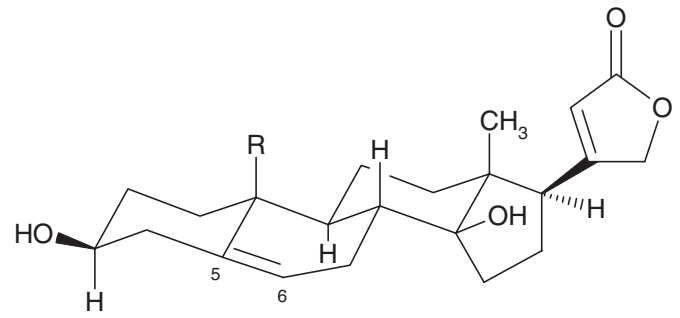

Xysmalogenin $\left(\mathrm{R}=\mathrm{CH}_{3}\right)$

Pachygenol $\left(\mathrm{R}=\mathrm{CH}_{2} \mathrm{OH}\right)$

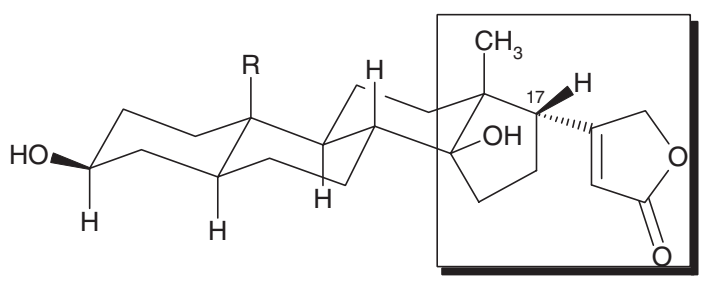

Allouzarigenin $\alpha$-ständiger Butenolidring

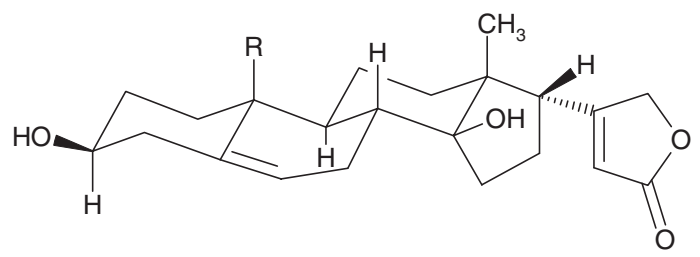

Alloxysmalogenin

Aglykone der Uzarasteroidglykoside. Die bitter schmeckenden und für die antidiarrhoische Wirkung der Uzarawurzel verantwortlich gemachten Steroidglykoside leiten sich vom Uzarigenin und Xysmalogenin als niedrigst substituierte Aglykone ab. Uzarigenin unterscheidet sich vom Digitoxigenin (vgl. $>A b b$. 24.42) durch die trans-Verknüpfung der Ringe $A$ und $B$, d. h. das H-5 ist im Uzarigenin a-ständig angeordnet, wohingegen das Digitoxigenin ein $\mathrm{H}-5 \beta$ aufweist. Dementsprechend ist die in beiden Steroiden $\beta$-ständige C-3-OH-Gruppe im Uzarigenin äquatorial, im Digitoxigenin hingegen axial angeordnet. Im Xysmalogenin/Alloxysmalogenin liegt gleich wie im Progesteron eine 5,6-Doppelbindung vor, während aus den systematisch nahestehenden Gomphocarpus-Arten isolierte Steroide eine $\Delta^{7,8}$-ungesättigte Partialstruktur aufweisen. Weiter akkumuliert die Uzarawurzel auch biogenetisch eng verwandte, an C-19 oxidierte Steroidglykoside, die sich vom Coroglaucigenin (Coroglaucigenin- $\beta$-D-glucosid) bzw. Pachygenol (Pachygenol- $\beta$-D-glucosid) ableiten (Pauli u. Fröhlich 2000)

Uzara können die nachfolgenden 3 Punkte angesehen werden:

- die für Cardenolide ungewöhnlichen, einer verzweigten Struktur entsprechenden Zuckerkomponenten der Sophorose (vgl. () Abb. 24.61);

- das Vorkommen von nachweislich schwächer wirksamen $17 \beta \mathrm{H}$-allo-Cardenoliden wie Allo-Uzarin;

- die hohe Polarität der glykosidischen Inhaltsstoffe und ein daraus resultierender pharmakokinetischer Effekt (schlechte Resorption, Beschränkung auf orale Anwendung, $>$ oben).
Anwendungsgebiete. Unspezifische, akute Durchfallerkrankungen (Kommission E).

\subsubsection{Condurango- oder Kondurango- rinde}

Herkunft. Condurango cortex (Condurangorinde DAC 2003; Kondurangorinde Helv 10) besteht aus der getrockneten Rinde der Zweige und Stämme von Marsdenia cundurango RchB. fil. (DAC) bzw. Marsdenia reichenbachii Triana (M. cundurango Rchb. fil.) (Helv) (Familie: Apocynaceae [IIB22c], bisher Asclepiadaceae), einer auf den 
- Abb. 24.61<smiles></smiles>

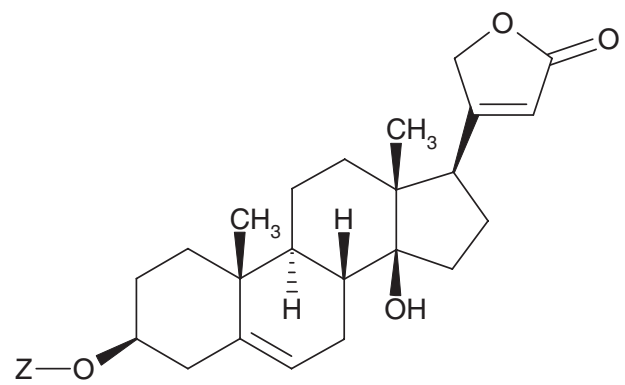<smiles>[Z]O[C@@H]1[CH][C@H]2CC[C@H]3[C@@H](CC[C@]4(C)[C@@H](C5=CC(=O)OC5)CC[C@]34O)[C@@]2(C)CC1</smiles>

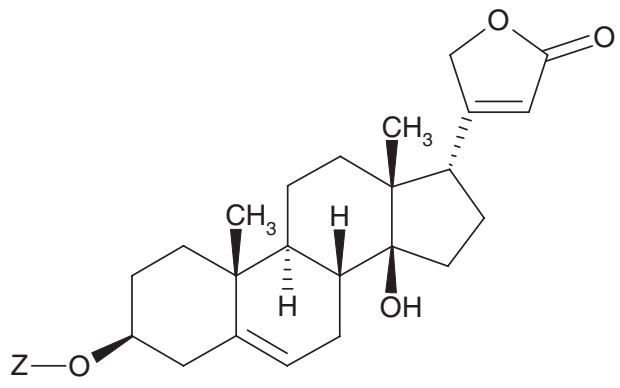

3

4

\begin{tabular}{|l|l|}
\hline Glykoside & Aglykone \\
\hline Uzarin (1) & Uzarigenin \\
Xysmalorin (2) & Xysmalogenin \\
Allouzarin (3) & Allouzarigenin \\
Alloxysmalorin (4) & Alloxysmalogenin \\
\hline
\end{tabular}

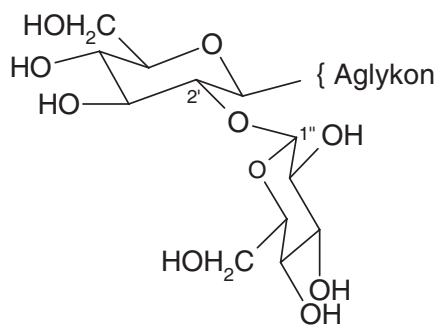

$Z=$ Sophorose

Die nach Extraktion der Uzarawurzel durch Kristallisation gewonnenen Hauptglykoside „Uzarin“ und „Xysmalorin“ erwiesen sich in HPLC-Untersuchungen als Epimerenmischungen (Ghorbani et al. 1997). Als Hauptinhaltsstoffe der Droge sind sie zwar strukturell eng mit Dixgitoxigenin, dem C-5-Epimeren des Uzarigenins, verwandt, weisen aber insbesondere stereochemische Besonderheiten auf (vgl. $>$ Abb. 24.60). Bei beiden Kristallisaten handelt es sich um Sophoroside ( $=\beta$-D-Glucosido-(1 $\rightarrow 2)-\beta$-D-glucoside) der an C-17 epimeren Steroide Uzarigenin und Allouzarigenin bzw. Xysmalogenin und Alloxysmalogenin

Westhängen der Kordilleren in Südamerika (Ecuador, Peru, Kolumbien) heimischen Liane. Die Droge stammt aus Kulturen.

Sensorische Eigenschaften. Condurangorinde riecht schwach süßlich-aromatisch; sie schmeckt bitter und schwach kratzend.

\section{Inhaltsstoffe}

- 1-3\% eines als „Condurangin“ bezeichneten Gemisches verschiedener Steroidesterglykoside (DAC/Helv $=$ mindestens $1,8 \%$, berechnet als Condurangoglykosid A) mit einem $\mathrm{C}_{21}$-Steroidgerüst und einer linearen Tri-, Tetra- oder Pentasaccharidkette ( $>$ Abb. 24.62); 
- Abb. 24.62

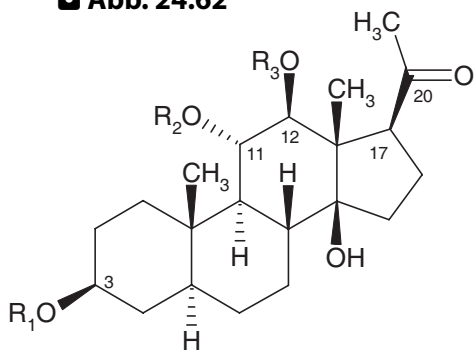

\begin{tabular}{|l|l|l|l|l|}
\hline Glykoside & Aglykone & $\mathrm{R}_{1}$ & $\mathrm{R}_{2}$ & $\mathrm{R}_{3}$ \\
\hline Condurangosid A & Gagaimogenin A & $\mathrm{SA}$ & $\mathrm{A}$ & $\mathrm{A}$ \\
Condurangosid $\mathrm{A}_{0}$ & Gagaimogenin A & SC & $\mathrm{A}$ & $\mathrm{A}$ \\
Condurangosid B & Gagaimogenin B & $\mathrm{SA}$ & $\mathrm{B}$ & $\mathrm{A}$ \\
Condurangosid $\mathrm{B}_{0}$ & Gagaimogenin B & $\mathrm{SC}$ & $\mathrm{B}$ & $\mathrm{A}$ \\
Condurangoglykosid A & Condurangogenin A & $\mathrm{SA}$ & $\mathrm{A}$ & $\mathrm{C}$ \\
Condurangoglykosid $\mathrm{A}_{0}$ & Condurangogenin A & $\mathrm{SC}$ & $\mathrm{A}$ & $\mathrm{C}$ \\
\hline
\end{tabular}

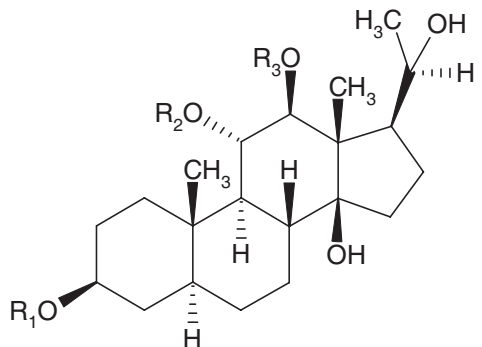

\begin{tabular}{|l|l|l|l|l|}
\hline Glykoside & Aglykone & $\mathrm{R}_{1}$ & $\mathrm{R}_{2}$ & $\mathrm{R}_{3}$ \\
\hline Condurangosid C & Gagaimogenin C & SA & $\mathrm{A}$ & $\mathrm{B}$ \\
Condurangosid C & Gagaimogenin C & SC & A & B \\
Condurangoglykosid C & Condurangogenin C & SA & A & C \\
Condurangoglykosid C & Condurangogenin C & SC & A & C \\
\hline
\end{tabular}

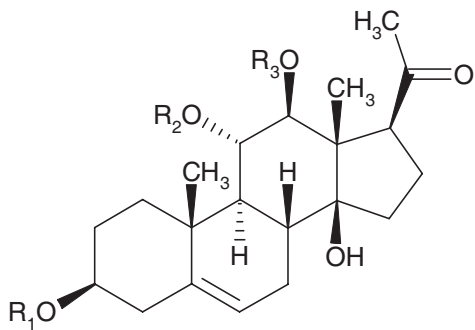

\begin{tabular}{|l|l|l|l|l|}
\hline Glykoside & Aglykone & $\mathrm{R}_{1}$ & $\mathrm{R}_{2}$ & $\mathrm{R}_{3}$ \\
\hline Condurangosid $\mathrm{D}_{01}$ & Marsdenin & $\mathrm{SD}$ & $\mathrm{H}$ & $\mathrm{H}$ \\
Condurangoglykosid $\mathrm{E}$ & Condurangogenin E & $\mathrm{SA}$ & $\mathrm{A}$ & $\mathrm{C}$ \\
Condurangoglykosid $\mathrm{E}_{0}$ & Condurangogenin E & $\mathrm{SC}$ & $\mathrm{A}$ & $\mathrm{C}$ \\
Condurangoglykosid $\mathrm{E}_{2}$ & Condurangogenin E & $\mathrm{SB}$ & $\mathrm{A}$ & $\mathrm{C}$ \\
Condurangoglykosid $\mathrm{E}_{3}$ & Condurangogenin E & $\mathrm{SD}$ & $\mathrm{A}$ & $\mathrm{C}$ \\
\hline
\end{tabular}

Abkürzungen:

Cym Cymarose; Ole Oleandrose;

Pac Pachymonose = 3-O-Methy-6-desoxyallose;

Glc Glucose; A Acetyl; B Benzoyl; C Cinnamoyl

"Condurangin" ist ein komplexes Gemisch einer großen Anzahl von $\mathrm{C}_{21}$-Steroidglykosiden (Pregnanderivate), die als Condurangoside bzw. Condurangoglykoside bezeichnet werden. Es handelt sich um Substanzen, die sich von verschiedenen Aglykonen ableiten (Condurangogenine B und D nicht berücksichtigt). Die meisten Glykoside sind Diester mit Essigsäure, Benzoesäure oder Zimtsäure an der C-11- bzw. C-12-Hydroxylgruppe. Die lineare Tri-, Tetra- oder Pentasaccharidkette ist über das $\mathrm{OH}-\mathrm{C}-3$ verknüpft und besteht vorwiegend aus seltenen 1 $\rightarrow$ 4-verknüpften Zuckern (Berger et al. 1988; Umehara et al. 1994). Es ist unklar, ob die früher beschriebenen Condurangoglykoside $A_{1}$ und $C_{1}$ (Pentasaccharide; Zuckerkette nicht abgebildet) in der Condurangorinde vorkommen, da sie in den zitierten neueren Arbeiten nicht mehr aufgeführt werden. Weiter kommen in der Droge in sehr kleiner Menge ähnlich gebaute Steroidalkaloidglykoside (Condurangamin A und B; Formeln nicht wiedergegeben) vor, die an C-11 bzw. C-20 mit Nicotinsäure verestert sind 
- Sterole ( $\beta$-Sitosterol) und Triterpene ( $\beta$-Amyrin);

- Flavonolglykoside, $C$-Glykosylflavone, Cumarine;

- Alkaloide (Condurangamin A und B);

- Carbonsäuren (Chlorogen- und Kaffeesäure), Vanillin, Cyclite (u. a. Conduritol).

\section{Analytische Kennzeichnung}

Prüfung auf Identität. Die als "Condurangin" bezeichneten Bitterstoffe sind in heißem Wasser schwerer löslich als in kaltem. Darauf beruht ein Nachweis (Helv): Droge mit kaltem Wasser extrahieren; Filtrat erwärmen; bei $80^{\circ} \mathrm{C}$ entsteht eine Trübung, die beim Abkühlen wieder verschwindet. DC-Fingerprintchromatogramm (DAC) [Fließmittel: Ethylacetat-Methanol-Wasser (80:15:5); Referenzsubstanzen: Phenazon, Hydrochinon; Nachweis: Anisaldehydreagens]. Im Tageslicht erscheinen braune, graue, grüne und violette Zonen, die allerdings den entsprechenden Conduranginen nicht zugeordnet werden.
Gehaltsbestimmung. DC-Spektrophotometrie (DAC, Helv) [Fließmittel: Heptan-Toluol (1:1); Nachweis: Fluoreszenzlöschung im UV 254 nm]. Die Conduranginfraktion bleibt am Start, während Begleitstoffe wandern. Die fluoreszenzmindernde Zone am Start wird abgekratzt, extrahiert und spektrophotometrisch bei $280 \mathrm{~nm}$ gegen eine Kompensationslösung bestimmt.

Verwendung. Fein geschnittene oder auch grob gepulverte Droge zur Herstellung eines Infuses, Mazerats, Fluidextrakts (Condurango extractum fluidum Helv 10) oder eines Weins (Condurango vinum Helv 10).

Wirkungen. Zur Anregung der Speichel- und Magensaftsekretion (Kommission E).

Anwendungsgebiete. Als Amarum und magenberuhigendes Mittel bei Appetitlosigkeit und nervöser Dyspepsie. Die homöopathische Arzneimittellehre kennt die spezifische Verwendung gegen Rhagaden (Hautläsionen) an Lippen und Mundwinkeln.

\section{Schlüsselbegriffe}

Amarum

Antidiarrhoikum

Condurangin

Condurango cortex

Condurangorinde
Condurangoside

Kondurangorinde

Marsdenia cundurango

Marsdenia reichenbachii

Pachycarpus schinzianus

\author{
Uzarawurzel \\ Uzarigenin \\ Wirkung (antidiarrhoisch) \\ Xysmalobium undulatum \\ Xysmalogenin
}

\section{Literatur}

Abdel Tawab M, Bahr U, Karas M et al. (2003) Degradation of ginsenosides in humans after oral administration. Drug Metab Disp 31: 1065-1071

Aiken C, Chen CH (2005) Betulinic acid derivatives as HIV-1 antivirals. Trends Mol Med 11:31-36

Akao T, Terasawa T, Hiai S, Kobashi K (1992) Inhibitory effects of glycyrrhetic acid derivatives on $11 \beta$ - and $3 \alpha$-hydroxysteroid dehydrogenases of rat liver. Chem Pharm Bull 40: 3021-3024

Altmann A, Poeckel D, Fischer L et al. (2004) Coupling of boswellic acidinduced $\mathrm{Ca}^{2+}$ mobilisation and MAPK activation to lipid metabolism and peroxide formation in human leucocytes. Br J Pharmacol 141: 223-232

Ammon HPT (2003) Boswelliasäuren (Inhaltsstoffe des Weihrauchs) zur Behandlung chronisch entzündlicher Erkrankungen. MMP 26: 309-315

Bader G (1994) Pharmakologische und biopharmazeutische Bewertung von Triterpensaponinen. Pharmazie 49: 391-400
Bae E-A, Park S-Y, Kim D-H (2000) Constitutive $\beta$-glucosidases hydrolyzing ginsenoside $\mathrm{Rb}_{1}$ and $\mathrm{Rb}_{2}$ from human intestinal bacteria. Biol Pharm Bull 23:1481-1485

Bae E-A, Choo M-K, Park E-K et al. (2002) Metabolism of ginsenoside Rc by human intestinal bacteria and its related antiallergic activity. Biol Pharm Bull 25: 743-747

Bässler D, Okpanyi S, Schrödter A et al. (2003) Bioavailability of $\beta$-aescin from horse chestnut seed extract: comparative clinical studies of two galenic formulations. Advances in Therapy 20: 295-304

Bauer R, Wagner H (1983) Cucurbitacinhaltige Drogen. Analyse und Standardisierung von Arzneidrogen und Phytopräparaten durch Hochleistungsflüssigkeitschromatographie (HPLC) und andere chromatographische Verfahren (II). Dtsch Apoth Ztg 123: 13131321

Behboudi S, Morein B, Villacres-Eriksson MC (1999) Quillaja saponin formulations that stimulate proinflammatory cytokines elicit a potent acquired cell-mediated immunity. Scand J Immunol 50: 371-377 
Beltramino R, Penenory A, Buceta AM (2000) An open-label, randomized multicenter study comparing the efficacy and safety of Cylco 3 Fort $^{\circledR}$ versus hydroxyethyl rutoside in chronic venous lymphatic insufficiency. Angiology 51:535-544

Berger S, Junior P, Kopanski L (1988) Structural revision of pregnane ester glycosides from Condurango cortex and new compounds. Phytochemistry 27: 1451-1458

Berges RR, Windeler J, Trampisch HJ, Senge T (1995) Randomised, placebo-controlled, double-blind clinical trial of $\beta$-Sitosterol in patients with benign prostatic hyperplasia. Lancet 345: 15291532

Bhattacharya TK, Ghosh MN, Subramanian SS (1980) A note on antiinflammatory activity of carpesterol. Fitoterapia 51: 265-267

Bombardelli E, Morazzoni P, Griffini A (1996) Aesculus hippocastanum L. Fitoterapia 67: 483-511

Borelli F, Ernst E (2002) Cimicifuga racemosa: a systematic review of its clinical efficacy. Eur J Clin Pharmacol 58: 235-241

Borelli F, Izzo AA, Ernst E (2003) Pharmacological effects of Cimicifuga racemosa. Life Sci 73: 1215-1229

Bouaziz N, Michiels C, Janssens D et al. (1999) Effect of Ruscus extract and hesperidin methylchalcone on hypoxia-induced activation of endothelial cells. Int Angiology 18: 306-312

Boyaka PN, Marinaro M, Jackson RJ et al. (2001) Oral QS-21 requires early IL-4 help for induction of mucosal and systemic immunity. J Immunol 166: 2283-2290

Brinkhaus B, Lindner M, Schuppan D, Hahn EG (2000) Chemical, pharmacological and clinical profile of the East Asian medical plant Centella asiatica. Phytomedicine 7: 427-448

Brom S (1996) Benigne Prostatahyperplasie. Rationale Therapie der BPH mit neuen Wirkstoffen. Dtsch Apoth Ztg 136: 607-614

Burdette JE, Liu J, Chen S-N et al. (2003) Black cohosh acts as mixed competitive ligand and partial agonist of the serotonin receptor. J Agric Food Chem 51: 5661-5670

Buschauer A (1989) Entwicklung neuer positiv inotroper Arzneistoffe: Suche nach einem Digitalisersatz. Pharm Ztg Wiss 1.2/134: 3-16

Calis I, Yürüker A, Rüegger H, Wright AD, Sticher O (1992) Triterpene saponins from Primula veris subsp. macrocalyx and Primula elatior subsp. meyeri. J Nat Prod 55: 1299-1306

Chen S-N, Li W, Farbicant DS et al. (2002a) Isolation, structure elucidation, and absolute configuration of 26-deoxyactein from Cimicifuga racemosa and clarification of nomenclature associated with 27-deoxyactein. J Nat Prod 65: 601-605

Chen S-N, Fabricant DS, Lu Z-Z et al. (2002b) Cimiracemosides I-P, new 9,19-cyclolanostane triterpene glycosides from Cimicifuga racemosa. J Nat Prod 65: 1391-1397

Christen P (1989) Withanolide. Naturstoffe mit vielversprechendem Wirkungsspektrum. Pharm Unserer Zeit 18: 129-139

Cichewicz RH, Kouzi SA (2004) Chemistry, biological activity, and chemotherapeutic potential of betulinic acid for the prevention of cancer and HIV infection. Med Res Reviews 24: 90-114

Cinatl J, Morgenstern B, Bauer G et al. (2003) Glycyrrhizin, an active component of liquorice roots, and replication of SARS-assicocated coronavirus. Lancet 361: 2045-2046

Cleland JL, Kensil CR, Lim A et al. (1996) Isomerization and formulation stability of the vaccine adjuvant QS-21. J Pharm Sci 85: 22-28
Coldren D, Hashim P, Ali JM et al. (2003) Gene expression changes in the human fibroblast induced by Centella asiatica triterpenoids. Planta Med 69: 725-732

Coleman Cl, Hebert JH, Reddy P (2003) The effects of Panax ginseng on quality of life. J Clin Pharm Ther 28: 5-15

Cuendet M, Pezzuto JM (2004) Antitumor activity of bruceantin: an old drug with new promise. J Nat Prod 67: 269-272

Curreli F, Friedman-Kien AE, Flore O (2005) Glycyrrhizic acid alters Kaposi sarcoma-associated herpervirus latency, tiggering p53mediated apoptosis in transformed B lymphocytes. J Clin Inv 115 : 642-652

De Combarieu E, Falzoni M, Fuzzati N et al. $(2002,2003)$ Identification of Ruscus steroidal saponins by HPLC-MS analysis. Fitoterapia 73: 583-596; 74: 423

De Jong A, Plat J, Mensink RP (2003) Metabolic effects of plant sterols and stanols (review). J Nutr Biochem 14: 362-369

Della Loggia R, Tubaro A, Sosa S et al. (1994) The role of triterpenoids in the topical anti-inflammatory activity of Calendula officinalis flowers. Planta Med 60: 516-520

Diehm C, Trampisch HJ, Lange S, Schmidt C (1996) Comparison of leg compression stocking and oral horse-chestnut seed extract therapy in patients with chronic venous insufficiency. Lancet 347 : 292-294

Di Lazzaro A, Morana A, Schiraldi C et al. (2001) An enzymatic process for the production of the pharmacologically active glycoside desglucodesrhamnoruscin from Ruscus aculeatus. J Mol Catalysis B: Enzymatic 11: 307-314

Dinan L, Harmatha J, Lafont R (2001) Chromatographic procedures for the isolation of plant steroids. J Chromatogr A 935: 105-123

Dittgen M, Zimmermann H, Wober W et al. (1996) Untersuchung der Bioverfügbarkeit von $\beta$-Aescin nach oraler Verabreichung verschiedener Darreichungsformen. Pharmazie 51: 608-610

Dorai T, Aggarwal BB (2004) Role of chemopreventive agents in cancer therapy. Cancer Letters 215: 129-140

Einbond LS, Shimizu M, Xiao D et al. (2004) Growth inhibitory activity of extracts and purified components of black cohosh on human breast cancer cells. Breast Cancer Res and Treat 83: 221-231

Erdmann E (1995) Digitalis - friend or foe? Eur Heart J 16 [Suppl F]: 16-19

Ernst E, Cassileth BR (1999) How useful are unconventional cancer treatments? Eur J Cancer 35: 1608-1613

ESCOP (2003) ESCOP monographs. $2^{\text {nd }}$ edn. ESCOP, Exeter. Thieme, Stuttgart New York

Facino RM, Carini M, Stefani R et al. (1995) Anti-elastase and anti-hyaluronidase activities of saponins and sapogenins from Hedera helix, Aesculus hippocastanum, and Ruscus aculeatus: factors contributing to their efficacy in the treatment of venous insufficiency. Arch Pharm (Weinheim) 328: 720-724

Felix W (1992) Ödemprotektiva - Antiexsudativa (membranstabilisierende Substanzen). In: Spektrum Venenmittel, 3. Aufl. AesopusVerlag, Basel, S 24-41

Francis G, Kerem Z, Makkar HPS, Becker K (2002) The biological action of saponins in animal systems: a review. Br J Nutr 88: 587-605

Frohne D, Jensen U (1998) Systematik des Pflanzenreichs unter besonderer Berücksichtigung chemischer Merkmale und pflanzlicher Drogen. 5. Aufl. Wissenschaftliche Verlagsgesellschaft, Stuttgart 
Fukai T, Marumo A, Kaitou K et al. (2002) Anti-helicobacter pylori flavonoids from licorice extract. Life Sci 71: 1449-1463

Fuzzati N, Gabetta B, Jayakur K et al. (1999) Liquid chromatography electrospray mass spectrometric identification of ginsenosides in Panax ginseng roots. J Chromatogr A 854: 69-79

Ghorbani M, Kaloga M, Frey H-H et al. (1997) Phytochemical reinvestigation of Xysmalobium undulatum roots (Uzara). Planta Med 63: 343-346

Goad LJ (1991) Phytosterols. In: Charlwood BV, Banthorpe DV (eds) Methods in plant biochemistry, vol 7: Terpenoids. Academic Press, London, pp 369-433

Griffini A, Lolla E, Peterlongo F (1997) Liquid chromatography-thermospray mass spectrometry analysis of $\beta$-escin. Fitoterapia 68 : 520-526

Grimaldi R, De Ponti F, D'Angelo L et al. (1990) Pharmacokinetics of the total triterpenic fraction of Centella asiatica after single and multiple administrations to healthy volunteers. A new assay for asiatic acid. J Ethnopharmacol 28: 235-241

Guo JS, Cheng CL, Koo MWL (2004) Inhibitory effects of Centella asiatica water extract and asiaticoside on inducible nitric oxide synthase during gastric ulcer in rats. Planta Med 70: 1150-1154

Guo Z, Vangapandu S, Sindelair RW et al. (2005) Biologically active quassinoids and their chemistry: potential leads for drug design. Curr Med Chem 12: 173-190

Hänsel R (1984) Traditionelle Reizkörpertherapie, gesehen als Immunstimulation. Dtsch Apoth Ztg 124:54-59

Hasegawa H, Lee K-S, Nagaoka T et al. (2000) Pharmacokinetics of ginsenoside deglucosylated by intestinal bacteria and its transformation to biologically active fatty acid esters. Biol Pharm Bull 23: 298-304

Hegnauer R (1973) Chemotaxonomie der Pflanzen. Bd 6, BirkhäuserVerlag, Basel Stuttgart, S 596-597

Hoever G, Baltina L, Michaelis M et al. (2005) Antiviral activity of glycyrrhizic acid derivatives against SARS-coronavirus. J Med Chem 48: 1256-1259

Horikawa T, Mimaki Y, Kameyama A et al. (1994) Aculeoside A, a novel steroidal saponin containing a deoxyaldoketose from Ruscus aculeatus. Chem Lett 12: 2303-2306

Hostanska K, Nisslein T, Freudenstein J et al. (2004a) Cimicifuga racemosa extract inhibits proliferation of estrogen receptor-positive and negative human breast carcinoma cell lines by induction of apoptosis. Breast Cancer Res Treat 84: 151-160

Hostanska K, Nisslein T, Freudenstein J et al. (2004b) Evaluation of cell death caused by triterpene glycosides and phenolic substances from Cimicifuga racemosa in human MCF-7 breast cancer cells. Biol Pharm Bull 27: 1970-1975

Hostettmann K, Marston A (1995) Saponins. In: Phillipson JD, Ayres DC, Baxter $\mathrm{H}$ (eds) Chemistry and pharmacology of natural products. University Press, Cambridge

Hübner G, Wray V, Nahrstedt A (1999) Flavonol oligosaccharides from the seeds of Aesculus hippocastanum. Planta Med 65: 636-642

Isaac O (1994) Calendula officinalis L. - Die Ringelblume. Portrait einer Arzneipflanze. Z Phytother 16: 356-370

Isaac O (2000) Die Ringelblume - eine alte Arzneipflanze neu betrachtet. Z Phytother 21: 138-142

Jäger K, Eichlisberger R, Jeanneret C, Lobs KH (1999) Pharmacodynamic effects of Ruscus extract (Cyclo 3 Fort $^{\circledR}$ ) on superficial and deep veins in patients with primary varicose veins assessment by duplex-sonography. Clin Drug Inv 17: 265-273

Janovsky JV, Erb L (1886) Zur Kenntniss der directen Brom- und Nitrosubstitutionsproducte der Azokörper. Ber Dtsch Chem Ges 19: 2155-2158

Jauch J, Bergmann J (2003) An efficient method for large-scale preparation of 3-O-acetyl-11-oxo- $\beta$-boswellic acid and other boswellic acids. Eur J Org Chem: 4752-4756

Jayaprakasam B, Seeram NP, Nair MG (2003) Anticancer and antiinflammatory activities of cucurbitacins from Cucurbita andreana. Cancer Letters 189: 11-16

Jia H, Jiang Y, Ruan Y et al. (2004) Tenuigenin treatment decreases secretion of Alzheimer's disease amyloid $\beta$-protein in cultured cells. Neurosci Lett 367: 123-128

Jiang Y, Zhang W, Tu P, Xu X (2005a) Xanthone glycosides from Polygala tenuifolia and their conformational analysis. J Nat Prod 68: 875-879

Jiang Z-Y, Zhang X-M, Zhou J, Chen J-J (2005b) New Triterpenoid Glycosides from Centella asiatica. Helv Chim Acta 88: 297-303

Kageyama Y, Suzuki H, Saruta T (1992) Glycyrrhizin induces mineralocorticoid activity through alterations in cortisol metabolism in the human kidney. J Endocrinol 135: 147-152

Kakáč B, Vejdělek ZJ (1974) Handbuch der photometrischen Analyse organischer Verbindungen. Bd 2. Verlag Chemie, Weinheim, S 1053-1079

Kameyama A, Shibuya Y, Kusuoku $\mathrm{H}$ et al. (2003) Isolation and structural determination of spilacleosides $A$ and $B$ having a novel 1,3-dioxolan-4-one ring. Tetrahedron Letters 44: 2737-2739

Kato H, Kanaoka M, Yano S, Kobayashi M (1995) 3-Monoglucuronylglycyrrhetinic acid is a major metabolite that causes licoriceinduced pseudoaldosteronism. J Clin Endocrinol Metab 80: 19291933

Kennelly EJ, Baggett S, Nuntanakorn P et al. (2002) Analysis of thirteen populations of black cohosh for formomonetin. Phytomedicine 9: 461-467

Kensil CR, Soltysik S, Wheeler DA, Wu J-Y (1996) Structure/function studies of QS-21, a unique immunological adjuvant from Quillaja saponaria. In: Waller GR, Yamasaki K (eds) Saponins used in traditional and modern medicine. Plenum Press, New York London, pp 165-171

Kimmatkar N, Thawani V, Hingorani L, Khiyani R (2003) Efficacy and tolerability of Boswellia serrata extract in treatment of osteoarthritis of knee - a randomized double blind placebo controlled trial. Phytomedicine 10: 3-7

Kny L (1963) Die direkte fluorometrische Bestimmung der Digitalisglykoside am Papierchromatogramm. Pharmazie 18: 209-222, 295307

Kommission E-Monographien des ehemaligen Bundesinstitutes für Arzneimittel, s. bei Blumenthal M (ed), The complete German Commission E monographs (1998). American Botanical Council, Austin

Kopp B, Krenn L, Jurenitsch J (1990) Bufadienolide in Meerzwiebeln. Bestimmung mittels Spektralphotometrie und HPLC. Dtsch Apoth Ztg 130: 2175-2180

Kreis W, May U (1990) Cardenolide glucosyltransferases and glucohydrolases in leaves and cell cultures of three Digitalis (Scrophulariaceae) species. J Plant Physiol 136: 247-252 
Krenn L, Schlifelner L, Stimpfl T, Kopp B (1996) A new HPLC method for the quantification of cardenolides in Convallaria majalis L. Pharmazie 51: 906-909

Lacaille-Dubois MA, Wagner H (2000) Bioactive saponins from plants: an update. In: Atta-ur-Rahman (ed) Studies in natural products chemistry, vol. 21. Bioactive Natural Products (Part B). Elsevier Science BV, Amsterdam, pp 633-687

Lauterbach F (1977) Enterale Resorption und Sekretion herzwirksamer Glykoside. Verh Dtsch Ges Inn Med 83: 33-45

Levi AJ, Boyett MR, Lee CO (1994) The cellular actions of Digitalis glycosides on the heart. Prog Biophys Molec Biol 62: 1-54

Li W, Gu C, Zhang H et al. (2000) Use of high performance liquid chromatography - tandem mass spectrometry to distinguish Panax ginseng CA Meyer (Asian ginseng) and Panax quinquefolius $\mathrm{L}$ (North American ginseng). Anal Chem 72: 5417-5422

Li W, Chen S, Fabricant D et al. (2002) High-performance liquid chromatographic analysis of black cohosh (Cimicifuga racemosa) constituents with in-line evaporative light scattering and photodiode array detection. Anal Chim Acta 471: 61-75

Löffler G, Petrides PE (2003) Biochemie und Pathobiochemie. 7. Aufl. Springer, Berlin Heidelberg New York, S 213-215

Loew D, Schrödter A (1999) Pharmakokinetik und Äquivalenz von Zubereitungen aus Hippocastani semen. In: Loew D, Blume $H$, Dingermann T (eds) Phytopharmaka V. Forschung und klinische Anwendung. Steinkopff, Darmstadt, S 135-143

Maeda C, Ohtani K, Kasai R et al. (1994) Oleanane and ursane glycosides from Schefflera octophylla. Phytochemistry 37: 1131-1137

Marukami T, Kishi A, Yoshikawa M (2001) Medicinal flowers IV. Marigold. (2): Structures of new ionone and sesquiterpene glycosides from Egyptian Calendula officinalis. Chem Pharm Bull 49: 974978

Matsuda H, Morikawa T, Ueda H, Yoshikawa M (2001a) Medicinal Foodstuffs. XXVI. Inhibitors of aldose reductase and new triterpene and its oligoglycoside, centellasapogenol $A$ and centellasponin A, from Centella asiatica (Gotu Kola). Heterocycles 55: 1499-1504

Matsuda H, Morikawa T, Ueda H, Yoshikawa M (2001b) Medicinal foodstuffs. XXVII. Saponin constituents of Gotu Kola (2): Structures of new ursane- and oleanane-type triterpene oligoglycosides centellasaponins $B, C$, and $D$, from Centella asiatica cultivated in Sri Lanka. Chem Pharm Bull 49: 1368-1371

Megges R, Portius HJ, Repke KRH (1977) Penta-acetyl-gitoxin: the prototype of a prodrug in the cardiac glycoside series. Pharmazie 32: 665-667

Mimaki Y, Kuroda M, Kameyama A et al. (1998a) New steroidal constitutents of the underground parts of Ruscus aculeatus and their cytostatic activity on HL-60 cells. Chem Pharm Bull 46: 298303

Mimaki Y, Kuroda M, Kameyama A et al. (1998b) Steroidal saponins from the underground parts of Ruscus aculeatus and their cytostatic activity on HL-60 Cells. Phytochemistry 48: 485-493

Mimaki Y, Kuroda M, Yokosuka A, Sashida Y (1998c) Two new bisdesmosidic steroidal saponins from the underground parts of Ruscus aculeatus. Chem Pharm Bull 46: 879-881

Mimaki Y, Kuroda M, Kameyama A et al. (1998d) Aculeoside B, a new bisdesmosidic spirostanol saponin from the underground parts of Ruscus aculeatus. J Nat Prod 61: 1279-1282
Mimaki Y, Kuroda M, Yokosuka A, Sashida Y (1999) A spirostanol saponin from the underground parts of Ruscus aculeatus. Phytochemistry 51: 689-692

Miró M (1995) Cucurbitacins and their pharmacological effects. Phytother Res 9: 159-168

Mizutani K, Kambara T, Masuda H et al. (1998) Glycyrrhetic acid monoglucuronide (MGGR): Biological activities. In: Ageta $\mathrm{H}$, Aimi $\mathrm{N}$, Ebizuka Y, Fujita T, Honda G (eds) Towards natural medicine research in the 21st century. Elsevier Science BV, Amsterdam, pp 225-235

Moreau RA, Whitaker BD, Hicks KB (2002) Phytosterols, phytostanols and their conjugates in foods: structural diversity, quantitative analysis, and health-promoting uses. Prog Lipid Res 41: 457-500

Mukherjee R, Jaggi M, Rajendran P et al. (2004) Betulinic acid and its derivatives as anti-angiogenic agents. Bioorg Med Chem Letters 14: $2181-2184$

Neukirch H, D'Ambrosio M, Dalla Via J, Guerriero A (2004) Simultaneous quantitative determination of eigth triterpenoid monoesters from flowers of 10 varieties of Calendula officinalis L. and characterisation of a new triterpenoid monoester. Phytochem Anal 15: 30-35

Niedner R (1973) Digitalistherapie. Die herzwirksamen Glykoside in Theorie und Praxis. 2. Aufl. Thieme, Stuttgart

Noé S (2000) Ruscus - der Mäusedorn. Dtsch Apoth Ztg 140: 589-593

Nyberg NT, Baumann H, Kenne L (2003) Solid-phase extraction NMR studies of chromatographic fractions of saponins from Quillaja saponaria. Anal Chem 75: 268-274

Okamura N, Miyauchi H, Choshi C et al. (2003) Simultaneous determination of glycyrrhizin metabolites formed by the incubation of glycyrrhizin with rat feces by semi-micro high-performance liquid chromatography. Biol Pharm Bull 26: 658-661

Okano M, Fukamiya N, Lee KH (2000) Bioactive quassinoids. In: Atta-ur-Rahman (ed) Studies in natural products chemistry, vol 23. Bioactive Natural Products (Part D). Elsevier Science BV, Amsterdam, pp 285-333

Oleszek WA (2002) Chromatographic determination of plant saponins. J Chromatogr A 967: 147-162

Osbourn A (1996) Saponins and plant defence - a soap story. Trends Plant Sci 1:4-9

Oschmann R, Biber A, Lang F, Stumpf H, Kunz K (1996) Pharmakokinetik von $\beta$-Aescin nach Gabe verschiedener Aesculus-Extrakte enthaltender Formulierungen. Pharmazie 51: 577-581

Osmers R, Friede M, Liske E et al. (2005) Efficacy and safety of isopropanolic black cohosh extract for climacteric symptoms. Obstet Gynecol 105: 1074-1083

Parrado F, Buzzi A (1999) A study of the efficacy and tolerability of a preparation containing Ruscus aculeatus in the treatment of chronic venous insufficiency of the lower limbs. Clin Drug Invest 18: 255-261

Pauli GF, Fröhlich R (2000) Chiral key positions in Uzara steroids. Phytochem Anal 11: 79-89

Phillipson JD, Wright CW, Kirby GC, Warhurst DC (1993) Tropical plants as sources of antiprotozoal agents. In: Downum KR, Romeo JT, Stafford HA (eds) Recent advances in phytochemistry, vol 27: Phytochemical potential of tropical plants. Plenum Press, New York, pp 1-40

Piersen CE (2003) Phytoestrogens in botanical dietary supplements: Implications for cancer. Integrative Cancer Therapies 2: 120-138 
Pillion DJ, Recchia J, Wang P et al. (1995) DS-1, a modified Quillaja saponin, enhances ocular and nasal absorption of insulin. J Pharm Sci 84: 1276-1279

Pillion DJ, Amsden JA, Kensil CR, Recchia J (1996) Structure-function relationship among Quillaja saponins serving as excipients for nasal and ocular delivery of insulin. J Pharm Sci 85: 518-524

Pittler MH, Ernst E (1999) Rosskastaniensamen-Extrakt zur Behandlung der chronisch-venösen Insuffizienz. Ein systematischer Review. In: Loew D, Blume H, Dingermann T (eds) Phytopharmaka V. Forschung und klinische Anwendung. Steinkopff, Darmstadt, pp 127-134

Pittler MH, Ernst E (2004) Horse chestnut seed extract for chronic venous insufficiency. Cochrane database of systematic reviews 2004, CD003230

Polonsky J (1985) Quassinoid bitter principles II. In: Herz W, Grisebach $\mathrm{H}$, Kirby GW, Tamm C (eds) Progress in the chemistry of organic natural products, vol 47. Springer, Berlin Heidelberg New York, pp 221-264

Popp M, Schenk R, Abel G (2003) Cultivation of Cimicifuga racemosa (L.) nuttal and quality of CR extract BNO 1055. Maturitas 44 [Suppl 1]: S1-S7

Rauwald HW, Janßen B (1988) Desglucoruscin und Desglucoruscosid als Leitstoffe des Ruscus aculeatus-Wurzelstocks. Pharm Ztg Wiss 1/133: 61-68

Rauwald HW, Grünwidl J (1991) Ruscus aculeatus extract: Unambiguous proof of the absorption of spirostanol glycosides in human plasma after oral administration. Planta Med 57 [Suppl. 2]: A75A76

Reznicek G, Zitterl-Eglseer K (2003) Quantitative determination of the faradiol esters in marigold flowers and extracts. Sci Pharm 71: 121-128

Runkel F, Prenner L, Häberlein H (2005) Ein Beitrag zum Wirkungsmechanismus von Efeu. Pharm Ztg 150: 269-274

Safayhi H, Sailer E-R (1997) Anti-inflammatory actions of pentacyclic triterpenes. Planta Med 63: 487-493

Saller R, Reichling J, Hellenbrecht D (1995) Phytotherapie. Klinische, pharmakologische und pharmazeutische Grundlagen. Haug, Heidelberg

Sampson JH, Raman A, Karlsen G et al. (2001) In vitro keratinocyte antiproliferant effect of Centella asiatica extract and triterpenoid saponins. Phytomedicine 8: 230-235

Sasaki K, Yonebayashi S, Yoshida M et al. (2003) Improvement in the bioavailability of poorly absorbed glycyrrhizin via various nonvascular administration routes in rats. Int J Pharm 265: 95-102

Schaumann W (1978) $\beta$-Methyl-digoxin, a new lipophilic digoxin derivative. In: Bodem G, Dengler HJ (eds) Cardiac glycosides. Springer, Berlin Heidelberg New York, pp 93-108

Scheline RR (1991) CRC handbook of mammalian metabolism of plant compounds. CRC Press, Boca Raton Ann Arbor Boston

Schmidt O (2003) Biopharmazeutische Charakterisierung von Efeublättertrockenextrakten durch in vivo und in vitro Studien. InauguralDissertation, Ruprecht-Karls-Universität Heidelberg

Schmitz B, El Agamy R, Lindner K (1992) Uzarawurzel - seit 80 Jahren bewährt bei akuten Durchfallerkrankungen. Pharm Ztg 137: 1697-1713

Scholey AB, Kennedy DO (2002) Acute, dose-dependent cognitive effects of Ginkgo biloba, Panax ginseng and their combination in healthy young volunteers: differential interactions with cognitive demand. Hum Psychopharmacol 17: 35-44

Schulz V, Hänsel R (2004) Rationale Phytotherapie. Ratgeber für Ärzte und Apotheker. 5. Aufl. Springer, Berlin Heidelberg New York Tokio

Seidlová-Wuttke D, Hesse O, Jarry H et al. (2003) Evidence for selective estrogen receptor modulator activity in a black cohosh (Cimicifuga racemosa) extract: comparison with estradiol-17 $\beta$. Eur J Endocrinol 149: 351-362

Shao Y, Harris A, Wang M et al. (2000) Triterpene Glycosides from Cimicifuga racemosa. J Nat Prod 63: 905-910

Shin HR, Kim JY, Yun TK et al. (2000) The cancer-preventive potential of Panax ginseng: a review of human and experimental evidence. Cancer Causes and Control 11: 565-576

Shukla YN, Srivastava R, Tripathi AK, Prajapati V (2000) Chracterization of an ursane triterpenoid from Centella asiatica with growth inhibitory activity against Spilarctia obliqua. Pharm Biol 38: 262267

Siems K, Jaensch M, Jakupovic J (1998) Structures of the two saponins isolated from commercially available root extract of Primula sp. Planta Med 64: 272-274

Soldati F, Sticher O (1980) HPLC separation and quantitative determination of ginsenosides from Panax ginseng, Panax quinquefolium and from ginseng drug preparations. Planta Med 39: 348-357

Sonnenborn U, Proppert Y (1990) Ginseng (Panax ginseng C.A. Meyer). Z Phytother 11:35-49

Sticher O (1998) Biochemical, pharmaceutical and medical perspectives of ginseng. In: Lawson LD, Bauer R (eds) Phytomedicines of Europe: Chemistry and biological activity. ACS symposium ser. 691. American Chemical Society, Washington DC, pp 221-240

Størmer FC, Reistad R, Alexander J (1993) Glycyrrhizic acid in liquorice - evaluation of health hazard. Food Chem Toxicol 31: 303-312

Sun J, Blaskovich MA, Jove R et al. (2005) Cucurbitacin Q: a selctive STAT3 activation inhibitor with potent antitumor activity. Oncogene 24: 3236-3245

Syrovets T, Büchele B, Krauss C et al. (2005a) Acetyl-boswellic acid inhibit lipopolysaccharide-mediated TNF- $\alpha$ induction in monocytes by direct interaction with IKB kinases. J Immunol 174: 498-506

Syrovets T, Gschwend JE, Büchele B et al. (2005b) Inhibition of $1 \kappa B$ kinase activity by acetyl-boswellic acids promotes apoptosis in androgen-independent PC-3 prostate cancer cells in vitro and in vivo. J Biol Chem 280: 6170-6180

Takada Y, Aggarwal BB (2003) Betulinic acid suppresses carcinogeninduced NF- $\kappa B$ activation through inhibition of $I_{\kappa} B \alpha$ kinase and p65 phosphorylation: abrogation of cyclooxygenase-2 and matrix metalloprotease-9. J Immunol 171: 3278-3286

Takechi M, Tanaka Y (1995) Haemolytic time course differences between steroid and triterpenoid saponins. Planta Med 61: 76-77

Tan YM, Yu R, Pezzuto JM (2003) Betulinic acid-induced programmed cell death in human melanoma cells involves mitogen-activated protein kinase activation. Clinical Cancer Research 9: 2866-2875

Thomas RE (1992) Molecular biology of cardiotonic steroids. In: Bohl M, Duax WL (eds) Molecular structure and biological activity of steroids. CRC Press, Boca Raton, Florida, pp 399-464

Thomas RE (1996) Cardiotonic steroids (Digitalis). In: Wolff ME (ed) Burger's medicinal chemistry and drug discovery, 5th edn, vol 2. Therapeutic agents. Wiley, New York, pp 231-261 
Thurnher D, Turhani D, Pelzmann M et al. (2003) Betulinic acid: a new cytotoxic compound against malignant head and neck cancer cells. Head Neck 25: 732-740

Tohda C, Matsumoto N, Zou K et al. (2004) A $\beta$ (25-35)-induced memory impairment, axonal atrophy, and synaptic loss are ameliorated by $\mathrm{M} 1$, a metabolite of protopanaxadiol-type saponins. Neuropsychopharmacology 29: 860-868

Trautwein EA, Duchateau GSMJE, Lin Y et al. (2003) Proposed mechanisms of cholesterol-lowering action of plant sterols. Eur J Lipid Sci Technol 105: 171-185

Tschesche R, Wulff G (1973) Chemie und Biologie der Saponine. In: Herz W, Grisebach H, Kirby GW (Hrsg) Fortschritte der Chemie organischer Naturstoffe, Bd 30. Springer, Berlin Heidelberg New York, S 461-606

Umehara K, Endoh M, Miyase T et al. (1994) Studies on differentiation inducers. IV. Pregnane derivatives from Condurango cortex. Chem Pharm Bull 42: 611-616

Van Rensen I (2000) Der stechende Mäusedorn - Ruscus aculeatus L. Z Phytother 21:271-286

Vanscheidt W, Jost V, Wolna P et al. (2002) Efficacy and safety of butcher's broom preparation (Ruscus aculeatus L. extract) compared to placebo in patients suffering from chronic venous insufficiency. Arzneim-Forsch Drug Res 52: 243-250

Villacres-Eriksson M, Behboudi S, Morgan AJ et al. (1997) Immunomodulation by Quillaja saponaria adjuvant formulations: In vivo stimulation of interleukin 12 and its effects on the antibody response. Cytokine 9: 73-82

Vollmer G, Zierau O (2004) Was sind Phytoestrogene und PhytoSERMs? Pharm Unserer Zeit 33: 378-383

Wagner H, Reger H (1986) Folium Hederae-Extrakte. HPLC-Analyse. Dtsch Apoth Ztg 126: 2613-2617

Wang P, Kim Y-J, Navarro-Villalobos M et al. (2005a) Synthesis of the potent immunomodulatory adjuvant QS-21A. JACS 127: 32563257

Wang H-K, Sakurai N, Shih CY, Lee K-H (2005b) LC/TIS-MS fingerprint profiling of Cimicifuga species and analysis of 23-epi-26-deoxyactein in Cimicifuga racemosa commercial products. J Agric Food Chem 53: 1379-1386

Watanabe K, Mimaki Y, Sakagami H, Sashida Y (2002) Cycloartane glycosides from the rhizomes of Cimicifuga racemosa and their cytotoxic activities. Chem Pharm Bull 50: 121-125

Whiting PW, Clouston A, Kerlin P (2002) Black cohosh and other herbal remedies associated with acute hepatitis. Med J Aust 177: 432435

Wiegrebe H, Wichtl M (1993) High-performance liquid chromatographic determination of cardenolides in Digitalis leaves after solid-phase extraction. J Chromatogr 630: 402-407

Wulff G (1968) Neuere Entwicklungen auf dem Saponingebiet. Dtsch Apoth Ztg 108: 797-808

Wuttke W, Jarry H, Westphalen S et al. (2002) Phytoöstrogene - eine Alternative zur Standardhormonersatztherapie? Der Gynäkologe 35: $1007-1020$
Wuttke W, Seidlová-Wuttke D, Gorkow C (2003) The Cimicifuga preparation BNO 1055 vs. conjugated estrogens in a double-blind placebo-controlled study: effects on menopause symptoms and bone markers. Maturitas 44 [Suppl 1]: S67-S77

Yasukawa K, Akihisa T, Oinuma $\mathrm{H}$ et al. (1996) Inhibitory effect of taraxastane-type triterpenes on tumor promotion by 12-O-tetradecanoylphorbol-13-acetate in two-stage carcinogenesis in mouse skin. Oncology 53: 341-344

Yoshikawa M, Murakami T, Ueno T et al. (1995) Bioactive saponins and glycosides. I. Senegae radix. (1): E-senegasaponins $a$ and $b$ and $Z$-senegasaponins $a$ and $b$, their inhibitory effect on alcohol absorption and hypoglycemic activity. Chem Pharm Bull 43: 21152122

Yoshikawa M, Murakami T, Matsuda H et al. (1996a) Bioactive saponins and glycosides. II. Senegae radix. (2): Chemical structures, hypoglycemic activity, and ethanol absorption-inhibitory effect of E-senegasaponin C, Z-senegasaponin C, and Z-senegins II, III, and IV. Chem Pharm Bull 44: 1305-1313

Yoshikawa M, Murakami T, Matsuda H et al. (1996b) Bioactive saponins and glycosides. III. Horse chestnut. (1): The structures, inhibitory effects on ethanol absorption, and hypoglycemic activity of escins la, Ib, Ila, Ilb, and IIla from seeds of Aesculus hippocastanum L. Chem Pharm Bull 44: 1454-1464

Yoshikawa M, Murakami T, Yamahara J, Matsuda H (1998) Bioactive saponins and glycosides. XII. Horse chestnut. (2): Structures of escins IIIb, IV, and VI and isoescins la, Ib, and V, acylated polyhydroxyoleanene triterpene oligoglycosides, from the seeds of Aesculus hippocastanum L. Chem Pharm Bull 46: 17641769

Yoshikawa M, Matsuda H (2000) Chemical and pharmacological studies on triterpene saponins, escins, from horse chestnut seeds. In: Oleszek W, Marston A (eds) Saponins in food, feedstuffs and medicinal plants. Kluwer Academic Publishers, Dordrecht Boston London, pp 189-203

Yoshikawa M, Murakami T, Kishi A et al. (2001) Medicinal flowers. III. Marigold. (1): Hypoglycemic, gastric emptying inhibitory, and gastroprotective principles and new oleanane-type triterpene oligoglycosides, calendasaponins A, B, C, and D, from Egyptian Calendula officinalis. Chem Pharm Bull 49: 863-870

Zhao W, Entschladen F, Liu H et al. (2003) Boswellic acid acetate induces differentiation and apoptosis in highly metastatic melanoma and fibrosarcoma cells. Cancer Detection and Prevention 27: 6775

Ziegler HL, Franzyk H, Safirafianpour M et al. (2004) Erythrocyte membrane modifying agents and the inhibition of Plasmodium falciparum growth: structure-activity relationships for betulinic acid analogues. Bioorg Med Chem 12: 119-127

Zitterl-Eglseer K, Sosa S, Jurenitsch J et al. (1997) Anti-oedematous activities of the main triterpendiol esters of marigold (Calendula officinalis L.). J Ethnopharmacol 57: 139-144 